LBNL-45959

\title{
Practical Diagnostics for Evaluating Residential Commissioning Metrics
}

\author{
Craig Wray, Iain Walker, Jeff Siegel, Max Sherman
}

\author{
Environmental Energy Technologies Division \\ Indoor Environment Department \\ Lawrence Berkeley National Laboratory \\ Berkeley, CA 94720
}

July 2002 and Standards, of the U.S. Department of Energy under contract no. DE-AC03-76SF00098. 
The Lawrence Berkeley National Laboratory, 1 Cyclotron Road, Berkeley, CA 94720 is a national laboratory of the U.S. Department of Energy managed by the Regents of the University of California for the U.S. Department of Energy under Contract Number DEAC03-76SF00098. This report was prepared as a result of work sponsored by the California Energy Commission (Commission). It does not necessarily represent the views of the Commission, its employees, or the State of California. The Commission, the State of California, its employees, contractors, and subcontractors make no warranty, express or implied, and assume no legal liability for the information in this report, nor does any party represent that the use of this information will not infringe upon privately owned rights. This report has not been approved or disapproved by the Commission nor has the Commission passed upon the accuracy or adequacy of the information in this report.

THE GOVERNMENT AND THE CONTRACTOR MAKE NO EXPRESS OR IMPLIED WARRANTY AS TO THE CONDITIONS OF THE RESEARCH OR ANY INTELLECTUAL PROPERTY, GENERATED INFORMATION, OR PRODUCT MADE OR DEVELOPED UNDER THIS AGREEMENT, OR THE OWNERSHIP, MERCHANTABILITY, OR FITNESS FOR A PARTICULAR PURPOSE OF THE RESEARCH OR RESULTING PRODUCT; THAT THE GOODS, SERVICES, MATERIALS, PRODUCTS, PROCESSES, INFORMATION, OR DATA TO BE FURNISHED HEREUNDER WILL ACCOMPLISH INTENDED RESULTS OR ARE SAFE FOR ANY PURPOSE INCLUDING THE INTENDED PURPOSE; OR THAT ANY OF THE ABOVE WILL NOT INTERFERE WITH PRIVATELY OWNED RIGHTS OF OTHERS. NEITHER THE GOVERNMENT NOR THE CONTRACTOR SHALL BE LIABLE FOR SPECIAL, CONSEQUENTIAL, OR INCIDENTAL DAMAGES ATTRIBUTED TO SUCH RESEARCH OR RESULTING PRODUCT, INTELLECTUAL PROPERTY, GENERATED INFORMATION, OR PRODUCT MADE OR DELIVERED UNDER THIS AGREEMENT. 


\section{TABLE OF CONTENTS}

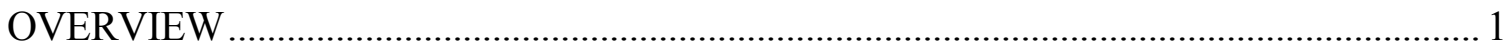

INTRODUCTION

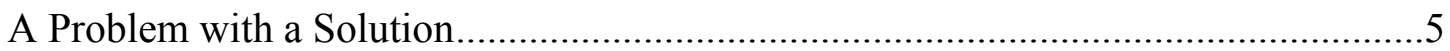

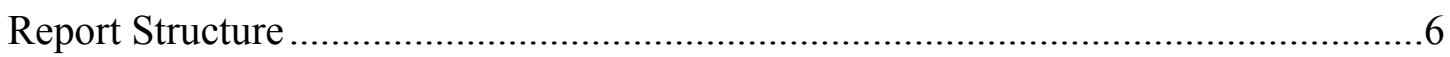

WHAT IS RESIDENTIAL COMMISSIONING? ……………................................................ 7

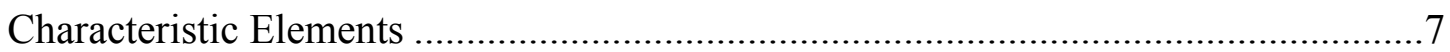

The Commissioning Process ....................................................................................

METRICS AND DIAGNOSTICS OVERVIEW ……………........................................

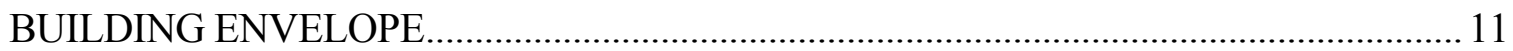

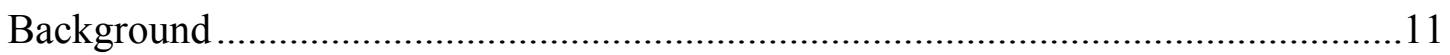

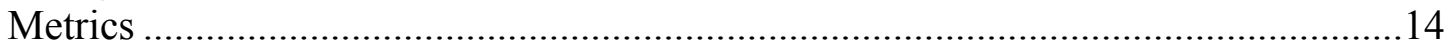

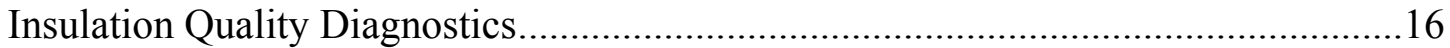

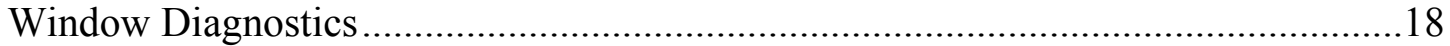

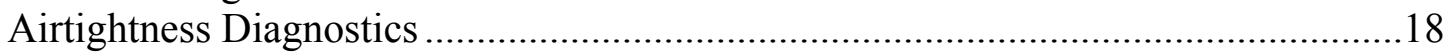

Envelope Moisture Diagnostics ...............................................................................19

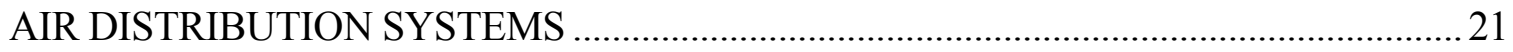

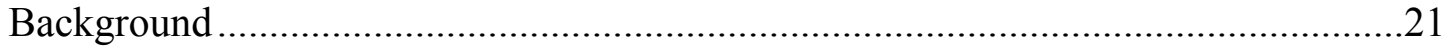

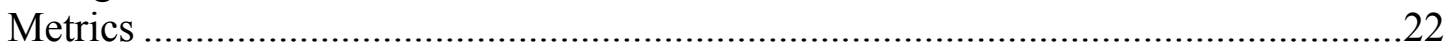

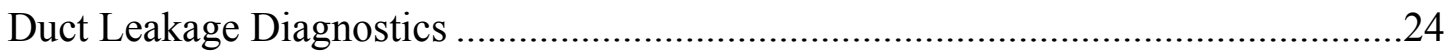

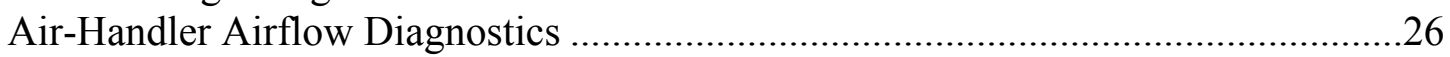

Distribution System Airflow Diagnostics ................................................................28

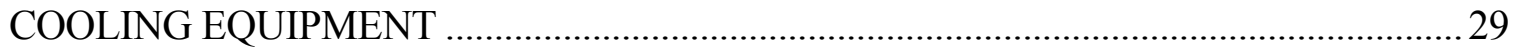

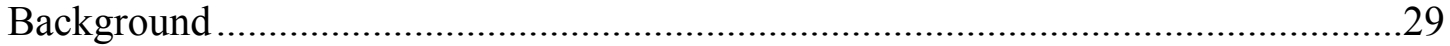

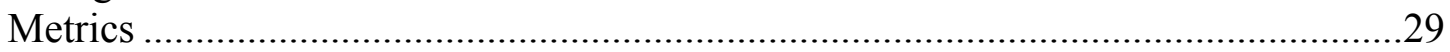

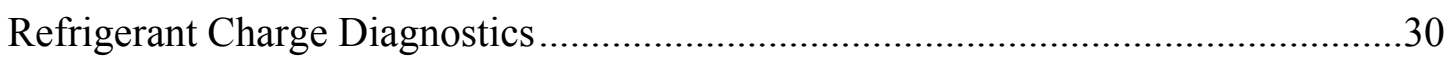

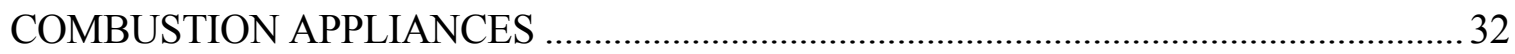

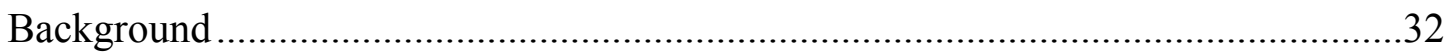

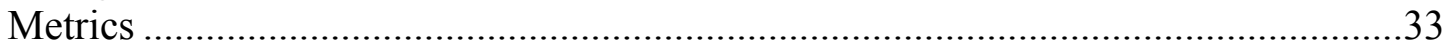

Combustion Appliance Diagnostics.........................................................................33

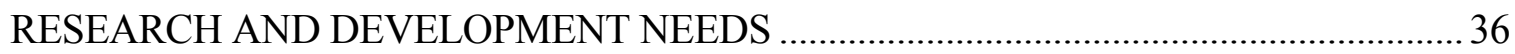

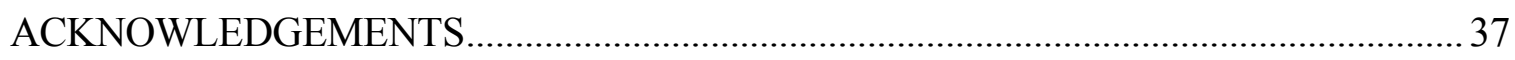

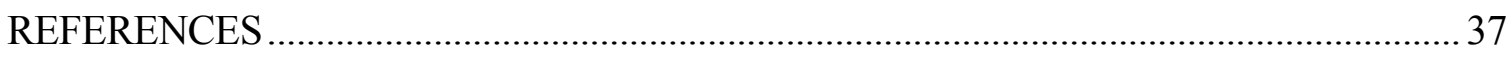


EVALUATION OF THE DELTAQ DUCT LEAKAGE TEST …………………………..... 48

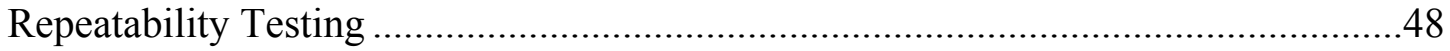

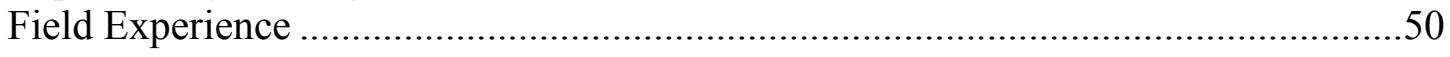

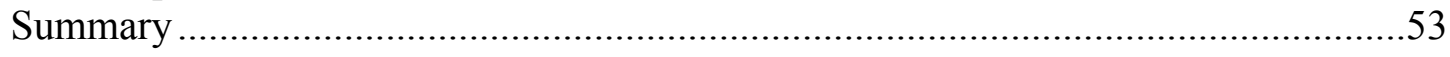

EVALUATION OF AIR-HANDLER AIRFLOW TESTS …………………………….......54

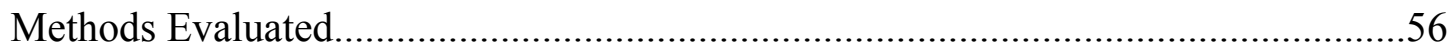

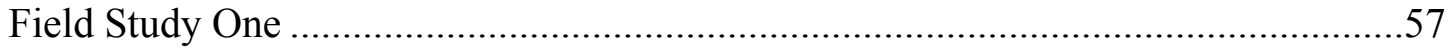

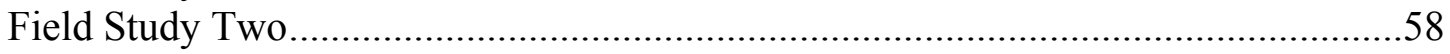

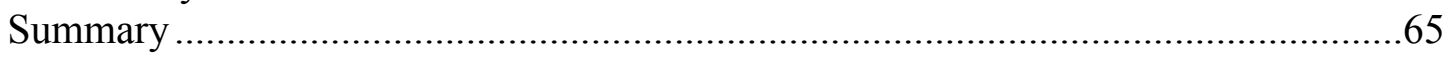

EVALUATION OF DISTRIBUTION SYSTEM AIRFLOW TESTS …………………….......66

Residential Applications for Flow Hoods and Accuracy Requirements .......................66

Experimental Assessment of Accuracy ……………….......................................68

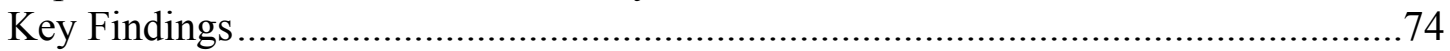

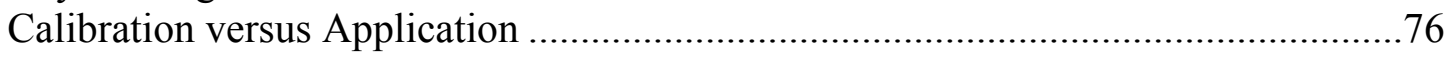

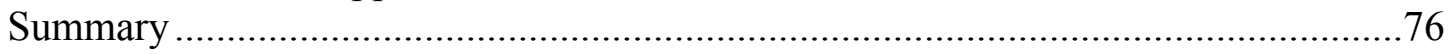

EVALUATION OF REFRIGERANT CHARGE DIAGNOSTICS........................................ 77

Superheat Test Methods Evaluated............................................................................77

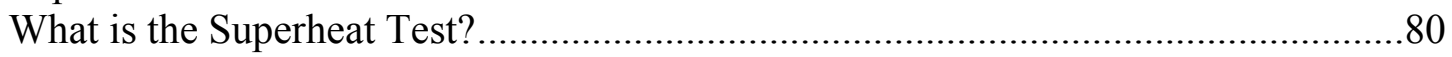

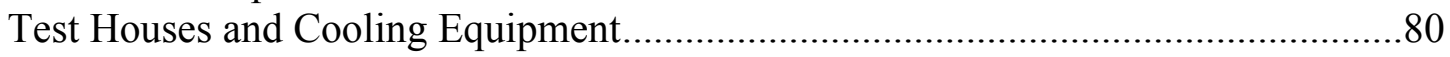

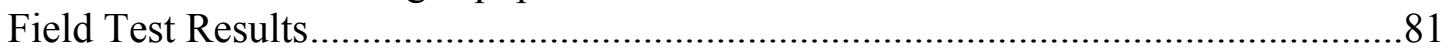

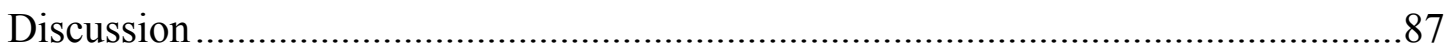

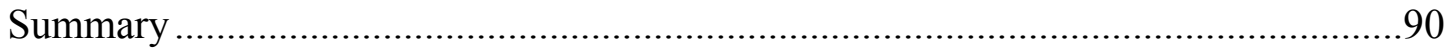

APPENDIX B: FOOTNOTES TO DIAGNOSTICS OVERVIEW ………………………....... 92

APPENDIX C: DISCUSSION OF EXCLUDED DIAGNOSTICS ………………………....95

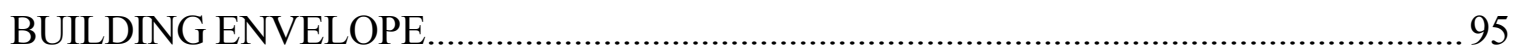

Envelope Assembly Deficiencies ..........................................................................95

Envelope Assembly Thermal Conductance …………………………………..........96

Envelope Material Thermal Conductivity ……………….........................................99

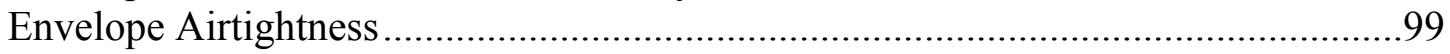

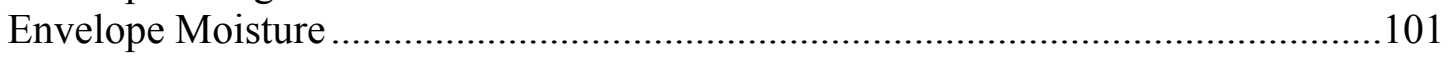

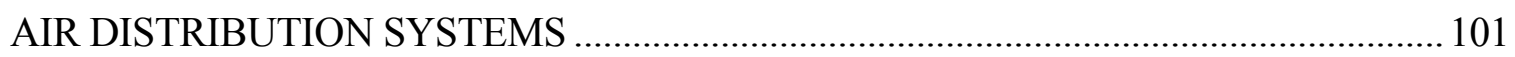

Duct Leakage ………………………………………..............................101

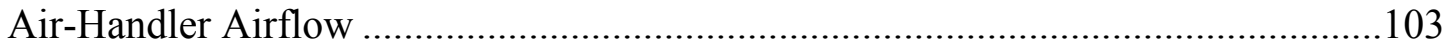

Thermal Distribution System and Ventilation System Airflows ...............................105

Thermal Distribution System Delivery Efficiency and

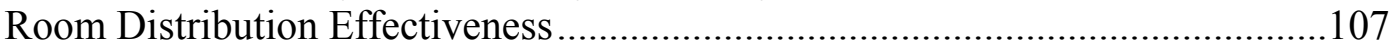

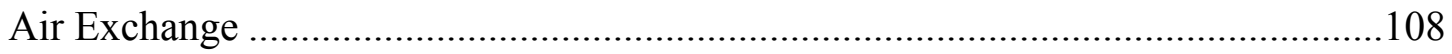




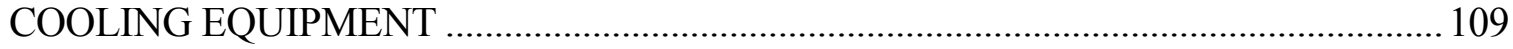

Steady-State Capacity, Power Consumption, and Efficiency ......................................109

Refrigerant Charge Level..............................................................................110

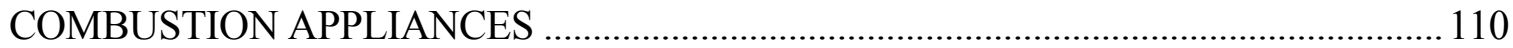

Backdrafting and Spillage Potential.......................................................................110

Combustion/Dilution Air Supply ........................................................................111

Furnace Heat Exchanger Leakage …………………….........................................111

Fuel- and Electricity-Related Performance..............................................................112

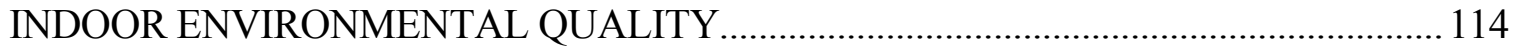

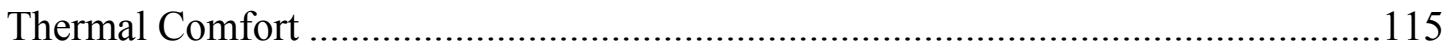

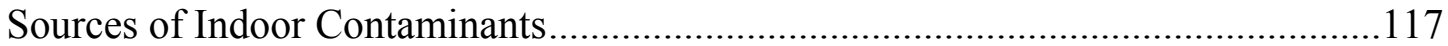

Indoor Contaminant Concentrations .....................................................................118

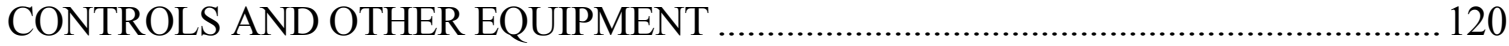

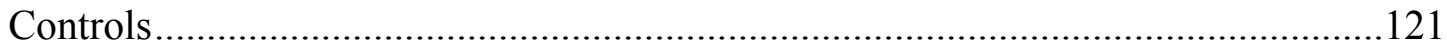

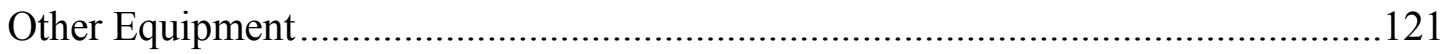




\section{LIST OF FIGURES}

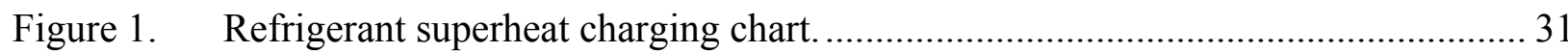

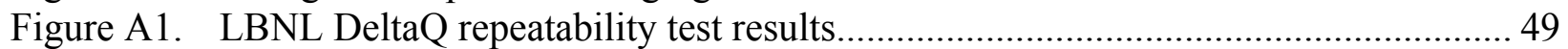

Figure A2. Comparison of duct pressurization and DeltaQ test results

for total (supply plus return) duct leakage............................................................. 52

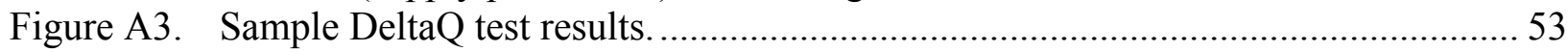

Figure A4a. Effects of reduced airflow on heat pump capacity (Rodriguez et al. 1995). ........... 55

Figure A4b. Effects of reduced airflow on heat pump EER (Rodriguez et al. 1995).................. 55

Figure A5. Comparison of air-handler airflow measurements for six houses. ........................... 58

Figure A6. Comparison of air-handler airflow measurements for four houses. .........................59

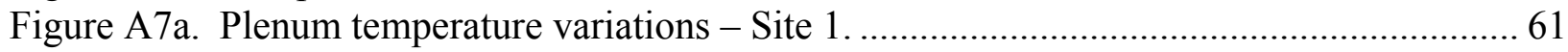

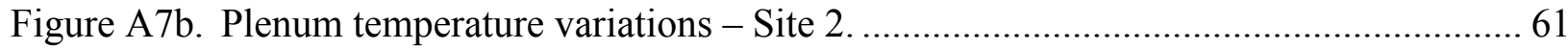

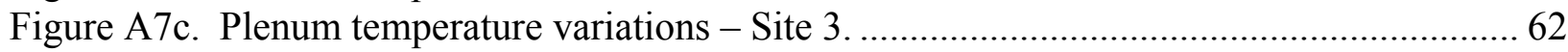

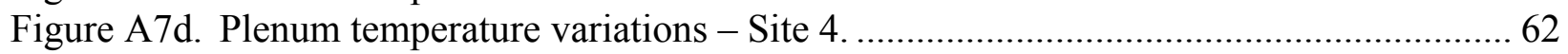

Figure A8. Laboratory apparatus configured for supply flows................................................. 70

Figure A9. Laboratory results for Standard Hood 6............................................................. 71

Figure A10. Laboratory results for Standard Hood 7.............................................................. 71

Figure A11. Laboratory results for Prototype Hood 8 ............................................................ 72

Figure A12. Laboratory results for Propeller Hood 9............................................................ 72

Figure A13. Laboratory results for Active Hood 10 ………………………………………... 73

Figure A14. Total capacity variation - Capillary tube (Farzad and O'Neal 1988)....................... 78

Figure A15. Total capacity variation - TXV (Farzad and O'Neal 1989).................................... 78

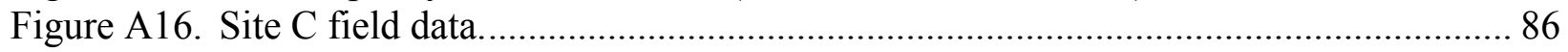




\section{LIST OF TABLES}

Table 1a. List of diagnostics related to building envelope metrics. .................................... 10

Table 1b. List of diagnostics related to air distribution system metrics. ................................... 11

Table 1c. List of diagnostics related to cooling equipment metrics. ...................................... 12

Table 1d. List of diagnostics related to combustion appliance metrics................................... 13

Table 1e. List of diagnostics related to indoor environmental quality metrics........................ 14

Table 1f. Continued list of diagnostics related to indoor environmental quality metrics. ...... 15

Table 1g. List of diagnostics related to control and other equipment metrics......................... 15

Table 2. Comparison of backdrafting and spillage potential test results. ................................ 36

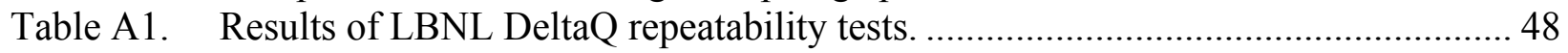

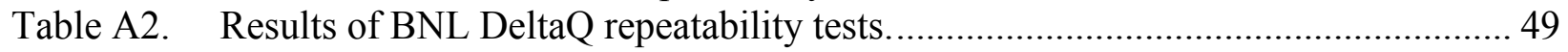

Table A3. Comparison of duct leakage obtained using various test methods. .......................... 50

Table A4. Initial field evaluations - DeltaQ test results.......................................................... 51

Table A5. Fractional errors in air-handler airflow measurements, Hood 8 versus fan-assisted Hood 10, with and without duct leakage effects................................... 60

Table A6a. Measured supply plenum dry-bulb air temperatures

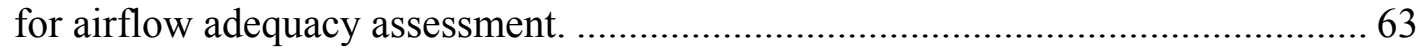

Table A6b. Return plenum air temperatures and temperature difference targets

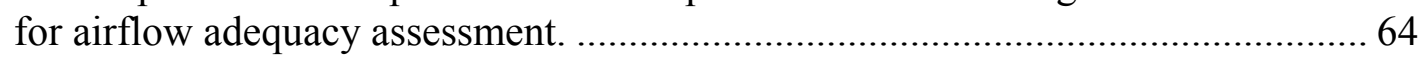

Table A6c. Measured temperature difference deviations from targets and diagnoses

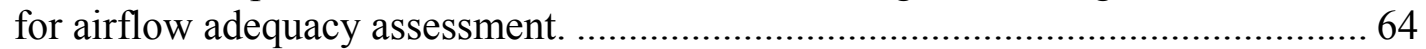

Table A7. Summary of accuracy requirements for residential flow hood applications............. 68

Table A8. Summary of laboratory test results: Supply and return flows................................... 73

Table A9. Summary of field test results: Nine supply flows..................................................... 74

Table A10. Summary of field test results: One return flow...................................................... 74

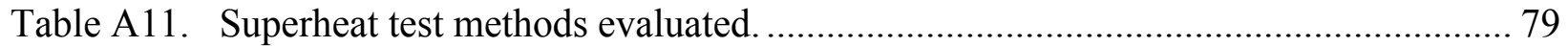

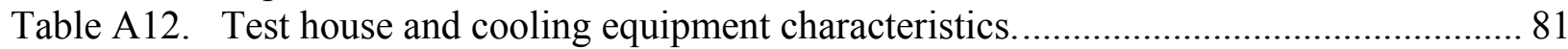

Table A13a. Measured parameters for determining "as found" target superheat........................... 82

Table A13b. Measured parameters for determining "post charging" target superheat................... 82

Table A14a. Measured pressures for determining "as found" actual superheat............................. 84

Table A14b. Measured pressures for determining "post-charging" actual superheat. .................. 84

Table A15a. Measured temperatures for determining "as found" actual superheat....................... 85

Table A15b. Measured temperatures for determining "post-charging" actual superheat.............. 85

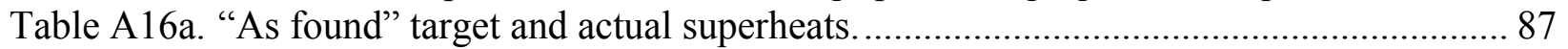

Table A16b. "Post charging” target and actual superheats.............................................................. 87

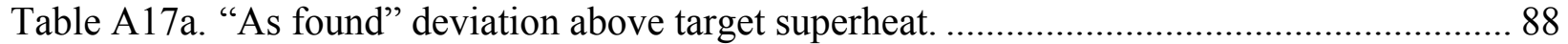

Table A17b. "Post charging" deviation above target superheat. ..................................................... 88

Table A18. Summary of cooling equipment performance.......................................................... 90 


\section{LIST OF SYMBOLS}

$\mathrm{I}_{\mathrm{i}} \quad$ Instantaneous air change rate in period $\mathrm{i}, 1 /$ time.

$\mathrm{I}_{\mathrm{m}} \quad$ Effective air change rate, 1/time.

$\overline{\mathrm{C}} \quad$ Time-averaged concentration.

$\overline{\mathrm{F}} \quad$ Time-averaged contaminant source strength, $\mathrm{cfm}\left(\mathrm{m}^{3} / \mathrm{s}\right)$.

i Hour of year.

$\mathrm{N} \quad$ Number of discrete time periods in period of interest.

$\bar{Q} \quad$ Effective ventilation rate, $\operatorname{cfm}\left(\mathrm{m}^{3} / \mathrm{s}\right)$.

V Volume of occupied space, $\mathrm{ft}^{3}\left(\mathrm{~m}^{3}\right)$.

$\Delta \mathrm{t} \quad$ Length of each discrete time period.

$\overline{\tau_{\mathrm{e}}} \quad$ Time-averaged effective turn-over time.

$\tau_{\mathrm{e}, \mathrm{i}} \quad$ Instantaneous turn-over time in period $\mathrm{i}$.

$\tau_{\mathrm{e}, \mathrm{i}-1}$ Instantaneous turn-over time in previous period. 


\section{OVERVIEW}

Background: Currently, houses do not perform optimally or even as many codes and forecasts predict, largely because they are field assembled and there is no consistent process to identify problems or to correct them. The emerging process of residential commissioning can rectify this situation by providing performance assurances.

Residential commissioning is defined within this report as a performance assurance process in the form of agreed upon metrics, diagnostics, and norms that goes beyond assuring the owner that all required equipment is correctly installed, the final product is correctly assembled, and the house can perform as intended. It includes activities such as rating, auditing, supercommissioning, and retro-commissioning. As such, it represents an expansion of processes currently carried out by people such as home energy raters, home inspectors, auditors, and weatherization contractors. For California, this expansion includes the energy performance of the large number of existing houses, as well as the indoor environmental performance of all houses. Components and systems in a house that need commissioning include building envelopes, air distribution systems, cooling equipment, heat pumps, combustion appliances, controls, and other electrical appliances.

The work reported here is the second step in a larger project that is laying the groundwork for a residential commissioning industry in California focused on end-use energy and non-energy issues. This report describes our assessment of 107 diagnostic tools for evaluating residential commissioning metrics in the areas described above. Our assessment expands upon our recent literature review and annotated bibliography (Wray et al. 2000), which facilitates access to 469 documents related to residential commissioning published over the past 20 years.

Parallel work in the project includes ascertaining what potential benefits one can realistically expect from residential commissioning. A separate report describes the potential benefits in detail and the analyses we used to assess these benefits (Matson et al. 2002).

We will use the results of these efforts to prepare a separate commissioning guide that describes how non-experts could achieve the benefits that we identify. That guide will contain specific recommendations on what diagnostics to use and how to use them to commission new and existing houses. The guide will also explain the potential benefits of using these diagnostics.

Purpose, Scope, and Structure: In this report, we identify and describe 24 practical diagnostics that are ready now to evaluate residential commissioning metrics, and that we expect to include in the commissioning guide. Our discussion in the main body of this report is limited to existing diagnostics in areas of particular concern with significant interactions: envelope and HVAC systems. These areas include insulation quality, windows, airtightness, envelope moisture, fan and duct system airflows, duct leakage, cooling equipment charge, and combustion appliance backdrafting with spillage. Appendix $\mathrm{C}$ describes the 83 other diagnostics that we have examined in the course of this project, but that are not ready or are inappropriate for residential commissioning. Combined with Appendix B, Table 1 in the main body of the report summarizes the advantages and disadvantages of all 107 diagnostics.

We first describe what residential commissioning is, its characteristic elements, and how one might structure its process. Our intent in this discussion is to formulate and clarify these issues, but is largely preliminary because such a practice does not yet exist. Subsequent sections of the report describe metrics one can use in residential commissioning, along with the consolidated set of 24 practical diagnostics that the building industry can use now to evaluate them. 
Where possible, we also discuss the accuracy and usability of diagnostics, based on recent laboratory work and field studies by LBNL staff and others in more than 100 houses. These studies concentrate on evaluating diagnostics in the following four areas: the DeltaQ duct leakage test, air-handler airflow tests, supply and return grille airflow tests, and refrigerant charge tests. Appendix A describes those efforts in detail.

In addition, where possible, we identify the costs to purchase diagnostic equipment and the amount of time required to conduct the diagnostics. Table 1 summarizes these data. Individual equipment costs for the 24 practical diagnostics range from a few hundred dollars to many thousands of dollars. The higher costs are associated with infrared thermography and state-ofthe-art automated diagnostic systems. Most tests can be performed in one hour or less, using equipment priced toward the lower end of the cost spectrum.

Duct Leakage Tests: Much of our focus in evaluating duct leakage tests was on the DeltaQ test, because it is new. In cooperation with other projects that involve developing the DeltaQ test, LBNL and Brookhaven National Laboratory (BNL) have carried out repeatability tests to estimate uncertainties in this test method. In addition, several research teams have carried out the DeltaQ test in more than 100 houses to show that it is usable in a wide range of houses and to identify limits or problems in field applications. Many of these field tests also involved duct leakage tests using other methods.

Our initial analyses of duct leakage tests show that the DeltaQ test procedure is fairly rugged, unlike other test methods that use pressures measured across the building envelope. In windy conditions, indoor-outdoor pressure differences can vary widely during the test. However, these large variations do not lead to large variations in the test results. The test is also relatively insensitive to large changes in duct reference pressure. This is in contrast to the large leakage flow uncertainty in the duct pressurization test associated with estimating the pressures across the duct leaks.

Precision of the DeltaQ test is limited to about 10 to $20 \mathrm{cfm}$. Leakage flows less than this typically will be less than about $1 \%$ of fan flow and therefore are not significant in terms of energy losses or poor distribution.

Air-Handler Airflows: Several diagnostic tools and techniques are available to measure airhandler airflow. Two of the most promising tools include a fan-assisted flow meter, and a flow plate and grid. Both are commercially available. The following describes our field studies to evaluate these two methods, along with three other methods that one might consider.

Data from our field tests indicate that both a fan-assisted flow meter and a fan-assisted flow hood are borderline acceptable devices for determining air-handler airflow. The accuracy of these measurements is likely about $\pm 10 \%$. The latter method requires an accurate measurement of duct leakage. Methods that are more accurate $( \pm 5 \%)$ would be preferable for assessing airflow through an evaporator equipped with a fixed-orifice refrigerant control, given the significant impact of air-handler airflow on cooling performance with this type of control.

Based on data reported in the literature, the flow plate and grid appears to be an accurate device for determining air-handler airflow. However, we observed a consistent negative bias near 10\% compared to the fan-assisted devices that we evaluated. We suggest that the calibration of this device be assessed further in the laboratory.

One of the non-powered flow hoods that we evaluated (Hood 8) was a prototype. At this time, it is not a reliable means of determining air-handler airflow. Improving the accuracy of this hood 
and including duct leakage will enable the diagnostic package that includes it to provide better estimates of air-handler airflow. Because of our tests, we understand that the manufacturer of the hood is already trying to improve its accuracy.

The temperature drop method of assessing air-handler airflow adequacy, which is contained in Title 24, may be able to find the worst cases of low airflow, but is unreliable for identifying airflow inadequacies in many systems. It seems unlikely that this test can be improved, because of the large spatial variations in temperature that can occur in supply plenums, even after refrigerant charge problems are corrected.

A new air-handler airflow measurement standard needs development to address the use of fanassisted flow meters and the flow plate and grid in field applications. This standard should cover the most common air-handler and duct system configurations found in residential systems. Further work is needed to develop a prototype for this standard test procedure.

Supply and Return Grille Airflows: In order to determine the magnitude of errors associated with applying flow hoods to measure flows at residential supply and return grilles, we have performed detailed laboratory testing and field studies. We used several commercially available flow hoods together with some state-of-the-art fan-assisted flow hoods.

Of the flow hoods that we tested in the laboratory (i.e., ones that are reasonably available), active flow hoods are the most reliable and consistent for measuring distribution system airflows if the measurements are to be used in estimating duct leakage, air handler flow, and individual grille flows for room load and comfort. This does not mean that active hoods are the only ones that can work. There is no fundamental problem with passive hoods, and our field test results showed that some passive hoods can obtain good results when they are used with appropriate care on the right set of grille types and locations. Laboratory and field tests of a wider range of flow hoods should be pursued, in addition to evaluating improvements for residential flow hoods. Because the active flow hood is the most accurate, it can be used as a reference in field evaluations of other hoods.

A new flow hood measurement standard should be developed to address how flow hoods are operated in the field. This standard should have some standard grille sizes, types, and placements that would cover most common geometries found in residential systems. The laboratory tests we used are a prototype for this standard test procedure. Possible agencies for development of this standard are ASHRAE and ASTM.

Refrigerant Charge: Several diagnostics are available to assess the amount of refrigerant charge in a residential cooling system without a thermostatic expansion valve (TXV) control, but only the superheat test is practical, well developed, and reliable (when properly done). In our field study, we evaluated three commercially available methods for doing a superheat test, each involving different hardware, software, and measurements. All three methods, which we broadly characterize as "Superheat Calculation Methods", claim to make the superheat test easier.

Methods 2 and 3 correctly assess refrigerant charge levels. At this time, Method 1 seems inappropriate for assessing refrigerant charge levels of residential cooling equipment. Note that the reference method is too complicated and time intensive for a service technician to consider it as a practical alternative. However, this is not really a consideration, because it is intended only for research use.

There are problems with all of the methods, such as lost data for Methods 2 and 3, and some problems with deviations in pressure and temperature measurements. In the short term, diligence 
on the part of the service technician and the use of well-developed, reliable automation techniques seem to be the best solutions to these problems.

To address the significant performance degradation associated with refrigerant charge, we recommend that the building industry develop a standard method or methods to assess refrigerant charge. The results of this project suggest that the challenge will be to design a robust tool that works in most field conditions, rather than to measure the required quantities accurately enough. In particular, research is needed to develop a method of assessing refrigerant charge in cool weather. The utility of temporarily elevating indoor enthalpy also needs to be examined to extend the periods when the superheat method can be used to test cooling equipment in hot, dry climates. Ultimately, the performance of residential air conditioning systems would be dramatically improved by the development, application, and contractor training of a standard methodology to conduct refrigerant charge testing.

Research and Development Needs: It is important to recognize that many practical diagnostics are available now. However, some of these diagnostics require further research and development to assess or improve their usefulness and accuracy, so that the building industry can use them more extensively and reliably. In summary, the following nine areas need further work:

1. A practical diagnostic is needed to evaluate the in-situ thermal conductance of envelope assemblies.

2. Formal standards are needed for assessing water damage and measuring the moisture content in building assemblies.

3. Further research is needed to assess the impact of wind effects, as well as envelope and duct leakage, on the accuracy and repeatability of duct leakage tests, including the new DeltaQ test.

4. Formal standards are needed for the calibration and use of airflow diagnostic tools, such as flow hoods with and without fan assist, fan-assisted flow meters to measure air-handler airflow, and the flow plate and grid that temporarily replaces an air filter.

5. Formal standards are needed for superheat and subcooling tests of cooling equipment.

6. Research is needed to develop a method of assessing refrigerant charge in cool weather.

7. Research is needed to examine the utility of temporarily elevating indoor enthalpy, in order to extend the periods when the superheat method can be used to test cooling equipment in hot, dry climates.

8. Further research is needed to assess the accuracy and repeatability of methods that determine the potential for backdrafting and combustion gas spillage.

9. A simple and reliable test for furnace heat exchanger leakage still needs to be developed. The norm for the current tracer gas test is poorly defined and may be unreliable for defining acceptable leakage levels of combustion gas products. 


\section{INTRODUCTION}

\section{A Problem with a Solution}

California has one of the most advanced energy codes in the country: Title 24 (CEC 1998). In spite of this, houses still do not perform optimally, or even as many forecasts predict based on expectations of this code. For example, Walker et al. (1998a) found large variations in duct leakage, even between side-by-side houses with the same system design and installation crew. This has resulted in as much as factor of two variations in thermal distribution system efficiency for these houses. This and other studies (e.g., Jump et al. 1996) indicate that duct leakage testing and sealing can readily improve thermal distribution system efficiency and achieve a 25 to $30 \%$ reduction in installed cooling capacity and energy consumption. As another example, consider that for at least 20 years the building industry has recognized the substantial impact of envelope airtightness on thermal loads, energy use, comfort, and indoor air quality. However, Walker et al. (1998a) found 50\% variances in airtightness for houses with the same design and construction crews, within the same subdivision.

A substantial reason for these problems is that few houses are now built or retrofitted using formal design procedures, most are field assembled from a large number of components, and there is no consistent process to identify related energy and non-energy problems or to correct them. Solving the problems requires field performance evaluations of new and existing houses using appropriate and agreed upon procedures. Many procedural elements already exist in a fragmented environment; some are ready now to integrate into a new process called residential commissioning (Wray et al. 2000). For example, California's Title 24 energy code already provides some commissioning elements for evaluating the energy performance of new houses.

Components and systems in a house that need commissioning include building envelopes, air distribution systems, cooling equipment, heat pumps, combustion appliances, controls, and other electrical appliances. For simplicity and practicality, one might consider only evaluating individual components and systems. However, this approach is insufficient, because many of them interact. Therefore, commissioning must not only identify the energy and non-energy benefits associated with improving the performance of a component, it must also indicate how individual components interact in the complete building system.

A barrier to this solution is that the building industry and the consumer currently view commissioning as a cost, without sufficient perceived compensating benefit. Such a view has resulted in little demand and effort to provide commissioning services. To overcome this barrier, it is important to not only provide an integrated set of simple, rapid, inexpensive, and reliable commissioning methods, but also to quantify the potential benefits of commissioning.

Qualitatively, there are several potential benefits for builders, consumers, code officials, utilities, and energy planners. Builders and/or commissioning agents will be able to optimize system performance and reduce consumer costs associated with building energy use. Consumers will be more likely to get what they paid for and builders can show they delivered what was expected. Code officials will be better able to enforce existing and future energy codes. As energy reduction measures are more effectively incorporated into the housing stock, utilities and energy planners will benefit through greater confidence in predicting demand and greater assurance that demand reductions will actually occur. Performance improvements will also reduce emissions from electricity generating plants and residential combustion equipment. 


\section{Report Structure}

The work reported here is part of a project that is laying the groundwork for a residential commissioning industry in California focused on end-use energy and non-energy issues. Its ultimate goal is to increase the commissioning of houses, which will in turn improve or even optimize their energy and indoor environmental performance. To achieve this goal, the technical objective of the project is to collect and analyze data on the methods and techniques of residential commissioning, as well as on its costs and benefits. This includes identifying existing tools and techniques for verifying house performance. The results of this work will provide new insights on how to address the problems of energy and indoor environmental performance in new and existing houses. These results will also foster the discussion of how to integrate aspects of commissioning with other building industry processes to improve the value of a single site visit.

A literature review and annotated bibliography (Wray et al. 2000) have already been prepared as the first step toward meeting the project goal and objective. The bibliography facilitates access to 469 documents published over the past 20 years, which represents the active reporting period for building commissioning and closely related issues. Our review discussed metrics, diagnostics, and norms that those documents describe and that one might use within the residential commissioning process. The review also highlighted gaps in existing knowledge that require further research and development.

The work reported here expands upon the literature review. Specifically, it identifies and describes practical diagnostics that are ready now to evaluate residential commissioning metrics. Our discussion in the main body of this report is limited to existing diagnostics in areas of particular concern with significant interactions: envelope and HVAC systems. These areas include insulation quality, windows, airtightness, envelope moisture, fan and duct system airflows, duct leakage, cooling equipment charge, and combustion appliance backdrafting with spillage. Appendix $\mathrm{C}$ describes other diagnostics that we have examined in the course of this project, but that are not ready or are inappropriate for residential commissioning.

The remainder of this report first describes what residential commissioning is, its characteristic elements, and how one might structure its process. Our intent in this discussion is to formulate and clarify these issues, but is largely preliminary because such a practice does not yet exist. Subsequent sections describe metrics that can be used in residential commissioning, along with a consolidated set of practical diagnostics that the building industry can use now to evaluate them. Where possible, we also discuss the accuracy and usability of these diagnostics, based on recent laboratory work and field studies that are described in Appendix A. In addition, where possible, we identify the costs to purchase diagnostic equipment and the amount of time required to conduct the diagnostics. We conclude by describing areas in need of research and development, such as practical field diagnostics for envelope thermal conductance and combustion safety.

In a parallel part of the project, we have carried out a simulation study to demonstrate the potential benefits of residential commissioning for a sample of both new and existing California houses. A separate report describes the potential benefits in detail, along with the analyses we used to assess these benefits (Matson et al. 2002). So that non-experts in the building industry can achieve these benefits, we are developing a separate guide to document the commissioning procedures. It will contain specific recommendations on what diagnostics to use and how to use them. The guide will also explain the potential benefits of using these diagnostics. In addition, we are transferring project findings to the building industry through workshops and presentations. 


\section{WHAT IS RESIDENTIAL COMMISSIONING?}

Commissioning has its roots in shipbuilding, where the term describes the process that ensures a new vessel is sea worthy and ready for service. This process has many specific definitions. The variation relates to the scope of commissioning, and the activities related to it. Some commissioning projects begin early in the design stage and continue through ongoing operations and maintenance. Others include activities to optimize performance beyond design intents (super-commissioning) or to adjust performance of existing facilities (retro-commissioning).

In a very narrow sense, one can simply think of residential commissioning as a process only for new houses. This process would assure the owner that all required equipment is correctly installed, the final product is correctly assembled, and the house can perform as intended. Such a process might be carried out after installation and construction are complete and before the buyer occupies the new house.

For the purposes of this report, we broaden our definition of residential commissioning to include many other activities such as auditing, rating, super-commissioning (optimizing performance beyond design intents), or retro-commissioning (adjusting performance of existing houses). As such, it represents an expansion of processes currently carried out by people such as home energy raters, home inspectors, auditors, and weatherization contractors. This expansion includes the energy performance of the large number of existing houses, as well as the indoor environmental performance of all houses.

\section{Characteristic Elements}

Residential commissioning, like every other commissioning process, includes three characteristic elements. The following defines these elements and offers examples to aid understanding:

Metrics: There are three broad whole-building objectives related to achieving a safe, healthy, comfortable, and affordable house that has a minimal adverse impact on the external environment. They are: energy performance, indoor environmental performance, and durability. Various qualitative or quantitative metrics can represent each objective. For energy related to providing building services, they include fuel consumption, peak demand, and operating costs. For the indoor environment, they include indoor air quality and comfort. For durability, they include material degradation due to moisture and maintenance costs. Each metric is simply a scale to rank the performance element of interest. Metrics can also represent the performance of building components or systems. Three examples of such metrics are: specific leakage area, which is a metric for the airtightness of the building envelope; duct leakage, which is a metric for the air leakage from a duct system; and house depressurization, which is a metric for the backdrafting potential of combustion appliances.

It is necessary to consider relationships between metrics, due to the energy, indoor environmental, and durability performance interactions between components and systems (Koles et al. 1996). For example, it is necessary to quantify specific leakage area, duct leakage, and house depressurization to understand the impact that reducing duct leakage flows to save energy can have on combustion safety in tight houses.

Diagnostics: Diagnostics are usually defined as relatively quick short-term field procedures. These procedures involve measurements and perhaps analyses to evaluate performance metrics for a system or component under functional test or actual building site conditions. An example of a diagnostic is the use of airflow measuring equipment that creates and measures pressure 
differences, which one can then use in subsequent computerized analyses to calculate duct leakage.

While it is also possible and sometimes preferable to evaluate metrics using data taken over an entire season, time limitations make it impractical to collect and analyze such long-term information during commissioning. These limitations will largely depend on the value of the commissioning process to the involved parties. However, for an existing house, commissioning can often use readily available historical data either as part of diagnostics or to set norms.

Norms: A norm is a benchmark or set of benchmarks (e.g., California Title 24) against which one compares component, system, or whole-building performance. Examples of norms are the various building standards that specify requirements for minimum or maximum specific leakage area, for maximum duct leakage, and for maximum house depressurization levels. A specific example is the California Title 24 norm that duct leakage be $6 \%$ or less of the nominal total airflow through the air handler.

New and existing houses can use the same metrics and diagnostics, although some diagnostics may not be appropriate at all stages of the construction process. However, the norms for existing houses will have to be adjusted to account for the stage of the house in its life-cycle and the economic viability of meeting stricter standards than those in place at the time of construction. For example, a house built in 1930 does not come close to meeting current energy consumption limits. The retrofitting required to meet new insulation level requirements in this example would be prohibitively expensive.

\section{The Commissioning Process}

Many in the building industry think commissioning applies only to commercial buildings, even though it is still uncommon to commission these buildings at any stage of their life cycle. Most descriptions of commercial building commissioning include the following three general steps: develop a commissioning plan, carry out inspections and functional performance tests, and review operations, maintenance, and training procedures (Wray et al. 2000).

Commissioning processes for houses are different. One reason is that commercial buildings tend to be unique compared to one another, are large, have complex control systems, and have personnel that manage operations and maintenance (O\&M). As a result, a common step in the commissioning process for these buildings is developing unique documentation: a distinct commissioning plan and a building-specific O\&M manual. This step is not warranted for most houses, because they tend to be more similar compared to one another, are small, have few control systems, and have no O\&M personnel. Another reason is that we anticipate residential commissioning can sometimes provide better performance than is called for in the design; most commercial commissioning ignores this goal.

The residential commissioning process we envision has three main phases that can probably be encompassed in generic guidelines for specific commissioning issues or system and component types:

Audit and Diagnostic: The first phase of commissioning uses audit and diagnostic techniques to survey metrics for the house and then compares survey results with appropriate norms for the house. For new construction, the norms will be those such as California Title 24 standards or the equivalent local building codes. For an existing house, one might base the norms on design intents (if any were ever documented). Alternatively, one might base them upon what a particular component should be able to do relative to those in other similar houses. 
Tuning and Tweaking: The performance of many components and systems may not meet the norms, but it may be possible to improve their performance by making minor adjustments, repairs, or retrofits on the spot. Examples include sealing leaky ducts or correcting a refrigerant charge deficiency in a central air conditioner. Such tuning and tweaking can often provide significant improvements in performance for very little marginal cost. The purpose of this step is to improve the performance of the house to at least the design intent. Sometimes, that intent will be unknown. In those cases, the optimization will be to other norms, such as the best performance achievable within cost limits.

Opportunity Identification: After the tuning and tweaking, there still may be components that are not performing up to their potential. This commissioning step provides the client with information about what potential repair or retrofit opportunities need further consideration. Even when components are performing to their norms, the improved performance of new components or systems may make replacement worthwhile. Examples include adding insulation to areas such as the ceiling, walls and floors; replacing windows that a homeowner wishes to change anyway for aesthetic reasons or to solve comfort, condensation, or maintenance problems; and replacing an oversized inefficient cooling or heating system that is near the end of its service life with a properly sized and more efficient system.

\section{METRICS AND DIAGNOSTICS OVERVIEW}

Tables 1a through $1 \mathrm{~g}$ provide an overview of metrics and diagnostics for residential commissioning that we have considered in this project. Within each area of concern, we have grouped diagnostics into metric classifications. We include a "go/no-go (Y/N)" rating that we assigned to the diagnostics within each classification, based on our judgment of the practicality of using the diagnostic now for routine residential commissioning. Although we made these judgments after a careful review of the available relevant information, other reviewers of that information might select a different rating. We do not intend the "go/no-go (Y/N)" ratings in this report to reflect the usefulness of diagnostic procedures for any activity other than residential commissioning. To understand the reasons for our ratings, indexed footnotes to the tables (Appendix B) summarize the advantages and disadvantages of each diagnostic. The remainder of this report provides further information about these metrics and diagnostics, as do the references in the annotated bibliography by Wray et al. (2000).

The "go (Y)" ratings indicate which diagnostics are practical and ready now to commission houses. For each such diagnostic, the tables include a hyperlink to subsequent textual descriptions. Where applicable in these cases, the tables also identify the approximate amount of time required to conduct the diagnostics (including equipment setup and takedown) and the costs to purchase diagnostic equipment (excluding any taxes and shipping). Our time estimate for the DeltaQ duct leakage test assumes the diagnostician will use an automated procedure. The test will take about $50 \%$ longer if a non-automated procedure is used. We have excluded specific time and cost estimates for the "no-go (N)" rated diagnostics, because those data are often poorly defined. Instead, table footnotes in Appendix B describe relative time and cost.

Diagnostics involving airflow and pressure measurements must be carried out one at a time. To estimate the time required to carry out multiple tests of this type, one needs to add the individual times listed. In some cases, there may be some minor time reductions associated with having equipment already setup (e.g., 5 to 10 minutes). An example is measuring envelope airtightness with a blower door and then duct leakage only to outside using the duct pressurization test, which requires the use of the blower door as well. One exception is the DeltaQ test, which 
simultaneously measures envelope airtightness and duct leakage. Other diagnostics such as insulation inspection or window characterization can be carried out while these types of tests are underway, as long as envelope airtightness remains undisturbed during the test.

Table 1a. List of diagnostics related to building envelope metrics.

\begin{tabular}{|c|c|c|c|c|c|c|}
\hline Category & Class & Metric & Diagnostic & Rating & Time, h & Cost, $\$$ \\
\hline \multirow{28}{*}{$\begin{array}{l}\text { Building } \\
\text { Envelope }\end{array}$} & \multirow[t]{10}{*}{$\begin{array}{l}\text { Walls, Ceilings, } \\
\text { Floors }\end{array}$} & \multirow[t]{4}{*}{ Assembly Deficiencies } & Visual inspection & $\underline{Y 01}$ & 0.5 & N/A \\
\hline & & & Infrared thermometer & $\underline{\mathrm{Y} 02}$ & 0.5 & $200-1.3 \mathrm{~K}$ \\
\hline & & & Infrared thermography & $\underline{\mathrm{Y} 03}$ & 0.5 & $12 \mathrm{~K}-60 \mathrm{~K}$ \\
\hline & & & Insulation sampling & N01 & & \\
\hline & & \multirow[t]{4}{*}{ Assembly Conductance } & ETTU & N02 & & \\
\hline & & & Heat flux transducer & N03 & & \\
\hline & & & Hot box & N04 & & \\
\hline & & & Whole-building tests & N05 & & \\
\hline & & \multirow[t]{2}{*}{ Material Conductivity } & Guarded hot plate & N06 & & \\
\hline & & & Heat flowmeter & N07 & & \\
\hline & \multirow[t]{3}{*}{ Windows } & Glazing Emissivity & $\begin{array}{c}\text { Portable spectrometer or solar } \\
\text { transmission meter }\end{array}$ & $\underline{\mathrm{Y} 04}$ & 0.5 & $170-250$ \\
\hline & & Low-E Coating Location & Handheld laser thickness gauge & $\underline{\mathrm{Y} 05}$ & 0.5 & $130-700$ \\
\hline & & Interpane Gap Thickness & Handheld laser thickness gauge & $\underline{\mathrm{Y} 06}$ & 0.5 & $130-700$ \\
\hline & \multirow[t]{10}{*}{ Airtightness } & \multirow[t]{4}{*}{ Air Leakage } & Multi-/two-point with blower door & $\underline{\mathrm{Y} 07}$ & 0.5 & $1.6 \mathrm{~K}-3.5 \mathrm{~K}$ \\
\hline & & & Single-point test with blower door & N08 & & \\
\hline & & & AC pressurization & N09 & & \\
\hline & & & Pulse pressurization & N10 & & \\
\hline & & \multirow[t]{6}{*}{ Leak Location } & Smoke tube & $\underline{\mathrm{Y08}}$ & 0.5 & $30-50 /$ tube \\
\hline & & & Infrared thermography & $\underline{\text { Y09 }}$ & 1 & $12 \mathrm{~K}-60 \mathrm{~K}$ \\
\hline & & & $\begin{array}{c}\text { Component masking or on-site } \\
\text { sealing }\end{array}$ & N11 & & \\
\hline & & & Anemometry & N12 & & \\
\hline & & & Acoustic transmitters and sensors & N13 & & \\
\hline & & & Draft sensation & N14 & & \\
\hline & \multirow[t]{5}{*}{ Moisture } & \multirow[t]{5}{*}{ Moisture } & $\begin{array}{c}\text { Visual inspection, including } \\
\text { component dismantling }\end{array}$ & $\underline{\mathrm{Y} 10}$ & 0.5 & $\mathrm{~N} / \mathrm{A}$ \\
\hline & & & Subsurface impedance scanning & $\underline{\mathrm{Y} 11}$ & 0.5 & $300-6 \mathrm{~K}$ \\
\hline & & & Subsurface resistance probe & $\underline{\mathrm{Y} 12}$ & 0.5 & $150-900$ \\
\hline & & & $\begin{array}{c}\text { Surface analysis using } \\
\text { impermeable or } \\
\text { absorbent materials }\end{array}$ & N15 & & \\
\hline & & & Infrared thermography & N16 & & \\
\hline
\end{tabular}


Table 1b. List of diagnostics related to air distribution system metrics.

\begin{tabular}{|c|c|c|c|c|c|c|}
\hline Category & Class & Metric & Diagnostic & Rating & Time, $\mathbf{h}$ & Cost, \$ \\
\hline \multirow{19}{*}{$\begin{array}{c}\text { Air } \\
\text { Distribution } \\
\text { Systems }\end{array}$} & & \multirow[t]{5}{*}{ Duct Leakage } & Duct pressurization test & $\underline{\mathrm{Y} 13}$ & 0.5 & $1.5 \mathrm{~K}-2 \mathrm{~K}$ \\
\hline & & & Delta-Q test & $\underline{\mathrm{Y} 14}$ & 0.5 & $1.6 \mathrm{~K}-7 \mathrm{~K}$ \\
\hline & & & House pressure test & N17 & & \\
\hline & & & Nulling pressure test & N18 & & \\
\hline & & & Pressure pan test & N19 & & \\
\hline & & \multirow[t]{6}{*}{ Air-Handler Airflow } & Fan-assisted flow meter & $\underline{Y 15}$ & 0.5 & $1.5 \mathrm{~K}-2 \mathrm{~K}$ \\
\hline & & & Flow plate and grid & $\underline{Y 16}$ & 0.5 & $1.1 \mathrm{~K}$ \\
\hline & & & Sum of grille flows & N20* & & \\
\hline & & & Temperature split & $\mathrm{N} 21$ & & \\
\hline & & & Tracer gas & $\mathrm{N} 22$ & & \\
\hline & & & Fan curve interpolation & $\mathrm{N} 23$ & & \\
\hline & & \multirow{6}{*}{$\begin{array}{l}\text { Thermal Distribution } \\
\text { System } \\
\text { \& Ventilation System } \\
\text { Airflows }\end{array}$} & Fan-assisted flow hood & $\underline{\mathrm{Y} 17}$ & 1 & $1.5 \mathrm{~K}-2 \mathrm{~K}$ \\
\hline & & & Conventional flow hood & $\mathrm{N} 24$ & & \\
\hline & & & Anemometry & $\mathrm{N} 25$ & & \\
\hline & & & Flow grid & $\mathrm{N} 26$ & & \\
\hline & & & Pitot-static-tube traverse & $\mathrm{N} 27$ & & \\
\hline & & & Plastic bag test & $\mathrm{N} 28$ & & \\
\hline & & $\begin{array}{c}\text { Delivery Efficiency and } \\
\text { Room } \\
\text { Distribution Effectiveness }\end{array}$ & Short-term monitoring & N29 & & \\
\hline & & Air Exchange & Tracer gas & $\mathrm{N} 30$ & & \\
\hline
\end{tabular}

* If a fan-assisted flow hood that can cover each grille in turn is used along with accurate measurements of duct leakage flows, this method is acceptable. Conventional flow hoods that we have tested can be accurate enough for this technique, if they are used with appropriate care on the right set of grille types and locations.

Equipment prices in Tables 1a through 1d are based on data provided by manufacturers and distributors as of April 2001. These prices may change in the future as residential commissioning activities increase. Note that the total price for a diagnostic toolkit to carry out all tests is not the sum of each cost listed. In many cases, the equipment from one diagnostic can be used for other diagnostics, often with only slight modifications. An example is the envelope airtightness test and DeltaQ duct leakage test, where both tests use the same equipment (the DeltaQ test uses a blower door and a pressure measurement device to simultaneously determine envelope airtightness and duct leakage). Another example is using the fan-assisted flow meter to determine air-handler airflow and the fan-assisted flow hood to determine duct airflows. Both devices use a fan-assisted flow meter; the latter also has a flow capture hood.

\section{BUILDING ENVELOPE}

\section{Background}

The building envelope is important to house performance, because envelope loads dominate its heat transfer mechanisms. HVAC system thermal loads, equipment sizing, structural durability, 
and occupant comfort are all based on having the envelope perform as intended. In new houses, installation failures cause immediate problems.

Table 1c. List of diagnostics related to cooling equipment metrics.

\begin{tabular}{|c|c|c|c|c|c|c|}
\hline Category & Class & Metric & Diagnostic & Rating & Time, $h$ & Cost, $\$$ \\
\hline \multirow[t]{8}{*}{$\begin{array}{c}\text { Cooling } \\
\text { Equipment }\end{array}$} & & \multirow[t]{2}{*}{$\begin{array}{l}\text { Steady-State Capacity, } \\
\text { Power Consumption, } \\
\text { and Efficiency }\end{array}$} & $\begin{array}{c}\text { Short-term monitoring of } \\
\text { evaporator airflow, } \\
\text { air-over-evaporator enthalpy } \\
\text { change, } \\
\text { and condenser fan and compressor } \\
\text { power } \\
\end{array}$ & N31 & & \\
\hline & & & Coheating & N32 & & \\
\hline & & \multirow{5}{*}{$\begin{array}{c}\text { Refrigerant Charge } \\
\text { Level }\end{array}$} & Superheat/subcooling & $\underline{\mathrm{Y} 18}$ & 1 & $400-500$ \\
\hline & & & Gravimetric test & $\underline{\mathrm{Y} 19}$ & 2 & $1.5 \mathrm{~K}-2 \mathrm{~K}$ \\
\hline & & & Sight glass & N33 & & \\
\hline & & & TXV frosting & N34 & & \\
\hline & & & Motor signature analysis & N35 & & \\
\hline & & Fault Detection & Short-term monitoring & N36 & & \\
\hline
\end{tabular}

For example, Christian et al. (1998) indicate that insulation installation deficiencies can increase whole-wall heat transfer by about $14 \%$, which will increase energy consumption and reduce comfort. As the building ages, loss of durability caused by poor material selection and installation (e.g., insulation settling, air barrier damage from pre-installation UV exposure, water intrusion) can result in further performance reductions over time.

Having an appropriate window type installed correctly can be even more important. For example, Carmody et al. (2000) indicate that the solar heat gain coefficient (SHGC) for a doubleglazed window can be reduced about $60 \%$ by using a low-solar-gain low-emittance (low-e) coating and a vinyl frame, compared to using clear glazing and an aluminum frame. In turn, this can reduce the peak-cooling load for a typical southern-climate house by about $25 \%$. Glazing emittance and the location of the low-e coating (on the inside surface of the outer pane) are the most important contributors to this difference. In spite of the importance of these factors, mislabeled windows are still installed in some new California houses. A recent survey involving about 110 houses (approximately 2,800 windows) found on average that $3 \%$ of the windows are mislabeled (ConSol 2000). In two of the houses, as many as $17 \%$ of their windows were mislabeled. The mislabeling occurs during window manufacturing and is related to placing the virtually invisible low-e coating on the wrong pane (increases SHGC by about 20\%) or to having clear glazing instead of low-solar-gain low-e glazing.

Moisture problems are becoming increasingly prevalent throughout the country due to changes in the way buildings are constructed. Increasing energy efficiency and changes in the markets have driven construction practices toward designs that are much more susceptible to moisture problems. Even in California, whose dry climate normally exempts it from moisture concerns, the growth of moisture-related problems is troubling for builders, consumers, and policy-makers. Various studies have attributed poor durability, material degradation, odors, and unhealthy indoor environments to these moisture problems. Poor durability can lead to increased maintenance costs (e.g., repairing peeling paint or wallpaper, removing efflorescence). Moisture 
in building components can produce a "self-composting house" in which wood rot and fastener corrosion eventually causes structural failure (Halvorsen et al. 2000). Loss of structural integrity is particularly troublesome in California, because the ability to withstand seismic loading may be impaired. While odors may only be unpleasant, they can indicate the presence of toxigenic molds. Microbiological growth adjacent to infiltration paths due to moisture within the building envelope can contaminate the indoor air and increase health problems. Snell et al. (2000) have linked asthma to mold growth supported by increased moisture levels in the indoor air and on surrounding surfaces. The American Lung Association (1999) now lists asthma as the leading serious chronic illness of children in the U.S.

Table 1d. List of diagnostics related to combustion appliance metrics.

\begin{tabular}{|c|c|c|c|c|c|c|}
\hline Category & Class & Metric & Diagnostic & Rating & Time, $\mathbf{h}$ & Cost, \$ \\
\hline \multirow{21}{*}{$\begin{array}{l}\text { Combustion } \\
\text { Appliances }\end{array}$} & & \multirow{6}{*}{$\begin{array}{c}\text { Backdrafting and Spillage } \\
\text { Potential }\end{array}$} & $\begin{array}{c}\text { Visual inspection of vent sizing and } \\
\text { clearances }\end{array}$ & $\underline{Y 20}$ & 0.5 & N/A \\
\hline & & & House depressurization test & $\underline{Y 21}$ & 0.5 & $450-750$ \\
\hline & & & Downdrafting test & $\underline{\mathrm{Y} 22}$ & 0.5 & N/A \\
\hline & & & Appliance backdrafting test & $\underline{\mathrm{Y} 23}$ & 0.5 & N/A \\
\hline & & & $\begin{array}{c}\text { Cold-vent establishment pressure } \\
\text { test }\end{array}$ & $\underline{\mathrm{Y} 24}$ & 3 & $450-3.5 \mathrm{~K}$ \\
\hline & & & Long-term monitoring & N37 & & \\
\hline & & \multirow{5}{*}{$\begin{array}{l}\text { Combustion/Dilution } \\
\text { Air Supply }\end{array}$} & $\begin{array}{l}\text { Fan-assisted flow hood for active } \\
\text { device }\end{array}$ & N38 & & \\
\hline & & & $\begin{array}{c}\text { Fan-assisted flow meter + pressure } \\
\text { differences } \\
\text { for active or passive device }\end{array}$ & N39 & & \\
\hline & & & $\begin{array}{c}\text { Duct design tools + pressure } \\
\text { differences }\end{array}$ & $\mathrm{N} 40$ & & \\
\hline & & & Anemometry & $\mathrm{N} 41$ & & \\
\hline & & & Pitot-static-tube traverse & $\mathrm{N} 42$ & & \\
\hline & & \multirow{2}{*}{$\begin{array}{c}\text { Furnace Heat Exchanger } \\
\text { Leakage }\end{array}$} & $\begin{array}{c}\text { Heat exchanger surface and flame } \\
\text { observation }\end{array}$ & $\mathrm{N} 43$ & & \\
\hline & & & Tracer gas injection and detection & N44 & & \\
\hline & & \multirow{8}{*}{$\begin{array}{c}\text { Fuel- and Electricity- } \\
\text { Related } \\
\text { Performance }\end{array}$} & Fuel pressure measurement & N45 & & \\
\hline & & & $\begin{array}{l}\text { Input capacity based on meter } \\
\text { clocking }\end{array}$ & N46 & & \\
\hline & & & $\begin{array}{c}\text { Output capacity based on air- } \\
\text { handler airflow } \\
\text { and temperature rise } \\
\end{array}$ & N47 & & \\
\hline & & & $\begin{array}{l}\text { Temperature, } \mathrm{CO}_{2} \text {, and } \mathrm{O}_{2} \text { analysis } \\
\text { for combustion efficiency }\end{array}$ & N48 & & \\
\hline & & & Visual inspection of flame & N49 & & \\
\hline & & & $\begin{array}{c}\text { Furnace AFUE short-term } \\
\text { monitoring }\end{array}$ & N50 & & \\
\hline & & & Water heater recovery efficiency & N51 & & \\
\hline & & & $\begin{array}{l}\text { Water heater EF short-term } \\
\text { monitoring }\end{array}$ & N52 & & \\
\hline
\end{tabular}




\section{Metrics}

The literature that we have reviewed reports several metrics of interest for commissioning the building envelope. Insulation level and location are simple metrics to determine for opaque envelope elements under construction. The insulation level can be defined in terms of its type, thickness, and/or density. Other related qualitative metrics include the presence of anomalies such as missing insulation, insulation settling in a wall, or uneven distribution over a ceiling. These metrics are more difficult to determine in existing houses.

Table 1e. List of diagnostics related to indoor environmental quality metrics.

\begin{tabular}{|c|c|c|c|c|c|c|}
\hline Category & Class & Metric & Diagnostic & Rating & Time, $\mathrm{h}$ & Cost, $\$$ \\
\hline \multirow{16}{*}{$\begin{array}{c}\text { Indoor } \\
\text { Environmental } \\
\text { Quality }\end{array}$} & \multirow[t]{11}{*}{ Thermal Comfort } & \multirow[t]{2}{*}{ Air Temperature } & Aspirated shielded thermometer & N53 & & \\
\hline & & & Porous media thermography & N54 & & \\
\hline & & \multirow[t]{3}{*}{ Humidity } & Wet-bulb psychrometer & N55 & & \\
\hline & & & $\begin{array}{c}\text { Electronic capacitance } \\
\text { psychrometer }\end{array}$ & N56 & & \\
\hline & & & Dewpoint psychrometer & N57 & & \\
\hline & & \multirow[t]{3}{*}{ Air Velocity } & Hot-wire anemometer & N58 & & \\
\hline & & & Kata thermometer & N59 & & \\
\hline & & & Vane anemometer & N60 & & \\
\hline & & \multirow[t]{3}{*}{ Radiant Environment } & $\begin{array}{c}\text { Ellipsoid operative temperature } \\
\text { sensor }\end{array}$ & N61 & & \\
\hline & & & Globe thermometer & N62 & & \\
\hline & & & Plane radiant asymmetry sensor & N63 & & \\
\hline & \multirow{5}{*}{$\begin{array}{c}\text { Sources of Indoor } \\
\text { Contaminants }\end{array}$} & \multirow[t]{2}{*}{ Source Characterization } & Visual inspection & N64 & & \\
\hline & & & $\begin{array}{c}\text { Contaminant concentration } \\
\text { sampling }\end{array}$ & N65 & & \\
\hline & & \multirow[t]{3}{*}{ Source Control } & Visual inspection & N66 & & \\
\hline & & & $\begin{array}{l}\text { Contaminant concentration } \\
\text { sampling }\end{array}$ & N67 & & \\
\hline & & & $\begin{array}{c}\text { Airflow and air exchange } \\
\text { measurement }\end{array}$ & N68 & & \\
\hline
\end{tabular}

Two metrics that are more specific but that are even more difficult to actually measure in the field are the thermal conductance or resistance of opaque elements, respectively denoted by the assembly U-value (heat loss or gain per unit area and per unit temperature difference) and assembly R-value (inverse of U-value). Christian and Kosny (1995) have refined the conductance metric for wall sections using terms such as center-of-cavity (not including framing or additional elements such as doors or windows), clear-wall (including framing but no additional elements such as doors or windows), and whole-wall conductance (including framing, doors, and windows).

Windows also use the conductance metric. It is listed on window labels such as that of the National Fenestration Rating Council (NFRC). Like opaque envelope elements, it is difficult to 
actually measure this metric in the field. Window radiative behavior can be described by metrics such as emittance, solar heat gain coefficient (SHGC), daylight transmittance, and UV transmittance. These radiative metrics are simpler to determine in the field.

Table 1f. Continued list of diagnostics related to indoor environmental quality metrics.

\begin{tabular}{|c|c|c|c|c|c|c|}
\hline Category & Class & Metric & Diagnostic & Rating & Time, h & Cost, \$ \\
\hline \multirow{13}{*}{$\begin{array}{c}\text { Indoor } \\
\text { Environmental } \\
\text { Quality } \\
\text { (continued) }\end{array}$} & \multirow{13}{*}{$\begin{array}{c}\text { Indoor } \\
\text { Contaminant } \\
\text { Concentrations }\end{array}$} & \multirow{4}{*}{$\begin{array}{l}\text { Carbon Monoxide \& } \\
\text { Carbon Dioxide } \\
\left(\mathrm{CO} \text { and } \mathrm{CO}_{2}\right)\end{array}$} & $\begin{array}{c}\text { Active sampling (electrochemical } \\
\text { cell for } \mathrm{CO})\end{array}$ & N69 & & \\
\hline & & & $\begin{array}{l}\text { Active sampling (infrared gas } \\
\text { analyzer) }\end{array}$ & N70 & & \\
\hline & & & Passive sampler & N71 & & \\
\hline & & & $\begin{array}{c}\text { Active sampling (grab bag and gas } \\
\text { chromatograph) }\end{array}$ & N72 & & \\
\hline & & \multirow{2}{*}{$\begin{array}{l}\text { Nitrogen Oxides } \\
\qquad\left(\mathrm{NO}_{\mathrm{x}}\right)\end{array}$} & $\begin{array}{c}\text { Active sampling } \\
\text { (chemiluminesence) }\end{array}$ & N73 & & \\
\hline & & & Passive sampler & N74 & & \\
\hline & & Formaldehyde $(\mathrm{HCOH})$ & Passive sampler & N75 & & \\
\hline & & \multirow[t]{2}{*}{ Radon (Rn) } & $\begin{array}{l}\text { Active sampling (continuous } \\
\text { radiation monitor) }\end{array}$ & N76 & & \\
\hline & & & $\begin{array}{c}\text { Passive sampling (alpha-track } \\
\text { canister } \\
\text { or electret chamber) }\end{array}$ & N77 & & \\
\hline & & \multirow{3}{*}{$\begin{array}{c}\text { Particulates } \\
\text { and Bioaerosols }\end{array}$} & \begin{tabular}{|c|} 
Active sampling (optical particle \\
sampler)
\end{tabular} & N78 & & \\
\hline & & & $\begin{array}{c}\text { Active sampling (vacuum sample }+ \\
\text { gravimetric } \\
\text { or microscopic) }\end{array}$ & N79 & & \\
\hline & & & $\begin{array}{c}\text { Passive sampling (tape extraction }+ \\
\text { count) }\end{array}$ & N80 & & \\
\hline & & VOCs & $\begin{array}{c}\text { Active sampling (grab bag and gas } \\
\text { chromatograph) }\end{array}$ & N81 & & \\
\hline
\end{tabular}

Table 1g. List of diagnostics related to control and other equipment metrics.

\begin{tabular}{|c|c|c|c|c|c|c|}
\hline Category & Class & Metric & Diagnostic & Rating & Time, h & Cost, $\$$ \\
\hline Controls & Thermostat, & Calibration, & Observation and monitor operation & N82 & & \\
\hline \& Other & $\begin{array}{c}\text { Humidistat, } \\
\text { Timers, }\end{array}$ & Setback/Setup, & & & & \\
\hline \multirow[t]{3}{*}{ Equipment } & Fan/Motor Speed, & Deadband Width, and & & & & \\
\hline & $\begin{array}{c}\text { Damper/Valve } \\
\text { Position }\end{array}$ & $\begin{array}{c}\text { Controlled Variable } \\
\text { Variation }\end{array}$ & & & & \\
\hline & Plug Load & Load and Consumption & Observation and monitor operation & N83 & & \\
\hline
\end{tabular}

Subbarao et al. (1985) have attempted to combine the thermal conductance and radiative behavior of all assemblies by characterizing their impact on long-term thermal performance. They have suggested using two short-term parameters: building heat loss coefficient for conductance and equivalent clear aperture area for solar radiation. Saunders et al. (1994) defined a similar metric (building load coefficient), but included infiltration as well. 
The airtightness of the building envelope elements, both at the component level and together as a system, is a general metric often described in the literature that we reviewed. In rare cases, economic factors are included with the airtightness metrics (e.g., $\$ / \mathrm{CFM}_{50}$ ). A simple metric of interest with respect to airtightness is air barrier type and location. Terms that are more specific are airflow or air change rate at a standard pressure differential (e.g., $\mathrm{CFM}_{50}, \mathrm{CFM}_{25}, \mathrm{ACH}_{50}$ ), or effective leakage area (e.g., ELA 4 ). In some cases, the intermediate parameters of equations used to calculate these metrics are used instead. They include terms such as the flow coefficient and pressure exponent.

Airtightness metrics are sometimes normalized by floor area and/or building height to allow comparison between buildings. An example is the specific leakage area (SLA) metric in Title 24, which is the effective leakage area normalized by conditioned floor area. Another example is the normalized leakage (NL) in ASHRAE Standard 119 (1994), which is effective leakage area normalized by conditioned floor area and by eave height relative to that of a one-story house. For energy purposes, NL is a convenient metric because it approximately represents the seasonal average air change rate due to natural infiltration alone. For an airtight one-story house, a normalized leakage of 0.1 is approximately equivalent to $2.1 \mathrm{ACH}_{50}$ or an effective leakage area of $1.4 \mathrm{in}^{2} / 100 \mathrm{ft}^{2}(\mathrm{SLA}=1.0)$. An NL of 0.1 for a two-story house is approximately equivalent to $1.7 \mathrm{ACH}_{50}$ or an effective leakage area of $1.2 \mathrm{in}^{2} / 100 \mathrm{ft}^{2}(\mathrm{SLA}=0.8)$. Using the same NL regardless of house height ensures that different height houses are on a level playing field in terms of energy consumption associated with infiltration. It also means that taller houses need to be more airtight. In contrast, the SLA metric allows taller houses to have more natural infiltration and use more energy compared to a one-story house.

Three fundamental metrics characterize the thermal mass of the building envelope: time constant, capacity, and availability. All are difficult to determine in the field. The time constant of the building (Sonderegger et al. 1981) represents how quickly internal temperatures within a building assembly respond to an external change in temperature or heat flux. Capacity represents the maximum amount of thermal energy that can be stored or released due to a uniform change in temperature of the building assembly. Uniform temperatures are not achieved instantaneously, which leads to thermal gradients within a building assembly. This means that only part of the assembly is thermally charged or discharged initially. Availability represents the fraction of the capacity that remains available to store or release heat at any given time.

There are several metrics for moisture damage, but the literature that we reviewed does not commonly refer to them. Simple qualitative metrics include visible wetness or degradation of interior or exterior finishes and structural components. Degradation can include staining, streaking, bacterial or fungal growth, and wood rot. More complex and quantitative terms used by researchers involved with this issue and moisture-damage susceptibility include vapor partial pressure, condensation potential, mass of condensed water, surface water activity, water intrusion rate, diffusion path length, drying potential, and moisture content. The latter metric is the one most easily quantified during a field test.

\section{Insulation Quality Diagnostics}

Visual Inspection: The literature that we reviewed described several quantitative techniques for evaluating the thermal performance of insulation systems (Wray et al. 2000). As described in Appendix C, these include the use of field diagnostic tools such as heat flux transducer arrays; hot boxes; and the Envelope Thermal Test Unit (Modera et al. 1984), which is based on the guarded hot box concept. Some field techniques involve whole-building thermal conductance 
tests (Janssen and Rasmussen 1985, Sandberg and Jahnsson 1995). However, due to measurement biases in some cases, lack of portability or commercial availability in other cases, the need for expert users, excessive time requirements, and expensive equipment, these diagnostics are impractical in a residential commissioning environment. As a result, qualitative visual inspections (Consol 1999) will often play a key role instead.

Visual inspection determines the presence or absence of deficiencies such as incorrect framing, incorrect insulation type, incorrectly installed insulation, incorrect air and vapor barrier placement, barrier damage, and blocked ventilation pathways (e.g., between attic and soffitt vents). Such inspections are simpler and most useful when carried out during construction. The inspection of building assemblies should happen before construction crews seal the framing and insulation from view, while it is easier to correct problems. In existing houses, it is often difficult or impossible to inspect these assemblies. Consequently, techniques that are more complex and expensive are generally required in these houses to avoid destroying the exterior or interior surfaces of the assembly. Other visual inspection steps can include checking that labels from each insulation bag are stapled in the attic. The presence of these labels helps ensure that the correct amount of insulation has been installed.

These inspections do not quantify assembly thermal resistance or conductance (R- or U-value). However, one can subsequently calculate assembly thermal performance using data from these inspections in conjunction with building plans or an assembly material audit. Well-developed commercially available software can facilitate these calculations. Some of this software can also predict thermal parameters such as local and average surface temperatures, as well as heat loss or gain rates. Unfortunately, most of this software is intended for research use rather than design or commissioning. Current efforts sponsored by the ASHRAE Technical Committee on Energy Calculations to create simplified analysis methods may help alleviate this shortcoming.

Infrared Inspection: Infrared thermography systems and thermometers (radiometers) detect long-wave radiation during a scan of a building assembly and convert the long-wave radiation signal to a surface temperature using a fixed surface emissivity. Most thermography systems and scanning radiometers produce false color images of the scan on a video display for easier viewing of intensity differences. Scanning thermography equipment is expensive: the cost of a new system is in the range of $\$ 12,000$ to $\$ 60,000$. "Point source" radiometers are substantially less expensive ( $\$ 200$ to $\$ 1,300)$. They simply display a spot-area-average temperature as a meter reading. The spot area increases as the distance from the surface of interest increases. This device provides a crude screening mechanism to rapidly locate envelope element deficiencies.

The field use of any infrared inspection technique (ASTM 1990) is limited and may not be repeatable for several reasons. These include: equipment thermal instability at very high or very low outdoor temperatures; poor resolution at low indoor-outdoor temperature differences; and distortion of surface temperature patterns by solar radiation and wind effects, differential heating or cooling rates of dry and wet areas, and non-uniform or specular emissivities. Infrared inspection generally is not useful for quantifying assembly thermal conductance or even framing fractions (Davis Energy Group 2000).

Within the limitations described above, infrared inspection can qualitatively identify areas of anomalous heat transfer caused by design and/or construction deficiencies of the building envelope. Examples include lack of insulation, displaced or improperly installed insulation, wet insulation, thermal bridging, air leakage, and air intrusion. Pressurizing or depressurizing the building using a blower door during a thermographic scan can highlight air leakage paths that 
might otherwise be confused as insulation anomalies. Thermographic scanning can also be useful in identifying envelope sections with internal convective loops.

\section{Window Diagnostics}

Until recently, there were no practical field diagnostics to evaluate window radiative properties and behavior (e.g., glazing gap thickness, emittance, solar heat gain coefficient, daylight transmittance, and UV transmittance). A few inexpensive (\$130 to \$700) quantitative tools are now commercially available and more tools are under development.

An example is a prototype handheld spectrometer to determine window emittance class (Griffith 1999). This surface-contact tool uses an infrared emitter and detector to evaluate the aggregate normal reflectance of a multi-pane glazing assembly. Simple LEDs indicate whether the glazing is clear, has high-solar-gain (low-e) coating, or has low-solar-gain (spectrally-selective low-e) coating. The spectrometer works best when used on the pane with the coating, but it cannot distinguish which pane has the coating. However, other tools that use laser reflection to measure glazing gap thickness are available for this purpose (EDTM 2000). A digital numeric display or visible laser reflections on a sliding scale indicate gap thickness and which pane has the coating. Commercially-available solar transmission meters are also available to determine window emittance class (EDTM 2000). However, they are less direct and more difficult to use than the handheld spectrometer, because they require measuring the solar irradiance with and without the glazing in the irradiance path. This can be difficult for fixed (non-opening) windows. These meters cost about $\$ 170$ to $\$ 250$.

Using non-contact infrared thermography techniques in the field to assess window performance is generally impractical, due to radiation transmission and reflection effects. The magnitude of these effects can be highly variable depending on the physical properties of the glass, the presence of surface coatings, and the surface finish.

\section{Airtightness Diagnostics}

To quantitatively evaluate the airtightness of building envelope elements, there are three diagnostic techniques. They include using a blower door, AC pressurization (Sherman and Modera 1986), or pulse pressurization (Modera et al. 1987). However, only the first technique is well developed, commercially available, and discussed here. Appendix C further describes the latter two.

A blower door consists of a calibrated flow meter combined with a fan mounted in a fabric or rigid panel, which is located in an open door or window. The device determines airflow through the envelope as a function of pressure differences imposed by the blower (ASTM 1997, ASTM 1999a, CGSB 1986). Including pressure gauges, it typically costs about $\$ 1,600$ to $\$ 3,500$.

A two-point blower door test with multiple pressure difference and flow readings at each point provides a statistically better envelope leakage estimate than multiple points with a single reading at each point (Sherman and Palmiter 1994, ASTM 1997). However, a two-point test cannot distinguish leakage differences due to envelope changes at different pressures (e.g., a vent damper opening as the pressure differential increases). Multiple points (greater than two) can more clearly show such compliance, as well as instrumentation failures. Single point tests, although quick, are unreliable for quantifying leakage, because there is no method to check the accuracy of the result. However, single-point tests are useful qualitatively during air-sealing work to assess progress toward a planned air-tightness goal. 
Blower door tests are susceptible to wind effects (Modera and Wilson 1990) and stack effects. A practical wind speed limit with a single outdoor pressure tap located in a sheltered region is approximately $8 \mathrm{mph}(13 \mathrm{~km} / \mathrm{h})$ or less. This constraint limits times for accurate testing. Manifolds connecting pressure taps on four faces of a building can be used in some cases for linear pressure-difference averaging and fluctuation damping in an attempt to reduce windeffect-related precision errors and to extend conditions under which the test may be carried out (CGSB 1986). General guidelines suggest testing only when the outdoor temperatures are in the range of 41 to $95^{\circ} \mathrm{F}$ ( 5 to $35^{\circ} \mathrm{C}$ ). In cold climates, this constraint severely limits times for accurate testing.

To identify envelope leak locations, several techniques are available (ASTM 1995). The most practical diagnostic is to use commercially-available smoke tubes while pressurizing or depressurizing the building using a blower door. This technique shows the location of leak entries and exits indoors or outdoors, but not the leakage paths themselves within the envelope assemblies. Smoke released near a leak is sucked into leak entries and diffused at leak exits. This technique is inexpensive and rapid, but knowledge of likely leak locations is required to minimize the search effort. Searching for leaks on the building exterior can be especially difficult or impossible due to wind effects. The acidic nature of the smoke can cause material damage or occupant irritation if used in large quantities. Smoke tubes cost about $\$ 30$ to $\$ 50$ per tube.

Comparisons of thermographic scan images before and after pressurizing or depressurizing the building using a blower door can highlight air leakage paths that might otherwise be confused as insulation anomalies. Sufficient time between these scans must elapse for the leaks to equilibrate to the temperature of the air passing through them. The time depends on the airflow rate through the cracks, the temperature differential, and the envelope thermal mass. Although this technique is rapid, it is expensive and subject to the limitations described in the section about using infrared thermography for inspecting opaque building envelope assemblies. Other detection methods are required as a supplement to confirm leaks located using this technique.

\section{Envelope Moisture Diagnostics}

Diagnostics to assess moisture damage are poorly developed. In particular, most diagnostics can only evaluate the presence of moisture, rather then the susceptibility to moisture damage. These diagnostics typically involve visual and electrical inspection techniques.

In some cases, researchers have used conventional or pulsed infrared thermography to carry out rapid, non-destructive, broad-area scans with the intent of locating moist areas (Marshall 1980, Knehans and Styer 1983, Vavilov et al. 1991, Grinzato et al. 1992, Bison et al. 1993, Bison et al. 1994, Wild et al. 1998, Barker 1999). However, these infrared methods still in development; require expensive cameras, high-power flashes, sophisticated analyses, and highly trained personnel; and are useful only under limited conditions. As such, infrared techniques for moisture inspection are not ready for use in residential commissioning.

There are no formal standards for assessing water damage or measuring the moisture content in building assemblies. Two inspection agencies have recently developed diagnostic protocols in an attempt to fill this void (NHCID 1998, GAHI 2000). These protocols address water damage that has occurred in southeastern US houses clad with Exterior Insulation and Finish Systems (EIFS).

The NHCID (New Hanover County Inspection Department) protocol is the most developed one available. It provides guidelines for locating and assessing moisture related damage in wood frame structures clad with drainable EIFS. It describes the use of a dielectric moisture meter for 
qualitative investigation, followed by subsequent quantitative assessment of suspected wet areas with a conductance meter. It also describes locations for wall scanning and probing, including below windows, doors, flashing, penetrations, and joints. In addition, it provides a comprehensive reporting format to document measurements. This protocol contains no precision and bias specifications, but it does suggest a field method for "calibrating" a dielectric meter.

The GAHI (Georgia Association of Home Inspectors) protocol provides brief guidelines and recommendations for visually inspecting and testing houses clad with EIFS. The visual inspections focus on observing exterior water damage, as well as assessing exterior water drainage and intrusion management systems. It recommends that visual observations suggesting water entry be followed by moisture testing using a dielectric meter and then a conductance meter. It suggests conducting destructive structural investigations if moisture contents greater than $30 \%$ are measured. A related document (EIMA 2000) is largely based on the GAHI protocol. Its visual inspections focus on observing interior water damage, as well as assessing exterior water drainage and intrusion management systems. The EIMA (EIFS Industry Members Association) protocol requires only a conductance meter. It suggests conducting destructive structural investigations beginning at a lower threshold: $20 \%$. The EIMA protocol also provides a cursory form as guidance for recording inspection data.

Visual Inspection: A visual surface inspection for excess moisture within the building envelope can be carried out by determining the presence or absence of deficiencies such as wetness, microbiological growth, (e.g., mold and mildew), discoloration, texture changes, and material dimensional changes, decay, or structural dislocation. Surface inspections are a useful screening technique, but the absence of visible deficiencies does not exclude the presence of excess moisture within the envelope. As a result, invasive tests may be necessary when occupants have associated allergic symptoms and/or there is high relative humidity indoors with no significant internal moisture sources and proper ventilation. Invasive tests can include tactile probing of envelope sections with a sharp probe and dismantling of envelope sections for internal inspection. Internal inspection involves looking for similar problems as those listed for surface inspections, as well as for problems such as leaks from plumbing systems.

Visual inspection focuses on observing existing problems. It is not appropriate in general for use during construction, except for evaluating envelope detailing and plumbing system integrity. To evaluate moisture-damage susceptibility of new construction, one can refer to best practices guides and lists of likely defects that may lead to future damage (Lstiburek and Carmody 1994, RDH 2000).

As a supplement to visual inspection, impermeable or absorbent materials temporarily applied to surfaces can be used in qualitative comparative tests (Lichtman et al. 1999). However, these supplemental tests tend to be impractical, because they are time consuming.

Electrical Inspection: Two types of electrical devices are well-developed and commercially available for field-assessments of the moisture content in building materials: surface scanning dielectric meters and penetrating conductance meters. The dielectric devices cost about $\$ 300$ to $\$ 6,000$; the conductance devices cost about $\$ 150$ to $\$ 900$.

Surface scanning devices emit low-frequency electromagnetic waves and detect their disturbance to determine average moisture content. These devices are believed to be good indicators of high relative moisture content near the surface of non-conductive porous building materials (wood, drywall, plaster, roofing, insulation, carpet, and concrete). As a result, they are best used for 
comparative sampling over different regions of a surface to indicate the range of moisture content (e.g., a suspected wet region to a known dry region of similar material). Apparent high moisture content regions can then be checked with a subsurface resistance probe. An advantage of this device is that it does not damage envelope surfaces. A further advantage is that it can rapidly test large regions and provide continuous readings. These devices are contact pressure sensitive (Margotta et al. 1984).

Penetrating conductance devices determine the moisture content of non-conductive porous building materials near their exposed surfaces. This method measures the resistance between the probes and correlates the resistance to moisture content. A disadvantage of this method is that it damages the envelope surface during probe insertion, such that surfaces often require repair after such tests, even when there are no moisture problems. It is also time consuming to insert and remove probes at each test site. However, probe insertion has the advantage that it can also provide a tactile indicator of subsurface structural decay.

Although several studies report the accuracy of these devices for use with wood products (James 1988, Warren 1994, ASTM 1998), there appear to be no published data describing their accuracy for other materials, especially when combined as building assemblies. For wood, ASTM (1998) describes conductance meter accuracy of about $7 \%$ relative error (about \pm 0.5 to $2 \%$ moisture content); dielectric meter accuracy is about $\pm 5 \%$ moisture content. Warren (1994) notes that dielectric meters improperly weight moisture content for materials more than about $3 \mathrm{~mm}(0.125$ inch) thick and are sensitive to undesirable field penetration beyond the target zone.

Simpson (1999) indicates that accuracy decreases when wood fibers are saturated (25 to $30 \%$ moisture content). Above 30\%, readings are at best relative comparisons of whether the sampled material is gaining or losing moisture. These devices are susceptible to static electricity and related errors at low (less than $8 \%$ ) moisture content. Conductive materials such as metal fasteners, flashing, and joints can cause falsely elevated moisture content readings.

\section{AIR DISTRIBUTION SYSTEMS}

\section{Background}

Residential air distribution systems include fans and ducts for space conditioning and ventilation. Poor construction and operation of the air distribution systems can cause comfort problems, poor indoor air quality, and structural moisture problems, as well as wasted energy. In particular, ducts that are part of the thermal distribution system may be the single worst performer in the energy performance of a house (Jump et al. 1996). Much of the problem is due to installing ducts outside conditioned space, duct leakage, duct insulation compression, and other poor installation practices.

Compared to the space conditioning system, the ventilation system in most houses is simple. It consists of operable windows, infiltration, and a few (if any) intermittently-operated local exhaust fans. However, such systems are not always reliable for their intended purposes. To address this issue, more houses are beginning to also use whole-house ventilation. For some of these houses, this function is an integral part of the space conditioning system operation. Furthermore, the proposed ASHRAE Standard 62.2 (2002) requires mechanical ventilation in all new houses. Such ventilation practices and requirements mean that minimizing the impact of airhandler and ventilation airflows on fan power is of increasing importance to utilities and energy planners (in terms of peak power) and residents (higher energy bills). At the same time, ensuring 
good delivery effectiveness and room-by-room distribution efficiency of thermal and ventilation distribution systems depends on maintaining proper airflow through these systems.

\section{Metrics}

There are numerous metrics related to duct leakage and the thermal performance of residential air distribution systems, most of which have been developed over the past ten years. Metrics related directly to duct leakage include duct leakage flows (e.g., $\mathrm{CFM}_{25}, \mathrm{CFM}_{50}$ ), duct leakage class, and effective duct leakage area (e.g., ELA4, ELA 25 ). These metrics can be subdivided into leakage to indoors and outdoors, as well as into return, supply, cabinet, and boot components. They can also be normalized by the airflow through the air-handler or by the conditioned floor area of the house. Other metrics include airflow through the air handler, airflow and pressure drop within a duct, power delivered to the duct system, power lost from supply ducts due to conduction and leakage, and fractional conduction loss (Walker et al. 1996).

Three metrics that are more complicated include thermal regain, delivery effectiveness, and distribution system efficiency (ASHRAE 1999). Each of these can be defined either on a design condition basis or on a seasonal basis. Thermal regain represents the fraction of heat transferred unintentionally into or out of a duct that returns to the conditioned space. Delivery effectiveness is the thermal energy transferred to or from the conditioned space divided by the thermal energy transferred at the equipment-distribution system heat exchanger. Distribution system efficiency is the energy actually consumed by the equipment connected to the distribution system divided by the energy that the equipment would consume if the distribution system was adiabatic, had no impact on equipment operation, and did not influence building loads. "Tons at the register" (Walker et al. 1998b, 1998c) is another relevant metric. It is a measure of enthalpy flow delivered intentionally at each supply grille.

Airflow and ventilation-related metrics are similarly numerous, and have been developed over a longer period (about 20 years). Many can be used at component, room, or whole-house levels. They include metrics such as duct and ventilation airflows, air exchange rates, temporal and spatial ventilation effectiveness and efficiency, and indoor-outdoor and interzonal pressure differentials. Some of these metrics can be subdivided. In particular, the temporal distribution of air within a room or entire house can be represented by metrics such as age of air, turnover time, and effective ventilation rate. Carbon dioxide $\left(\mathrm{CO}_{2}\right)$ levels indoors are sometimes used as a surrogate metric to quantify ventilation adequacy, but may be inappropriate when there are other pollutants of concern within the house. Ohnishi et al. (1998) has defined three metrics to describe whole-house ventilation performance: supply rate fulfillment, exhaust rate fulfillment, and overall ventilation rate fulfillment. An additional metric useful to discussing infiltration-based ventilation airflow potential is infiltration degree-days (IDD). Parameters used in infiltration or ventilation simulation models also represent metrics that can be used to characterize how a house will perform in terms of ventilation. Such terms include surface pressure coefficients, as well as terrain and shielding parameters, all of which are related to wind effects.

When assessing time-varying airflows and ventilation in terms of controlling indoor air quality, the quantity of interest is often the temporal average rather than the peak. Apart from duct and ventilation airflows, and indoor-outdoor and interzonal pressure differentials, perhaps the most important airflow and ventilation-related metric that can be practically determined during residential commissioning is the effective ventilation rate. 
The concept of effective ventilation (Sherman and Wilson 1986, Yuill 1986, Yuill 1991) describes the proper ventilation rate averaging process. In this concept, the average (effective) rate is the steady-state one that would yield the same average contaminant concentration over the period of interest in the occupied space as does the actual sequence of time-varying discrete ventilation rates over the same period and in the same space. This effective rate is only equal to the simple arithmetic average rate when the discrete ventilation rates are constant over the period of interest and the contaminant concentration has reached its steady state value. Simple arithmetic averaging of instantaneous ventilation rates or concentrations cannot generally be used to determine these averages due to the non-linear response of indoor concentrations to the ventilation rate variations.

An important constraint in the effective ventilation concept is that the contaminant source strength F must be constant over the period of interest and must be uncorrelated with the ventilation rate. These conditions are satisfied in many residential buildings, because the emission rates of many contaminants that are controlled by whole-building ventilation vary slowly. Sherman and Wilson (1986) describe how to deal with pollutants that have step-wise constant emission rates. Pollutants such as carbon monoxide, radon, and formaldehyde, whose emission rates can be affected by ventilation, cannot use this concept and require analyses that are more complex.

For constant source strength pollutants, the relationship between effective air change rate, effective ventilation rate, volume, source strength, average concentration, and time-averaged effective turn-over time is given by :

$$
\mathrm{I}_{\mathrm{m}}=\frac{\overline{\mathrm{Q}}}{\mathrm{V}}=\frac{\mathrm{F}}{\mathrm{V} \cdot \overline{\mathrm{C}}}=\frac{1}{\overline{\tau_{\mathrm{e}}}}
$$

The time-averaged effective turn-over time in Equation 1 represents the characteristic time for the concentration in the occupied space to approach steady-state over the time period of interest. It can be determined from a sequence of discrete instantaneous ventilation air change rates $\mathrm{I}_{\mathrm{i}}$ using the following (Sherman and Wilson 1986):

$$
\begin{array}{ll}
\overline{\tau_{e}}=\frac{1}{N} \sum_{i=1}^{N}\left(\tau_{e, i}\right) & \\
\tau_{e, i}=\frac{1-e^{\left(-I_{i} \cdot \Delta t\right)}}{I_{i}}+\tau_{e, i-1} \cdot e^{\left(-I_{i} \cdot \Delta t\right)} & \text { for } I_{i}>0, \\
\tau_{e, i}=\Delta t+\tau_{e, i-1} & \text { for } I_{i}=0
\end{array}
$$

ASHRAE Standard 136 (ASHRAE 1993c) provides a set of factors to assist in calculating the annual effective air change rate of houses, for use in evaluating the impact of these air change rates on indoor air quality. These factors were determined using Equations 2 through 4 . Metrics such as envelope airtightness (in terms of normalized leakage area as defined by ASHRAE Standard 119) and ventilation system airflows need to be determined to use Standard 136.

Several metrics represent the performance of heat recovery devices in ventilation processes. These include terms such as sensible, latent, and total energy recovery effectiveness; sensible

\footnotetext{
${ }^{*}$ Nomenclature for Equations 1 through 4 is described in the List of Symbols within the Table of Contents.
} 
and total heat recovery efficiency; temperature ratio; ventilation reduction factor; and exhaustair-contamination ratio. Determining these metrics requires complex tests, which are not practical during residential commissioning.

From this list of metrics, the simplest and most practical ones to determine in the course of residential commissioning are airflow through the air handler, duct pressure drop and airflow, duct leakage flows or area, and interzonal pressure differences.

\section{Duct Leakage Diagnostics}

Several quantitative diagnostics are available to uniquely determine duct leakage (Walker et al. 1998a, Walker et al. 1999, Francisco and Palmiter 2000): the duct pressurization test, the DeltaQ test, the house pressure test, and the nulling pressure test. The pressure pan test (Siegel and Manclark 1998) is not included in this list, because its pressure indication does not uniquely determine leakage. As a result, we do not recommend it for commissioning except as a rapid screening supplement to more elaborate tests.

Researchers are in the process of improving the cost and accuracy of duct leakage testing. They are also rewriting the ASTM Standard E1554 (1994) for measuring duct leakage to include newer methods. We expect its revision will be complete in 2002. The standard (and our discussion) focuses on the existing duct pressurization test and the new DeltaQ test, because they are the simplest in terms of equipment and procedure, are more robust, and in some cases are more flexible in terms of the types of houses or systems that can be tested. Appendix $\mathrm{C}$ describes the other duct leakage diagnostics.

Duct Pressurization Test: This test is the most common one performed on duct systems. It is analogous to airtightness testing of building envelopes in that the test measures airflows at specified pressure differences. All the supply and return grilles in a system are covered and a measured amount of air is blown into the ducts through a small fan-assisted flow meter. Resulting duct pressures indicate how leaky the ducts are. The test measures the combined size of holes in the duct system, but not the flow through them to outside at operating conditions. The test device is expensive: typical costs are about $\$ 1,500$ to $\$ 2,000$.

To translate from hole size to airflow, these tests require that a duct system operating pressure be assumed (often based on measured plenum and/or grille pressures). An advantage of measuring these pressures is that they are also a useful indicator of ducts that are undersized or that are restrictive due to their topology and fittings.

The conversion from hole size to airflow has large uncertainties for leaky duct systems, because the assumed pressure may be a poor indicator of the pressures at duct leaks, whose location is unknown. However, for verifying that ducts have little leakage, a pressurization test is useful because even large errors in estimating the pressure difference across the holes will not result in large leakage flow uncertainties. This is one reason why many utility and weatherization programs use this test as a screening tool and why codes and standards are gradually adopting it. Other reasons include:

- Robustness. The duct pressurization test has almost no restrictions on the type of system it can be used on, or the weather conditions during the test. In particular, it can be used in unfinished or finished houses. This test is susceptible to wind and stack effects, but less so than for the DeltaQ test, because it does not use envelope pressure in its calculations to determine duct leakage. 
- Repeatability. The combined results of several research projects (Walker et al. 1998a, 1998b) together with the field experience of other users have shown that the repeatability of duct pressurization testing is very good.

- Simplicity. It is easy to interpret the results of a duct pressurization test without having to perform many (or any - with the appropriate hardware) calculations. This allows the test crew to evaluate the ducts during the test and to immediately assess the validity of the results.

- Familiarity. Work crews that have performed envelope leakage tests are familiar with the test method for ducts, because envelope testing uses a similar apparatus and calculation methods.

There are several variations of this duct leakage test, which involve increasing time and equipment requirements (and complexity):

- Total Leakage. This is the simplest test and the most used. Both supply and return ducts are tested at the same time, so the split between supply and return leaks must be guessed. In addition, the fraction of total leakage that leaks to outside for energy losses also must be guessed.

- Leakage to outside. For these tests, the house is pressurized using another fan to the same pressure as the ducts so that any duct leakage is to outside. This test has the additional complication of requiring two fans and extra pressure measurements. In addition, it requires more time because the pressures across the ducts and the building envelope must be balanced.

- Supply/return split. To separate supply and return ducts, a physical barrier must be installed, usually inside the air handler cabinet or return plenum. The two sides of the duct system can then be tested separately to determine the supply/return split.

Because the pressurization test is usually implemented to measure the total leakage of the ducts and not just the leakage to outside, it will overestimate the leakage required for energy loss estimates. However, from a code compliance testing point of view, this error is in the right direction because it means that the true losses will be less than those indicated by the test. In other words, a system whose total leakage passes a leakage specification is guaranteed to have leakage to outside that is less than the specification.

For energy ratings of homes with leaky ducts (e.g., assessing distribution system efficiency using ASHRAE Standard 152P), the simple pressurization test can be inappropriate due to the assumptions about pressures across the duct leaks (Walker et al. 1998b, Francisco and Palmiter 1999). In these cases, other methods such as the DeltaQ test may give better results. Leaky ducts tend to produce a larger pressure signal for the DeltaQ test, which reduces its uncertainty.

One of the biggest drawbacks to the pressurization test is the requirement of covering all the grilles and attaching the flow and pressurization equipment. Sealing grilles can be difficult (e.g., hard to reach on high vaulted ceilings) and time consuming (e.g., taping each grille, often while standing on a ladder). In addition, detailed versions of the test require inserting a blockage to separate the supply and return and using a blower door to match the duct and house pressures both of which can be time consuming. Sometimes, it is also difficult or impossible to install the air-handler seal due to the equipment configuration. All of these seals are susceptible to failure during the test. If any of the seals fail, the test will overestimate the duct leakage because it will include the seal leakage. 
DeltaQ Test: This new test is based on changing the airflows through distribution system leaks by turning the air handler on and off while pressurizing and then depressurizing the building envelope to various pressure differentials using a blower door. The test gets its name from the difference in flows (the common symbol for flows being Q), hence the name DeltaQ. A unique feature of this test (compared to duct pressurization) is that it determines envelope leakage at the same time as duct leakage.

Air leakage to outside through supply and return leaks is determined directly with the ducts at operating pressures. Testing the system at operating pressure significantly reduces the uncertainty that occurs when converting measured duct leakage at other than operating pressures to measured operating pressures. The DeltaQ test can only be used in finished houses, because it requires an envelope that can be pressurized.

A substantial advantage of the DeltaQ test is that it is cheaper than other duct leakage tests. It uses equipment (a blower door) that is widely available and that almost all people interested in duct leakage already have (e.g., weatherization program participants). This minimizes the capital cost to carry out the tests. In addition, there are no requirements for grille sealing or for separation of the supply and return systems at the air handler by a seal. Compared to the duct pressurization test, the DeltaQ test is less time-consuming (lower labor costs) and is less susceptible to leakage caused by poor sealing or seal failure during the test. However, there can be a tradeoff between increased capital costs for automating the test and the time savings resulting from the automation. Together, data acquisition systems and computers to record the data cost about $\$ 3,200$ to $\$ 4,500$. However, the time saving, record keeping ability, and operator error reductions resulting from automating the test outweigh the higher capital cost of this option. Without automation, pressure gauges to carry out this test cost about $\$ 450$ to $\$ 750$.

Test precision and bias are susceptible to wind speed and direction variation that result in envelope pressure fluctuations. Resulting fractional errors in duct leakage can be large, although absolute flow errors will remain small. The practical limit for wind speeds when accurate testing can be carried out is not currently known. Research is in progress to determine the wind limitations for this test. As Appendix A describes, preliminary data for a single building indicate good repeatability: 0.5 to $1.0 \%$ of air-handler flow for a $95 \%$ confidence interval (Wempen 2000). These data are from 20 tests in mild weather for wind speeds of $5 \mathrm{mph}(8 \mathrm{~km} / \mathrm{h})$ or less with a tight duct system and envelope (about 7\% return leakage, 2\% supply leakage, and a normalized envelope leakage of about 0.5 ).

This test is also susceptible to stack effects, which may affect the apparent leakage area of the envelope and duct system. This bias is not expected to be large. Outdoor temperature limits to reduce stack-effect-induced pressure variation are unknown, but we expect that the suggested outdoor temperature limitations for envelope airtightness tests are probably also applicable.

\section{Air-Handler Airflow Diagnostics}

Several diagnostic tools and techniques can be used to determine airflow through the air-moving equipment of cooling and heating systems. However, there is currently no reference method for field use. Two of the most promising practical and commercially available tools include a fanassisted flow meter (Walker et al. 1999) and a flow plate and grid (Palmiter and Francisco 2000).

Other techniques to measure air-handler airflow include using:

- the sum of duct branch flows, 
- the air temperature difference across the air-handler (Downey and Proctor 1999),

- a tracer gas (Walker et al. 1998b), or

- fan curve interpolation.

Measuring individual duct branch flows and summing them can lead to substantial errors, depending on the type of flow hood that is used. As described later in this report, much of the uncertainty is due to inaccuracy when commercially available flow hoods are used, or when duct leakage is not properly taken into account.

Of the other techniques, the second is prone to errors of more than $20 \%$ in many cases and near a factor of two in worst cases, due to flow nonuniformities and radiant effects (Palmiter and Francisco 2000). As shown in Appendix A, it is particularly problematic when used to assess airflows in systems that have inadequate refrigerant charge, because of the wide variation in air temperatures downstream of the evaporator coil.

While using a tracer gas can be very accurate, it requires expensive, delicate equipment and a well-trained technician. It is also subject to flow-nonuniformity-induced errors, which are difficult to assess in the field.

Fan curve interpolation cannot be relied upon, because manufacturer's fan curve data are not easily or generally available for residential systems. When it is available, it may not accurately represent the installed performance of the fan due to system effects. These effects can vary significantly and are difficult to estimate. In addition, it is not possible to measure the static pressure drop in the duct system at the same locations as those used to produce the manufacturer's fan curve.

Fan-Assisted Flow Meter: This device uses a calibrated flow meter combined with a fan to determine air-handler airflow. It can be attached to the air-handler cabinet at its access door, or at a return grille if the return ducting is well sealed. It is time-consuming to attach the flow measurement device to the air handler or return. Additional time is required to seal off the return upstream of the air handler if the device is connected to the air-handler cabinet.

With the air handler running, air is blown into the air handler or return (with the return sealed if connecting to the air handler). The goal of this test is to reproduce the pressure difference between the supply plenum and conditioned space under normal system operating conditions. If this operating pressure cannot be achieved due to capacity limits of the fan on the flow meter, then multiple measurements of flow and supply plenum static pressure are used to extrapolate to the operating pressure. The measurement device is essentially the same as the one used in duct pressurization tests (cost is about $\$ 1,500$ to $\$ 2,000$ ).

The actual accuracy of this method is not well defined at this time and cannot be easily estimated, due to the possibility of flow pattern changes within the air handler or static pressure measurement errors. However, based on field tracer gas tests (Walker et al. 1998b), we expect the accuracy of the test method is approximately $\pm 10 \%$. As Appendix A indicates, airflows obtained using this method in three houses also agreed very well with the measured sum of supply grille flows and supply duct leakage (within 2 to 3\%). Agreement was poorer when compared to the sum of return grille flows and return duct leakage, but this may have been due to difficulties in measuring return flows. Further research is needed to establish the accuracy of this method. 
Flow Plate and Grid: This new device uses a calibrated multiple-orifice plate with attached upstream and downstream pressure manifolds to determine air-handler airflow. The device is inserted into an air filter body in place of the filter. The pressure drop of the device is intended to be similar to that of an air filter. In general, the "measured" airflow needs to be corrected to account for the difference in supply plenum static pressure with the device installed instead of the filter. In addition, when the flow plate is mounted at a filter grille, the return duct leakage needs to be added to the measured flow. The device costs about $\$ 1,100$.

Using fan-assisted flow meter measurements as a reference, preliminary comparisons of airflows obtained using the flow plate and grid in 74 houses indicate its measurements are within $17 \%$ of the "reference" method (Palmiter and Francisco 2000). In 54\% of the houses, differences are less than $5 \%$. Reasons for differences are not reported, but might be related to plenum static pressure measurement errors. Francisco (2000) has indicated that upstream flow disturbances, such as $90^{\circ}$ bends in the return duct as close as 3 inches $(75 \mathrm{~mm})$ to the plate, do not adversely affect measurement accuracy.

As described in Appendix A, comparisons of field measurements that we conducted in three houses indicate a negative bias of 9 to $14 \%$ for airflows obtained using the flow plate and grid relative to fan-assisted flow meter measurements. The reason for the bias is unknown, but it is unlikely due to flow bypass because we taped the rigid plate to the air handler cabinet in each test.

\section{Distribution System Airflow Diagnostics}

Several diagnostics are available to determine airflow rates through air distribution systems. They include: a fan-assisted flow hood (Walker et al. 1999), a conventional flow hood (no fan assist), anemometry, a pitot-static-tube traverse, or a flow grid. Of these, the first is consistently accurate and reliable. The other methods are error prone due to the effects of flow nonuniformities, difficulties in estimating effective flow areas (anemometry), uncertainty in determining insertion depth (pitot-static tube), low velocities, misaligned sampling of the air stream, fouling (flow grid), and duct leakage.

Of particular note, our laboratory and field tests indicate that conventional non-powered flow hoods are sometimes an order of magnitude less accurate than fan-assisted flow hoods: potential errors are about $20 \%$ to $30 \%$ of measured flow. As a result, these hoods can be inadequate to measure flows in residential systems. The measurement errors are likely due to recirculation regions that occur within the hood, and non-uniformity of flow at the flow-hood sampling points. Manufacturers recommend using a hood size close to the grille size to reduce this problem. However, this is often not possible, because most of these hoods are intended for use in commercial buildings and are much larger than most residential grilles. The extent of this problem also depends on flow rate, duct topology upstream of the grille (e.g., nearby elbows), and grille type. Grilles with more side discharge than direct discharge are more likely to cause recirculation regions. It is possible to obtain reasonable results using some conventional flow hoods if the field tests are carefully done, the grilles are appropriate, and grille location does not restrict flow hood placement. Appendix A provides detailed results.

ASHRAE (1988) recommends using a pitot-static-tube traverse of the duct section upstream of a grille, with and without the hood in place, to determine a flow correction factor that will account for measurement errors. Such a practice is impractical for most residential systems. First, traverses can be difficult or impossible in many cases. Second, the correction can be very 
specific to a given grille. Obtaining this correction factor for each grille makes the use of the flow hood redundant.

A new simple $\$ 200$ device has recently become available to measure exhaust fan flows (Nelson 2001). It involves placing a gasketed box with a calibrated variable-sized orifice over the fan inlet and measuring the pressure drop across the orifice. The manufacturer reports that its accuracy is about $10 \%$ over a range of 10 to $120 \mathrm{cfm}$. However, it requires independent testing to assess its accuracy and usability.

Fan-Assisted Flow Hood: A fan-assisted flow hood is similar to a conventional hood, but also has a fan-assisted flow meter attached by a flex duct. Unlike a conventional hood, this device does not require an elaborate seal at the gap between the hood and the adjacent building surface, because the integrated fan maintains a relatively neutral pressure difference between the interior and exterior of the hood. At the same time, the fan assist also eliminates the backpressure problems that are created by conventional flow hoods. The location of the measurement device at the end of 6 feet $(2 \mathrm{~m})$ or more of flex duct attached to the flow hood virtually eliminates errors due to flow non-uniformities. These devices are not yet commercially available, but can be easily constructed of readily available components.

\section{COOLING EQUIPMENT}

\section{Background}

Even in new houses, cooling systems rarely perform as intended (Sherman et al. 1987). Aside from inadequate airflow across evaporator coils, refrigerant charge deficiency is a significant cause of this problem. Refrigerant charge has a particularly important impact on the capacity and efficiency of cooling equipment without a thermostatic expansion valve (TXV). For example, laboratory test data from Farzad and O'Neal (1988) for capillary-tube-controlled equipment indicate that a common charge deficiency of $15 \%$ can reduce equipment cooling capacity by 8 to $22 \%$ and the energy efficiency ratio (EER) by 4 to $16 \%$, depending on outdoor conditions.

\section{Metrics}

Because refrigerant has such an important impact on performance for cooling equipment that does not use a TXV for refrigerant flow control, the refrigerant mass ("charge") within the system is a metric in itself. Coil volume and refrigerant line length are related metrics, because they affect the amount of refrigerant that a system requires.

The literature refers to performance characteristics for cooling equipment in terms of capacity and efficiency. Capacity represents the ability of the cooling equipment to remove heat. Manufacturers often report it in units of tons $(12,000 \mathrm{Btu} / \mathrm{h})$ and usually referred to it in terms of the nameplate rating or the ARI rating. Sometimes, it is called the "installed" capacity. These metrics typically represent the capacity for a fixed set of indoor and outdoor operating conditions. A related metric is the required capacity that is determined using load calculations and that is used to size equipment. These capacities can represent the system as a whole or its components (e.g., evaporator, condensing unit).

Common metrics associated with the efficiency issues are the energy-efficiency ratio (EER) and the seasonal energy-efficiency ratio (SEER). EER is an instantaneous measure that represents the total cooling capacity of the cooling equipment $(\mathrm{Btu} / \mathrm{h})$ divided by the total electrical input (Watts). The electrical input includes the power supplied to the condensing unit and air-handler fan. SEER is an integrated measure that represents the total cooling capacity of the cooling 
equipment $(\mathrm{Btu} / \mathrm{h})$ during its normal annual usage period divided by the total electrical input (Watt-hours) during the same period. It includes the effects of equipment cycling on capacity and power consumption. The term coefficient of performance (COP) is also a common metric that is applied to heat pumps more so than air conditioners. It is defined in the same way as the EER, but it uses common units instead and is dimensionless.

To account for equipment, installation, and operation deficiencies, Neal (1998) has proposed the use of another metric: field adjusted SEER (SEERFA). This metric represents the seasonal performance of an installed cooling system (equipment and attached ducts). System performance degradation may occur due to improper refrigerant charge, inadequate evaporator airflow, duct leakage, and equipment oversizing. Neal also describes an approximate method for quantifying SEERFA. That method uses several correction factors to adjust the "rated" SEER of the cooling equipment and extend it to encompass system performance. Neal bases the correction factors on limited data from his literature review. There has been no subsequent fieldwork to validate their use. Substantial research is required before Neal's metric and method can be broadly applied within the scope of residential commissioning. That work includes: developing a practical diagnostic that can determine absolute or fractional charge deviation; determining the variation of SEER with evaporator airflow; determining appropriate corrections to accommodate the range of airflow deviations, duct leakage, and oversizing found in the field; and determining how each of the performance degradation effects should be combined.

Of these metrics, refrigerant charge is the most practical to determine during the course of residential commissioning. Apart from simply measuring total electricity consumption over a fixed period, evaluating the other metrics in the field requires complex and time-consuming diagnostics.

\section{Refrigerant Charge Diagnostics}

Several diagnostic techniques are available to assess the amount of refrigerant charge in residential cooling equipment. These techniques include: superheat or subcooling tests, a gravimetric test, a sight glass, thermostatic expansion valve (TXV) frosting, "feeling the lines", or motor signature analysis. Of these, only the superheat and subcooling tests are quantitative, practical, well developed, and reliable. Those latter two tests are not standardized, but equipment manufacturers commonly specify them.

When a charging scale, refrigerant recovery unit, vacuum gauge, and vacuum pump are used (total cost of about $\$ 1,500$ to $\$ 2,000$ ), the gravimetric test can accurately determine the amount of refrigerant and non-condensable fluids in a cooling system by removing, weighing, and replacing them. However, this test is problematic because the amount of refrigerant required for optimal system performance is often unknown. This problem occurs due to the use of refrigerant line lengths and coils that do not conform to manufacturer's specifications. In particular, it is difficult to quickly estimate the internal volume of coils, especially when tubing wall thickness is unknown. Furthermore, volumetric calculations are insufficient to account for evaporator heat transfer characteristics that differ from those of the manufacturer-specified coil. Only a functional performance test such as the superheat and subcooling tests can account for this difference.

Superheat/Subcooling Tests: These tests (Downey and Proctor 1999) assess charge adequacy by determining the refrigerant thermodynamic state at a specific point in the system. For the superheat test, which is used for cooling equipment with a fixed metering device (capillary-tube 
or short-tube orifice), the location is the compressor inlet at the condensing unit. The intent is to ensure that the refrigerant vapor is fully evaporated upon leaving the evaporator. For the subcooling test, which is used for TXV-equipped cooling equipment, the location is the condenser exit at the condensing unit. In this case, the intent is to ensure that the refrigerant vapor is fully condensed upon leaving the condenser. Superheat tests are more important than subcooling tests, because non-TXV-controlled equipment is substantially more sensitive to typical charge deficiencies.

Consider the superheat test. Refrigerant suction line temperature and pressure, condenser inlet air dry-bulb temperature, and evaporator inlet air wet-bulb temperature are measured after the cooling equipment runs for about 15 minutes to achieve equilibrium (steady-state operation). "Measured" superheat is based on the difference between the measured suction line temperature and the refrigerant saturation temperature corresponding to the measured refrigerant pressure. Proper charge is typically indicated by a "measured" superheat not lower than $5^{\circ} \mathrm{F}\left(3^{\circ} \mathrm{C}\right)$ and within $5^{\circ} \mathrm{F}\left(3^{\circ} \mathrm{C}\right)$ of a target superheat at test conditions. Refrigerant charge is low if the "measured" superheat is more than $5^{\circ} \mathrm{F}\left(3^{\circ} \mathrm{C}\right)$ above the target superheat at test conditions. Charge is high if the "measured" superheat is more than $5^{\circ} \mathrm{F}\left(3^{\circ} \mathrm{C}\right)$ below the target superheat at test conditions.

The target superheat is determined using the equipment "superheat chart". Figure 1 (Downey and Proctor 1999) shows such a chart, which typically relates superheat ( 5 to $40^{\circ} \mathrm{F}, 3$ to $22^{\circ} \mathrm{C}$ ) as a function of outdoor air dry-bulb and return-air wet-bulb temperatures. The intent of these targets is to facilitate equipment charge evaluation when it is operating at other than design conditions. Lower superheats are not listed, because they correspond to overcharging, which increases the risk of compressor flooding and associated damage.

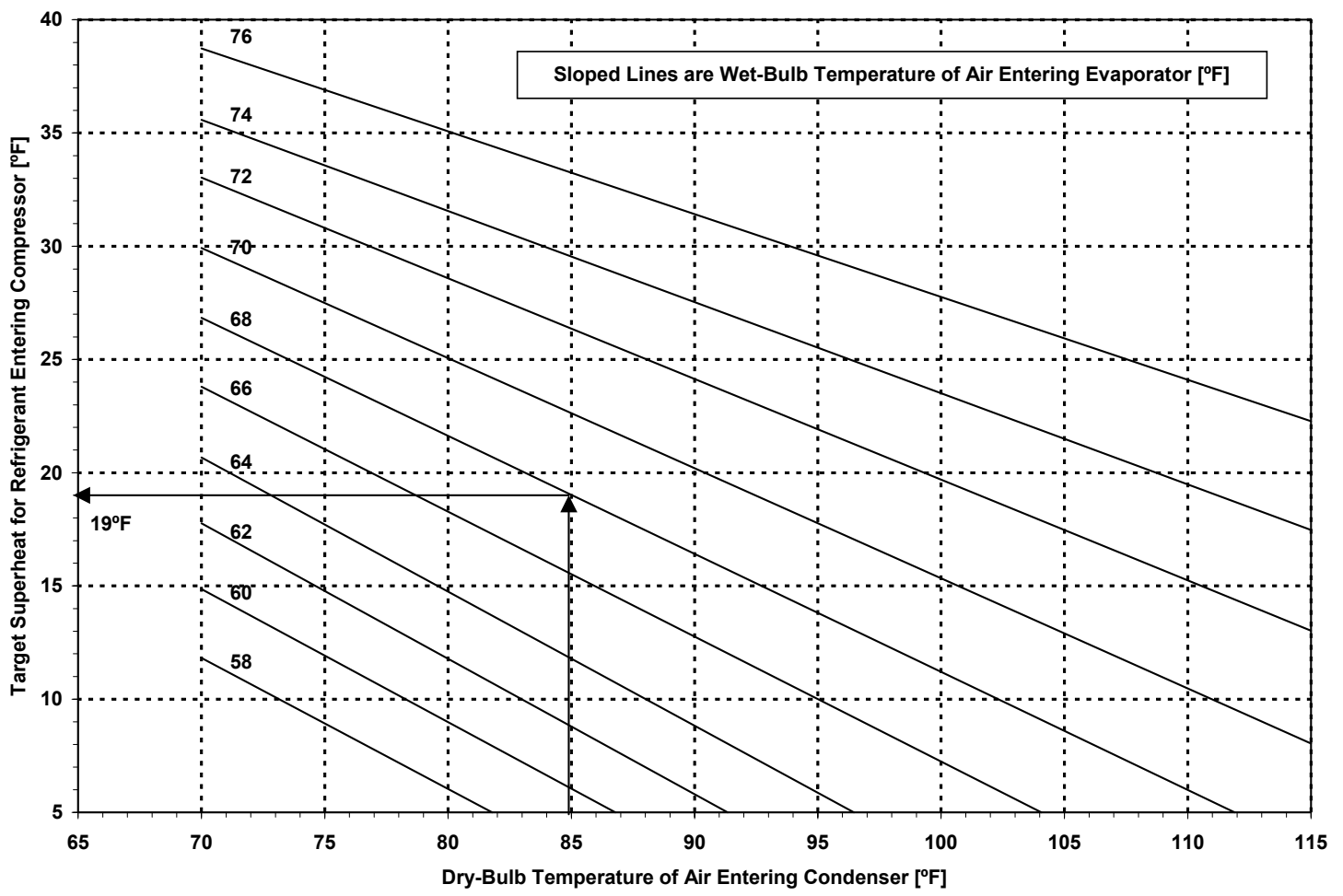

Figure 1. Refrigerant superheat charging chart. 
At this time, there are no standards specifying temperature and pressure measurement accuracy or specific measurement locations for a superheat test. As a result, there can be significant variability in "measured" superheats. Example problems include measuring the indoor wet-bulb within the house rather than within the return plenum downstream of return duct leaks, measuring outdoor air temperature remotely from the condensing unit in direct sunlight with an unshielded sensor, and measuring refrigerant line temperature downstream of a line restriction or with an uninsulated sensor that has poor surface contact. Uncertainties in these measurements can easily lead to "measured" superheat errors of $10^{\circ} \mathrm{F}\left(6^{\circ} \mathrm{C}\right)$ or more. Laboratory test data from Farzad and O'Neal (1988) for capillary-tube-controlled equipment indicate a $10^{\circ} \mathrm{F}\left(6^{\circ} \mathrm{C}\right)$ superheat error can result in a charge assessment difference of about 5 to $9 \%$, depending on outdoor temperature.

The superheat test cannot be used in hot, dry climates (e.g., summer in Fresno, California), when there is a low return-air wet-bulb temperature coincident with a high outdoor air dry-bulb temperature. To help understand this issue, consider Bakersfield, CA when the outdoor dry- and wet-bulb temperatures respectively are $104^{\circ} \mathrm{F}$ and $70^{\circ} \mathrm{F}\left(40^{\circ} \mathrm{C}\right.$ and $\left.21^{\circ} \mathrm{C}\right)$. These temperatures correspond to the $0.4 \%$ design cooling condition (ASHRAE 2001). For these conditions, the lowest return-air wet-bulb temperature for which the superheat test can be used is $66^{\circ} \mathrm{F}\left(19^{\circ} \mathrm{C}\right)$. If the indoor air temperature is $75^{\circ} \mathrm{F}\left(24^{\circ} \mathrm{C}\right)$ and the humidity ratio is the same indoors and outdoors, then the corresponding indoor (return-air) wet-bulb temperature of $61^{\circ} \mathrm{F}\left(16^{\circ} \mathrm{C}\right)$ is too low to use the superheat test. Testing in the spring when outdoor air dry-bulb temperatures are not too hot can circumvent this problem. Alternatively, the indoor wet-bulb temperature can be elevated artificially by overheating and humidifying the house. This latter technique requires further development to determine appropriate strategies.

The superheat test also cannot be used in cool weather (outdoor air temperature less than $50^{\circ} \mathrm{F}$ or $10^{\circ} \mathrm{C}$ ). This limitation is primarily to protect the compressor from failure due to insufficient lubricant circulation under these conditions.

Equipment to carry out the superheat test includes a means of measuring various temperatures and a refrigerant pressure gauge. The cost of non-automated equipment to do this is about $\$ 400$ to $\$ 500$.

Automated devices to carry out the superheat test, along with other fault detection diagnostics, are commercially available. However, they are expensive $(\$ 2,000$ to $\$ 20,000)$ and require further development. Appendix A describes our laboratory and field evaluation of two such devices.

\section{COMBUSTION APPLIANCES}

\section{Background}

While poor design or installation of either the combustion equipment or air-moving equipment can reduce efficiency, it can also lead to downdrafting, and possibly backdrafting with combustion gas spillage. Downdrafting is inward airflow from outdoors through a flue or chimney when no connected combustion appliance is operating. Appliance backdrafting is the failure of an operating combustion appliance to reverse a downdraft and to establish a proper flow of combustion gas products toward outdoors through the attached flue or chimney. Spillage is the entry of combustion gas products into the indoor air. Excessive depressurization of a house when exhaust devices are operating can cause some or all of these phenomena.

Substantial work has been carried out in Canada and the United States over the past 20 years in an attempt to understand backdrafting and spillage events related to combustion equipment 
venting and the operation of exhaust devices in houses, how long such events last, and how frequently they occur (Nagda et al. 1995). In spite of these efforts, we still lack the ability to reliably answer questions of whether backdrafting and spillage can occur, how long such events last and how frequently they occur (especially where stable backdrafting might occur), and whether the spillage gases are hazardous or toxic to occupants (Nagda 1995). However, although the frequency of spillage events might be very low, spillage directly affects the indoor environment and may pose significant health, comfort, or indoor air quality problems in some cases.

\section{Metrics}

As with cooling equipment, capacity and efficiency are common metrics for the performance of combustion appliances. The capacity metric is the nameplate output rating, but the burner "input" capacity of these appliances is also a metric. A related metric is the required capacity that is determined using load calculations and that is used to size equipment. Common metrics associated with the efficiency issues are the steady-state combustion efficiency, the annual fuel utilization efficiency (AFUE) for space heating equipment, and the Energy Factor (EF) for water heating equipment. The Energy Factor includes other water heater metrics such as standby losses, recovery efficiency, and the tank volume.

Familiar metrics for installation and operation of combustion appliances include safety issues such as clearance to combustibles, vent sizing, and outdoor airflow rates to support combustion. Performance metrics that describe the ability of an appliance to properly vent its combustion gases or conversely its potential for backdrafting and spillage of these gases into a house are less familiar. They include house depressurization or the draft (pressure differential) in the attached vent. These metrics can apply either to startup (cold flue) conditions or to steady-state operation. For the startup case, a particular metric is the cold-vent establishment pressure (CVEP), which represents the maximum indoor-outdoor pressure differential against which the hot combustion gases from the combustion appliance can establish a proper flow through the vent.

Two other important metrics involved with this issue are the concentrations of carbon monoxide (CO) and nitrogen dioxide $\left(\mathrm{NO}_{2}\right)$ in the combustion gases. If the appliance backdrafts, exposure to elevated concentrations of $\mathrm{CO}$ indoors can be lethal to occupants, while exposure to $\mathrm{NO}_{2}$ can lead to chronic respiratory problems.

One other relevant metric is heat exchanger leakage, which involves the direct leakage of combustion gases into the space conditioning air flowing through the air-handling unit. This metric is more important for existing houses than for new houses. However, it may be desirable to check new equipment to detect manufacturing defects.

\section{Combustion Appliance Diagnostics}

Of the metrics listed above, the potential for appliance backdrafting and spillage is the most critical one to assess in the course of residential commissioning. Heat exchanger leakage is also an important metric to evaluate, but there is no simple and reliable diagnostic at this time. Furthermore, the norm is poorly defined and may be unreliable for defining acceptable leakage levels of combustion gas products. Apart from these metrics, visually checking clearance to combustibles, vent sizing, and combustion air intake sizes, or measuring carbon monoxide concentrations at draft hoods of unsealed appliances, evaluating the other metrics in the field requires complex and time consuming diagnostics. 
Appliance Backdrafting and Spillage Diagnostics: The National Fuel Gas Code (NFPA 1999) describes a very simple test to assess appliance backdrafting and spillage. The test involves moving a lighted match or taper around the edge of the relief opening of a draft hood while the combustion appliance is operating. If the flame is drawn into the hood, it is assumed the appliance is venting correctly. If the flame is blown outward away from the hood or extinguishes, it is assumed that the appliance is backdrafting and spilling combustion gases indoors. It is important to note that this test does not require operating exhaust devices within the house. As such, the test does not specifically assess depressurization-induced backdrafting and spillage.

Several other "snapshot" style test protocols have been developed (CGSB 1995, ASTM 1999b) to indicate the potential for depressurization-induced problems. Specifically, four tests available to assess the backdrafting and spillage potential are: the house depressurization test, the downdrafting test, the appliance backdrafting test, and the cold-vent establishment pressure (CVEP) test.

House Depressurization Test: The house depressurization test (CGSB 1995, ASTM 1999b) involves measuring the change in indoor-outdoor pressure differentials created by operating various combinations of installed air-moving equipment (space conditioning, ventilation, fireplace, and laundry) that can depressurize the house when combustion appliances are off. Measured changes in pressure differentials due to operating the air-moving equipment are then compared with prescribed pressure limits to determine the potential for depressurization-induced backdrafting and spillage. These limits are based on field tests in several Canadian houses.

The flue or chimney must be allowed to cool to within 5 to $10^{\circ} \mathrm{F}\left(3\right.$ to $\left.6^{\circ} \mathrm{C}\right)$ of the room air temperature after the combustion appliances are turned off and before the test begins. A blower door can be used to accelerate the cooling. Another prerequisite for the test is that the flue or chimney be checked for blockage. Qualitative diagnostics such as visual inspection (Oberholtzer 1993) and using a smoke tube, cigarette smoke, or match or lighter flame to identify the presence of a draft in the flue or chimney can be used. However, no diagnostics are currently used to quantify the restriction of a venting system. Duct leakage test diagnostics could be applied, but accessing the upper end of a flue or chimney to seal it temporarily can be difficult, potentially hazardous, and time consuming.

A disadvantage of this test is that the prescribed limits may not accurately represent the potential for backdrafting and spillage of the specific appliances in the house being tested.

Pressure gauges to carry out this test cost about $\$ 450$ to $\$ 750$.

Downdrafting Test: The downdrafting test (ASTM 1999b) involves conditions similar to the house depressurization test. However, there is no pressure measurement, so manometers are not required. Instead, only a simple observation (yes/no) is recorded of whether the flue or chimney had a downdraft at the time of the test. A smoke tube, cigarette smoke, match flame, or lighter flame is used to identify the occurrence of depressurization-induced downdrafting.

An advantage of this test is that it requires the least time and equipment. However, a disadvantage is that it does not represent the potential for an appliance to reverse a downdraft. For example, a weak downdraft that might be reversible is considered as much a failure as a strong irreversible downdraft.

Appliance Backdrafting Test: The appliance backdrafting test (ASTM 1999b) involves conditions similar to the house depressurization test. However, there is no pressure measurement, 
so manometers are not required. Instead, it determines how long a combustion appliance takes to establish a draft after its burner is fired. A smoke tube, cigarette smoke, match flame, or lighter flame is used to identify the establishment of a draft in the flue or chimney. The time to establish a draft is then compared to a prescribed time limit ( 5 minutes) to determine whether any depressurization-induced backdrafting that occurs is acceptable.

A disadvantage of this test is that the prescribed time limits may not accurately represent the acceptability for backdrafting of the specific appliances in the house being tested.

$\mathrm{CO}$ in the combustion gas or indoor air must be monitored during this test to assess whether hazardous conditions exist. The test must be terminated if such conditions occur.

CVEP Test: The cold vent establishment pressure (CVEP) test (Koontz and Nagda 1996, Grimsrud et al. 1996, ASTM 1999b) involves similar conditions to the house depressurization test. This test also identifies the pressure limit at which each appliance establishes a draft in an initially cold flue or chimney while operating, with the house air-moving systems and other combustion appliances off. A blower door is used to vary the depressurization of the house from $15 \mathrm{~Pa}$ or $25 \mathrm{~Pa}$ (whichever will induce actual backdrafting) toward zero until a draft is established. This element of the test is repeated for each combustion appliance, with the flue or chimney being allowed to cool to near the outdoor air temperature between each pressure limit subtest. A blower door can be used to accelerate the cooling. A smoke tube, cigarette smoke, match flame, or lighter flame is used to identify the stagnation or establishment of a draft in the flue or chimney and the cessation of any backdrafting.

Like the house depressurization test, this test measures the change in indoor-outdoor pressure differentials created by operating various combinations of installed air-moving equipment (space conditioning, ventilation, fireplace, and laundry) that can depressurize the house when combustion appliances are off. These measured changes in pressure differentials due to operating the air-moving equipment are then compared with the measured CVEP limits to determine the potential for depressurization-induced backdrafting and spillage.

Grimsrud et al. 1996 indicate that two trained technicians can carry out the tests in one house over a period of 4 to 6 hours. A computerized data acquisition system that monitors the necessary pressure difference and that adjusts the blower door fan speed to maintain each desired envelope pressure difference can be used to facilitate the CVEP test, especially when determining the CVEP limits. A temperature sensor appropriately located could be used as a backdrafting indicator when a data acquisition system is used. As with the DeltaQ duct leakage test, there can be a tradeoff between increased capital costs for automating the test and the time savings resulting from the automation. Together, data acquisition systems and computers to record the data cost about $\$ 3,200$ to $\$ 4,500$. However, the time saving, record keeping ability, and operator error reductions resulting from automating the test outweigh the higher capital cost of this option. Without automation, pressure gauges to carry out this test cost about $\$ 450$ to $\$ 750$.

This test has the advantage that it does not use prescribed limits like the house depressurization test or appliance backdrafting test. Consequently, its results might more accurately represent the potential for depressurization-induced backdrafting and spillage of the specific appliances in the house being tested (Koontz and Nagda 1996). 
As in the appliance backdrafting test, $\mathrm{CO}$ in the combustion gas or indoor air must be monitored during this test to assess whether hazardous conditions exist. The test must be terminated if such conditions occur.

Test Limitations: Due to the short-time span of all these tests, it may be desirable to sample multiple times over the life cycle of the building, particularly when the envelope airtightness, airmoving equipment, or combustion appliances change. However, even weeklong monitoring as suggested by Grimsrud and Hadlich (1995) is probably impractical during commissioning to achieve this end.

Table 2 shows a comparison of results from carrying out several of these tests in six houses (Nagda and Koontz 2000). Columns 2 through 4 show results based on detailed continuous monitoring of vent performance, where the failure criteria is having a positive pressure in the vent relative to the room containing the appliance (causes flow from the vent to the room). The house fails if either the furnace or domestic hot water (DHW) heater fail. These data constitute the "truth standard" in this comparison. Columns 5 through 7 show results obtained using the ASTM appliance backdraft test. Columns 8 through 10 compare the ASTM test results to those obtained from long-term monitoring. Column 11 shows results obtained using the CGSB house depressurization test. Column 12 compares the CGSB test results to those obtained from longterm monitoring. The check marks in columns 8 through 10 and in column 12 indicate that the ASTM or CGSB test (as listed) obtained the same result as continuous monitoring.

Table 2. Comparison of backdrafting and spillage potential test results.

\begin{tabular}{c|c|c|c|c|c|c|c|c|c|c|c|}
\cline { 2 - 14 } \multicolumn{1}{c|}{} & \multicolumn{2}{c|}{$\begin{array}{c}\text { Continuous Monitoring } \\
\text { (Positive Vent dP wrt Room) }\end{array}$} & \multicolumn{2}{c|}{$\begin{array}{c}\text { ASTM Worst-Case } \\
\text { Backdraft Test }\end{array}$} & \multicolumn{3}{c|}{$\begin{array}{c}\text { ASTM Matches } \\
\text { Continuous Monitoring? }\end{array}$} & $\begin{array}{c}\text { CGSB } \\
\text { Downdraft Test }\end{array}$ & $\begin{array}{c}\text { CGSB } \\
\text { Matches? }\end{array}$ \\
\hline House & Furnace & DHW & House & Furnace & DHW & House & Furnace & DHW & House & House & House \\
\hline 1 & Fail & Pass & Fail & Pass & Fail & Fail & False Pass & False Fail & $\checkmark$ & Pass & False Pass \\
\hline 2 & Fail & Pass & Fail & Pass & Pass & Pass & False Pass & $\checkmark$ & False Pass & Fail & $\checkmark$ \\
\hline 3 & Fail & Fail & Fail & Pass & Fail & Fail & False Pass & $\checkmark$ & $\checkmark$ & Pass & False Pass \\
\hline 4 & Pass & Fail & Fail & Pass & Fail & Fail & $\checkmark$ & $\checkmark$ & $\checkmark$ & Fail & $\checkmark$ \\
\hline 5 & Fail & Fail & Fail & Pass & Fail & Fail & False Pass & $\checkmark$ & $\checkmark$ & Fail & $\checkmark$ \\
\hline 6 & - & Fail & Fail & - & Fail & Fail & - & $\checkmark$ & $\checkmark$ & Pass & False Pass \\
\hline
\end{tabular}

All these tests are problematic because they can easily result in false positive or negative test results. Wind effects, especially gusts, may be a significant cause of these problems. Further research is needed to assess the accuracy and repeatability of these tests. However, given that life safety and chronic health problems have been associated with combustion gas spillage, it is still better to use these imperfect methods than not.

\section{RESEARCH AND DEVELOPMENT NEEDS}

For every building element discussed above, practical diagnostics are available now to commission envelope and HVAC system performance. However, some of these diagnostics require further research and development to assess or improve their usefulness and accuracy, so that the building industry can use them more extensively and reliably. In particular, the following nine areas need further work:

1. A practical diagnostic is needed to evaluate the in-situ thermal conductance of envelope assemblies.

2. Formal standards are needed for assessing water damage and measuring the moisture content in building assemblies. 
3. Further research is needed to assess the impact of wind effects, as well as envelope and duct leakage, on the accuracy and repeatability of duct leakage tests, including the new DeltaQ test.

4. Formal standards are needed for the calibration and use of airflow diagnostic tools, such as flow hoods with and without fan assist, fan-assisted flow meters to measure air-handler airflow, and the flow plate and grid that temporarily replaces an air filter.

5. Formal standards are needed for superheat and subcooling tests of cooling equipment.

6. Research is needed to develop a method of assessing refrigerant charge in cool weather.

7. Research is needed to examine the utility of temporarily elevating indoor enthalpy, in order to extend the periods when the superheat method can be used to test cooling equipment in hot, dry climates.

8. Further research is needed to assess the accuracy and repeatability of methods that determine the potential for backdrafting and combustion gas spillage.

9. A simple and reliable test for furnace heat exchanger leakage still needs to be developed. The norm for the current tracer gas test is poorly defined and may be unreliable for defining acceptable leakage levels of combustion gas products.

\section{ACKNOWLEDGEMENTS}

This report describes work supported by the California Energy Commission through the Public Interest Energy Research program under contract no. 500-98-033, and by the Assistant Secretary for Energy Efficiency and Renewable Energy, Office of Building Technology, State and Community Programs, Office of Building Research and Standards, of the U.S. Department of Energy under contract no. DE-AC03-76SF00098.

The authors wish to acknowledge the contributions of LBNL staff who were involved in carrying out field and laboratory measurements that are described in this report: Jennifer McWilliams, Darryl Dickerhoff, Jacob Wempen, Duo Wang, and Bass Abushakra.

\section{REFERENCES}

ACCA. 1995a. “ACCA Manual D - Residential Duct Systems”. Washington, DC: Air Conditioning Contractors of America.

ACCA. 1995b. “ACCA Manual S - Residential Equipment Selection”. Washington, DC: Air Conditioning Contractors of America.

Alnor. 1998. "LoFlo Balometer ${ }^{\circledR}$ Owners Manual”. Skokie, IL: Alnor Instrument Company.

American Lung Association. 1999. "Asthma in Children Fact Sheet". Asthma Web Site. http://www.lungusa.org/asthma/ascpedfac99.html. September 1999.

Andrews, J.W. 2000. "Measurement Uncertainties in the DeltaQ Test for Duct Leakage". Brookhaven National Laboratory Report BNL-67894.

Andrews, J.W., R.F. Krajewski, and J.J. Strasser. 1996. "Electric Coheating in the ASHRAE Standard Method of Test for Thermal Distribution Efficiency-Test Results on Two New York State Homes". ASHRAE Transactions, Vol. 102, Part 1, pp. 870-880. 
Andrews, J.W., B.L. Pierce, R. Hedrick, M. Lubliner, B. Reid, and D. Saum. 1998. "Repeatability of ASHRAE Standard 152P: Results of a Round Robin Test", ASHRAE Transactions, Vol. 104, Part 1B, pp. 1376-1388.

ASHRAE. 1988. “ANSI/ASHRAE Standard 111-1988, Practices for Measurement, Testing, Adjusting, and Balancing of Building Heating, Ventilation, Air-Conditioning and Refrigeration Systems". Atlanta, GA; American Society of Heating, Refrigerating, and Air-Conditioning Engineers, Inc.

ASHRAE. 1992. “ANSI/ASHRAE Standard 55-1992, Thermal Environmental Conditions for Human Occupancy”. Atlanta, GA; American Society of Heating, Refrigerating, and AirConditioning Engineers, Inc.

ASHRAE. 1993a. “ANSI/ASHRAE Standard 103-1993, Method of Testing for Annual Fuel Utilization Efficiency of Residential Central Furnaces and Boilers". Atlanta, GA; American Society of Heating, Refrigerating, and Air-Conditioning Engineers, Inc.

ASHRAE. 1993b. "ANSI/ASHRAE Standard 118.2-1993, Method of Testing for Rating Residential Water Heaters". Atlanta, GA; American Society of Heating, Refrigerating, and AirConditioning Engineers, Inc.

ASHRAE. 1993c. "ANSI/ASHRAE Standard 136-1993, A Method of Determining Air Change Rates in Detached Dwellings". Atlanta, GA; American Society of Heating, Refrigerating, and Air-Conditioning Engineers, Inc.

ASHRAE. 1994. “ANSI/ASHRAE Standard 119-1988 (RA 94), Air Leakage Performance for Detached Single-Family Residential Buildings". Atlanta, GA; American Society of Heating, Refrigerating, and Air-Conditioning Engineers, Inc.

ASHRAE. 1995. “ANSI/ASHRAE Standard 116-1995, Methods of Testing for Rating Seasonal Efficiency of Unitary Air Conditioners and Heat Pumps”. Atlanta, GA; American Society of Heating, Refrigerating, and Air-Conditioning Engineers, Inc.

ASHRAE. 1997. "ANSI/ASHRAE Standard 129-1997, Measuring Air-Change Effectiveness". Atlanta, GA; American Society of Heating, Refrigerating, and Air-Conditioning Engineers, Inc.

ASHRAE. 1999. "BSR/ASHRAE Draft Standard 152P-1999, Method of Test for Determining the Design and Seasonal Efficiencies of Residential Thermal Distribution Systems". Atlanta, GA; American Society of Heating, Refrigerating, and Air-Conditioning Engineers, Inc.

ASHRAE. 2001. “ASHRAE Handbook - Fundamentals”. Atlanta, GA: American Society of Heating, Refrigerating, and Air-Conditioning Engineers, Inc.

ASHRAE. 2002. "ASHRAE Standard 62.2P - Ventilation and Acceptable Indoor Air Quality in Low-Rise Residential Buildings”. Atlanta, GA: American Society of Heating, Refrigerating and Air-Conditioning Engineers, Inc. April.

ASTM. 1990. “ASTM Standard C1060-90, Standard Practice for Thermographic Inspection of Insulation Installations in Envelope Cavities of Frame Buildings". Philadelphia, PA; American Society for Testing and Materials.

ASTM. 1994. "ASTM Standard E1554-94, Standard Test Methods for Determining External Air Leakage of Air Distribution Systems by Fan Pressurization”. Philadelphia, PA; American Society for Testing and Materials. 
ASTM. 1995. “ASTM Standard E1186-87, Standard Practices for Air Leakage Site Detection in Building Envelopes”. Philadelphia, PA; American Society for Testing and Materials.

ASTM. 1997. “ASTM Standard E1827-96, Standard Test Methods for Determining Airtightness of Buildings Using an Orifice Blower Door”. Philadelphia, PA; American Society for Testing and Materials.

ASTM. 1998. "ASTM Standard D4444-92, Standard Test Methods for Use and Calibration of Handheld Moisture Meters". West Conshohocken, PA: American Society for Testing and Materials.

ASTM. 1999a. "ASTM Standard E779-99, Standard Test Method for Determining Air Leakage Rate by Fan Pressurization”. Philadelphia, PA; American Society for Testing and Materials.

ASTM. 1999b. “ASTM Guide E1998-99, Standard Guide For Assessing DepressurizationInduced Backdrafting and Spillage From Vented Combustion Appliances". Philadelphia, PA; American Society for Testing and Materials.

Barker, K.M. and M.G. Knettel. 1999. "Moisture Entrapment in Buildings with EIFS and Stucco Facades in the State of Florida". Proceedings of SPIE, Vol. 3700, Thermosense XXI, ed. J.R. Snell. March. pp. 463-469.

Bison, P.G., C. Bressan, E. Grinzato, S. Marinetti, and V. Vavilov. 1993. "Active Thermal Testing of Moisture in Bricks". Proceedings of SPIE, Vol. 1933, Thermosense XV, ed. L.R. Allen. April. pp. 207-214.

Bison, P.G., E. Grinzato, and S. Marinetti. 1994. "Moisture Evaluation by Dynamic Thermography Modeling”. Proceedings of SPIE, Vol. 2245, Thermosense XVI, ed. J.R. Snell. March. pp. 176-182.

Blasnik, M., T. Downey, J. Proctor, and G. Peterson.1996. "Assessment of HVAC Installations in New Homes in APS Service Territory”. Proctor Engineering Group Report for Arizona Public Service Company.

Burch, D.M. 1980. "Infrared Audits of Roof Heat Loss". ASHRAE Transactions, Vol. 86, Part 2, pp. 209-226.

Carmody, J., S. Selkowitz, D. Arasteh, and L. Heschong. 2000. "Residential Windows: A Guide to New Technologies and Energy Performance". 2nd Edition. New York: W.W. Norton \& Company.

CEC. 1998. "Low-Rise Residential Alternative Calculation Method Approval Manual for 1998 Energy Efficiency Standards for Low-Rise Residential Buildings”. Sacramento, CA: California Energy Commission. http://www.energy.ca.gov/title24/residential_acm/index.html.

Choat, E.E. 1999. Resolving Duct Leakage Claims. ASHRAE Journal, March 1999. pp. 49-53. Atlanta, GA: American Society of Heating, Refrigerating, and Air-Conditioning Engineers, Inc.

Christian, J.E. and J. Kosny. 1995. “Toward a National Opaque Wall Rating Label”. Proceedings of Thermal Performance of the Exterior Envelopes of Buildings VI, Clearwater Beach, FL, pp. 221-239. Atlanta, GA; American Society of Heating, Refrigerating, and Air-Conditioning Engineers, Inc. 
Christian, J.E., J. Kosny, A.O. Desjarlais, and P.W. Childs. 1998. "The Whole Wall Thermal Performance Calculator - On the Net". Proceedings of the ASHRAE Thermal Performance of the Exterior Envelopes of Buildings VII Conference. Clearwater Beach, FL. Dec 6-10. pp.287-299.

CGSB. 1986. "CAN/CGSB-149.10-M86, Determination of the Airtightness of Building Envelopes by the Fan Depressurization Method". Ottawa, CA; Canadian General Standards Board.

CGSB. 1995. "CAN/CGSB-51.71-95, Method To Determine The Potential For Pressure-Induced Spillage From Vented, Fuel-Fired, Space Heating Appliances, Water Heaters and Fireplaces”. Ottawa, CA; Canadian General Standards Board.

CMHC. 1998. “Renovator's Technical Guide”. Ottawa, ON: Canada Mortgage and Housing Corporation.

ConSol. 1999. "CIEE Final Project Report: Protocols for Energy Efficient Residential Building Envelopes”. Stockton, CA; ConSol.

ConSol. 2000. "Energy Efficient Residential New Construction: Market Transformation, Spectrally Selective Glass". Report to the US Department of Energy, Contract No. DE-FG0199EE27585. Stockton, CA; ConSol. December.

Cummings, J.B. 1998. "Standards and Verification Protocols for Commissioning Airflows in Buildings". Proceedings of the 6th National Conference on Building Commissioning, Lake Buena Vista, Florida. Portland, OR; Portland Energy Conservation Institute.

Davis Energy Group. 2000. "Residential Construction Quality Assessment Project: Phase I Final Report". Report to the California Energy Commission, CEC Report P400-00-022. November.

DeWerth, D.W. and S.M. Sobieski. 1985. "A Three Step Method for Detecting Unacceptable Flue Gas Leakage from Furnace Heat Exchangers". ASHRAE Transactions, Vol. 91, Part 2B, pp. 760-772.

Downey, T. and J. Proctor. 1999. "Residential Central Air Conditioner Service Program Final Report”. Report of Proctor Engineering Group to Pacific Gas \& Electric Company. January 29.

Douglas, J. 2000. Personal communication with Jeff Siegel. November.

Dutton, J. 1994. "Fundamentals of Gas Utilization, Third Edition”. Scarborough, Ontario, Canada; Centennial College Press.

EDTM. 2000. “Manual IG Thickness Gauge, \#MG1500”. Electronic Design To Market, Inc. website http://www.edtm.com/mg1500.htm.

EIMA. 2000. "EIMA Guidelines \& Checklist". Morrow, GA: EIFS Industry Members Association. http://www.dryvit.com/eima.htm. November 1.

Farzad, M. and D.L. O’Neal. 1988. “An Evaluation of Improper Refrigerant Charge on the Performance of a Split System Air Conditioner with Capillary Tube Expansion”. Texas A\&M University, Energy Systems Laboratory Report ESL-TR-88/07-01. July.

Farzad M. and D.L. O'Neal. 1989. "An Evaluation of Improper Refrigerant Charge on the Performance of a Split System Air Conditioner with a Thermal Expansion Valve". Texas A\&M Energy Systems Laboratory, ESL-TR-89/08-01. 
Fitzgerald, J., R. Nevitt, and M. Blasnik. 1994. "User-Friendly Pressure Diagnostics". Home Energy Magazine, Vol. 11, No. 5. Berkeley, CA; Energy Auditor \& Retrofitter, Inc.

Flannigan, B. 1992. "Approaches to Assessment of the Microbial Flora of Buildings". Proceedings IAQ92: Environments for People, San Francisco, California; October 19-21, 1992; pp. 139-145. Atlanta, GA; American Society of Heating, Refrigerating, and Air-Conditioning Engineers.

Francisco, P.W. 2000. Personal Communication with Craig Wray. August.

Francisco, P. and L. Palmiter. 1997. “A Technical Review of ASHRAE Standard 152P”. ECOTOPE Report. Seattle, WA: ECOTOPE. December.

Francisco, P. and L. Palmiter. 1999. "Field Validation of ASHRAE Standard 152”. Final Report, ASHRAE Project 1056-RP.

Francisco, P.W. and L. Palmiter. 2000. "Performance of Duct Leakage Measurement Techniques in Estimating Duct Efficiency: Comparison to Measured Results". Proceedings, 2000 ACEEE Summer Study on Energy Efficient Buildings. Washington, D.C.; American Council for an Energy-Efficient Economy.

Fugler, D.W. 1989. "Canadian Residential Combustion Spillage Monitoring”. ASHRAE Transactions, Vol. 95, Part 1, pp. 100-106.

GAHI. 2000. "The GAHI Protocol for Exterior Insulation Finishing Systems (EIFS) Moisture Intrusion Inspections - One \& Two Family Homes”. Atlanta, GA: Georgia Association of Home Inspectors. http://www.gahi.com/eifsprot.html. November 1.

Griffith, B.T. 1999. "Field Verification of Components: Hand-Held Detector for Low-E and Spectrally Selective Coatings". Berkeley, CA; Lawrence Berkeley National Laboratory, Environmental Energy Technologies Division, Building Technologies Department, Windows \& Daylighting Group website http://windows.lbl.gov/win prop/component_verification.

Grimsrud, D. and D. Hadlich. 1995. "Residential Depressurization Protocol Development and Field Study". Report of Minnesota Building Research Center, University of Minnesota to Gas Research Institute, GRI-95/0324. August.

Grimsrud, D.T., M.D. Koontz, and N.L. Nagda. 1996. "Field Protocol for Determining Depressurization-Induced Backdrafting and Spillage from Vented Residential Gas Appliances (Version 2.0)". Report of Minnesota Building Research Center, University of Minnesota; ENERGEN Consulting, Inc.; and GEOMET Technologies, Inc. to Gas Research Institute and Pacific Gas and Electric Company, GRI-95/0303. August.

Grinzato, E., C. Bressan, P.G. Bison, A. Mazzoldi, P. Baggio, and C. Bonacina. 1992. "Evaluation of Moisture Content in Porous Material by Dynamic Energy Balance". Proceedings of SPIE, Vol. 1682, Thermosense XIV, ed. J.K. Eklund. April. pp. 213-221.

Halvorsen, D., K. Youso, and J. Buchta. 2000. "Special Report: Water Intrusion Can Silently Destroy Houses”. Minneapolis Star Tribune, June 18.

Hassani, V.A. and M. Stetz. 1994. "Application of Infrared Thermography to Room Air Temperature Measurements”. ASHRAE Transactions, Vol. 100, Part 2, pp. 1238-1247.

James, W.L. 1988. “Electric Moisture Meters for Wood.” General Technical Report FPL-GTR-6. Madison, WI: U.S. Department of Agriculture, Forest Service, Forest Products Laboratory. 
Janssen, J.E. and R.W. Rasmussen. 1985. "An Instrument for Measuring Building-Envelope Thermal Resistance". Proceedings of Thermal Performance of the Exterior Envelopes of Buildings III, Clearwater Beach, FL, pp. 723-738. Atlanta, GA; American Society of Heating, Refrigerating, and Air-Conditioning Engineers, Inc.

Jump, D.A., I.S. Walker, and M.P. Modera. 1996. "Field Measurements of Energy Efficiency and Duct Retrofit Effectiveness in Residential Forced Air Distribution Systems". Proceedings, 1996 ACEEE Summer Study on Energy Efficient Buildings. Washington, D.C.: American Council for an Energy-Efficient Economy.

Keithly, P. 1999. "HVAC Controls Specifications: The Good, The Bad, and the Ugly". Proceedings of the 7th National Conference on Building Commissioning, Portland, OR. Portland, OR; Portland Energy Conservation Institute.

Knehans, A.H. and P.E. Styer. 1983. "Thermography - A Diagnostic Tool to Locate Wet Insulation in Built-Up Roofing Systems". ASHRAE Transactions, Vol. 89, Part 2B, pp. 112-117.

Koles, G., R. Hitchcock, and M.H. Sherman. 1996. "Metrics for Building Performance Assurance". Lawrence Berkeley Laboratory Report LBL-39203.

Koontz, M.D. and N.L. Nagda. 1996. "Protocols for Assessing Pressure-Induced Spillage from Gas-Fired Furnaces and Water Heaters (Version 1.1)". Report of ENERGEN Consulting, Inc. and GEOMET Technologies, Inc. to Gas Research Institute and Pacific Gas and Electric Company, GRI-95/0266. July.

Levermore, G.J., D.J. Lowe, and J.W. Ure. 1999. “Occupant Feedback Questionnaire Producing a Fingerprint and a Score”. ASHRAE Transactions, Vol. 105, Part 2, SE-99-5-3.

Lichtman, G., R. Johnson, and D. Steussy. 1999. "Construction Defects Underfoot: Concrete Slab Foundations Affected by Moisture Intrusion, Deterioration”. Claims Magazine, June. Seattle, Washington.

Lstiburek, J. and J. Carmody. 1994. "Moisture Control Handbook: Principles and Practices for Residential and Small Commercial Buildings". New York: Van Nostrand Reinhold.

Margotta, P., J. Corrasi, and J. Craig. 1984. "Wagner Model L-600 Moisture Meter Comparison". Wood Technology Program, University of Massachusetts at Amherst.

Marshall, S.J. 1980. "Detecting Moisture in Buildings Using Infrared Thermography”. Proceedings of SPIE, Vol. 0254, Thermosense III, ed. R.P. Madding. September. pp. 111-117.

Matson, N.E., C.P. Wray, I.S. Walker, and M.H. Sherman. 2002. "Potential Benefits of Commissioning California Homes", Lawrence Berkeley National Laboratory Report to the California Energy Commission. LBNL-48258.

Miller, W.A., H.D. Haynes, F.P. Griffin, W.P. Levins, and M.A. Karnitz. 1989. "Motor-Current Signature Analysis - A Potential Diagnostic for Air Conditioners". ASHRAE Transactions, Vol. 95, Part 1, pp. 312-317.

Modera, M.P., M.H. Sherman, and S.G. de Vinuesa. 1984. "In-Situ Measurement of Wall Thermal Performance: Data Interpretation and Apparatus Design Recommendations". Lawrence Berkeley Laboratory Report LBL-17773.

Modera, M., M. Sherman, and P. Vacheron. 1987. "Pulse Pressurization: A Technique for Measuring Building Air Leakage”. Lawrence Berkeley Laboratory Report LBID-1321. 
Modera, M.P. and D.J. Wilson. 1990. "The Effects of Wind on Residential Building Leakage Measurements". ASTM STP 1067, Air Change Rate and Air Tightness in Buildings, Philadelphia, PA: American Society for Testing and Materials, pp. 132-145. LBL-24195.

Moschandreas, D.J. and S.C. Sofuoglu. 1999. "Indoor Air Pollution Index". Proceedings of the 8th International Conference on Indoor Air Quality and Climate, Edinburgh, Scotland.

Nagda, N.L. 1995. "Workshop on Depressurization, Backdrafting and Indoor Air Quality: Issues and Research Needs". Report of ENERGEN Consulting, Inc. to Gas Research Institute and Pacific Gas and Electric Company, GRI-95/0403. October.

Nagda, N.L., R.W. Krug, and M.D. Koontz. 1995. "Depressurization, Backdrafting, and Spillage from Vented Gas Appliances - A Literature Review”. Report of ENERGEN Consulting, Inc. and GEOMET Technologies, Inc. to Gas Research Institute and Pacific Gas and Electric Company, GRI-95/0426. November.

Nagda, N.L. and M. Koontz. 2000. "Rationale for Proposed Method for Assessing Backdrafting and Spillage”. Presentation at ASTM E6.41 - Mechanical Systems Meeting, Toronto, ON. April 11 .

NAHB. 1997. "Field Demonstration of Alternative Insulation Products". Upper Marlboro, MD; NAHB Research Center Report prepared for U.S. EPA.

Neal, C.L. 1998. "Field Adjusted SEER [SEERFA] Residential Buildings: Technologies, Design, and Performance Analysis". Proceedings of the 1998 ACEEE Summer Study on Energy Efficient Buildings, 1.197. Washington, D.C.; American Council for an Energy-Efficient Economy.

Nelson, G. 2001. Personal Communication with Craig Wray. March.

NFPA. 1999. "NFPA 54-1999: National Fuel Gas Code”. Quincy, MA: National Fire Protection Association.

NHCID. 1998. "Moisture Testing Guide for Wood Frame Construction Clad with Exterior Insulation and Finish Systems (EIFS), Version 3.01". Prepared for EIFS Review Committee. Wilmington, NC: New Hanover County Inspection Department. August 4.

Oberholtzer, D.L. 1993. "Chimney Diagnostics for Safer and Healthy Appliance Venting”. Proceedings of the ASHRAE Indoor Air Quality Conference '93, Philadelphia, PA, pp. 249-253. Atlanta, GA; American Society of Heating, Refrigerating, and Air-Conditioning Engineers, Inc.

Ohnishi, S., T. Sawachi, Y. Taniguchi, H. Ohsawa, and H. Seto. 1998. “A New Experimental Approach for the Evaluation of Domestic Ventilation Systems, Part 3 - Evaluation of Ventilation Systems for an Entire House". ASHRAE Transactions, Vol. 104, Part 1A, pp. 598-611.

O'Neal, D.L., C.J. Ramsey, and M. Farzad. 1989. "An Evaluation of the Effects of Refrigerant Charge on a Residential Central Air Conditioner with Orifice Expansion". Texas A\&M Energy Systems Laboratory, ESL-PA-89/03-01.

Palmiter, L. and P.W. Francisco. 2000. "Development of a Simple Device for Field Air Flow Measurement of Residential Air Handling Equipment: Phase II". Final Report of Ecotope, Inc. to the U.S. Department of Energy, STTR Grant \#DE-FG03-97ER86060. June.

Proctor, J. 1997. "Field Measurements of New Residential Air Conditioners in Phoenix, Arizona”. ASHRAE Transactions, Vol. 103, Part 1. 
Proctor, J. 1998. "Monitored In-Situ Performance of Residential Air-Conditioning Systems". ASHRAE Transactions, Vol. 104. Part 1. 1833-1840.

Proctor, J. 2000. "AC Performance Associated with AB970". Presentation to the California Energy Commission. November 28.

http://www.energy.ca.gov/ab970 standards/documents/presentations/2000-1128 PROCTOR.PPT.

Proctor, J. 2002. Personal Communication with Craig Wray. April.

RDH. 2000. "Building Envelope Rehabilitation: Consultant Guide”. Report of RDH Building Engineering Limited to Canada Mortgage and Housing Corporation. Ottawa, ON: Canadian Housing Information Centre. April.

Rodriguez, A.G. 1995. "Effect of Refrigerant Charge, Duct Leakage, and Evaporator Air Flow on the High Temperature Performance of Air Conditioners and Heat Pumps". Texas A\&M Energy Systems Laboratory, ESL-TH-95/08-01.

Sandberg, P.I. and S. Jahnsson. 1995. "Development of a Method for the Measurement of Specific Heat Loss in Occupied Detached Houses". Proceedings of Thermal Performance of the Exterior Envelopes of Buildings VI, Clearwater Beach, FL, pp. 425-430. Atlanta, GA; American Society of Heating, Refrigerating, and Air-Conditioning Engineers, Inc.

Saunders, D.H., J.J. Duffy, F.S. Luciani, W. Clarke, D. Sherman, L. Kinney, and N.H. Karins. 1994. "Measured Performance Rated Method for Weatherised Homes". ASHRAE Transactions, Vol. 100, Part 1, pp. 1554-1566.

Sherman, M. 1986. "Exegesis of Proposed ASHRAE Standard 119: Air Leakage Performance for Detached Single-Family Residential Buildings". Berkeley, CA; Lawrence Berkeley Laboratory Report LBL-21040.

Sherman, M. and M. Modera. 1986. "Low-Frequency Measurement of Leakage in Enclosures”. Lawrence Berkeley Laboratory Report LBL-20121.

Sherman, M.H. and D.J. Wilson. 1986. "Relating Actual and Effective Ventilation in Determining Indoor Air Quality”. Lawrence Berkeley National Laboratory Report LBL-20424.

Sherman, M.H., R.F. Szydlowski, P.G. Cleary, M.P. Modera, and M.D. Levine. 1987. "Development and Implementation of Survey Techniques for Assessing In-Situ Appliance Efficiencies". Lawrence Berkeley Laboratory Report LBL-23455.

Sherman, M.H. and L. Palmiter. 1994. "Uncertainties in Fan Pressurization Measurements". In Airflow Performance of Envelopes, Components and Systems, Philadelphia, American Society for Testing and Materials (STP 1255), Modera \& Persily Eds., pp. 262-283, 1994. LBL-32115.

Siegel, J. and B. Davis. 1998. "Measured Heating System Efficiency Retrofits in Eight Manufactured (HUD-Code) Homes". Proceedings of the 1998 ACEEE Summer Study on Energy Efficient Buildings, 2.189. Washington, D.C.; American Council for an Energy-Efficient Economy.

Siegel, J. and B. Manclark. 1998. "Pressure Pans: New Uses and Old Fundamentals". Home Energy Magazine, Vol. 15, No. 1, January/February 1998 pp. 37-42. Berkeley, CA; Energy Auditor \& Retrofitter, Inc. 
Simpson, W.T. 1999. "Chapter 12: Drying and Control of Moisture Content and Dimensional Changes, Wood Handbook - Wood as an Engineering Material.” General Technical Report FPLGTR-113. Madison, WI: U.S. Department of Agriculture, Forest Service, Forest Products Laboratory.

Snell, J., M. Sandel, J. Zotter, D. George, and K. Bennett. 2000. "Public Health Concerns and Opportunities for Energy Efficiency Upgrades in Subsidized Housing”. Proceedings of the 2000 ACEEE Summer Study on Energy Efficiency in Buildings.

Sonderegger, R.C., P.E. Condon, and M.P. Modera. 1980. "In-Situ Measurements of Residential Energy Performance using Electric Coheating”. ASHRAE Transactions, Vol. 86, Part 1, pp. 394407.

Sonderegger, R. C., M. H. Sherman, and J. W. Adams. 1981. "The Envelope Thermal Test Unit (ETTU): Field Measurement of Wall Performance”. Berkeley, CA; Lawrence Berkeley Laboratory Report, LBL-13436.

Subbarao, K., D. Mort, and J. Burch. 1985. "Short Term Measurements for the Determination of Envelope Retrofit Performance”. ASHRAE Transactions, Vol. 91, Part 2B, pp. 1516-1524.

Vavilov, V.P., A.I. Ivanov, and A.A. Sengulye. 1991. “Qualitative and Quantitative Evaluation of Moisture in Thermal Insulation by Using Thermography". Proceedings of SPIE, Vol. 1467, Thermosense XIII, ed. G.S. Baird. March. pp. 230-233.

Walker, I., M. Modera, A. Tuluca, and I. Graham. 1996. "Energy Effectiveness of Duct Sealing and Insulation in Two Multifamily Buildings". Proceedings of 1996 ACEEE Summer Study, Asilomar, CA. Washington, D.C.; American Council for an Energy-Efficient Economy.

Walker, I., M. Sherman, M. Modera, and J. Siegel. 1998a. "Leakage Diagnostics, Sealant Longevity, Sizing and Technology Transfer in Residential Thermal Distribution Systems". Lawrence Berkeley National Laboratory Report LBNL-41118. http://epb1.1bl.gov/EPB/Publications/lbl-41118.pdf.

Walker, I., M. Sherman, M. Modera, and J. Siegel. 1998b. "Leakage Diagnostics, Sealant Longevity, Sizing and Technology Transfer in Residential Thermal Distribution Systems: Part II". Lawrence Berkeley National Laboratory Report LBNL-42691.

Walker, I.S., J. Siegel, K. Brown, and M.H. Sherman. 1998c. "Saving Tons at the Register". Proceedings of 1998 ACEEE Summer Study, Pacific Grove, CA. Washington, D.C.; American Council for an Energy-Efficient Economy. Also Lawrence Berkeley National Laboratory Report LBNL-41957. http://epb1.lbl.gov/EPB/Publications/lbnl-41957.pdf.

Walker, I., M. Sherman, and J. Siegel. 1999. "Distribution Effectiveness and Impacts on Equipment Sizing”. Lawrence Berkeley National Laboratory Report LBNL 43724. http://epb1.lbl.gov/EPB/Publications/lbnl-43724.pdf.

Walker, I.S., C.P. Wray, D.J. Dickerhoff, and M.H. Sherman. 2001. Evaluation of Flow Hood Measurements for Residential Register Flows. Lawrence Berkeley National Laboratory Report LBNL Report 47382.

Warren, S.R. (editor). 1994. “ASTM Hand-Held Moisture Meter Workshop”. Madison, WI: Forest Products Society. 
Wempen, J. 2000. "Repeatability of the DeltaQ Duct Leakage Test Method". Final Report for the Office of Science, DOE Energy Research Undergraduate Laboratory Fellowship Program. August 8.

Wilcox, B., K. Nittler, D.A. Ross, and J. Proctor. 2001. "Split System Space Cooling Refrigerant Charge and Airflow Measurement". Contractors Report, California energy Commission

Publication No. P 400-01-014. March 20. http://www.energy.ca.gov/reports/2001-03-20 400-01014.PDF.

Wild, W., K.A. Buscher, and H. Wiggenhauser. 1998. “Amplitude Sensitive ModulationThermography to Measure Moisture in Building Materials”. Proceedings of SPIE, Vol. 3361, Thermosense XX. March. pp. 156-163.

Wray, C.P., M.A. Piette, M.H. Sherman, R.M. Levinson, N.E. Matson, D.A. Driscoll, J.A. McWilliams, T.T. Xu, and W.W. Delp. 2000. "Residential Commissioning: A Review of Related Literature". Lawrence Berkeley National Laboratory Report LBNL-44535.

http://epb1.lbl.gov/EPB/Publications/lbnl-44535.pdf.

Yuill, G.K. 1986. "The Variation of the Effective Natural Ventilation Rate with Weather Conditions". Renewable Energy Conference '86, Solar Energy Society of Canada Inc., pp.70-75.

Yuill, G.K. 1991. "The Development of a Method of Determining Air Change Rates in Detached Dwellings for Assessing Indoor Air Quality". ASHRAE Transactions, Vol. 97, Part 2. 


\section{APPENDIX A: LABORATORY AND FIELD STUDY RESULTS}

This appendix describes several recent laboratory and field studies that LBNL staff and others have carried out at more than 100 houses. The purpose of these evaluations is to determine the accuracy and usability of existing diagnostics that we expect to include in the commissioning guide we are preparing. Because these studies precede writing the guide, they do not necessarily use the expedited commissioning techniques that we will describe in the guide.

Our efforts concentrated on evaluating diagnostics in the following four areas:

- Duct leakage (DeltaQ) tests

- Air-handler airflow tests

- Distribution system (supply and return grille) airflow tests

- Refrigerant charge tests

The majority of our effort in this project focused on detailed measurements in four California houses, over the course of one day in each house. To the extent possible, we chose specific houses to maximize the range of system types and commissioning issues studied. However, not every diagnostic was tested at each site. These studies in general were not intended to provide statistically representative samples, so it was not necessary to test houses representative of every climate zone throughout California. To the extent that it was possible to cooperate with other field projects, we augmented the number of houses in our evaluation discussions. We also used data from available literature to supplement these discussions.

The length of time we spent in each house does not represent how long it might take to commission a house, because actual commissioning may not address every facet of performance in each house. Furthermore, the time that we spent in each house was more research oriented and focused on collecting sufficient data that would enable us to evaluate specific diagnostics that might be useful in commissioning. 


\section{EVALUATION OF THE DELTAQ DUCT LEAKAGE TEST}

Much of our focus in evaluating duct leakage tests was on the DeltaQ test, because it is new. In cooperation with other projects that involve developing the DeltaQ test, LBNL and Brookhaven National Laboratory (BNL) have carried out repeatability tests to estimate uncertainties in this test method. In addition, several research teams have carried out the DeltaQ test in more than 100 houses to show that it is usable in a wide range of houses and to identify limits or problems in field applications. Many of these field tests also involved duct leakage tests using other methods. The following summarizes the results of these efforts.

\section{Repeatability Testing}

To evaluate the repeatability of the DeltaQ test method, we carried out multiple DeltaQ tests of a building at LBNL (Wempen 2000). The test building is located in a coastal hillside canyon at LBNL in Berkeley, California. Canyon walls, trees, and nearby similarly-sized buildings significantly shelter the test building from direct exposure to coastal winds. The test building has a $24 \mathrm{ft}(7.3 \mathrm{~m})$ by $50 \mathrm{ft}(15.2 \mathrm{~m})$ floor plan, with the long axis aligned with the prevailing winds. Interior floor to ceiling height was $8 \mathrm{ft}(2.4 \mathrm{~m})$. There are no interior walls or partitions. Fanassisted flow hood and tracer gas measurements indicated the air-handler airflow in this building is approximately $1,000 \mathrm{cfm}$. We tested the same envelope, air-handler, and duct system configuration 20 times over several days in mild weather with wind speeds up to $5 \mathrm{mph}(8 \mathrm{~km} / \mathrm{h})$.

Table A1 summarizes the repeatability test results in terms of the average leakage, the standard deviation, and the $95 \%$ confidence interval (C.I.). The repeatability errors (95\% C.I.) listed in Table A1 are quite small in absolute terms, but are large compared to the small average leakage flows. However, we need to consider these errors in proper perspective. In terms of the uncertainty in calculating energy losses from the duct system and in terms of testing if a system meets low leakage specifications, the uncertainty as a fraction of air-handler airflow is the most important factor. Compared to this flow, the duct leakage and uncertainty in leakage are small. In this case, the $95 \%$ confidence intervals for supply and return leakage are in the range of 0.5 to $1.0 \%$ of the fan flow. This is an excellent result. In the future, we expect to repeat these tests with greater supply and return leakage (and changed trailer envelope leakage).

Table A1. Results of LBNL DeltaQ repeatability tests.

\begin{tabular}{|c|c|c|c|c|c|}
\hline \multicolumn{6}{|c|}{ Absolute Leakage, $\mathrm{cfm}$} \\
\hline \multicolumn{2}{|c|}{ Average } & \multicolumn{2}{|c|}{ Standard Deviation } & \multicolumn{2}{|c|}{$95 \%$ Confidence Interval } \\
\hline Supply & Return & Supply & Return & Supply & Return \\
\hline 19 & 66 & 11 & 16 & 5 & 7 \\
\hline \multicolumn{6}{|c|}{ Fractional Leakage, $\%$ of $1,000 \mathrm{cfm}$ Air-Handler Airflow } \\
\hline \multicolumn{2}{|c|}{ Average } & \multicolumn{2}{|c|}{ Standard Deviation } & \multicolumn{2}{|c|}{$95 \%$ Confidence Interval } \\
\hline Supply & Return & Supply & Return & Supply & Return \\
\hline 1.9 & 6.6 & 1.1 & 1.6 & 0.5 & 0.7 \\
\hline
\end{tabular}

We expect that fluctuations in envelope pressure difference during the DeltaQ test (mostly due to fluctuating wind speed and direction) could lead to increased test result variations. However, our 
repeatability results (shown in Figure A1) indicate that the test result variability does not increase very much with the measured envelope pressure difference variability, which is represented by the standard deviation of the envelope pressure differences that we measured with the air handler and blower door off. This is a good result, because we want the test to be relatively insensitive to these pressure fluctuations and to be repeatable over a wide range of weather conditions.

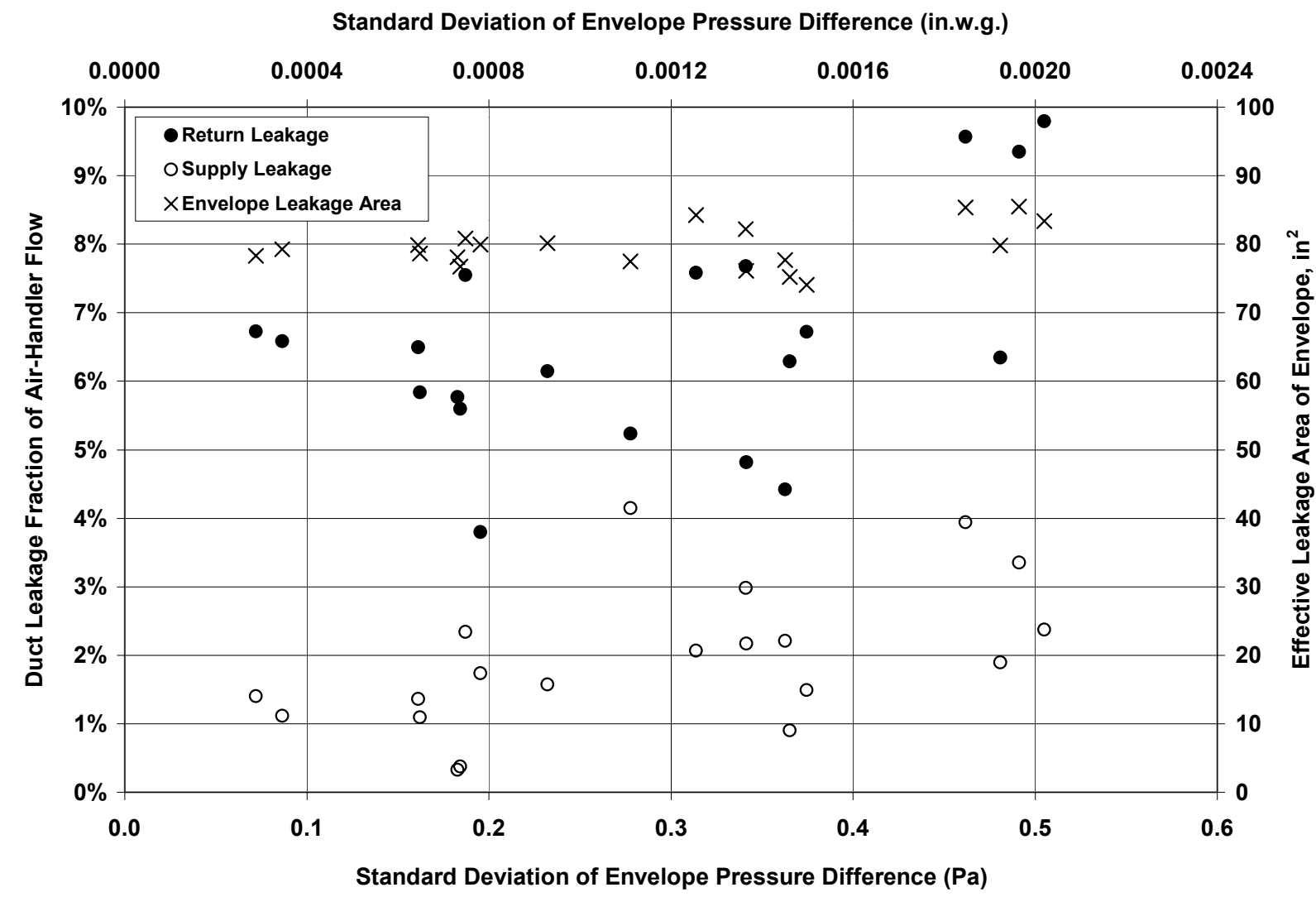

Figure A1. LBNL DeltaQ repeatability test results.

John Andrews (2000) of BNL has performed the DeltaQ test three times each in two Long Island, NY houses. For each house, Table A2 shows the average leakage and the average absolute difference from the mean for the three tests. The average differences are similar in magnitude to the LBNL tests described above, but are proportionally less as a fraction of the duct system leakage because the duct leakage was much higher in the BNL systems.

Table A2. Results of BNL DeltaQ repeatability tests.

\begin{tabular}{|c|cc|cc|}
\hline \multirow{2}{*}{ House } & \multicolumn{2}{|c|}{ Supply Leakage, cfm } & \multicolumn{2}{c|}{ Return Leakage, cfm } \\
\cline { 2 - 5 } & Average & $\begin{array}{c}\text { Average Difference } \\
\text { from the Mean }\end{array}$ & Average & $\begin{array}{c}\text { Average Difference } \\
\text { from the Mean }\end{array}$ \\
\hline \hline 1 & 214 & 8 & 46 & 14 \\
\hline 2 & 72 & 19 & 286 & 9 \\
\hline
\end{tabular}




\section{Field Experience}

Initial Pilot Test: We performed the pilot test of the DeltaQ procedure in a Berkeley, California house with well-known system characteristics, where we have already made several other duct leakage measurements. For this first house, we performed the measurements manually, without computer control or data acquisition. Table A3 summarizes the test results.

Table A3. Comparison of duct leakage obtained using various test methods.

\begin{tabular}{|c|c|c|c|c|c|}
\hline \multirow{2}{*}{ Case } & \multicolumn{5}{|c|}{ Duct Leakage, cfm } \\
\cline { 2 - 6 } & DeltaQ & NPT & Tracer Gas & Duct Pressurization $^{1}$ & Duct Pressurization $^{2}$ \\
\hline \hline Supply & 5 & 17 & n/a & 30 & 51 \\
\hline Return & 181 & 151 & 160 & 95 & 116 \\
\hline
\end{tabular}

${ }^{1}$ Determined using operating pressures based on plenum pressure measurements.

${ }^{2}$ Determined using operating pressures based on pressure pan measurements.

The agreement between the DeltaQ test, nulling pressure test (NPT), and tracer gas results indicates that the duct pressurization test is overestimating the supply leakage and underestimating the return leakage. Most of the difference is due to uncertainty in the duct pressurization test when estimating the pressures across the duct leaks.

Initial Field Evaluations: In an effort to determine the practical limits of using the DeltaQ test, several researchers from LBNL, BNL, and Davis Energy Group (DEG) have applied this test procedure to 17 other houses. In most cases, they also performed duct pressurization tests and air-handler airflow tests. BNL staff performed the DeltaQ tests manually (Andrews 2000). LBNL and DEG staff performed the DeltaQ tests using LBNL-developed automation software. Table A4 lists the air-handler airflow and DeltaQ test results for the 17 houses.

The 17 test houses cover a wide age range from new to old (zero to 100 years), a large range of sizes (up to about 3,700 $\mathrm{ft}^{2}$ ), and a large range of duct system sizes (as shown by the range of airhandler airflows). The duct system materials include sheet metal, duct board, and flexible plastic. The majority of the ducts in the California and Nevada houses are located in the attic, with some systems having ducts in crawlspaces. The New York houses have the majority of their ducts located in unheated and uninsulated basements. The last four houses listed in Table A4 are the ones that we monitored in detail to evaluate various diagnostics.

Figure A2 illustrates DeltaQ and duct pressurization test results for the pilot test and for 12 of the 17 houses. It includes an equality line representing perfect agreement between tests. Comparing aggregate results, the average total leakage (supply plus return) fraction of air-handler airflow was slightly higher for the duct pressurization test (21\%) than for the DeltaQ test $(19 \%)$. Comparing individual tests, the average absolute difference of $7 \%$ of air-handler airflow was considerably larger.

CSUC/LBNL Field Tests: Experienced HVAC technicians and undergraduate engineering students in conjunction with California State University Chico and LBNL have recently completed field tests of over 100 more California houses, with the goal in part to assess duct leakage in systems that are between 5 and 20 years old. The field tests involve using the DeltaQ 
and duct pressurization tests, and measuring air-handler airflows. The DeltaQ tests used a computer-based data acquisition and control program developed by LBNL.

Table A4. Initial field evaluations - DeltaQ test results.

\begin{tabular}{|c|c|cc|cc|}
\hline & \multirow{2}{*}{$\begin{array}{c}\text { Air-Handler } \\
\text { Airflow }\end{array}$} & \multicolumn{2}{|c|}{$\begin{array}{c}\text { Duct Leakage } \\
(\mathrm{cfm})\end{array}$} & \multicolumn{2}{c|}{$\begin{array}{c}\text { Leakage Fraction of } \\
\text { Air-Handler Airflow }\end{array}$} \\
\cline { 3 - 6 } & $(\mathrm{cfm})$ & Supply & Return & Supply & Return \\
\hline Long Island, NY & 679 & 214 & 46 & $32 \%$ & $7 \%$ \\
\hline Long Island, NY & 912 & 72 & 286 & $8 \%$ & $31 \%$ \\
\hline Las Vegas, NV & 1,551 & 81 & 14 & $5 \%$ & $1 \%$ \\
\hline Las Vegas, NV & 1,900 & 18 & 23 & $1 \%$ & $1 \%$ \\
\hline Las Vegas, NV & 2,114 & 3 & 11 & $0 \%$ & $1 \%$ \\
\hline Alameda, CA & 1,265 & 48 & 64 & $4 \%$ & $5 \%$ \\
\hline Folsom, CA & 1,200 & 52 & 46 & $4 \%$ & $4 \%$ \\
\hline Pleasanton, CA & 1,600 & 61 & 47 & $4 \%$ & $3 \%$ \\
\hline San Francisco, CA & 515 & 58 & 106 & $11 \%$ & $21 \%$ \\
\hline Tracy, CA & 1,782 & 109 & 61 & $6 \%$ & $3 \%$ \\
\hline Tracy, CA & 1,525 & 70 & 64 & $5 \%$ & $4 \%$ \\
\hline Tracy, CA & 2,494 & 102 & 53 & $4 \%$ & $2 \%$ \\
\hline Walnut Creek, CA & 879 & 136 & 58 & $15 \%$ & $7 \%$ \\
\hline \hline Larkspur, CA (Site 1) & 1,216 & 123 & 205 & $10 \%$ & $17 \%$ \\
\hline Sacramento, CA (Site 2) & 1,257 & 10 & 48 & $1 \%$ & $4 \%$ \\
\hline Sacramento, CA (Site 3) & 1,345 & 19 & 49 & $1 \%$ & $4 \%$ \\
\hline Concord, CA (Site 4) & 804 & 96 & 265 & $12 \%$ & $33 \%$ \\
\hline
\end{tabular}

Our initial analyses also show that the DeltaQ test is fairly rugged. In windy conditions, indooroutdoor pressure differences can vary widely during the test. However, these large variations do not lead to large variations in the test results. This is an important factor, because previous work by Walker et al. (1998a) showed that other test methods that use the pressures measured across the building envelope have high sensitivity to wind and envelope conditions.

The DeltaQ test does not have these sensitivities because it uses multiple pressure readings over a wide range, so that an individual poor measurement does not corrupt the entire test. Also, many of the test pressures are significantly higher than those imposed on the building by the weather, which reduces the sensitivity to weather effects. Figure A3 shows the results of a sample DeltaQ test. In Figure A3, Qs represents supply leakage, and Qr represents return leakage. LSQ refers to the least squares equation fit applied to the difference in flows (DeltaQ's) when calculating duct 
leakage. To better illustrate the variation in DeltaQ flows, Figure A3 shows them multiplied by a factor of 10 .

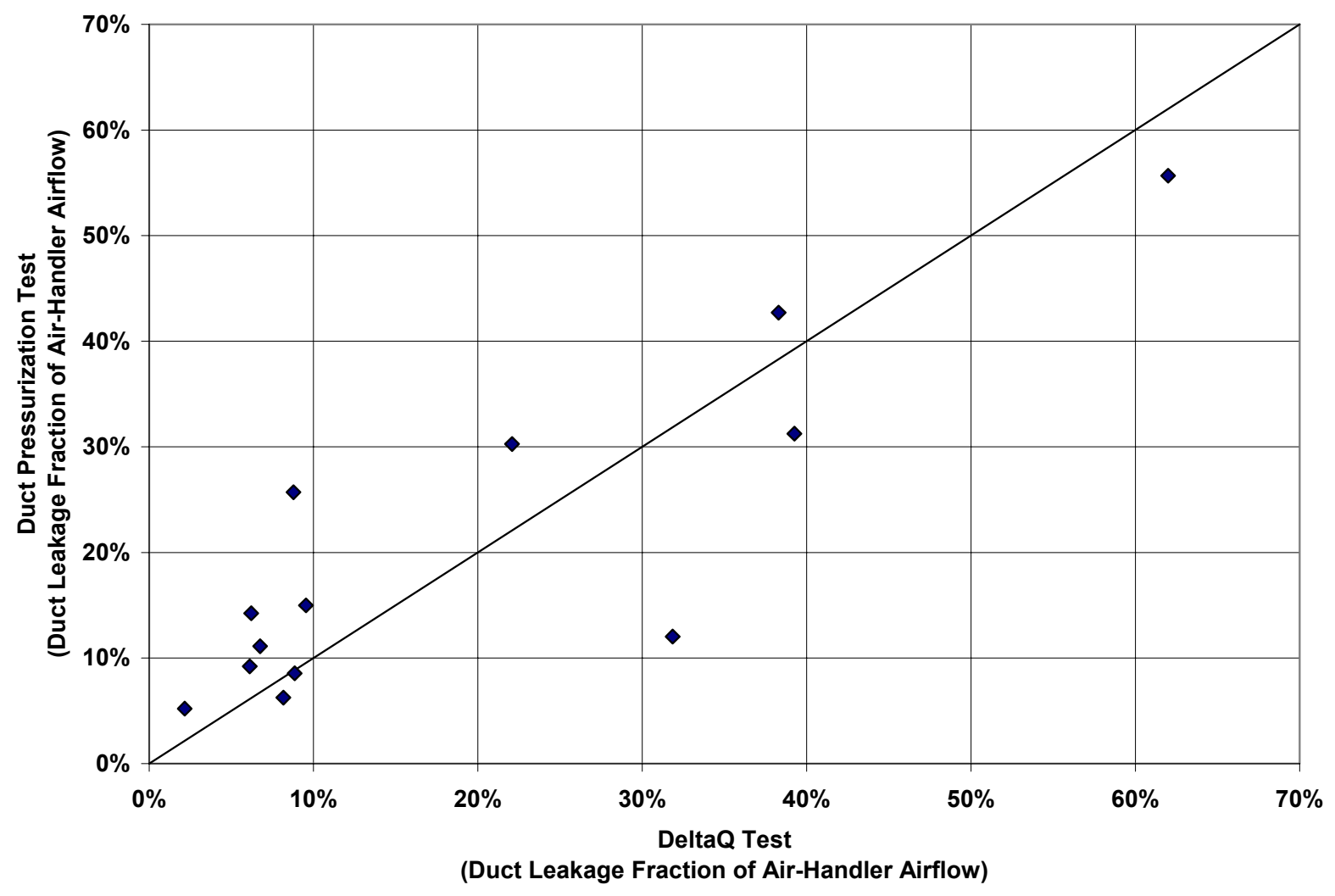

Figure A2. Comparison of duct pressurization and DeltaQ test results for total (supply plus return) duct leakage.

We have carried out related work to assess the potential for errors caused by uncertainty in the duct reference pressure that the DeltaQ test uses to calculate duct leakage. We found that even fairly large changes in duct reference pressure did not change the final duct leakage result a great deal. Even when this pressure is changed by a factor of two, the supply and return leakage only changes by about 10 to $15 \%$.

When the duct leakage is small, the DeltaQ test can sometimes yield negative numbers for supply or return leakage. Two factors contribute to this behavior. One is that the precision of the test is limited to about 10 to $20 \mathrm{cfm}$. The other is that, at these low leakage levels, the results become more sensitive to "outliers" in the measured data. Generally, when negative numbers result from the test, this shows that the duct system is not leaky and the test result should be interpreted to mean that the leakage is less than the precision of the test procedure (i.e., less than 10 to $20 \mathrm{cfm}$ ). This implies that the leakage flows typically will be less than about $1 \%$ of fan flow and therefore are not significant in terms of energy losses or poor distribution. Also, any system with this little leakage will pass any of the existing (and probably future) leakage limits found in energy codes. For example, the CEC "Low-Rise Residential Alternative Calculation Method Approval Manual" (1998) specifies a 6\% of fan flow limit for duct leakage. Voluntary programs such as EPA Energy Star ducts have a 10\% of fan flow limit. Therefore, these precision errors are not a significant barrier to the use of the DeltaQ test. 
DeltaQ Duct Leakage Test

Site 3 - September 20, 2000

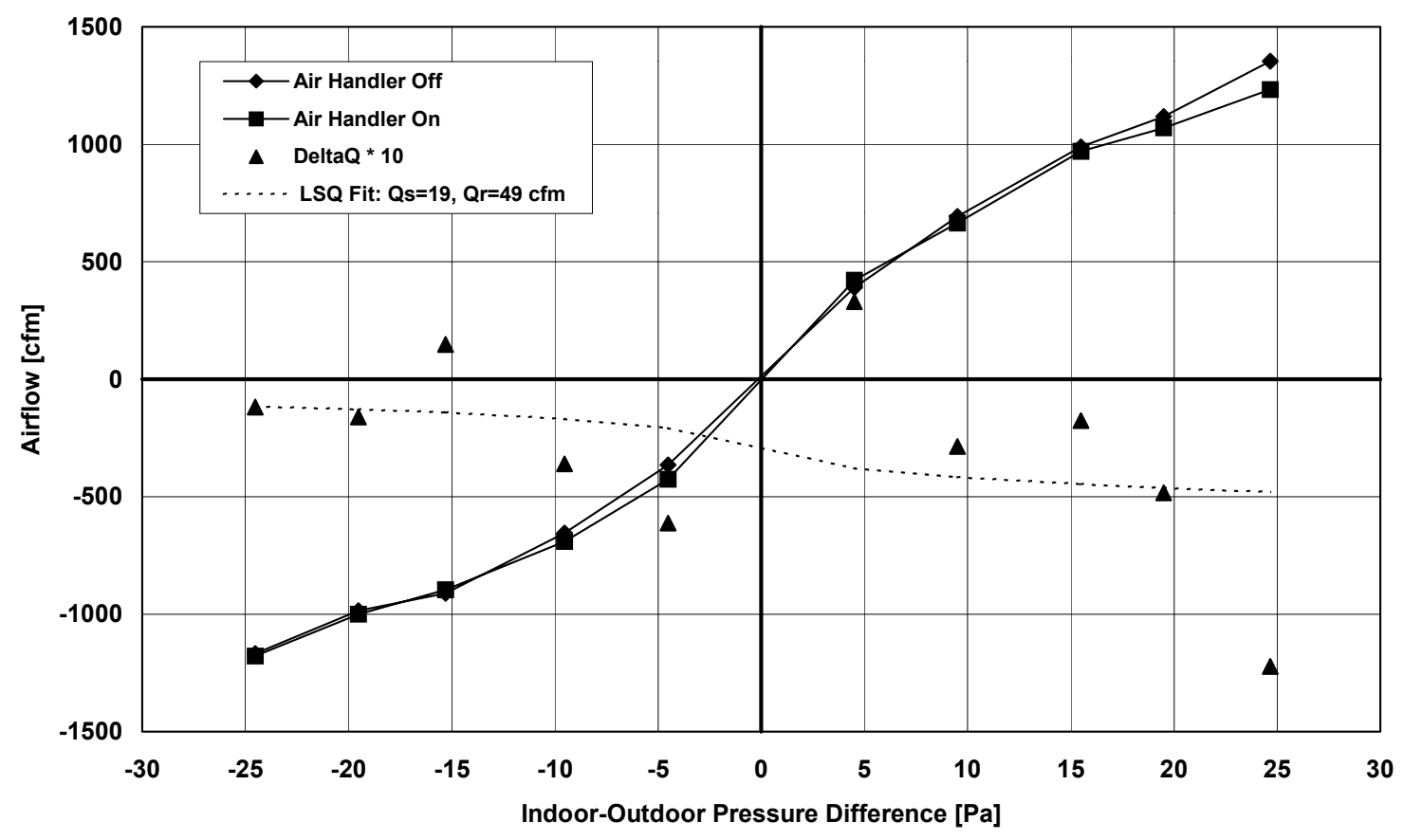

Figure A3. Sample DeltaQ test results.

\section{Summary}

Our initial analyses of duct leakage tests at over 100 houses and at our laboratory show that the DeltaQ test procedure is fairly rugged, unlike other test methods that use pressures measured across the building envelope. In windy conditions, indoor-outdoor pressure differences can vary widely during the test. However, these large variations do not lead to large variations in the test results. The test is also relatively insensitive to large changes in duct reference pressure. This is in contrast to the large leakage flow uncertainty in the duct pressurization test associated with estimating the pressures across the duct leaks.

Precision of the DeltaQ test is limited to about 10 to $20 \mathrm{cfm}$. Leakage flows less than this typically will be less than about $1 \%$ of fan flow and therefore are not significant in terms of energy losses or poor distribution. 


\section{EVALUATION OF AIR-HANDLER AIRFLOW TESTS}

ACCA Manual S (1995b) describes a design procedure for estimating the air-handler airflow required for a residential cooling system at design conditions. It depends on the evaporator sensible load and on the dry-bulb air temperature drop across the evaporator. For air entering the evaporator with a dry-bulb air temperature of $75^{\circ} \mathrm{F}$ and a $50 \%$ relative humidity, the procedure attempts to achieve a dry-bulb temperature of 54 to $58^{\circ} \mathrm{F}$ for the air leaving the evaporator. For sensible heat ratios (SHR) in the range of 0.80 to 0.85 , the resulting flows are in the range of 415 to $545 \mathrm{cfm} /$ ton of total evaporator capacity (sum of sensible and latent capacities). The lower airflows correspond to lower SHRs (higher latent loads) and result in a colder evaporator and leaving air temperature. These conditions are intended to minimize fan power and achieve adequate humidity control while avoiding evaporator icing.

Manufacturers typically recommend a lower airflow range: 350 to $450 \mathrm{cfm}$ per nominal ton of evaporator total capacity. The lower airflow is more appropriate for use in humid climates. Using the dry-bulb temperatures described above for air entering and leaving the evaporator (with $54^{\circ} \mathrm{F}$ as a minimum), an airflow of $350 \mathrm{cfm} /$ ton corresponds to an SHR of 0.67 . The airflow target introduced in the AB970 2001 revisions to Title 24 is in the lower half of the manufacturer range: $385 \mathrm{cfm} /$ ton (Wilcox et al. 2001).

Often, installed equipment does not meet any of the targets described above. For example, Blasnik et al. (1996) tested 28 systems and found that more than 50\% had flows below 350 $\mathrm{cfm} /$ ton. The average system had $86 \%$ of the manufacturer's recommended airflow (standard deviation of $16 \%$ ). The worst system had as little as $57 \%$ of the manufacturer's recommended airflow. Seven systems had flows that were at or above the manufacturers recommended flow. A common reason for low airflow was an undersized, restrictive flex duct system.

Manufacturers recommend corrective action when airflows are below $350 \mathrm{cfm} /$ ton, because airflows this low can cause evaporator icing. Ice on the evaporator insulates it and increases system flow resistance, which reduces air-handler airflow. The resulting reduction in heat transfer from the air to the refrigerant can cause liquid refrigerant to enter the compressor and damage it.

Too low an airflow also reduces total and sensible capacity, and reduces efficiency. However, latent capacity increases as airflow decreases (ACCA 1995b). This occurs because sensible capacity decreases faster than total capacity. Rodriguez (1995) tested the effect of reduced airflow on two 3.5-ton heat pumps. One heat pump had a reciprocating compressor and a shorttube-orifice expansion device; the other had a scroll compressor and a TXV. Figure A4 shows the impact of reduced airflow on equipment performance in terms of total capacity and energy efficiency ratio (EER). For the short-tube-orifice-controlled heat pump, these data indicate that at a $14 \%$ reduction in flow (e.g., to $344 \mathrm{cfm} /$ ton from $400 \mathrm{cfm} /$ ton), total capacity is reduced $7 \%$ and EER is reduced 6\%. For the TXV-controlled heat pump, the reductions in capacity and EER are less (only about $2 \%$ at the same airflow reduction).

Several diagnostic tools and techniques are available to measure air-handler airflow. Two of the most promising tools include a fan-assisted flow meter (Walker et al. 1999), and a flow plate and grid (Palmiter and Francisco 2000). Both are commercially available. The following describes our field studies to evaluate these two methods, along with three other methods that one might consider. 


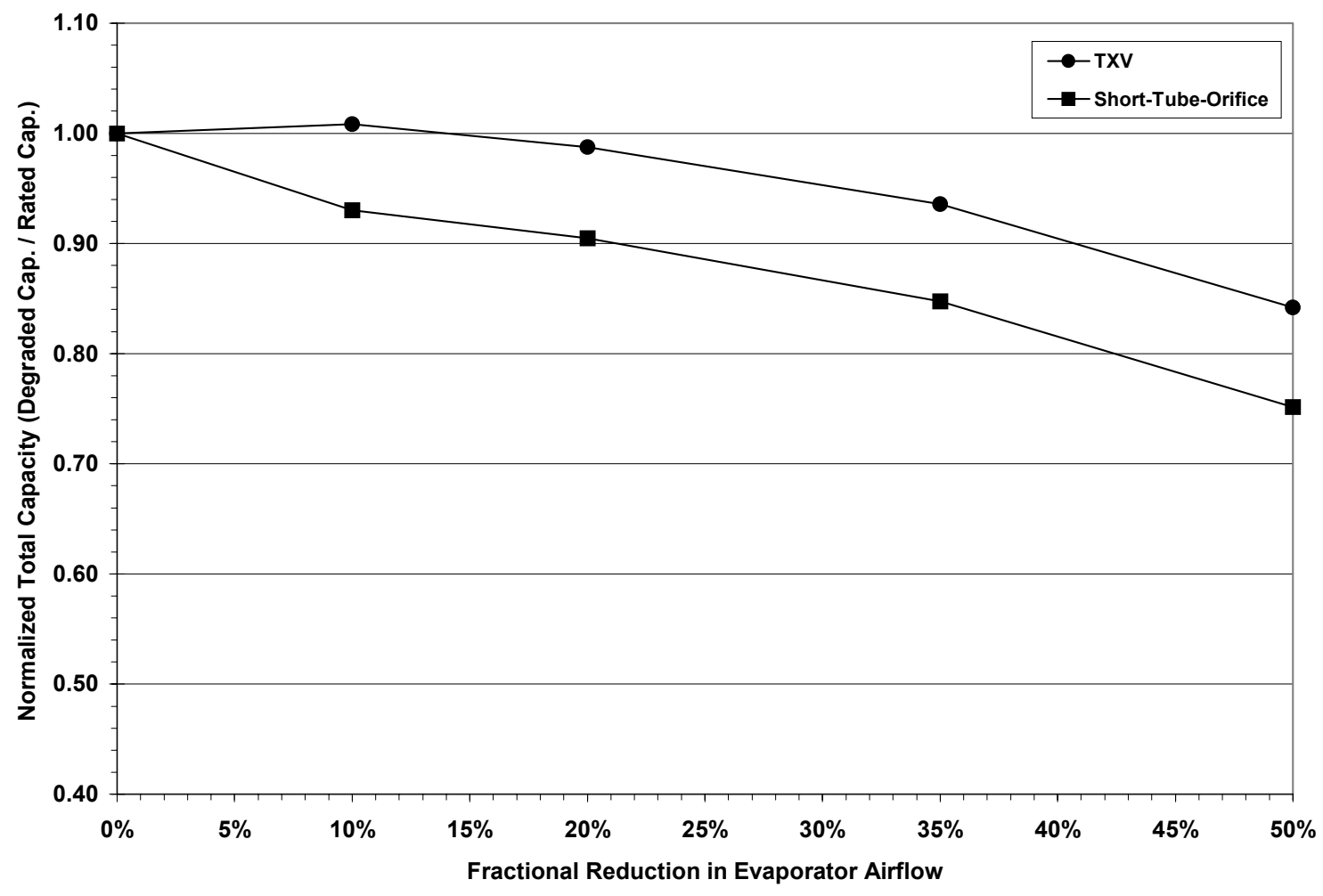

Figure A4a. Effects of reduced airflow on heat pump capacity (Rodriguez et al. 1995).

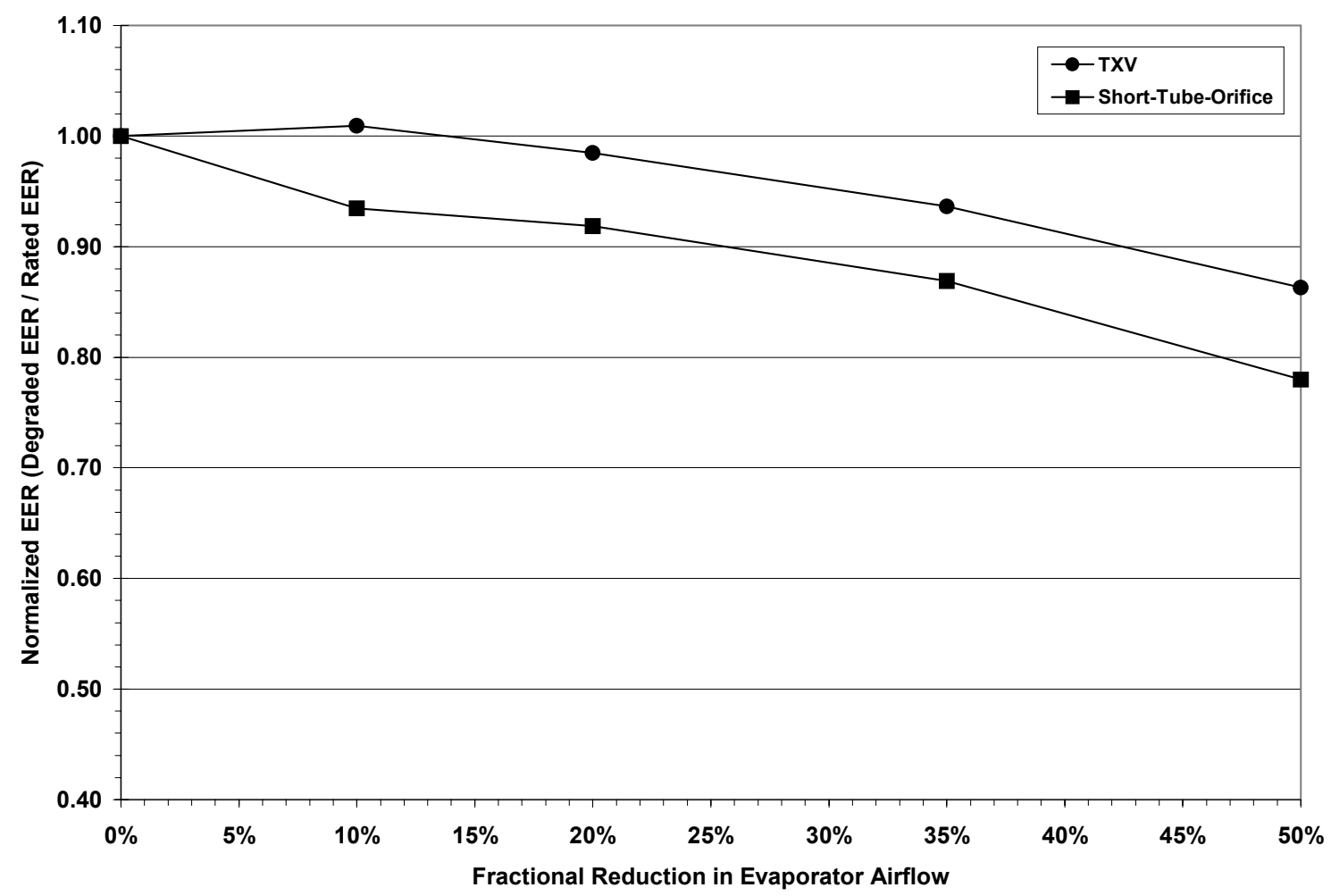

Figure A4b. Effects of reduced airflow on heat pump EER (Rodriguez et al. 1995). 


\section{Methods Evaluated}

Fan-Assisted Flow Meter: This device uses a calibrated flow meter combined with a fan to determine air-handler airflow. It is essentially the same device as the one used in duct pressurization tests. There are two possible test configurations: attached to the air-handler cabinet at its access door, or attached at a return grille if the return ducting is well sealed. If the return duct is leaky, then its leakage needs to be added to the measured flow. Attaching the device is time-consuming. If the device is connected to the air-handler cabinet, additional time is required to seal off the return upstream of the air handler.

With the air handler running, air is blown into the air handler or return (with the return sealed if connecting to the air handler). The goal of this test is to reproduce the pressure difference between the supply plenum and conditioned space under normal system operating conditions. If this operating pressure cannot be achieved due to capacity limits of the fan on the flow meter, then multiple measurements of flow and supply plenum static pressure are used to extrapolate to the operating pressure.

For our evaluations, we attached the fan-assisted flow meter to the air-handler cabinet, to avoid having to include the duct leakage in our measurement.

Flow Plate and Grid: This new device uses a calibrated multiple-orifice plate with attached upstream and downstream pressure manifolds to determine air-handler airflow. During a test, it is inserted into an air filter body in place of the filter. The pressure drop of the device is intended to be similar to that of air filter. In general, the "measured" airflow needs to be corrected to account for the difference in supply plenum static pressure with the device installed instead of the filter. Also, when the flow plate is mounted at a filter grille, the return duct leakage needs to be added to the measured flow.

Other Techniques: In addition to the two methods described above, we evaluated three other methods:

- the sum of duct branch flows,

- the dry-bulb temperature drop of air entering and leaving the evaporator in cooling mode or temperature rise of air entering and leaving the furnace heat exchanger in heating mode (Downey and Proctor 1999), and

- a tracer gas (Walker et al. 1998b).

Measuring individual duct branch flows and summing them can lead to substantial errors, depending on the type of flow hood that is used. As described elsewhere in this report, much of the uncertainty is due to inaccuracy when commercially available flow hoods are used, or when duct leakage is not properly taken into account. The uncertainty in the larger duct flows will govern the uncertainty in the total flow. If an accurate flow hood (such as a fan-assisted one) is used, and there is an accurate estimate of duct leakage, then this method can be an acceptable means of measuring air-handler airflow.

Of the other two techniques, the second is prone to heating mode errors of more than $20 \%$ in many cases and near a factor of two in worst cases, due to flow nonuniformities and radiant effects (Palmiter and Francisco 2000). However, because of its simplicity, this technique has been introduced as a test method in Title 24 (Wilcox et al. 2001). The test does not actually determine the airflow rate. Instead, it is intended to indicate whether the airflow is adequate 
(using a target based on $385 \mathrm{cfm} / \mathrm{ton}$ ). It specifies a target temperature difference as a function of the dry-bulb and wet-bulb temperatures of the air entering the evaporator. Airflow is considered adequate if the measured temperature difference is within $3^{\circ} \mathrm{F}$ of the target. If it is above the target upper bound, then the airflow is too low. If it is below the target lower bound, then the evaporator capacity is too low (or less likely, the airflow is too high).

While using a tracer gas can be very accurate, it requires expensive, delicate equipment and a well-trained technician. It is also subject to flow-nonuniformity-induced mixing errors, which are difficult to assess in the field.

We considered one other method but excluded it from our field evaluation: fan curve interpolation. This method cannot be relied upon, because manufacturer's fan curve data are not easily or generally available for residential systems. When it is available, it may not accurately represent the installed performance of the fan due to system effects. These effects can vary significantly and are difficult to estimate. In addition, it is not possible to measure the static pressure drop in the duct system at the same locations as those used to produce the manufacturer's fan curve.

\section{Field Study One}

Our evaluations of techniques to measure air-handler airflow began a few years ago with a field study in five new houses located in California and one new house in Texas (Walker et al. 1998b). All the houses except one have split-system central air conditioners and are heated by natural gas. The Texas house has a heat pump with electric strip heat.

In our tests, we used one or more of three different techniques in each house:

- directly measuring the air-handler airflow using a tracer gas,

- directly measuring the air-handler airflow using a fan-assisted flow meter attached to the air handler cabinet, and

- indirectly determining the air-handler airflow as the sum of supply duct flows (measured using a fan-assisted flow hood) and supply duct total leakage (estimated using duct pressurization techniques).

Not all tests were carried out in every house. The tests that were carried out in a house were done at least twice. The various cases included flows "as found"; flows with different duct leakage; and, in one case, flows with different cooling equipment. In all, this resulted in 14 sets of measurements. Figure A5 shows the results of our tests. The notation for the cases in Figure A5 is house number and then case number.

There was generally good agreement between the three test methods. Using the tracer gas test results as a benchmark, the fan-assisted flow meter results on average were within $11 \%$ $(200 \mathrm{cfm})$; the sum of supplies plus duct leakage on average were within $10 \%(150 \mathrm{cfm})$.

In our flow hood evaluations, we found that a fan-assisted flow meter coupled to a flow hood is an accurate device for measuring supply and return airflows (relative absolute error of $2 \%$ ). Clearly, this accuracy does not necessarily represent that of the fan-assisted flow meter applied to measuring air-handler airflow. The latter accuracy is not well defined at this time and cannot be easily estimated, due to the possibility of flow pattern changes within the air handler or static pressure measurement errors. Further research is needed to establish the accuracy of this method. 


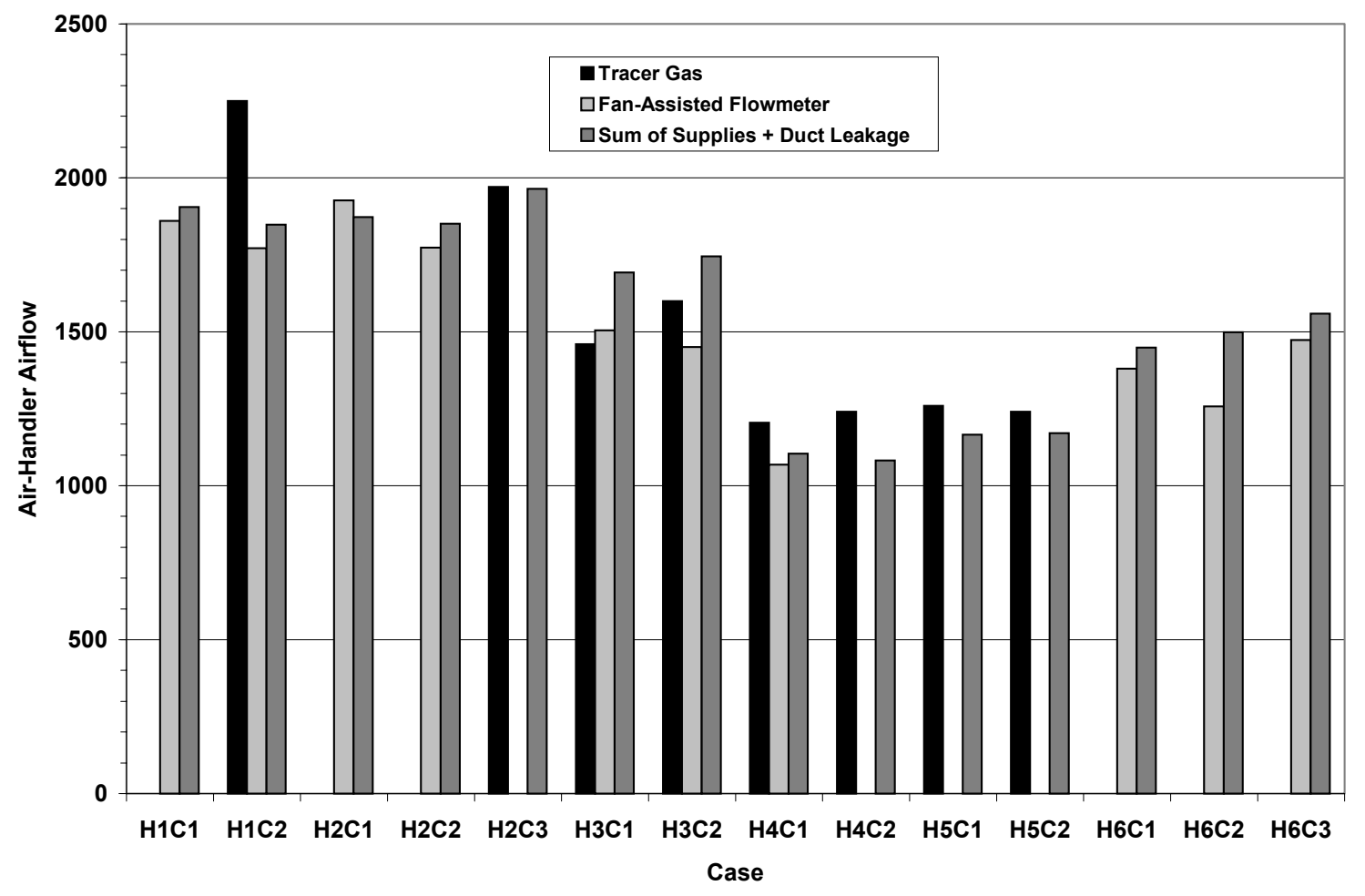

Figure A5. Comparison of air-handler airflow measurements for six houses.

\section{Field Study Two}

In September 2000, we carried out another field study to compare methods of measuring airhandler airflow. This study focused on two methods: the flow plate and grid, which is new, and the prototype non-powered Hood 8, which is part of an automated diagnostics package that includes Method 2 from our evaluation of refrigerant charge assessment tools.

Our evaluations in this field study included four California houses: two new ones and two older ones. All the houses have split-system central air conditioners and are heated by natural gas.

In these tests, we used two different techniques in each house:

- directly measuring the air-handler airflow using a fan-assisted flow meter attached to the air handler cabinet, and

- indirectly determining the air-handler airflow as the sum of supply duct flows (measured using our fan-assisted Hood 10 and the prototype non-powered Hood 8) and supply duct leakage to outside (measured using the DeltaQ test).

Results: Figure A6 shows the results of our tests. The duct leakages shown in Figure A6 are from DeltaQ test measurements of leakage to outdoors. Due to time limitations, we did not use the duct pressurization test to measure total leakage. However, in the two older houses (Houses 1 and 4), the ducts were located in a well-vented crawlspace and garage respectively. The ducts of the other two houses were located in well-vented attics. Consequently, we believe that the duct leakage measured by the DeltaQ test in each of these houses is a good approximation of total duct leakage. 


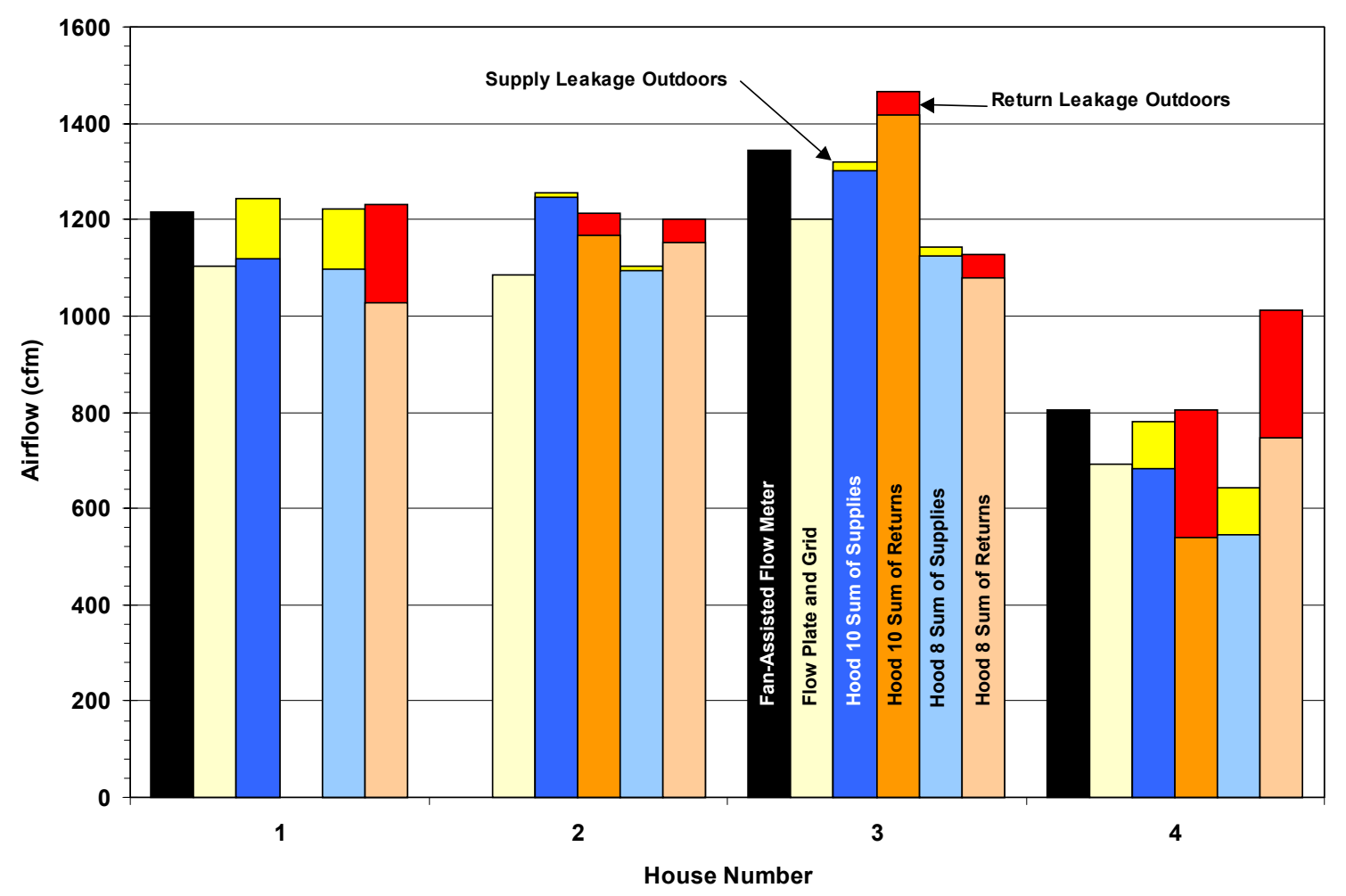

Figure A6. Comparison of air-handler airflow measurements for four houses.

The "Hood 10 Sum of Returns" (fan-assisted flow hood) datum is missing in Figure A6 for the return flow of House 1. We did not use that hood to measure one return grille flow in House 1, because there was a leak on the other side of the wall from indoors to the grille boot. That leak drew air from a corner of a cabinet toe-kick, such that the flow could not be captured without great difficulty. This leak could not be measured by Hood 8 either, but the technician using that device reported the results as if all flows had been measured. Comparing results, it appears the leak may have been small and we should have measured the grille flow anyway.

The fan-assisted flow meter datum is also missing in Figure A6 for House 2. There were two problems with the measurement. One, the technician measuring this flow did not recognize that the attic was not directly connected to the house through the ceiling access hatch. Instead, that hatch led from the garage to the attic. As a result, air supplied to the air handler cabinet did not come from inside the house as it should and the test is invalid. We attempted to correct this error by applying pressure corrections to account for the inadvertent pressurization of the house by the supply duct flows. However, even with this correction, the flow was about $40 \%$ low. We suspect that the return plenum seal that was used in this test may have failed, because it was extremely difficult to install and the house pressure increase would also have tended to force it open. A failed seal means that some flow would bypass the flow meter without being measured. To prevent large measurement errors with this technique, care is necessary to ensure that the return is properly sealed.

Comparison of Results: The airflows obtained using the fan-assisted flow meter in three houses agreed within 2 to $3 \%$ of the measured sum of supply grille flows (fan-assisted Hood 10) and supply duct leakage (DeltaQ). Agreement was poorer when compared to the sum of return grille 
flows (Hood 10) and return duct leakage (DeltaQ), but this may have been due to difficulties in measuring return flows, as we describe later in our flow hood evaluations (some of the returns were too large to be measured all at once with the flow hood).

Airflow measurements using the flow plate and grid show a negative bias of 9 to $14 \%$ relative to fan-assisted flow meter measurements. The reason for the bias is unknown, but it is unlikely due to flow bypass because we taped the rigid plate to the air handler cabinet in each test. We did not expect to find such a consistent bias, but it is within the measurement deviations reported by Palmiter and Francisco (2000).

Using fan-assisted flow meter measurements as a reference, preliminary comparisons of airflows obtained using the flow plate and grid in 74 houses indicate its measurements are within 17\% of the "reference" method (Palmiter and Francisco 2000). In 54\% of the houses, differences are less than 5\%. Reasons for differences are not reported, but might be related to plenum static pressure measurement errors. Francisco (2000) has indicated that upstream flow disturbances, such as $90^{\circ}$ bends in the return duct as close as 3 inches $(75 \mathrm{~mm})$ to the plate, do not adversely affect measurement accuracy.

Unfortunately, the diagnostic package that includes the prototype non-powered Hood 8 does not include a distinct protocol such as the DeltaQ test or duct pressurization test to measure duct leakage. As a result, this package does not offer a reliable means of determining air-handler airflow. In particular, Table A5 shows that the air-handler airflow measurements obtained using Hood 8 differed by as much as 30\% from those obtained using the fan-assisted flow hood (and flow meter). This is true even when duct leakage is included. This was expected, given the inaccuracy of Hood 8 (RMS errors of about 21\% for supply flows and 33\% for return flows, based on our laboratory tests). Improving the accuracy of this hood and including duct leakage will enable the diagnostic package to provide better estimates of air-handler airflow.

Table A5. Fractional errors in air-handler airflow measurements, Hood 8 versus fan-assisted Hood 10, with and without duct leakage effects.

\begin{tabular}{|c|cc|cc|}
\hline \multirow{2}{*}{ Site } & \multicolumn{4}{|c|}{ Hood 8 Fractional Error } \\
\cline { 2 - 5 } & $\begin{array}{c}\text { Sum of } \\
\text { Supplies }\end{array}$ & $\begin{array}{c}\text { Sum of } \\
\text { Returns }\end{array}$ & $\begin{array}{c}\text { Sum of Supplies } \\
\text { plus Duct Leakage }\end{array}$ & $\begin{array}{c}\text { Sum of Returns } \\
\text { plus Duct Leakage }\end{array}$ \\
\hline 1 & $-12 \%$ & $-17 \%$ & $-2 \%$ & $-1 \%$ \\
\hline 2 & $-13 \%$ & $-8 \%$ & $-12 \%$ & $-4 \%$ \\
\hline 3 & $-15 \%$ & $-18 \%$ & $-13 \%$ & $-15 \%$ \\
\hline 4 & $-30 \%$ & $-4 \%$ & $-18 \%$ & $30 \%$ \\
\hline
\end{tabular}

Assessing the Temperature Drop Method: During our tests of the four houses, we also collected continuous return and supply plenum temperature data for use in evaluating refrigerant charge diagnostics. These data are also useful to examine the temperature drop method of assessing air-handler airflow adequacy that is now included in Title 24. Figure A7 shows these data. 
Site 1: Return and Supply Plenum Temperatures

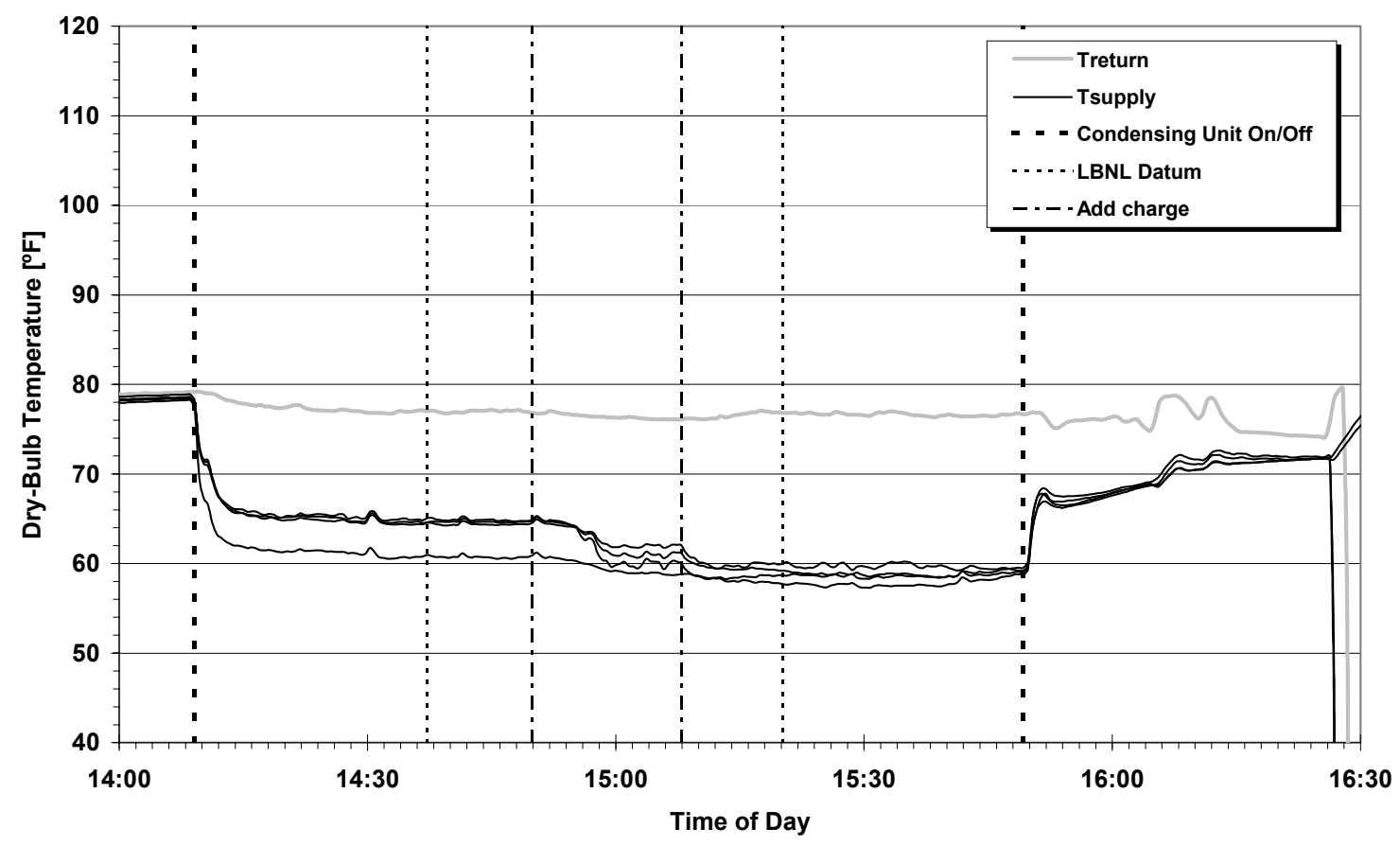

Figure A7a. Plenum temperature variations - Site 1.

Site 2: Return and Supply Plenum Temperatures

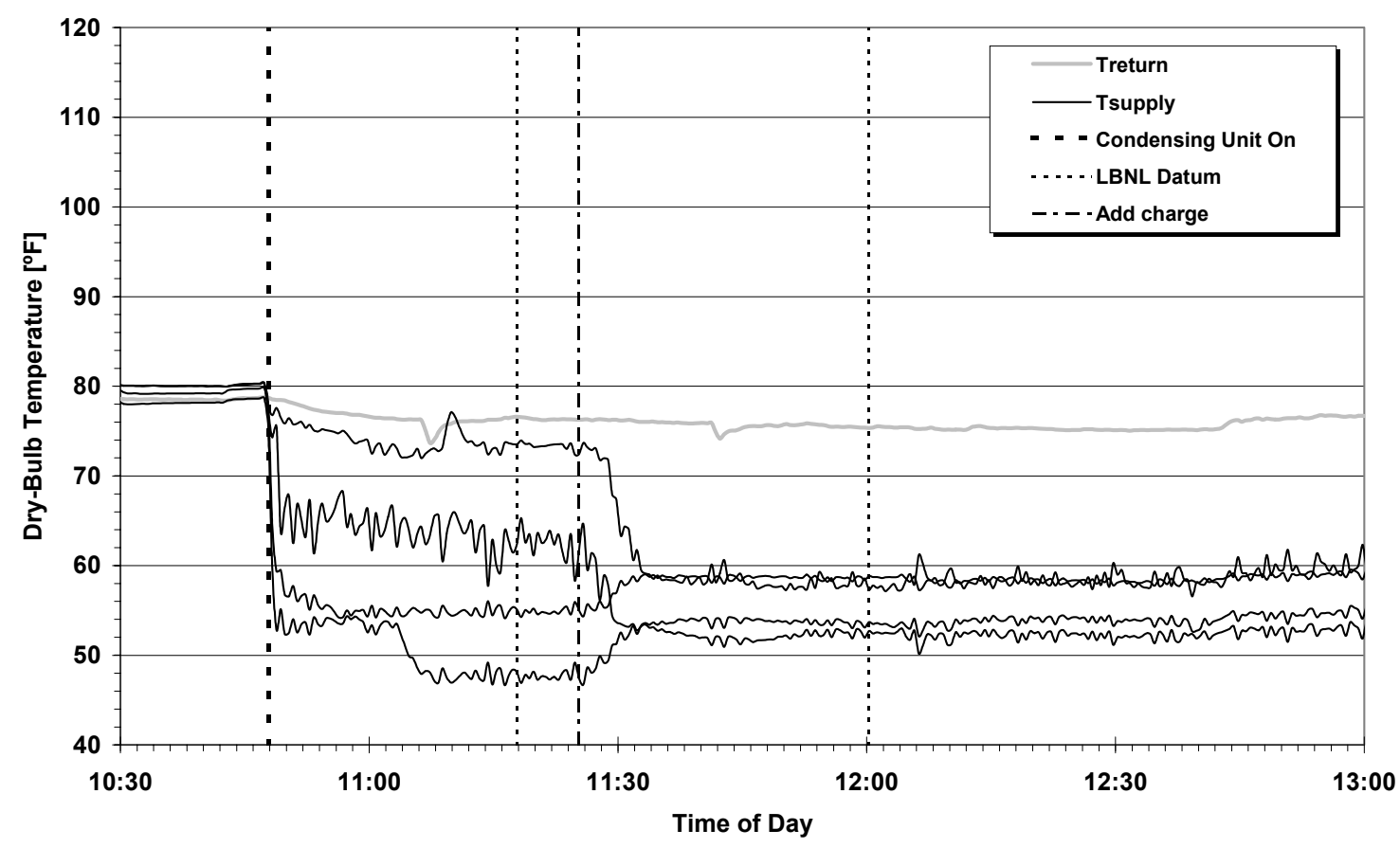

Figure A7b. Plenum temperature variations - Site 2. 


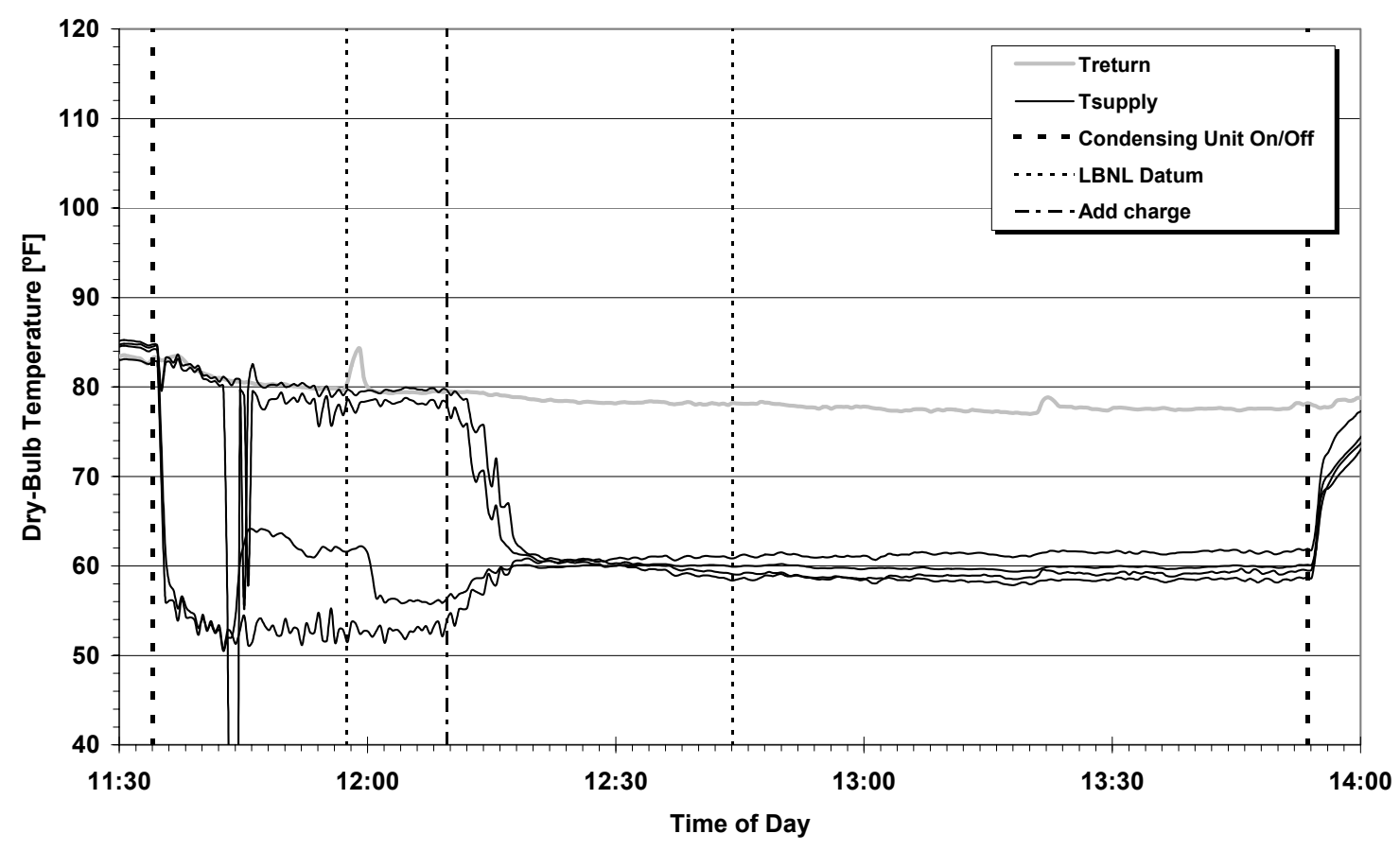

Figure A7c. Plenum temperature variations - Site 3.

Site 4: Return and Supply Plenum Temperatures

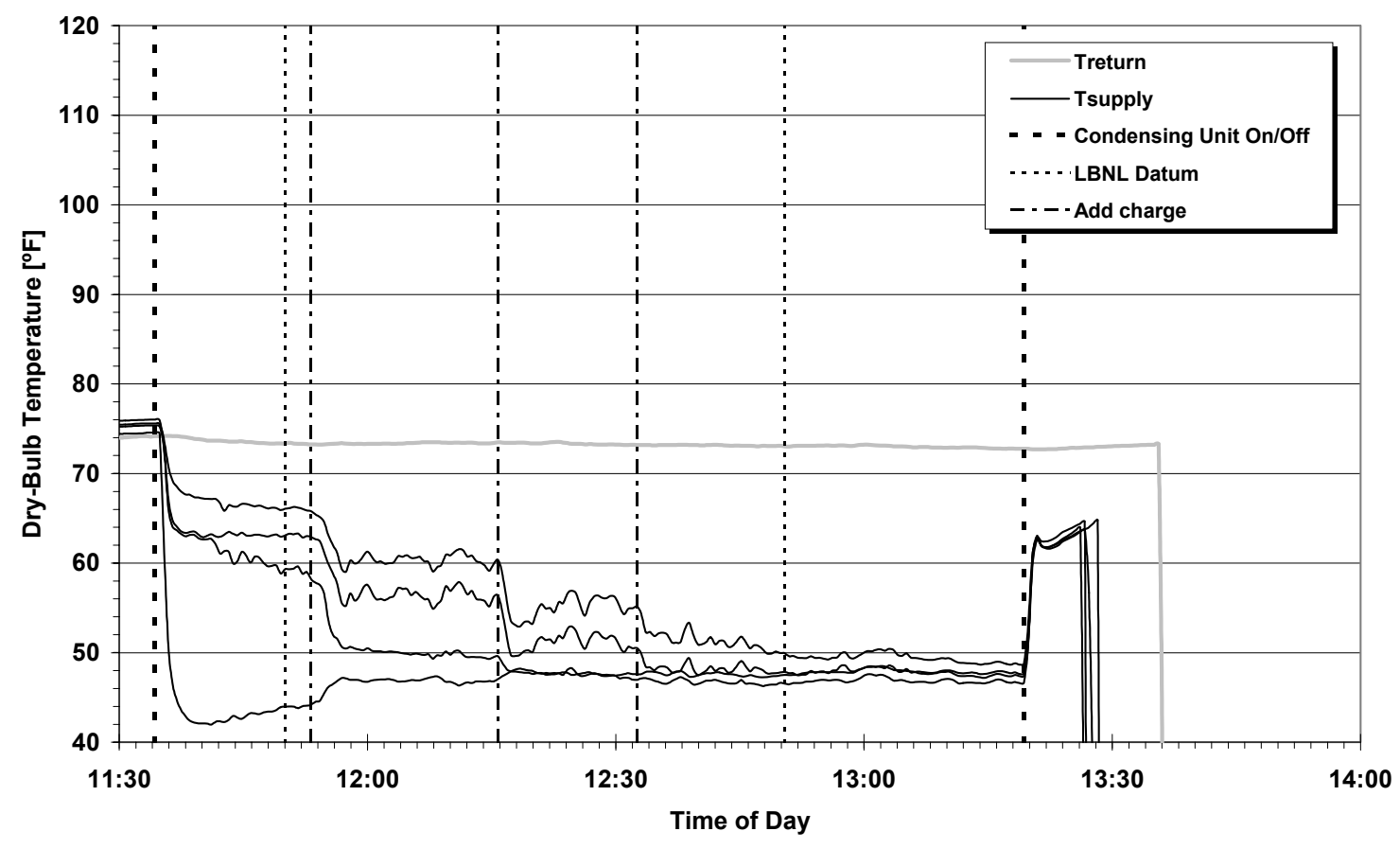

Figure A7d. Plenum temperature variations - Site 4. 
We measured return air temperatures upstream of the air-handler fan, as near the transverse center of the return plenum as was possible. The supply air temperatures were measured downstream of the evaporator at approximately the center of each transverse quadrant of the supply plenum. This latter measurement differs from the Title 24 protocol, which requires that the air temperature be measured at the transverse center of the supply plenum, which can be difficult to achieve in a large plenum and may be of questionable value, as discussed below.

Figure A7 shows that supply plenum temperature is highly variable spatially and extremely sensitive to charge (all four cooling systems were substantially undercharged). Table A6 summarizes the results of these measurements at the "LBNL Datum" times shown in Figure A7 with the system "as found" and after charge was corrected. Before charge was added, the supply temperatures vary quadrant to quadrant by as much as $30^{\circ} \mathrm{F}$. After charge was added, these variations drop to about 3 to $6^{\circ} \mathrm{F}$. However, Figure A7 shows that there are still some occurrences of as much as $10^{\circ} \mathrm{F}$ even after charge is corrected (Site 2).

Table A6a. Measured supply plenum dry-bulb air temperatures for airflow adequacy assessment.

\begin{tabular}{|c|c|cc|}
\hline \multirow{2}{*}{ Site } & Condition & $\begin{array}{c}\text { Supply Plenum } \\
\text { Minimum } \\
{\left[{ }^{\circ} \mathrm{F}\right]}\end{array}$ & $\begin{array}{c}\text { Supply Plenum } \\
\text { Maximum } \\
{\left[{ }^{\circ} \mathrm{F}\right]}\end{array}$ \\
\hline \hline \multirow{2}{*}{1} & As Found & 61 & 65 \\
\cline { 2 - 4 } & Post-Charging & 58 & 60 \\
\hline \multirow{2}{*}{2} & As Found & 48 & 74 \\
\cline { 2 - 4 } & Post-Charging & 53 & 59 \\
\hline \multirow{2}{*}{3} & As Found & 51 & 80 \\
\cline { 2 - 4 } & Post-Charging & 58 & 61 \\
\hline \multirow{2}{*}{4} & As Found & 44 & 66 \\
\cline { 2 - 4 } & Post-Charging & 44 & 50 \\
\hline
\end{tabular}

Table A6 also summarizes the results of the proposed airflow adequacy tests, along with normalized airflows for comparison. Those airflows are based on air-handler airflow measurements using Hood 7 (including duct leakage) and on the nominal total capacity of the evaporator when available. For the two older houses (Sites 1 and 4), no evaporator capacity data were available. In these cases, we have used the rated capacity of the condensing unit.

A comparison between the diagnoses of the proposed test and the normalized airflows shows that the proposed test does not always work. Only Site 1 has adequate airflow, assuming the target is $385 \mathrm{cfm} /$ ton. If we consider only the "as found" cases, we see that the test can provide almost any answer, because of the large differences in supply plenum temperatures. This indicates the test should not be used until charge is corrected.

If we now consider only the "post-charging" cases, the test reliably diagnoses the correct flow condition in two of the four cases: Site 1, which has adequate airflow, and Site 4, which has very low airflow ( $42 \%$ less than the assumed target of $385 \mathrm{cfm} / \mathrm{ton})$. Unfortunately, the test missed the 
two cases where the airflow is significantly low (18\% low at Site 2, 14\% low at Site 3); these airflow deficiencies are sufficient to cause substantial losses in cooling capacity and efficiency. This finding is consistent with results from independent field tests of 13,000 cooling systems: when tests more accurate than the temperature drop method were used, they indicated that $70 \%$ of the systems tested had inadequate airflow, whereas the temperature drop method was only able to identify $21 \%$ of the systems as having low airflow (Proctor 2002).

Table A6b. Return plenum air temperatures and temperature difference targets for airflow adequacy assessment.

\begin{tabular}{|c|c|ccc|}
\hline \multirow{2}{*}{ Site } & Condition & $\begin{array}{c}\text { Return Dry-Bulb } \\
\text { Temperature } \\
{\left[{ }^{\circ} \mathrm{F}\right]}\end{array}$ & $\begin{array}{c}\text { Return Wet-Bulb } \\
\text { Temperature } \\
{\left[{ }^{\circ} \mathrm{F}\right]}\end{array}$ & $\begin{array}{c}\text { Temperature } \\
\text { Difference } \\
\text { Target }\left[{ }^{\circ} \mathrm{F}\right]\end{array}$ \\
\hline \hline \multirow{2}{*}{1} & As Found & 77 & 65 & 18.3 \\
\cline { 2 - 5 } & Post-Charging & 77 & 65 & 18.3 \\
\hline \multirow{2}{*}{2} & As Found & 77 & 62 & 20.4 \\
\cline { 2 - 5 } & Post-Charging & 75 & 61 & 21.0 \\
\hline \multirow{2}{*}{3} & As Found & 81 & 66 & 19.6 \\
\cline { 2 - 5 } & Post-Charging & 78 & 61 & 19.5 \\
\hline \multirow{2}{*}{4} & As Found & 73 & 60 & 19.4 \\
\cline { 2 - 5 } & Post-Charging & 73 & & \\
\hline
\end{tabular}

Table A6c. Measured temperature difference deviations from targets and diagnoses for airflow adequacy assessment.

\begin{tabular}{|c|c|c|c|c|c|}
\hline Site & Condition & $\begin{array}{c}\text { Minimum } \\
\text { Deviation } \\
{\left[{ }^{\circ} \mathrm{F}\right]}\end{array}$ & $\begin{array}{c}\text { Maximum } \\
\text { Deviation } \\
{\left[{ }^{\circ} \mathrm{F}\right]}\end{array}$ & $\begin{aligned} & \text { Diagnoses } \\
&-3<\text { Deviation }<+3: \text { OK } \\
&>+3: \text { Low Airflow } \\
&<-3: \text { Low Capacity }\end{aligned}$ & $\begin{array}{c}\text { Normalized } \\
\text { Airflow } \\
\text { (cfm/ton) }\end{array}$ \\
\hline \multirow{2}{*}{1} & As Found & -2.3 & -6.3 & OK / Low Capacity & \multirow{2}{*}{414} \\
\hline & Post-Charging & 0.7 & -1.3 & $\mathrm{OK} / \mathrm{OK}$ & \\
\hline \multirow{2}{*}{2} & As Found & 8.6 & -17.4 & Low Flow / Low Capacity & \multirow{2}{*}{314} \\
\hline & Post-Charging & 1.0 & -5.0 & OK / Low Capacity & \\
\hline \multirow{2}{*}{3} & As Found & 10.4 & -18.6 & Low Flow / Low Capacity & \multirow{2}{*}{330} \\
\hline & Post-Charging & 0.5 & -2.5 & $\mathrm{OK}$ & \\
\hline \multirow{2}{*}{4} & As Found & 10.2 & -11.8 & Low Flow / Low Capacity & \multirow{2}{*}{222} \\
\hline & Post-Charging & 6.6 & 3.6 & Low Flow / Low Flow & \\
\hline
\end{tabular}




\section{Summary}

Data from our field tests indicate that both a fan-assisted flow meter and a fan-assisted flow hood are borderline acceptable devices for determining air-handler airflow. The accuracy of these measurements is likely about $\pm 10 \%$. The latter method requires an accurate measurement of duct leakage. Methods that are more accurate $( \pm 5 \%)$ would be preferable for assessing airflow through an evaporator equipped with a fixed-orifice refrigerant control, given the significant impact of air-handler airflow on cooling performance with this type of control.

Based on data reported in the literature, the flow plate and grid appears to be an accurate device for determining air-handler airflow. However, we observed a consistent negative bias near 10\% compared to the fan-assisted devices that we evaluated. We suggest that the calibration of this device be assessed further in the laboratory.

One of the non-powered flow hoods that we evaluated (Hood 8) was a prototype. At this time, it is not a reliable means of determining air-handler airflow. Improving the accuracy of this hood and including duct leakage will enable the diagnostic package that includes it to provide better estimates of air-handler airflow. Because of our tests, we understand that the manufacturer of the hood is already trying to improve its accuracy.

The temperature drop method of assessing air-handler airflow adequacy, which is contained in Title 24, may be able to find the worst cases of low airflow, but is unreliable for identifying airflow inadequacies in many systems. It seems unlikely that this test can be improved, because of the large spatial variations in temperature that can occur in supply plenums, even after refrigerant charge problems are corrected.

A new air-handler airflow measurement standard needs development to address the use of fanassisted flow meters and the flow plate and grid in field applications. This standard should cover the most common air-handler and duct system configurations found in residential systems. Further work is needed to develop a prototype for this standard test procedure. 


\section{EVALUATION OF DISTRIBUTION SYSTEM AIRFLOW TESTS}

For many years, the HVAC industry has used flow hoods to measure grille airflows in nonresidential buildings, usually as part of a testing and balancing procedure; residential HVAC systems very rarely have been tested (usually by the research community). Now, utility programs, weatherization programs, and codes and standards such as California's Title 24 are beginning to consider the need to commission residential HVAC systems. Such efforts could include using flow hoods to determine if individual rooms are getting correct airflow, and to estimate total air handler flow and duct air leakage.

Flow hoods have two basic parts: a flow capture device and a measurement device. The flow capture device is usually a fabric hood mounted over a rigid frame (often collapsible for storage and transportation). It directs the airflow over a sensing element in the measurement device. The hood has a larger open end, usually sized to fit a standard square commercial grille of $610 \mathrm{~mm} \times$ $610 \mathrm{~mm}(24 \times 24$ inches); many manufacturers also offer other hood sizes. Flow measurement techniques differ between manufacturers and include pressure difference, thermo-anemometry, plate deflection, and spinning propellers. Most flow hoods can measure flows in either direction (for supply and return grilles). Some hoods have a system of user operable openings and flaps that reduce backpressures at higher flows.

A few studies have evaluated flow hood measurement uncertainty in commercial applications (Choat 1999); they found that flow hoods are poor at measuring commercial grille flows. However, there are no published studies about uncertainty associated with using flow hoods to measure residential grille airflows. Our paper discusses residential applications of flow hoods and the accuracy requirements in each case. It then discusses our laboratory tests and field study of several flow hoods, which show that some commercially available hoods can be inadequate for measuring flows in residential systems, and that powered flow hoods equipped with measurement devices that are insensitive to grille airflow patterns give reliable and consistent results.

\section{Residential Applications for Flow Hoods and Accuracy Requirements}

Flow hoods have several residential applications that may require different levels of accuracy in order to be acceptable. Applications can be split into two subsets: those based on individual grille flows, and those based on the total of all supply or return grille flows.

Subset 1, Individual Grille Flows: Measurements of individual grille flows can be used to identify parts of a system with large leaks (e.g., disconnected ducts), to determine flow imbalance between different spaces in a building, and, when combined with temperature and humidity measurements, to determine if enough heating or cooling is delivered by a grille to the space it serves. For identifying large leaks or disconnected ducts, the airflow changes are large and the accuracy of the measurement is not critical: being within $\pm 50 \%$ of the correct flow is reasonable. Similarly, imbalances in residential airflows between different spaces in a building are only critical at higher flow rates and an accuracy of $\pm 25 \%$ is probably reasonable.

The accuracy requirement related to providing enough heating or cooling airflow to a space for occupant comfort depends on how well the space, the rest of the building, and outside are thermally connected. For most typical residential rooms, there is little thermal resistance to other parts of the building; this reduces the sensitivity of room temperature to deviations in individual supply grille airflows. A simple steady-state heat balance for a room with an insulated exterior wall containing a window and uninsulated partitions for its other surfaces shows that a 
reasonable limit is to have supply grille airflows within $\pm 20 \%$ of their design specification to keep the room temperature within approximately $\pm 1^{\circ} \mathrm{C}\left(2^{\circ} \mathrm{F}\right)$ of the adjoining room temperatures. Therefore, the accuracy of the flow measurement device needs to be better than this $\pm 20 \%$ requirement. It is important to note that the sensitivity depends on building loads and therefore climate. The larger the load, the more precisely one needs to know the grille flow in order to maintain reasonable temperature limits. In addition, if transient performance is an issue (how fast a particular room is heated or cooled by the system), then the supply grille airflows need to be better defined.

Subset 2, Total Supply or Return Flows: One can sum individual grille measurements to find the total supply or return airflow, which in turn can be used to estimate air handler flow (if leakage is well known), duct leakage to outside (if air handler flow and leak location are well known), and supply/return imbalances (e.g., determining the degree of house depressurization in backdrafting investigations). From a residential commissioning perspective, the key uses are determining the air handler flow and duct leakage, because residences are generally not deliberately pressurized or depressurized.

For air handler flows, the desire to have the correct air handler flow is most critical for cooling systems, because inadequate air handler flows can reduce cooling capacity and efficiency, and can sometimes lead to coil icing. The effects of air handler flow become significant if the flow is about 15\% lower than desired. For example, Rodriguez (1995) found an 8\% reduction in equipment efficiency for a $15 \%$ flow reduction. If the grille flow measurements are to be used to estimate the effect of air handler flow on equipment performance and a reasonable limit for changing the equipment performance is about $5 \%$, then the total of all grille flows needs to have an accuracy better than about $\pm 10 \%$.

The requirements are more restrictive for using the results to calculate duct leakage. The current low leakage limits for the whole duct system are between 6\% (CEC 1998) and 10\% (State of Oregon and proposed EPA Energy Star ducts). Because these limits include both supply and return leaks, and because the supply and return grille flows are determined separately, the measurement technique needs to determine leakage flows on the order of $3 \%$ to $5 \%$ of air handler flow (assuming leakage flows are split evenly between supply and return). If duct leakage testing needs to verify these low leakage levels or provide reasonable estimates of the energy penalty of leakier ducts, then the duct leakage measurement accuracy needs to be better than $\pm 3 \%$. Assuming there is no uncertainty in the air handler flow measurement, this implies that the total of all supply or return grille flows needs to have an accuracy better than $\pm 3 \%$. Note that this implies an uncertainty almost the same as the measurement when verifying low leakage ducts and it would be preferable to have a much tighter specification in this case (about $\pm 1 \%$ of air handler flow). In addition, this does not address the uncertainty in measuring air handler flow or in estimating what fraction of the total leakage (the difference between air handler and grille flow) is to outside (as required for energy loss calculations).

Table A7 summarizes the accuracy criteria for using flow hoods in residential applications, in order of increasing accuracy requirements. 
Table A7. Summary of accuracy requirements for residential flow hood applications.

\begin{tabular}{|l|c|}
\hline Application & Required Minimum Accuracy \\
\hline Identifying large leaks/disconnected ducts & $\pm 50 \%$ \\
\hline Identifying room to room pressure imbalances & $\pm 25 \%$ \\
\hline Ensuring room load and comfort requirements are met & $\pm 20 \%$ \\
\hline $\begin{array}{l}\text { Determining air handler flow for cooling equipment } \\
\text { performance estimation }\end{array}$ & $\pm 10 \%$ \\
\hline Determining duct leakage & $\pm 3 \%$ \\
\hline
\end{tabular}

\section{Experimental Assessment of Accuracy}

Measuring residential airflows with a flow hood developed for commercial systems is a challenge for the following four key reasons:

1. Residential supply grille airflows are typically much lower than non-residential ones. Usually, residential flows range from 25 to $120 \mathrm{~L} / \mathrm{s}$ (53 to $250 \mathrm{cfm})$, with many in the lower half of this range and some substantially lower: some small interior bathrooms have design flows in the $5 \mathrm{~L} / \mathrm{s}(10 \mathrm{cfm})$ range. For comparison, commercial system flows typically exceed $120 \mathrm{~L} / \mathrm{s}(250 \mathrm{cfm})$. Manufacturers of commercially available hoods indicate their equipment is capable of measuring the lower flows; however, they provide no data to support using their measurement techniques for these flows.

2. Residential grilles do not have diffusers that make the flow spatially homogeneous. For supply grilles in particular, the vanes that direct the flow in a particular direction to control the throw of air from the grille into the room lead to highly non-uniform flows entering the flow hood.

3. Residential supply grilles are often physically smaller than those used in commercial systems. A typical residential supply grille is $150 \mathrm{~mm} \times 300 \mathrm{~mm}(6 \times 12$ inches $)$ rather than the $610 \mathrm{~mm}$ (24 inch) square grille used in commercial systems. This size difference introduces measurement errors, because the flow is non-uniform over the inlet of the flow hood.

4. Some residential systems have single return grilles that are closer to commercial grilles in terms of size and airflow; however, they often have dimensions larger than the $610 \mathrm{~mm}$ (24 inch) square standard flow hood opening. In these cases, it is necessary to combine several individual measurements over the face of the grille. There are substantial potential errors with this technique. For example, some flow hoods add resistance at the grille (insertion loss). This increases the airflow that bypasses the flow hood when it only covers part of the grille. As a result, the airflow measured by the flow hood is too low.

To determine the potential magnitude of errors associated with using flow hoods to measure flows at residential grilles, we conducted detailed laboratory tests on five hoods specifically intended for residential systems. These five hoods were comprised of two "standard" hoods from major manufacturers, one "prototype" hood that is currently being developed, one propeller hood, and a state-of-the-art "active" hood. We also performed a field test using eight hoods in a single house. Of these eight, two were for residential use, four were primarily for commercial 
use, and the remaining two were active flow hoods. Only the propeller hood and our active flow hood were common to both laboratory and field evaluations, because the flow hoods that we tested belonged to other organizations and we were restricted to the ones available to us at the time of testing. Characteristics of these hoods are described in the following section of this paper.

Our laboratory tests systematically varied potential sources of uncertainty and compared the flow hoods (numbered 6 though 10) to a very accurate standard. These tests evaluate the factory calibration and the sensitivity of the results to changes in entering flow pattern (which can be thought of as the robustness of the measurement technique/device); they do not evaluate insertion loss effects. In the field study, the flow hoods were used in one house with nine supply grilles and a single return. Hoods numbered 1 through 5 and 9 through 11 were used on the supply grilles; Hoods numbered 2 through 5, and 10, were used on the return grilles. Due to limited airflow capacity, not all of the available flow hoods could measure return flows.

Flow Hoods Tested: Hoods 1 through 7 are standard flow hoods from three manufacturers; Hoods 2, 6, and 7 were specifically developed for measuring residential flows. The standard hoods measure flow across a flow element within the throat of the hood. The element samples the flow at several fixed locations and combines the samples together in a manifold that contains a thermo-anemometer or that is connected to a pressure transducer. With fixed sampling locations, it is possible that non-uniform flows will not be sampled with sufficient spatial resolution, or that incorrect weighting might be applied to some samples.

Hood 8 is a prototype flow hood that uses a flow capture device like a "standard" flow hood, but uses a proprietary flow sampling and sensing technology. This hood is still under development and is not generally available.

Although Hood 9 (propeller flow hood) is no longer in production, some residential airflow practitioners still use it. This hood is intended for the smaller grilles and flows in residential systems. The sensing element is a freely spinning propeller, whose speed indicates the flow through the hood. A possible advantage of this hood is that it samples the whole flow (the propeller tip clearance to the flow capture housing is very small). However, it does not eliminate problems of non-uniform flow, because of inertial effects of the propeller and non-linear interactions between local airflow velocity and the rotational force applied to the propeller. In addition, it is possible that swirl in the flow will cause the propeller to spin either too fast or too slow, thus biasing the measurements.

Hoods 10 and 11 are active flow hoods (also known as fan-assisted or powered flow hoods), which were developed for research use to reduce the effects of backpressure on flow measurement. For a flow capture device, these hoods use a fabric capture hood from a standard flow hood (Hood 10) or a cardboard box (Hood 11). The outlet of the capture device connects to a calibrated fan and flow meter through a length of flex duct and a flow straightener. By adjusting fan speed until there is no pressure difference between the room and hood interior, one can compensate for the flow resistance of the capture hood, flexible duct, and flow meter. This pressure balancing ensures that placing the flow hood over the grille does not reduce the grille flow and minimizes the effects of air leakage between the flow hood edges and the surfaces they are pressed against.

Laboratory Test Apparatus: Figure A8 shows a schematic of our laboratory test apparatus. It represents a "single branch" system in which all flow passes through the reference nozzle and the 
flow hood. The reference nozzle combines a flow straightener, a nozzle, and a pitot-averagingarray to form a flow meter that is less sensitive to flow asymmetry than other flow meters. It has an accuracy of $\pm 0.5 \%$ of the flow reading. We used an adjustable fan to produce a range of typical residential grille flows through the apparatus: 25 to $120 \mathrm{~L} / \mathrm{s}$ (53 to $250 \mathrm{cfm}$ ) for supplies and up to $1,000 \mathrm{~L} / \mathrm{s}(2,000 \mathrm{cfm})$ for returns. Figure A8 shows the apparatus configured for supply flows; we reversed the nozzle and fan for return flows.

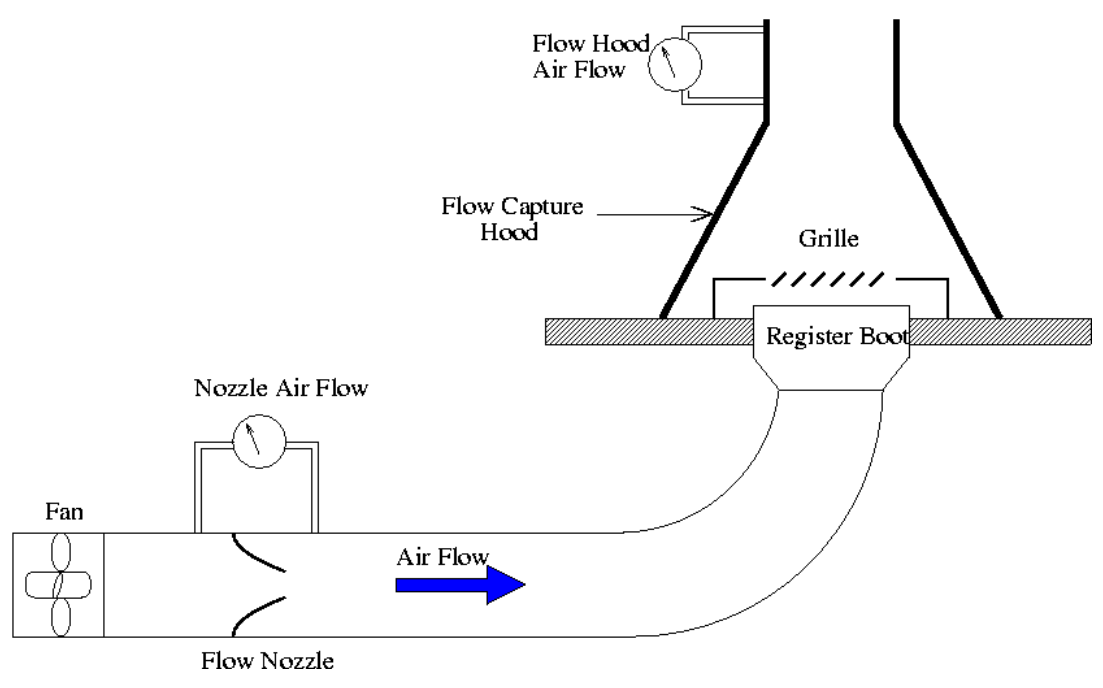

Figure A8. Laboratory apparatus configured for supply flows.

We changed the flow pattern entering the hoods by varying hood lateral placement relative to the grille (center, corner, and center edge), and by using different grille styles (one-way and fourway throws), different grille damper settings, and different boot types. To examine grille-induced swirl effects, we used two different four-way grilles with vanes in opposite directions. We positioned the dampers at a "full open" setting and, for the one-way throw grille, also with the damper blades partially closed (parallel with the outlet vanes). The rectangular boots had different entry conditions: from the long side or from the short side.

Test Results: Figures A9 through A13 show detailed results from our laboratory tests for the different test configurations. The legend differentiates between test configurations.

Center/Edge/Corner refers to the location of the hood relative to the grille. The term "w/damper" means that the damper in the grille was partially closed. Lastly, the $\mathrm{CW} / \mathrm{CCW}$ designation refers to the use of a four-way throw grille that introduces swirl in either the Clock-Wise (CW) or Counter-Clock-Wise (CCW) sense.

Table A8 summarizes our laboratory test results. The fractional errors listed here are the average of the individual fractional errors for each measurement and not the average error divided by the average flow rate. The average error is an estimate of the bias in the flow hood. The RMS errors do not let positive and negative errors cancel out and are a better indicator of the uncertainty in an individual grille measurement.

Tables A9 and A10 summarize the field test results relative to the reference active flow hood for supply and return flows respectively. Walker et al. (2001) describe our test results in more detail. 


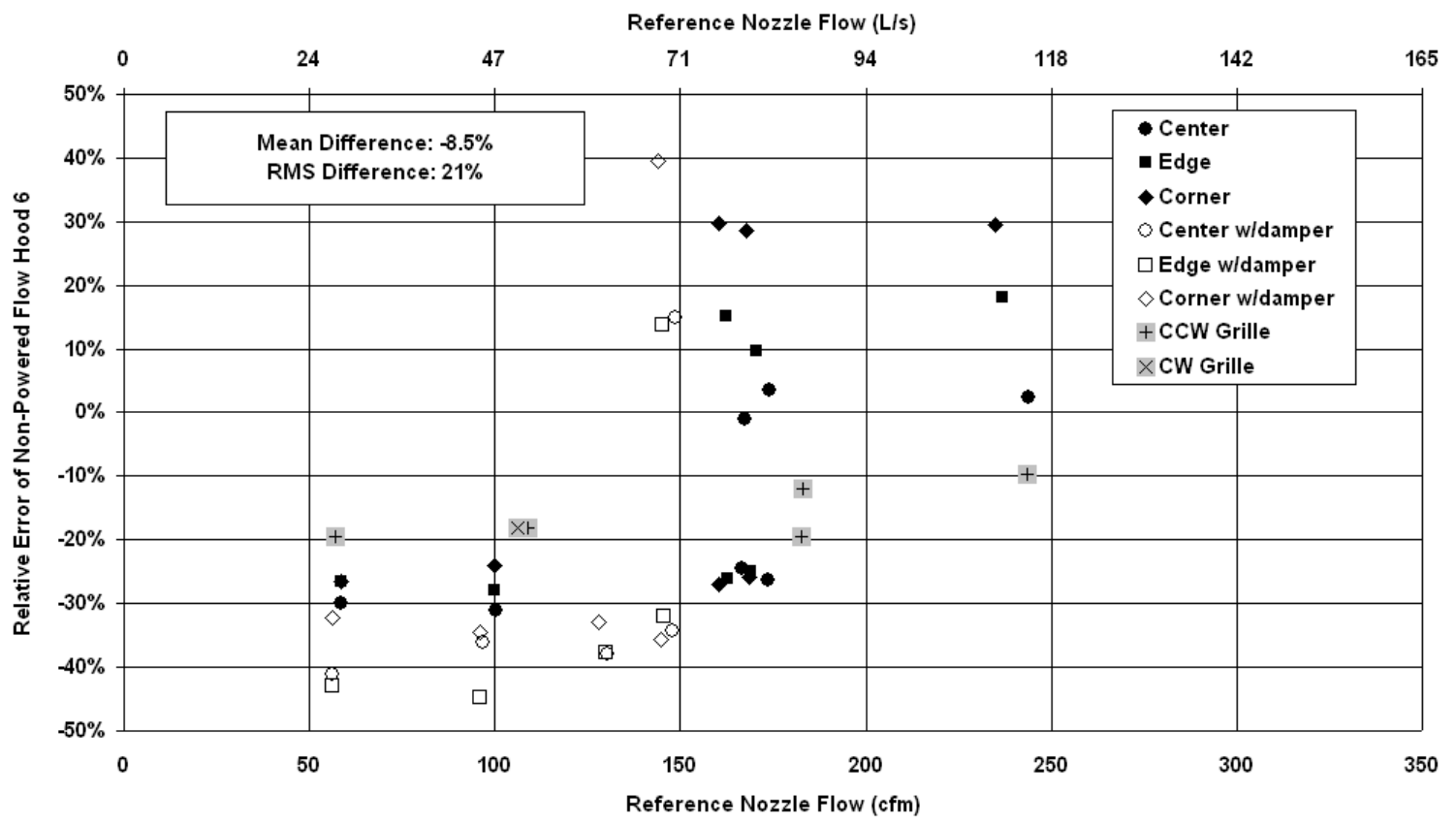

Figure A9. Laboratory results for Standard Hood 6.

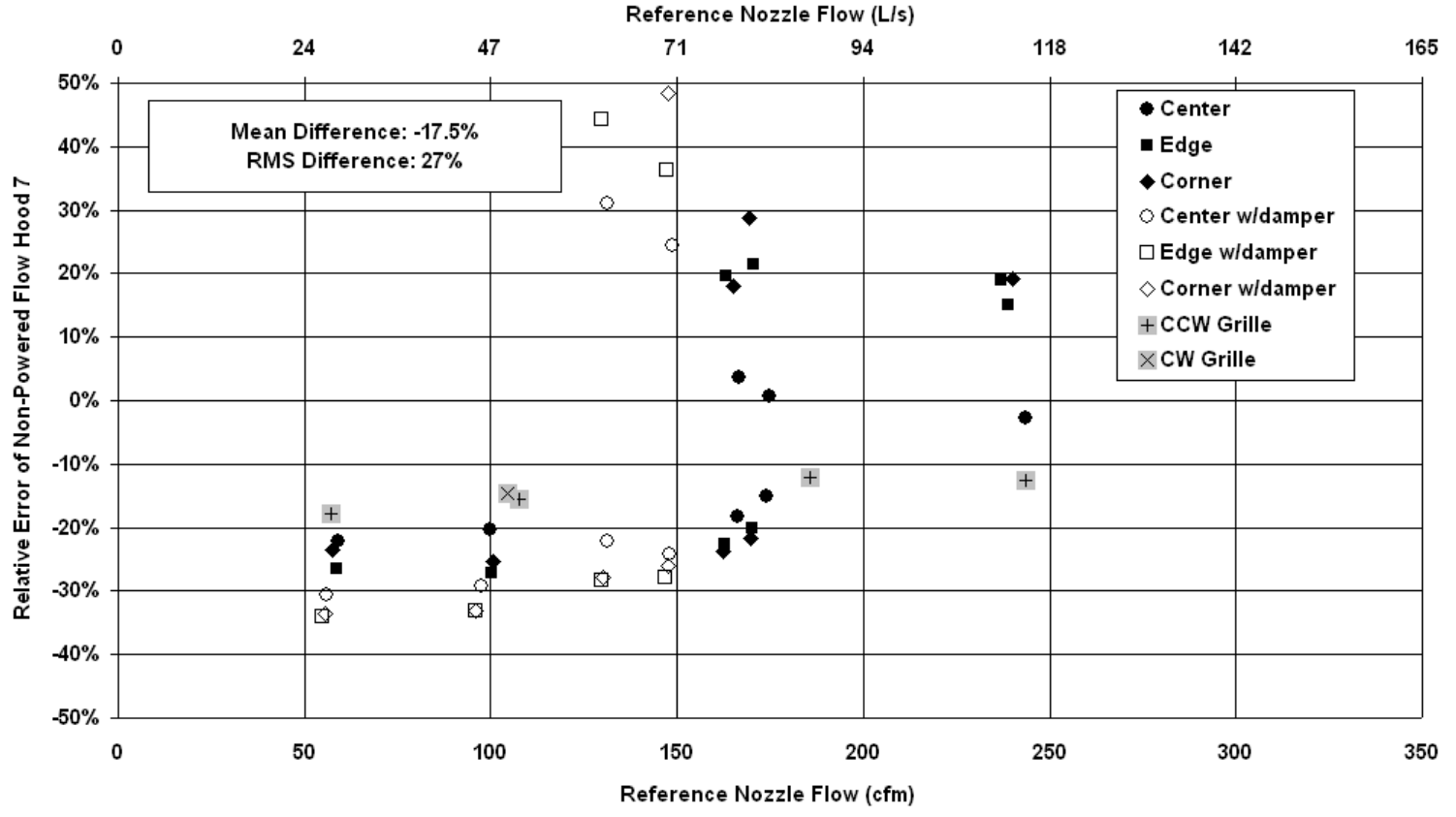

Figure A10. Laboratory results for Standard Hood 7. 


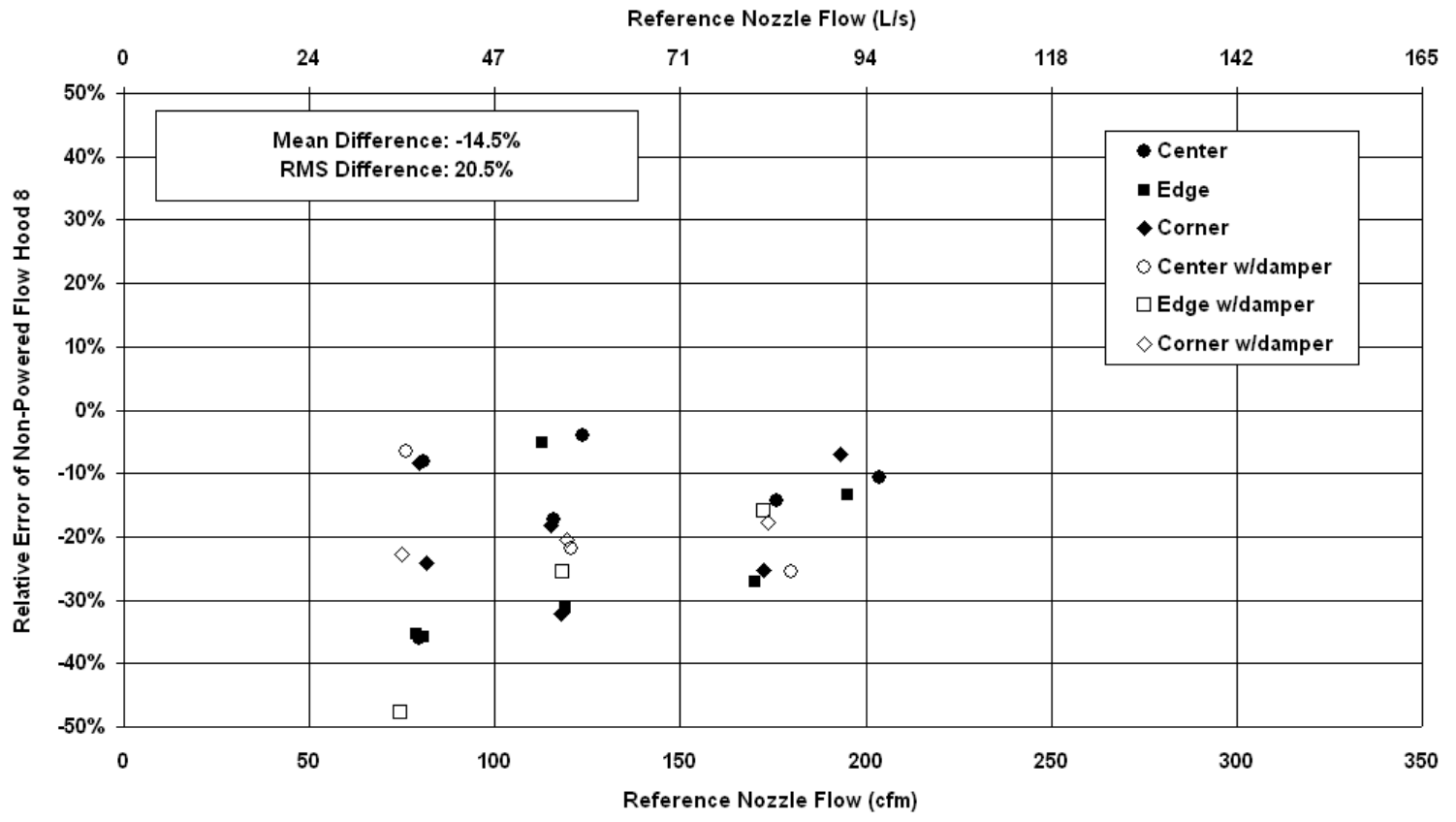

Figure A11. Laboratory results for Prototype Hood 8.

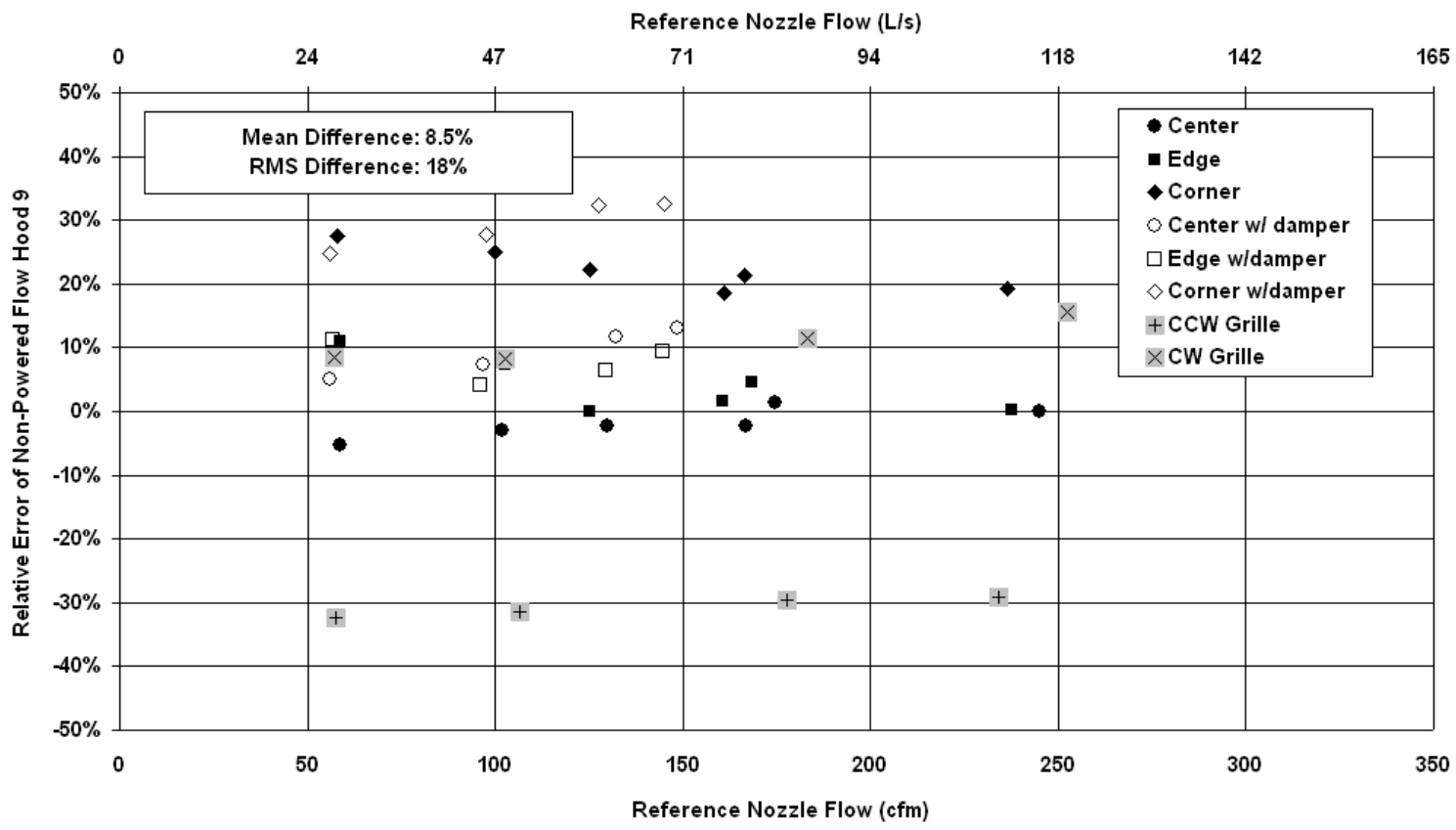

Figure A12. Laboratory results for Propeller Hood 9. 


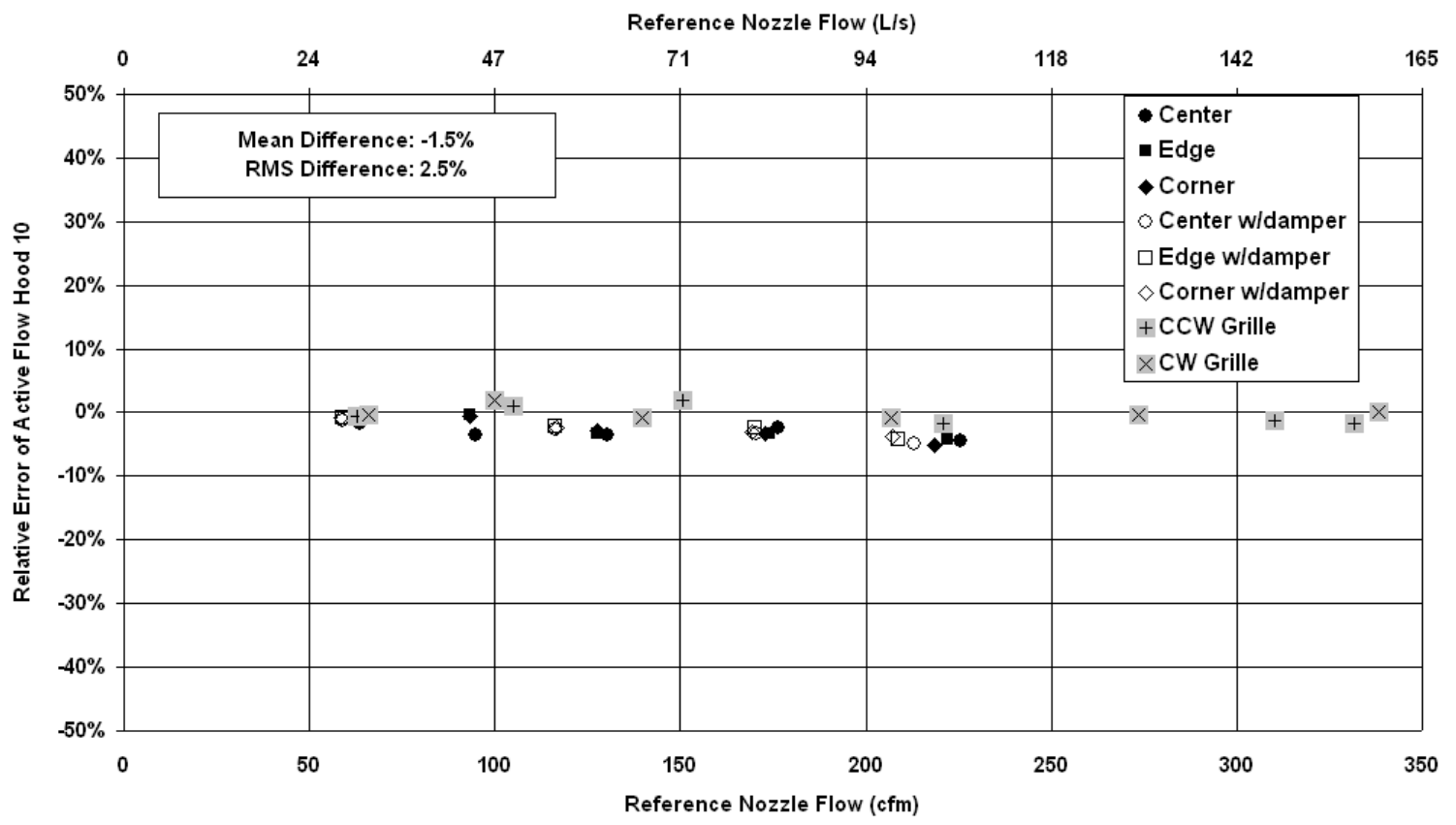

Figure A13. Laboratory results for Active Hood 10.

Table A8. Summary of laboratory test results: Supply and return flows.

\begin{tabular}{|c|c|c|c|c|}
\hline Hood ID & Hood Type & Average Difference & RMS Difference & Number of Tests \\
\hline \hline & & \multicolumn{2}{|c|}{ Supply Flows } & \\
\hline \hline 6 & Standard & $-8.5 \%(-8 \mathrm{cfm})$ & $21 \%(28 \mathrm{cfm})$ & 90 \\
\hline 7 & Standard & $-17.5 \%(-19 \mathrm{cfm})$ & $27 \%(36 \mathrm{cfm})$ & 74 \\
\hline 8 & Prototype & $-14.5 \%(-18 \mathrm{cfm})$ & $20.5 \%(25 \mathrm{cfm})$ & 43 \\
\hline 9 & Propeller & $8.5 \%(10 \mathrm{cfm})$ & $18 \%(25 \mathrm{cfm})$ & 75 \\
\hline 10 & Active & $-1.5 \%(-3 \mathrm{cfm})$ & $2.5 \%(5 \mathrm{cfm})$ & 87 \\
\hline \hline & & Return Flows & 3 \\
\hline \hline 8 & Prototype & $33 \%(488 \mathrm{cfm})$ & $33 \%(511 \mathrm{cfm})$ & 9 \\
\hline 10 & Active & $2.5 \%(25 \mathrm{cfm})$ & $3.5 \%(38 \mathrm{cfm})$ & \\
\hline
\end{tabular}


Table A9. Summary of field test results: Nine supply flows.

\begin{tabular}{|c|c|c|c|}
\hline \multirow{2}{*}{ Hood ID } & \multirow{2}{*}{ Hood Type } & \multicolumn{2}{|c|}{ Difference Relative to Active Hood 10 } \\
\cline { 3 - 4 } & Sum of all grille flows & RMS for individual grilles \\
\hline \hline 1 & Standard & $-1 \%(-9 \mathrm{cfm})$ & $8 \%(8 \mathrm{cfm})$ \\
\hline 2 & Standard & $3 \%(31 \mathrm{cfm})$ & $10 \%(14 \mathrm{cfm})$ \\
\hline 3 & Standard & $7 \%(78 \mathrm{cfm})$ & $15 \%(12 \mathrm{cfm})$ \\
\hline 4 & Standard & $48 \%(519 \mathrm{cfm})$ & $58 \%(65 \mathrm{cfm})$ \\
\hline 5 & Standard & $45 \%(484 \mathrm{cfm})$ & $56 \%(61 \mathrm{cfm})$ \\
\hline 9 & Propeller & $-1 \%(-7 \mathrm{cfm})$ & $8 \%(6 \mathrm{cfm})$ \\
\hline 11 & Active & $-1 \%(-10 \mathrm{cfm})$ & $6 \%(4 \mathrm{cfm})$ \\
\hline
\end{tabular}

Table A10. Summary of field test results: One return flow.

\begin{tabular}{|c|c|c|}
\hline Hood ID & Hood Type & Difference Relative to Active Hood 10 \\
\hline \hline 2 & Standard & $-17 \%(-177 \mathrm{cfm})$ \\
\hline 3 & Standard & $-4 \%(-42 \mathrm{cfm})$ \\
\hline 4 & Standard & $-1 \%(-9 \mathrm{cfm})$ \\
\hline 5 & Standard & $2 \%(18 \mathrm{cfm})$ \\
\hline
\end{tabular}

\section{Key Findings}

Our laboratory test results for the reference active flow hood (Hood 10, summarized in Table A8 and shown in Figure A13) show it is clearly better than the non-powered flow hoods: all its results fall in a narrow band (RMS error of only $2.5 \%, 5 \mathrm{cfm})$, with a small negative bias $(-1.5 \%$, $-3 \mathrm{cfm})$. A comparison of these results to the criteria presented in Table A7 shows that this hood can be used in all applications.

Table A8 indicates that the non-powered flow hoods we tested in the laboratory (Hoods 6 through 9) do not necessarily meet the accuracy criteria for many residential applications. RMS errors are in the $20 \%$ to $30 \%$ range, which is much larger than the $10 \%$ or better accuracies that are required for most distribution system diagnostics. In particular, the measurement accuracy is poor for individual grilles, as well as over the sum of many grilles. This means that these hoods can be inadequate for use in estimating duct leakage and air handler flow, and for assessing individual grille flows for room load and comfort. However, most of the flow hoods can be used in applications that require less accuracy (finding big leaks/disconnected ducts and estimating room-to-room pressure imbalances). The provision made by some manufacturers to change the flow resistance of the flow meter by opening or closing vents did not offer any advantages in improved accuracy.

Flow hood errors shown in Figures A9 through A12 are mostly due to non-uniformity of incoming flow from typical residential grilles. The non-uniformity has two sources: the duct system itself (including the grille) and the opening of the flow hoods being larger than the grilles. 
The duct system contributions include the effects of the flow pattern generated by the grille, the changes in flow pattern because of the use of grille dampers, swirl in the flow (either generated by the grille or upstream ducts), and the boot entry type. Because grille area is only a fraction of the total entry area of the flow hood, this guarantees non-uniform flow entering the flow hood; it also allows flexibility in the flow hood positioning over the grille. Positioning of the flow hood over the grille was found to be critical: the flow hood needs to be centered for best results. Because the results are sensitive to positioning (errors as much as $\pm 40 \%$ due to poor centering), this is a key issue in the field application of flow hoods. In field applications, our experience indicates that the user often has little choice over flow hood placement, because grilles are located near the intersection of walls, floors, and ceilings (or other obstructions); the ability to center the hood is probably limited more by these physical constraints than by visual acuity.

Figure A12 shows that the propeller flow hood (Hood 9) has considerable variation with inlet flow conditions. It is sensitive to swirl in the entering flow, to location of the hood over the grille, and to damper position. $\mathrm{CW}$ swirl is in the same direction as propeller rotation and results in the propeller spinning too fast, and produces an average $11 \%$ over estimate of flow.

Conversely, CCW swirl acts in opposition to propeller rotation, and produces an average $30 \%$ under estimate of flow. Even though this flow hood has a small range of positioning movement, it is still sensitive to positioning over the grille. Flow hood position relative to the grille changes the relative error by about $25 \%$, with corner placement giving the greatest sensitivity. The effects of damper position are also significant for Hood 9: compared to the results with the damper fully open, the dampered results are $11 \%$ higher on average and have about three times the RMS error. In field applications where occupants have set dampers to control airflow (and do not want them changed), this means that the flow hood errors could change from grille to grille.

Because our laboratory tests and field experience have demonstrated the accuracy of active flow hoods and their insensitivity to non-uniform flows, we used the active Hood 10 as the reference flow hood for our field studies. The field test results in Tables A9 and A10 show that some flow hoods gave acceptable results and others did not. For example, differences for the sum of all supply grille flows were less than $10 \%$ compared to the active reference (Hood 10) for five of the tested hoods (Hoods 1, 2, 3, 9, and 11). However, Hoods 4 and 5 gave supply flows that are much too high for most applications (these were two identical flow hoods from the same manufacturer). The results for Hoods 1, 9, and 11 indicate that they are acceptable for all the potential grille flow tests outlined in Table A7. The return flow uncertainty for Hood $2(-17 \%$, $-177 \mathrm{cfm})$ and the individual grille uncertainties for Hood 3 indicated by its RMS error $(15 \%$, $12 \mathrm{cfm}$ ) mean that these two hoods are acceptable for all the potential grille flow tests outlined in Table A7, except for determining air handler flow and duct leakage.

The findings based on our field tests apply only to the tested system; we expect that the errors reported for these field tests are lower than those from a typical HVAC diagnostic application. Experienced researchers conducted all the field tests on a system with grilles that were well placed, had fully open dampers, and did not introduce swirl or other extreme flow nonuniformities. They took as much time as necessary to achieve the best possible results for each flow hood (e.g., taking particular care to center the flow hoods). A field test survey involving more houses and typical flow hood users is needed to estimate the error distribution related to system type and hood usage. 


\section{Calibration versus Application}

As with other instrumentation, flow hoods are susceptible to large errors in field applications that are not apparent in manufacturers' accuracy specifications. Flow hoods are calibrated in a fixed position with uniform flow, resulting in typical accuracy specifications of about $\pm 3 \%$. Instruction manuals for flow hoods often warn of the possibility of errors due to airflow patterns from grilles differing from those during calibration (e.g. Alnor 1998). However, no estimates of the related error are given. Our laboratory and field tests show that the change in airflow pattern between calibration and application creates large flow measurement errors.

ASHRAE Standard 111 (ASHRAE 1988) also discusses flow hood accuracy issues. For example, Section 8.6.4.4 states: " System Effects: Perhaps the most important result of these tests has been to demonstrate that errors as great as $15 \%$ to $30 \%$ may be caused by neglecting the effect of approach conditions." This agrees closely with our laboratory test results. ASHRAE Standard 111 also indicates in Section 8.6.5 that one should "...consider most diffuser measurement as not reliable for certifiable accuracy". Current testing and balancing reporting procedures do not emphasize these issues.

Manufacturer's instructions and ASHRAE Standard 111 discuss the use of pitot-static-tube traverses to field calibrate the flow hood to account for the problems discussed above. However, this is not a practical solution in residential systems because:

- there will rarely be duct access so that a traverse can be performed,

- ducts are often made from flexible plastic duct that cannot be used for pitot-static tube insertion and mounting (unlike sheet metal ducts),

- almost no duct system has a long enough uninterrupted flow to meet the requirements for an accurate pitot-static-tube traverse, and

- most ducts are unique (in terms of fittings, length, and layout) and a traverse would be required for every grille, thus obviating the need for a flow hood.

\section{Summary}

Of the flow hoods that we tested in the laboratory (i.e., ones that are reasonably available), active flow hoods are the most reliable and consistent for measuring distribution system airflows if the measurements are to be used in estimating duct leakage, air handler flow, and individual grille flows for room load and comfort. This does not mean that active hoods are the only ones that can work. There is no fundamental problem with passive hoods, and our field test results showed that some passive hoods can obtain good results when they are used with appropriate care on the right set of grille types and locations. Laboratory and field tests of a wider range of flow hoods should be pursued, in addition to evaluating improvements for residential flow hoods. Because the active flow hood is the most accurate, it can be used as a reference in field evaluations of other hoods.

A new flow hood measurement standard should be developed to address how flow hoods are operated in the field. This standard should have some standard grille sizes, types, and placements that would cover most common geometries found in residential systems. The laboratory tests we used are a prototype for this standard test procedure. Possible agencies for development of this standard are ASHRAE and ASTM. 


\section{EVALUATION OF REFRIGERANT CHARGE DIAGNOSTICS}

Based on tests of more than 4000 residential cooling systems in California, it is clear that many systems have incorrect refrigerant charge levels (Proctor 2000). Data from these tests indicate that about $34 \%$ are undercharged, $28 \%$ are overcharged, and only $38 \%$ have correct charge. In the past, data from Blasnik et al. (1996) and Proctor $(1997,1998)$ have indicated that an undercharge of $15 \%$ is common.

Both undercharge and overcharge can reduce cooling equipment longevity, capacity, and efficiency. For example, laboratory test data for capillary-tube-controlled equipment (Farzad and O'Neal 1988) indicate that an undercharge of $15 \%$ will reduce cooling equipment total capacity by 8 to $22 \%$ and its energy efficiency ratio (EER) by 4 to $16 \%$. An overcharge of $10 \%$ will reduce capacity by 1 to $9 \%$ and EER by 4 to $11 \%$. Figures A14 and A15 show the capacity degradation of a 3 ton split-system air conditioner versus charge for various outdoor temperatures. These two figures indicate that TXV-controlled equipment is much less sensitive to deviations from the correct charge (Farzad and O'Neal 1989). Their work showed a similar pattern for EER degradation.

Laboratory test data indicate that some short-tube-orifice-controlled equipment behaves more like TXV-controlled equipment (O’Neal et al. 1989), while others behave like capillary-tubecontrolled equipment (Rodriguez 1995). Additional research with a larger sample of short-tubeorifice-controlled cooling equipment is needed to clarify how the performance of equipment like this depends on charge.

Several diagnostics are available to assess the correct amount of refrigerant charge in a system, but only the superheat and subcooling tests are practical, well developed, and reliable (when properly done). Superheat tests are for capillary-tube-controlled equipment; subcooling tests are for TXV-controlled equipment. The common assumption is that superheat tests are also appropriate for short-tube-orifice-controlled equipment. Neither test is standardized, but equipment manufacturers commonly specify them. However, many service technicians do not use the tests, primarily because of the time it takes to do them, but also because they do not have necessary equipment or appropriate indoor and outdoor conditions for the test.

\section{Superheat Test Methods Evaluated}

Carrying out superheat tests on systems with a capillary tube or short-tube orifice is more important than subcooling tests on TXV equipped systems, because a TXV tends to mitigate charge deficiency effects. Consequently, we focused our evaluation on three state-of-the art methods that may facilitate superheat tests on residential cooling systems. Each method involves different hardware, software, and measurements. All three methods, which we broadly characterize as "Superheat Calculation Methods", make the superheat test easier. Table A11 characterizes the methods, as well as our data collection truth standard (Reference). Although the methods include other tests (e.g., Method 3 also assesses air-handler airflow), our evaluation only focuses on the ability of the methods to assess refrigerant charge. 


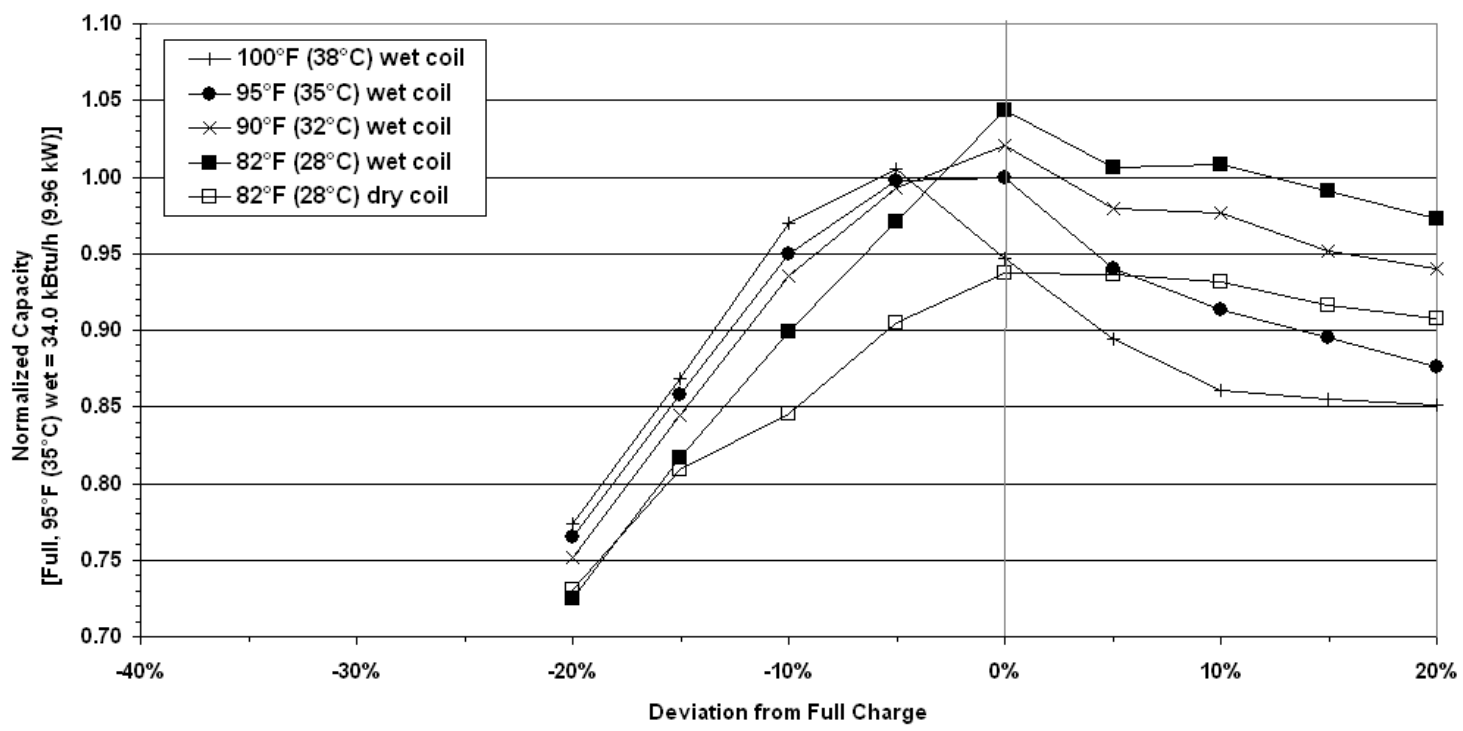

Figure A14. Total capacity variation - Capillary tube (Farzad and O'Neal 1988).

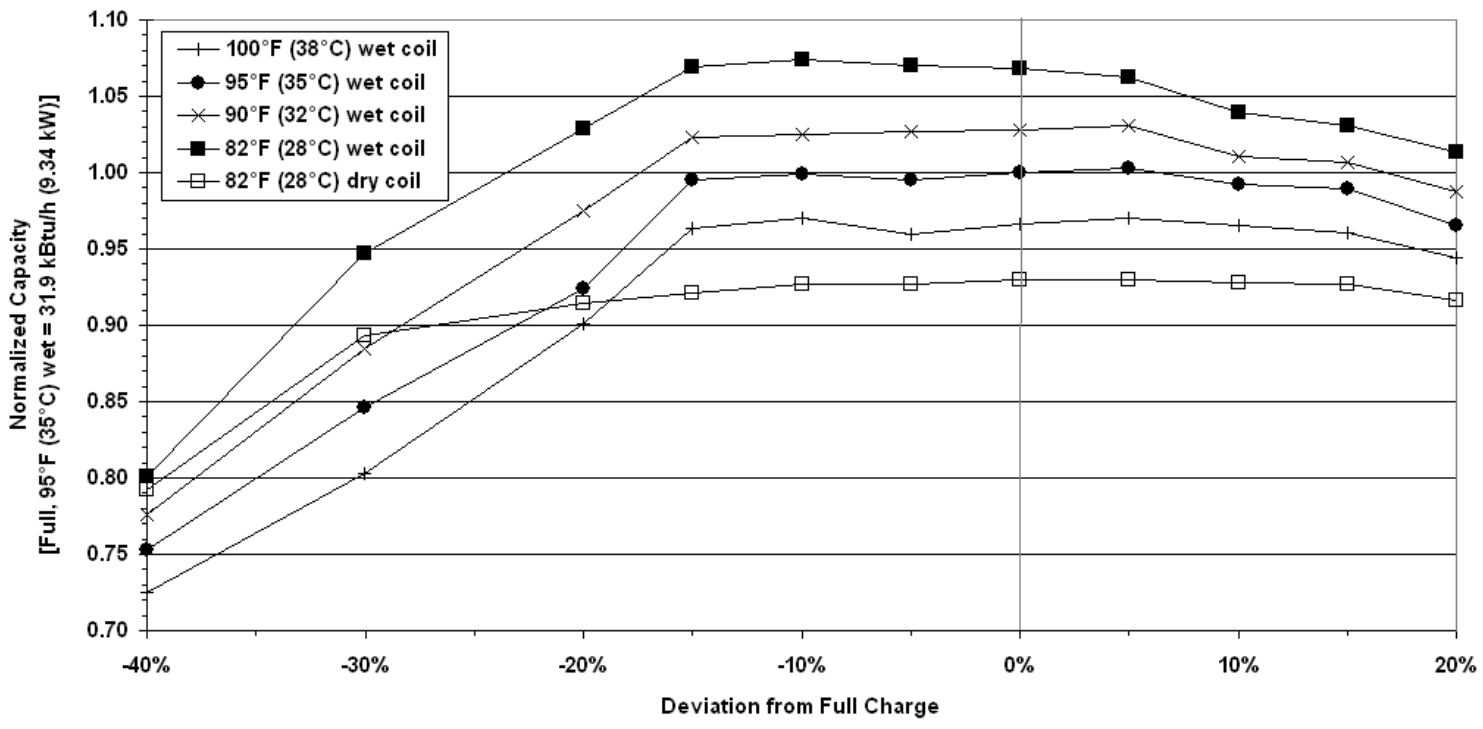

Figure A15. Total capacity variation - TXV (Farzad and O'Neal 1989). 
Table A11. Superheat test methods evaluated.

\begin{tabular}{|c|l|}
\hline Method & Description \\
\hline \hline Reference & $\begin{array}{l}\text { Uses Method 3 software (see below) with continuously monitored data collected using a } \\
\text { research-grade data acquisition system. This method is our "Truth Standard" for purposes of } \\
\text { comparison. }\end{array}$ \\
\hline 1 & $\begin{array}{l}\text { Personal Digital Assistant (PDA) with attached refrigerant pressure transducers and temperature } \\
\text { sensors, which is intended for use on light-commercial buildings. PDA also runs software that } \\
\text { provides diagnoses in the field. The data can be uploaded later from the PDA to a web site that } \\
\text { provides a more detailed analysis. }\end{array}$ \\
\hline 2 & $\begin{array}{l}\text { Data collection system including pressure transducers, temperature and humidity sensors, } \\
\text { software, and computer that collects data for superheat test and then provides recommended } \\
\text { action to technician. Currently designed for use by an authorized crew who carries out the test, } \\
\text { provides diagnoses to a contractor, and then verifies the efficacy of any work that is performed. }\end{array}$ \\
\hline 3 & $\begin{array}{l}\text { Software program that requires the technician to enter single point data from refrigerant manifold } \\
\text { gauges and temperature sensors into a computer, which then provides diagnoses based on } \\
\text { measured and target superheat comparison. To avoid computer use in the field, the contractor also } \\
\text { has the option of providing input data by telephone to a remote operator, who then enters it into } \\
\text { the software and relays diagnoses back to the technician. }\end{array}$ \\
\hline
\end{tabular}

Our goal in the evaluations was to assess the accuracy of these methods and to ascertain whether they are useful for residential commissioning. The central questions we are attempting to answer with this work are:

- What technologies are available to make a superheat test easier?

- How do these technologies work?

- How accurate are they, and how accurate do they need to be to accurately assess charge?

There are three caveats regarding our evaluation:

1. Our evaluation explored the strengths and limitations of the methods that we tested rather than testing them on a statistically significant number of homes. In particular, we only tested cooling equipment in four houses (two new ones and two older ones), all with short-tubeorifice controls.

2. Although we ostensibly compare different methods that might facilitate the superheat test, we could not always do an "apples-to-apples" comparison. The different methods all use different input data and different algorithms. These algorithms are either proprietary or were not accessible to us. Consequently, our results describe differences between the different methods and we state when the quantities being compared are not effectively the same.

3. As a reference standard, we used the superheat test even though it is prone to measurement error, can be time consuming, and the indoor and outdoor conditions that govern its use are limited. In particular, our evaluations used continuously monitored data that we collected and output from the software of Method 3 based on these data. We chose that method because it is the most fully developed product that we considered and because it has an extensive history of field tests. We also chose it because we did not have time or resources to do gravimetric tests, the preferred truth standard. A gravimetric analysis is useful for a wider range of conditions and is potentially more accurate. That method involves removing all of 
the refrigerant in a system, drawing a vacuum and leak testing the system, and then adding the manufacturer's recommended amount of refrigerant for the compressor, coils, and installed "line set" (refrigerant line length). However, the gravimetric test requires a matched indoor coil and outdoor unit, as well as a good measurement of the line set. Further drawbacks are the time and skill that it takes to do a gravimetric test, which is more complex than a superheat test.

\section{What is the Superheat Test?}

To understand our evaluations, it is important to understand the basic theory of the superheat test. Superheat is a thermodynamic metric, defined as the temperature rise above the vapor saturation temperature (i.e., the temperature at which all the liquid in a mixture is evaporated for a given pressure). For typical suction line pressures of 40 to $100 \mathrm{psig}$ (276 to $690 \mathrm{kPa}$ ) found in R-22 systems, the vapor saturation temperature will range from 17 to $59^{\circ} \mathrm{F}\left(-8\right.$ to $\left.15^{\circ} \mathrm{C}\right)$. Refrigerant pressure gauges commonly have a concentric scale to conveniently indicate the vapor saturation temperature that corresponds to the measured pressure for a given refrigerant.

For a superheat test of a cooling system, the actual superheat at operating conditions is determined by measuring the temperature and pressure of the refrigerant in the suction line, just before the refrigerant enters the compressor. The actual superheat is the difference between the suction line refrigerant temperature and the vapor saturation temperature at the measured pressure. The deviation of this superheat value from a target superheat is an indicator of whether the amount of refrigerant charge in the air conditioner is correct when it operates at design conditions. Note that the surface temperature of the suction line rather than the refrigerant temperature itself is measured in practice. This difference is a potential source of error in the test, as discussed later when we review our field test results.

Equipment manufacturers use laboratory tests to determine target superheat values as a function of the return air wet-bulb temperature entering the evaporator and of the outdoor air dry-bulb temperature entering the condenser. Those temperatures act as surrogate metrics to characterize two variables that affect the refrigerant evaporation rate in the evaporator: the cooling load on the evaporator and the heat rejection rate of the condensing unit. These data are typically available in a table or in a chart. In a superheat test, the technician measures the two air temperatures that we describe above and then obtains the corresponding target superheat from the table or chart.

If the measured superheat value is too low compared to the target superheat, there will be too much charge in the system at design operating conditions. In addition to energy and capacity impacts, there is a chance that liquid refrigerant will not completely evaporate at these conditions and could slug the compressor. If the measured superheat value is too large compared to the target superheat, there will be too little charge in the system at design operating conditions. In addition to energy and capacity impacts that are more serious than in the overcharge case, the suction line pressure and corresponding saturation temperature of the refrigerant will be very low. This can lead to ice formation on the evaporator, which can restrict heat transfer, increase airflow resistance, and reduce air-handler airflow. This will further reduce air conditioner performance and can shorten compressor life.

\section{Test Houses and Cooling Equipment}

We used each of the methods to test four separate California houses, which are cooled by splitsystem central air conditioners equipped with short-tube-orifice metering devices and R-22 
refrigerant. The rated capacity of all the tested air conditioners is 3 to 4 tons. Table A12 summarizes relevant house and equipment characteristics.

Table A12. Test house and cooling equipment characteristics.

\begin{tabular}{|c|c|c|c|c|}
\hline Site & House Location & $\begin{array}{c}\text { Cooling Equipment } \\
\text { Age } \\
{[\text { Years] }}\end{array}$ & $\begin{array}{c}\text { Condensing Unit } \\
\text { Rated Capacity } \\
{[\text { Tons (kW)] }}\end{array}$ & $\begin{array}{c}\text { Evaporator } \\
\text { Rated Capacity } \\
{[\text { Tons (kW)] }}\end{array}$ \\
\hline \hline A & Larkspur, CA & 17 & $3(11)$ & Unknown \\
\hline B & Sacramento, CA & $<1$ & $3.5(12)$ & $4(14)$ \\
\hline C & Sacramento, CA & $<1$ & $3(11)$ & $4(14)$ \\
\hline D & Concord, CA & $>15^{1}$ & $3.5(12)$ & Unknown \\
\hline
\end{tabular}

${ }^{1}$ Estimated. The house was about 25 years old and was occupied by the current owner 4 years ago. The system is very old and decrepit.

We conducted superheat tests in the "as found" condition and then repeated them each time after we added or removed refrigerant charge. However, we only report the measurements for the "as found" condition and the final "post-charging" condition. At each house, we operated the equipment for at least 15 minutes initially and after each charge change to allow system conditions to stabilize before conducting a superheat test.

\section{Field Test Results}

The following describes our field test results, compares the data that are required to determine the actual and target superheat values, and compares diagnoses generated by the various methods. In many cases, some of the field data are missing. Most of the time, one should interpret this as a failure of a product or operator error, indicated by "NA" in the tables. There are a couple of exceptions, indicated with "-" in the tables: we did not use Method 3 at Site D because the technician was unavailable. Additionally, Method 1 does not measure the return plenum wet-bulb temperature or use it in its analysis. We discuss the details and implications of intentional and unintentional missing data more fully throughout the following sections.

Determining the Target Superheat: An important part of conducting the superheat test is determining the target superheat. Methods 2 and 3 use a chart for this purpose, similar to the manufacturers chart described earlier. To use the chart, Method 3 requires measuring the drybulb temperature of the air entering the condenser and the wet-bulb temperature of the air entering the evaporator from the return plenum. It seems that Method 2 may use additional calculations (discussed in further detail later). Method 1 does not measure either of these temperatures. The manufacturer reports that this method uses a proprietary superheat chart, which ascertains the loads on the coils through some other algorithm. That method requires measuring the ambient temperature at the PDA, which is likely theorized to be close to the condenser entering temperature, because the short length of the device's refrigerant hoses requires it to be located near the condenser. It is not clear what Method 1 uses in place of the return plenum wet-bulb temperature, because it has no temperature or humidity sensors inside the house or ducts.

For each site, Table A13 lists the measured air temperature entering the condenser and the return plenum wet-bulb temperature for the "as found" and "post-charging" conditions. 
With the Reference results as a benchmark, it is clear that Method 1 sometimes measures a different temperature than the condenser entering temperature, even when its temperature sensor is no more than 6 feet away from the condensing unit. For example, in the Site D post-charging case, it measures a temperature that is approximately $16^{\circ} \mathrm{F}\left(9^{\circ} \mathrm{C}\right)$ too high. Since it is not clear how the Method 1 algorithm works, it is not clear how this difference might affect the method's analysis. However, it seems likely that any attempt to use this temperature to determine the load on the condenser might lead to significant errors.

Table A13a. Measured parameters for determining "as found" target superheat.

\begin{tabular}{|c|cccc|cccc|}
\hline \multirow{2}{*}{ Method } & \multicolumn{3}{|c|}{$\begin{array}{c}\text { Condenser Air Entering } \\
\text { Temperature }\left[{ }^{\circ} \mathrm{F}\left({ }^{\circ} \mathrm{C}\right)\right]\end{array}$} & \multicolumn{4}{c|}{$\begin{array}{c}\text { Return Plenum Wet-Bulb } \\
\text { Temperature }\left[{ }^{\circ} \mathrm{F}\left({ }^{\circ} \mathrm{C}\right)\right]\end{array}$} \\
\cline { 2 - 9 } & Site A & Site B & Site C & Site D & Site A & Site B & Site C & Site D \\
\hline \hline Ref. & $96^{1}(36)$ & $85(29)$ & $89(32)$ & $76(24)$ & $65(18)$ & $62(17)$ & $66(19)$ & $62(17)$ \\
\hline 1 & $105(41)$ & $88(31)$ & $87(31)$ & $85(29)$ & - & - & - & - \\
\hline $2^{2}$ & $108(42)$ & $85(29)$ & $91(33)$ & $73(23)$ & $66(19)$ & $61(16)$ & $65(18)$ & $61(16)$ \\
\hline 3 & $100(38)$ & $85(29)$ & $\mathrm{NA}^{3}$ & - & $67(19)$ & $63(17)$ & $\mathrm{NA}^{3}$ & - \\
\hline
\end{tabular}

${ }^{1}$ This value is incorrect - it is the ambient air temperature. The temperature probes measuring condenser entering air temperature failed for this test.

${ }^{2}$ Method 2 measures the humidity and temperature at the return grille(s). The number reported here is the average return grille wet-bulb temperature and not the return plenum wet-bulb temperature.

${ }^{3}$ Either operator error or a computer error caused the Method 3 data to be missing for Site $\mathrm{C}$ as found.

Table A13b. Measured parameters for determining "post charging" target superheat.

\begin{tabular}{|c|c|c|c|c|c|c|c|c|}
\hline \multirow[b]{2}{*}{ Method } & \multicolumn{4}{|c|}{$\begin{array}{l}\text { Condenser Air Entering } \\
\text { Temperature }\left[{ }^{\circ} \mathrm{F}\left({ }^{\circ} \mathrm{C}\right)\right]\end{array}$} & \multicolumn{4}{|c|}{$\begin{array}{l}\text { Return Plenum Wet-Bulb } \\
\text { Temperature }\left[{ }^{\circ} \mathrm{F}\left({ }^{\circ} \mathrm{C}\right)\right]\end{array}$} \\
\hline & Site A & Site B & Site $C$ & Site D & Site A & Site B & Site $C$ & Site D \\
\hline Ref. & $100^{1}(38)$ & $888(31)$ & $92(33)$ & $78(26)$ & 66 (19) & $61(16)$ & 64 (18) & 60 (16) \\
\hline 1 & $98(37)$ & $89(32)$ & $92(33)$ & $94(34)$ & - & - & - & - \\
\hline $2^{2}$ & $105(41)$ & $92(33)$ & $\mathrm{NA}^{3}$ & $77(25)$ & $65(18)$ & $60(16)$ & $\mathrm{NA}^{3}$ & $60(16)$ \\
\hline 3 & $101(38)$ & $\mathrm{NA}^{4}$ & $92(33)$ & - & 66 (19) & $\mathrm{NA}^{4}$ & $65(18)$ & - \\
\hline
\end{tabular}

${ }^{1}$ This value is incorrect - it is the ambient air temperature. The temperature probes measuring condenser entering air temperature failed for this test.

${ }^{2}$ Method 2 measures the humidity and temperature at the return grille(s). The number reported here is the average return grille wet-bulb temperature and not the return plenum wet-bulb temperature.

${ }^{3}$ A computer error caused the Method 2 data to be missing for Site C post-charging.

${ }^{4}$ Either operator error or a computer error caused the Method 3 data to be missing for Site B post-charging.

With the exception of Method 1 at Site D, all methods do a reasonable job measuring the condenser air entering temperature. However, there are still substantial differences in some cases (up to $4^{\circ} \mathrm{F}\left(2^{\circ} \mathrm{C}\right)$, Site B post-charging). Also, there is a noticeable deviation between methods at 
Site A. That deviation is difficult to analyze because the Reference condenser entering temperature sensor failed at this site. The other deviations do not exceed $2^{\circ} \mathrm{F}\left(1^{\circ} \mathrm{C}\right)$.

The other measurement necessary to determine the target superheat is the wet-bulb temperature of air entering or that will enter the evaporator. There are major differences between methods in how they measure this quantity:

- Reference uses a thermistor and a relative humidity $(\mathrm{RH})$ sensor in the return plenum.

- Method 1 does not measure this parameter.

- Method 2 uses the average of all RH and temperature measurements at the return grilles.

- Method 3 uses a thermocouple surrounded by a wet cotton sleeve in the return plenum.

Method 2 does not account for the effects of duct leakage, because it measures the temperature at the return grille instead of within the plenum. In systems with substantial return duct leakage such as Sites A and D (17 and 33\% respectively), we expect Method 2 will measure a lower wetbulb temperature, which will result in a target superheat that is lower than it should be. However, there is very little difference in the wet bulb temperatures, no matter what measurement methodology is used. Part of this is because Sites A and D have most of their ducts in a crawlspace and garage respectively, which are buffer spaces with similar temperature and humidity conditions as the house. If the ducts had been located in a hot attic, one would expect a substantial effect. In any case, from this small sample, there seems to be no effective difference between the various measurement techniques for this quantity.

Determining the Actual Superheat: There is much more consistency with how the three methods measure parameters that determine the actual superheat value. To establish the actual superheat, each method measures the temperature of the suction line near the service port at the compressor and the pressure in the suction line at this service port. The suction line pressure is then converted to a vapor saturation temperature using a standard vapor saturation temperature chart. The difference between the suction line and vapor saturation temperatures is the actual superheat. Table A14 lists the measured suction line pressures and Table A15 lists the associated saturation temperatures and the measured suction line temperature.

Several patterns are clear from these data. Differences in suction line pressures (up to 6 psig, $41 \mathrm{kPa}$, or $11 \%$ ) are sometimes greater than we expect based on the accuracy that is achievable for the types of gauges used. This means that vapor saturation temperatures will also be noticeably different. In the case of the largest pressure difference (Site $\mathrm{C}$ as found), there is a corresponding $5^{\circ} \mathrm{F}\left(3^{\circ} \mathrm{C}\right)$ difference in calculated vapor saturation temperatures, which will contribute to a $5^{\circ} \mathrm{F}\left(3^{\circ} \mathrm{C}\right)$ difference in actual superheat. Method 3 uses $5^{\circ} \mathrm{F}\left(3^{\circ} \mathrm{C}\right)$ as the expected accuracy of measurement of actual superheat.

To determine if the variation in pressures between different methods was due to gauge accuracy, we checked the calibration of the pressure gauges and transducers using a Heise pressure gauge (accuracy $\pm 0.6 \mathrm{psig}(4 \mathrm{kPa})$ ) and helium gas at various pressures. There were very small differences of 1 to $4 \mathrm{psig}$ ( 7 to $27 \mathrm{kPa}$ ) between the gauges at typical suction pressures. The larger errors occurred with the Method 2 pressure transducer. The gauges and transducer used in the reference as well as Methods 1 and 3 had errors less than 2 psig $(13 \mathrm{kPa})$, with 1 psig $(7 \mathrm{kPa})$ errors being most common. All gauges exhibited a negative bias. 
Table A14a. Measured pressures for determining "as found" actual superheat.

\begin{tabular}{|c|cccc|}
\hline \multirow{2}{*}{ Method } & \multicolumn{4}{|c|}{ Suction Line Pressure [psig (kPa)] } \\
\cline { 2 - 5 } & Site A & Site B & Site C & Site D \\
\hline \hline Ref. & $59(410)$ & $58(400)$ & $57(390)$ & $45(310)$ \\
\hline 1 & $63(430)$ & $63(430)$ & $51(350)$ & $49(340)$ \\
\hline 2 & $62(430)$ & $58(400)$ & $-56^{1}$ & $45(310)$ \\
\hline 3 & $62(430)$ & $63(430)$ & $\mathrm{NA}^{2}$ & - \\
\hline
\end{tabular}

${ }^{1}$ This value is erroneous and was traced to a computer error in Method 2.

${ }^{2}$ Either operator error or a computer error caused the Method 3 data to be missing for Site C as found.

Table A14b. Measured pressures for determining "post-charging” actual superheat.

\begin{tabular}{|c|cccc|}
\hline \multirow{2}{*}{ Method } & \multicolumn{4}{|c|}{ Suction Line Pressure [psig (kPa)] } \\
\cline { 2 - 5 } & Site A & Site B & Site C & Site D \\
\hline \hline Ref. & $67(460)$ & $70(480)$ & $78(540)$ & $64(440)$ \\
\hline 1 & $69(480)$ & $70(480)$ & $78(540)$ & $66(460)$ \\
\hline 2 & $69(480)$ & $67(460)$ & $\mathrm{NA}^{1}$ & $64(440)$ \\
\hline 3 & $68(470)$ & $\mathrm{NA}^{2}$ & $78(540)$ & - \\
\hline
\end{tabular}

${ }^{1}$ A computer error caused the Method 2 data to be missing for Site C post-charging.

${ }^{2}$ Either operator error or a computer error caused the Method 3 data to be missing for Site B post-charging.

Given the consistency of pressure gauges during calibration, we do not know why there are pressure differences between methods in the "as found" cases. We hypothesize that measurements at slightly different times under changing operating conditions might be the cause of these pressure differences. Unfortunately, we did not continuously monitor refrigerant pressure. However, periodic fluctuations in suction and liquid line temperatures during the tests seem to provide evidence in support of our hypothesis.

In particular, at Site $\mathrm{C}$ post-charging, we observed pulsating variations in suction line temperature with an amplitude of as much as $4^{\circ} \mathrm{F}\left(2^{\circ} \mathrm{C}\right)$ with a period of about 2 to 3 minutes peak to peak (see Figure A16). This does not mean that the vapor saturation temperatures (and therefore pressures) varied as much, but it does indicate that they would be varying. One might ask then, if pressures are varying, why are the pressures measured by each method after charge correction identical (Table A15b), and why is there almost no variation over time in suction line temperature before charge correction. 
Table A15a. Measured temperatures for determining "as found" actual superheat.

\begin{tabular}{|c|cccc|cccc|}
\hline \multirow{2}{*}{ Method } & \multicolumn{4}{|c|}{ Vapor Saturation Temperature $\left[{ }^{\circ} \mathrm{F}\left({ }^{\circ} \mathrm{C}\right)\right]$} & \multicolumn{4}{|c|}{ Suction Line Temperature $\left[{ }^{\circ} \mathrm{F}\left({ }^{\circ} \mathrm{C}\right)\right]$} \\
\cline { 2 - 9 } & Site A & Site B & Site C & Site D & Site A & Site B & Site C & Site D \\
\hline \hline Ref. & $34(1)$ & $32(0)$ & $32(0)$ & $22(-6)$ & $73(23)$ & $79(26)$ & $84(29)$ & $68(20)$ \\
\hline 1 & $36(2)$ & $36(2)$ & $27(-3)$ & $25(-4)$ & $74(23)$ & $76(24)$ & $84(29)$ & $68(20)$ \\
\hline 2 & $35(2)$ & $32(0)$ & $-28^{1}$ & $22(-6)$ & $65(18)$ & $77(25)$ & $87(31)$ & $68(20)$ \\
\hline 3 & $37(3)$ & $35(2)$ & NA $^{2}$ & - & $75(24)$ & $76(24)$ & $\mathrm{NA}^{2}$ & - \\
\hline
\end{tabular}

${ }^{1}$ This value is erroneous and was traced to a computer error in Method 2.

${ }^{2}$ Either operator error or a computer error caused the Method 3 data to be missing for Site $\mathrm{C}$ as found.

Table A15b. Measured temperatures for determining "post-charging" actual superheat.

\begin{tabular}{|c|cccc|cccc|}
\hline \multirow{2}{*}{ Method } & \multicolumn{3}{|c|}{ Vapor Saturation Temperature $\left[{ }^{\circ} \mathrm{F}\left({ }^{\circ} \mathrm{C}\right)\right]$} & \multicolumn{3}{|c|}{ Suction Line Temperature $\left[{ }^{\circ} \mathrm{F}\left({ }^{\circ} \mathrm{C}\right)\right]$} \\
\cline { 2 - 9 } & Site A & Site B & Site C & Site D & Site A & Site B & Site C & Site D \\
\hline \hline Ref. & $39(4)$ & $40(4)$ & $47(8)$ & $36(2)$ & $47(8)$ & $45(7)$ & $56(13)$ & $46(8)$ \\
\hline 1 & $40(4)$ & $41(5)$ & $46(8)$ & $39(4)$ & $48(9)$ & $48(9)$ & $59(15)$ & $46(8)$ \\
\hline 2 & $39(4)$ & $39(4)$ & $\mathrm{NA}^{1}$ & $37(3)$ & $43(6)$ & $44(7)$ & $\mathrm{NA}^{1}$ & $45(7)$ \\
\hline 3 & $40(4)$ & $\mathrm{NA}^{2}$ & $47(8)$ & - & $48(9)$ & NA $^{2}$ & $56(13)$ & - \\
\hline
\end{tabular}

${ }^{1} \mathrm{NA}=$ Not Available. A computer error caused the Method 2 data to be missing for Site $\mathrm{C}$ post-charging.

${ }^{2}$ Either operator error or a computer error caused the Method 3 data to be missing for Site B post-charging.

Regarding the variability in the pressure signal, the agreement between methods might simply be fortuitous, such that the measurements happened to occur at times when the pressures matched. Regarding the relatively constant as-found suction pressure, a possible explanation is that the small temperature differences between the refrigerant vapor and outdoors associated with the undercharge found at this site caused poor heat transfer in the suction line. This tends to mask the effect of pressure fluctuations on suction line temperature. This effect is not masked for the liquid line, because there are substantial temperature differences between the subcooled liquid refrigerant and outdoors. In addition, the heat transfer effectiveness from the subcooled refrigerant to the liquid line tubing wall is greater than that for the superheated refrigerant vapor to the suction line, because of the higher specific heat of the liquid.

The suction line temperatures in Table A15 show about the same amount of variation as the vapor saturation temperatures, but in a different pattern. Unlike the pressure measurements on which the latter temperatures are based, each method uses a different device to measure the suction line temperature and it is a much more complex parameter to measure.

- Reference uses a thermistor that is cable-tied to the suction line and insulated.

- Method 1 uses a large proprietary temperature sensor with an elastic clamping mechanism.

- Method 2 uses an RTD sensor that is cable-tied to the suction line and insulated.

- Method 3 uses a thermocouple that is taped to the suction line and insulated. 


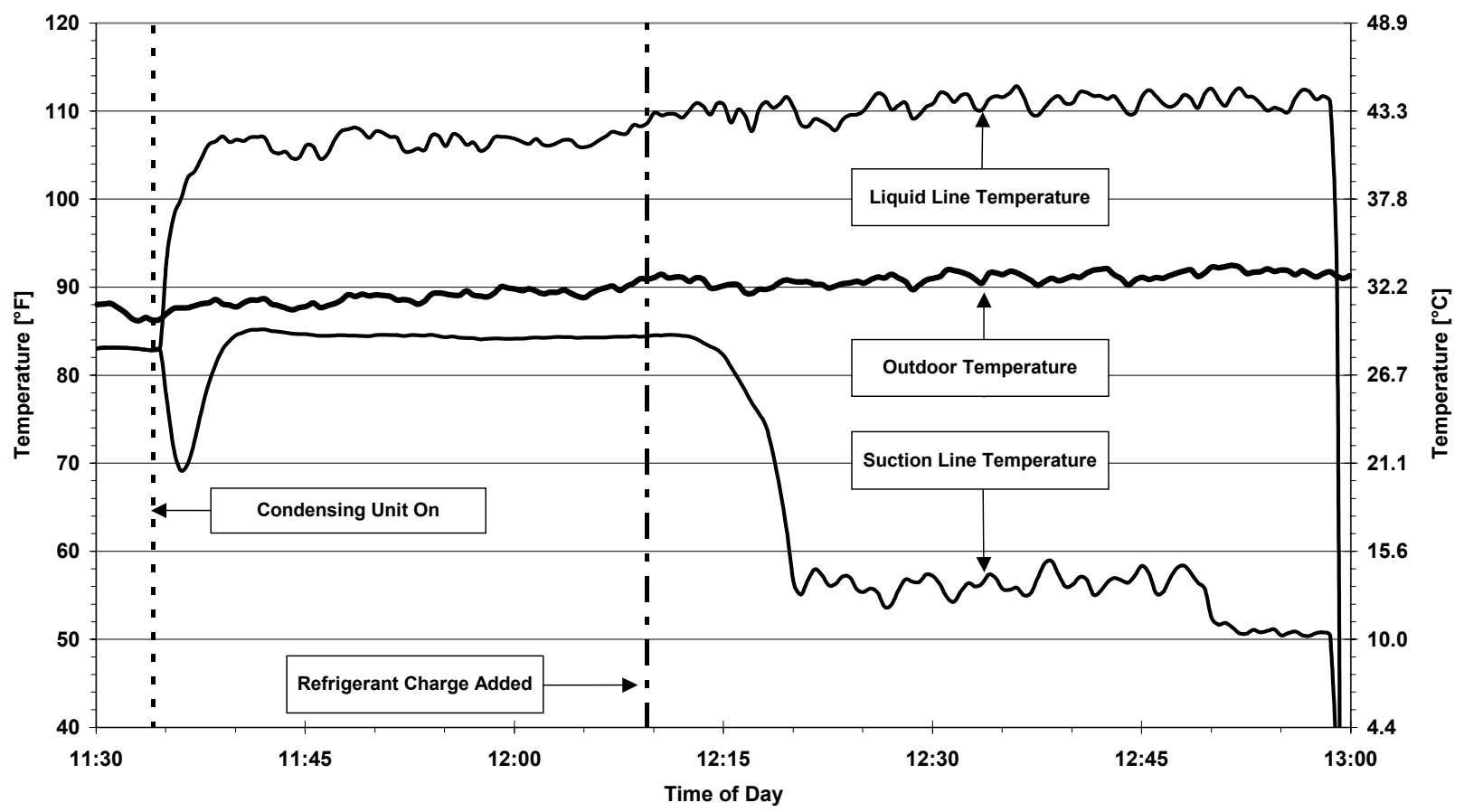

Figure A16. Site C field data.

The actual quantity needed is the temperature of the refrigerant inside the copper refrigerant line. However, this quantity is not measurable directly, so all methods measure the outside wall temperature of the copper tubing, assuming that the turbulence in the refrigerant and the high conductivity of the copper will transfer heat well from the refrigerant to the external sensor. Three heat transfer issues complicate this type of measurement:

- One issue is adequate contact between the sensor and the wall of the copper tube. All of the devices have some sort of clamping system to assure a close fit, but local variations in the copper surface as well as dirt accumulation or oxidation on the surface can add a contact resistance. This resistance leads to a higher temperature reading for the suction line than might otherwise occur. For some of the houses, we used heat sink compound with the Reference sensors. We found in the field, as well as in subsequent laboratory tests, that heat sink compound improved the temperature reading, but not significantly. Cleaning the heat sink compound off the lines after the test to avoid leaving an unsightly mess is time consuming. As a result, we do not recommend using heat sink compound for the superheat test.

- A more significant issue is whether the sensor is insulated. In particular, the Method 1 sensor has a high profile that makes insulating it difficult, but it already had a large plastic housing that provided some amount of insulation.

- Thermal mass of the temperature sensors is also an issue. Although all of the air conditioning systems operated for at least 15 minutes before each test (a requirement of the Method 3 software), we expect that the pressure and temperature of the refrigerant was still changing slightly even during the test (see Figure A16 for an example of this phenomena). Some of the temperature sensors, particularly the Method 1 sensor, had a very large mass. Such sensors 
have a slower response to temperature changes than a smaller sensor (e.g., the thermocouple used for Method 3).

Target and Actual Superheat with Deviation above Target: Combined, the results from the preceding sections determine the target superheat, the actual superheat, and the deviation from the target superheat (Actual - Target). These results appear in Tables A16 and A17. Method 1 results are excluded from Tables A16a and A16b because this method does not provide a target superheat.

Table A16a. "As found" target and actual superheats.

\begin{tabular}{|c|cccc|cccc|}
\hline \multirow{2}{*}{ Method } & \multicolumn{4}{|c|}{ Target Superheat $\left[{ }^{\circ} \mathrm{F}\left({ }^{\circ} \mathrm{C}\right)\right]$} & \multicolumn{4}{c|}{ Actual Superheat $\left[{ }^{\circ} \mathrm{F}\left({ }^{\circ} \mathrm{C}\right)\right]$} \\
\cline { 2 - 9 } & Site A & Site B & Site C & Site D & Site A & Site B & Site C & Site D \\
\hline \hline Ref. & $8(4)$ & $9(5)$ & $11(6)$ & $14(8)$ & $39(22)$ & $47(26)$ & $52(29)$ & $46(26)$ \\
\hline 1 & - & - & - & - & $38(21)$ & $40(22)$ & $57(32)$ & $43(24)$ \\
\hline 2 & $5(3)$ & $7(4)$ & $9(5)$ & $11(6)$ & $30(17)$ & $45(25)$ & $115^{2}$ & $47(26)$ \\
\hline 3 & $10(6)$ & $11(6)$ & $\mathrm{NA}^{3}$ & - & $38(21)$ & $41(23)$ & $\mathrm{NA}^{3}$ & - \\
\hline
\end{tabular}

${ }^{1}$ Method 1 does not calculate a target superheat

${ }^{2}$ This value is erroneous and was traced to a computer error.

${ }^{3}$ Either operator error or a computer error caused the Method 3 data to be missing for Site $\mathrm{C}$ as found.

Table A16b. "Post charging" target and actual superheats.

\begin{tabular}{|c|cccc|cccc|}
\hline \multirow{2}{*}{ Method } & \multicolumn{3}{|c|}{ Target Superheat $\left[{ }^{\circ} \mathrm{F}\left({ }^{\circ} \mathrm{C}\right)\right]$} & \multicolumn{3}{c|}{ Actual Superheat $\left[{ }^{\circ} \mathrm{F}\left({ }^{\circ} \mathrm{C}\right)\right]$} \\
\cline { 2 - 10 } & Site A & Site B & Site C & Site D & Site A & Site B & Site C & Site D \\
\hline \hline Ref. & $8(4)$ & $5(3)$ & $10(6)$ & $10(6)$ & $8(4)$ & $5(3)$ & $9(5)$ & $10(6)$ \\
\hline 1 & - & - & - & - & $8(4)$ & $7(4)$ & $13(7)$ & $8(4)$ \\
\hline 2 & $5(3)$ & $5(3)$ & $\mathrm{NA}^{2}$ & $10(6)$ & $4(2)$ & $7(4)$ & $\mathrm{NA}^{2}$ & $8(4)$ \\
\hline 3 & $7(4)$ & $\mathrm{NA}^{3}$ & $10(6)$ & - & $8(4)$ & $\mathrm{NA}^{3}$ & $9(5)$ & - \\
\hline
\end{tabular}

${ }^{1}$ Method 1 does not calculate a target superheat

${ }^{2} \mathrm{~A}$ computer error prevented the Method 2 from saving the data for Site $\mathrm{C}$ post-charging.

${ }^{3}$ Either operator error or a computer error caused the Method 3 data to be missing for Site B post-charging.

\section{Discussion}

Based on our results, we recommend that Method 1 not be used for superheat tests of residential cooling systems at this time. One reason is that Method 1 does not report a target superheat. Instead, it reports a qualitative text string related to charge deviation: high, low, or acceptable (denoted as $\mathrm{Hi}, \mathrm{Lo}$, or Ok, with a modifying plus or minus sign to indicate whether it is a little bit high or low), or N/A, which means that the input data that Method 1 uses to calculate the target are outside an acceptable range. For this reason, the superheat target values exclude Method 1. 
Table A17a. "As found" deviation above target superheat.

\begin{tabular}{|c|cccc|}
\hline \multirow{2}{*}{ Method } & \multicolumn{4}{|c|}{ Deviation above Target Superheat $\left[{ }^{\circ} \mathrm{F}\left({ }^{\circ} \mathrm{C}\right)\right]$} \\
\cline { 2 - 5 } & Site A & Site B & Site C & Site D \\
\hline \hline Ref. & $31(21)$ & $38(21)$ & $41(23)$ & $32(18)$ \\
\hline 1 & N/A & Hi++ & N/A & N/A \\
\hline 2 & $25(14)$ & $38(21)$ & $106^{2}$ & $36(20)$ \\
\hline 3 & $28(16)$ & $30(17)$ & $\mathrm{NA}^{3}$ & - \\
\hline
\end{tabular}

${ }^{1}$ Key to Method 1 results: N/A means Not Applicable/Out of Range, Hi++ means very high

${ }^{2}$ This value is erroneous and was traced to a computer error.

${ }^{3}$ Either operator error or a computer error caused the Method 3 data to be missing for Site $\mathrm{C}$ as found.

Table A17b. "Post charging" deviation above target superheat.

\begin{tabular}{|c|cccc|}
\hline \multirow{2}{*}{ Method } & \multicolumn{4}{|c|}{ Deviation above Target Superheat $\left[{ }^{\circ} \mathrm{F}\left({ }^{\circ} \mathrm{C}\right)\right]$} \\
\cline { 2 - 5 } & Site A & Site B & Site C & Site D \\
\hline \hline Ref. & $0(0)$ & $0(0)$ & $-1(-1)$ & $0(0)$ \\
\hline 1 & Ok- & Lo & Lo & Ok- \\
\hline 2 & $-1(-1)$ & $2(1)$ & NA $^{1}$ & $-2(-1)$ \\
\hline 3 & $1(1)$ & $\mathrm{NA}^{2}$ & $-1(-1)$ & - \\
\hline
\end{tabular}

${ }^{1}$ Key to Method 1 results: OK- means the reading is fine, but a little low, Lo means that the reading is low.

${ }^{2} \mathrm{~A}$ computer error prevented the Method 2 data from being saved for Site C post-charging.

${ }^{3}$ Either operator error or a computer error caused the Method 3 data to be missing for Site B post-charging.

The use of text strings is not a problem by itself. However, for three of the four "as found" cases, Method 1 listed N/A in response to its actual superheat test, even though the systems (including the two brand new ones) were substantially undercharged. Furthermore, it reported other problems to be more important than the undercharge, so it did not give a complete diagnosis. This indicates that Method 1, when configured as when we tested, has very limited utility for assessing the refrigerant level in residential cooling systems. It is important to note that our analysis is limited to assessing charge levels. Method 1 might be very useful at locating important problems with air conditioning systems, but, without a measured entering wet bulb temperature, it does not seem appropriate for the specific problem of diagnosing refrigerant charge problems.

A more troubling problem with Method 1 is that its web data analysis sometimes differs from the PDA field analysis or its diagnoses are wrong. For example, all the cases that the PDA listed as N/A in the field were later diagnosed as undercharged by the web data analysis. Furthermore, at Sites B and C post-charging, Method 1 indicated the charge level was "Lo", which is contrary to the correctly charged condition indicated by the other methods. Having a technician obtain a 
diagnosis in the field, repair the equipment according to that diagnosis, and then find out later that there was a different diagnosis that may eliminate the need for the repair or worse, indicate that the repair should not have been performed, is a severe shortcoming. The "mutating" diagnosis problem is probably easy to rectify by better coordinating the diagnoses of the PDA software and the web site. However, the incorrect indication of charge level may be more difficult to rectify. Until these problems are solved, the method is unreliable for assessing charge levels in residential cooling systems.

Regarding Methods 2 and 3, uncertainties in the measurements lead to variations in target superheat, actual superheat, and superheat deviation between methods. These variations are as much as $5^{\circ} \mathrm{F}\left(3^{\circ} \mathrm{C}\right)$ for target superheat (Site $\mathrm{A}$ as found), $9^{\circ} \mathrm{F}\left(5^{\circ} \mathrm{C}\right)$ for actual superheat (Site $\mathrm{A}$ as found), and $8^{\circ} \mathrm{F}\left(4^{\circ} \mathrm{C}\right)$ for superheat deviation (Site B as found). As a comparison, laboratory test data from Farzad and O'Neal (1988) for capillary-tube-controlled equipment indicate a $10^{\circ} \mathrm{F}$ $\left(6^{\circ} \mathrm{C}\right)$ error in superheat deviation can result in a charge assessment difference of about 5 to $9 \%$, depending on outdoor temperature.

In spite of these variations, Methods 2 and 3 agree on their diagnoses and should result in similar actions to correct charge deficiencies. As a result, the variations described above may seem less significant. However, at all four sites in this study, the air conditioners were so undercharged (about 15 to $30 \%)$ that even the smallest "as found" deviation $\left(25^{\circ} \mathrm{F}\left(14^{\circ} \mathrm{C}\right)\right.$ for Method 2 at Site A) indicates a substantial problem, and the agreement in diagnoses should be expected. This raises a question of whether the methods would perform as well for air conditioners that were better charged. Examining the post-charging cases in Table A17b offers a partial answer. Where comparisons are possible, the post-charging superheat deviations never differ by more than $2^{\circ} \mathrm{F}$ $\left(1{ }^{\circ} \mathrm{C}\right)$, which suggests that Methods 2 and 3 will produce very similar results for correctly charged systems.

Charge Effects on Equipment Performance: Table A18 shows the "as found" and "postcharging" total cooling capacities, energy efficiency ratios (EER), and power consumption that we measured or calculated, as well as the fractional changes in these parameters due to charging. A small amount of the changes in power draw, capacity, and EER can be attributed to small changes that occurred in ambient and outdoor temperatures between the "as found" and "post charging" conditions. Tables A13a and A13b list those temperatures.

The fractional charge increases listed in Table A18 are based on the total amount added divided by the factory charge listed by the manufacturer on the equipment rating plate. At Site $\mathrm{D}$, this rating was not available. Service technicians should record on the rating plate the actual amount of charge that they have installed. Many rating plates have space explicitly available for this purpose. However, our field experience indicates that this is rarely done.

The capacities, efficiencies, and power draws in Table A18 are based on detailed measurements of air-handler airflow, supply and return temperatures and humidity, and power consumption made as part of the Reference measurements. We did not measure power consumption at Site D, because we could not safely connect our current and voltage sensors to the cooling equipment. As a result, we could not assess efficiency changes at Site D. 
Table A18. Summary of cooling equipment performance.

\begin{tabular}{|c|c|c|c|c|c|}
\hline & & Site A & Site B & Site C & Site D \\
\hline \multirow{2}{*}{\multicolumn{2}{|c|}{$\begin{array}{l}\text { Charge Added [oz }(\mathrm{kg})] \\
\text { Fraction of Total }\end{array}$}} & $15(0.2)$ & $11(0.3)$ & $20.5(0.6)$ & $19(0.5)$ \\
\hline & & $17 \%$ & $13 \%$ & $33 \%$ & Unknown \\
\hline \multicolumn{2}{|c|}{ Air-Handler Airflow [cfm (L/s)] } & $1,240(587)$ & $1,260(593)$ & $1,320(623)$ & $780(368)$ \\
\hline \multirow{3}{*}{ Capacity } & "As Found" [tons $(\mathrm{kW})]$ & $2.1(7.4)$ & $2.2(7.7)$ & $2.4(8.4)$ & $1.7(6.0)$ \\
\hline & "Post Charging" [tons $(\mathrm{kW})]$ & $2.8(9.8)$ & $2.6(9.1)$ & $3.3(12)$ & $2.3(8.1)$ \\
\hline & Fractional Improvement & $33 \%$ & $18 \%$ & $38 \%$ & $35 \%$ \\
\hline \multirow{3}{*}{ EER } & "As Found" [Btu/Wh] & 5.2 & 7.0 & 8.8 & N/A \\
\hline & "Post Charging" [Btu/Wh] & 6.2 & 7.5 & 10.6 & $\mathrm{~N} / \mathrm{A}$ \\
\hline & Fractional Improvement & $19 \%$ & $7 \%$ & $20 \%$ & N/A \\
\hline \multicolumn{2}{|c|}{ Total Power Draw Increase $[\mathrm{Btu} / \mathrm{h}(\mathrm{W})]$} & $1,840(538)$ & $965(283)$ & $1,495(438)$ & N/A \\
\hline \multicolumn{2}{|c|}{ Fractional Increase } & $11 \%$ & $7 \%$ & $13 \%$ & N/A \\
\hline
\end{tabular}

As expected, properly charging the cooling equipment significantly improved performance in terms of increasing capacity and efficiency. After charging, total cooling capacity improved by 18 to $38 \%$ and EER improved by 7 to $20 \%$. Power consumption increased substantially after charging (increases of 280 to $540 \mathrm{~W}$, or 7 to $13 \%$ ). While this might seem to be a cause for concern to utilities in terms of peak electrical load, it is important to recognize that the increased capacity resulting from proper charging means that typically oversized cooling equipment is less likely to operate at its full-load. Proper charging thus increases the diversity of the aggregate airconditioning-related load when the performance of many houses is considered together, which effectively reduces the utility peak.

An interesting result from this research is that two of these systems (Site C and Site D) were so undercharged that their vapor saturation temperatures were below $32^{\circ} \mathrm{F}\left(0^{\circ} \mathrm{C}\right)$. This temperature approximates the evaporator surface temperature. As a result, the evaporators iced up during the "as found" tests. We expect this greatly limited the airflow through the systems. Had we measured the airflows while the coils were iced up and included that effect in our capacity calculations, the "as found" capacities for Sites C and D would be even lower than those reported in Table A18. The systems in Sites B, C, and, particularly, D were already prone to icing even with proper charge due to their low airflow $(314,330$, and $222 \mathrm{cfm} /$ ton respectively).

\section{Summary}

The importance of refrigerant charge to residential cooling performance is clear, as is the need to use a superheat test. Methods 2 and 3 correctly assess refrigerant charge levels. At this time, Method 1 seems inappropriate for assessing refrigerant charge levels of residential cooling equipment. Note that the reference method is too complicated and time intensive for a service technician to consider it as a practical alternative. However, this is not really a consideration, because it is intended only for research use.

There are problems with all of the methods, such as lost data for Methods 2 and 3, and some problems with deviations in pressure and temperature measurements. In the short term, diligence 
on the part of the service technician and the use of well-developed, reliable automation techniques seem to be the best solutions to these problems.

To address the significant performance degradation associated with refrigerant charge, we recommend that the building industry develop a standard method or methods to assess refrigerant charge. The results of this project suggest that the challenge will be to design a robust tool that works in most field conditions, rather than to measure the required quantities accurately enough. In particular, research is needed to develop a method of assessing refrigerant charge in cool weather. The utility of temporarily elevating indoor enthalpy also needs to be examined to extend the periods when the superheat method can be used to test cooling equipment in hot, dry climates. Ultimately, the performance of residential air conditioning systems would be dramatically improved by the development, application, and contractor training of a standard methodology to conduct refrigerant charge testing. 
APPENDIX B: FOOTNOTES TO DIAGNOSTICS OVERVIEW
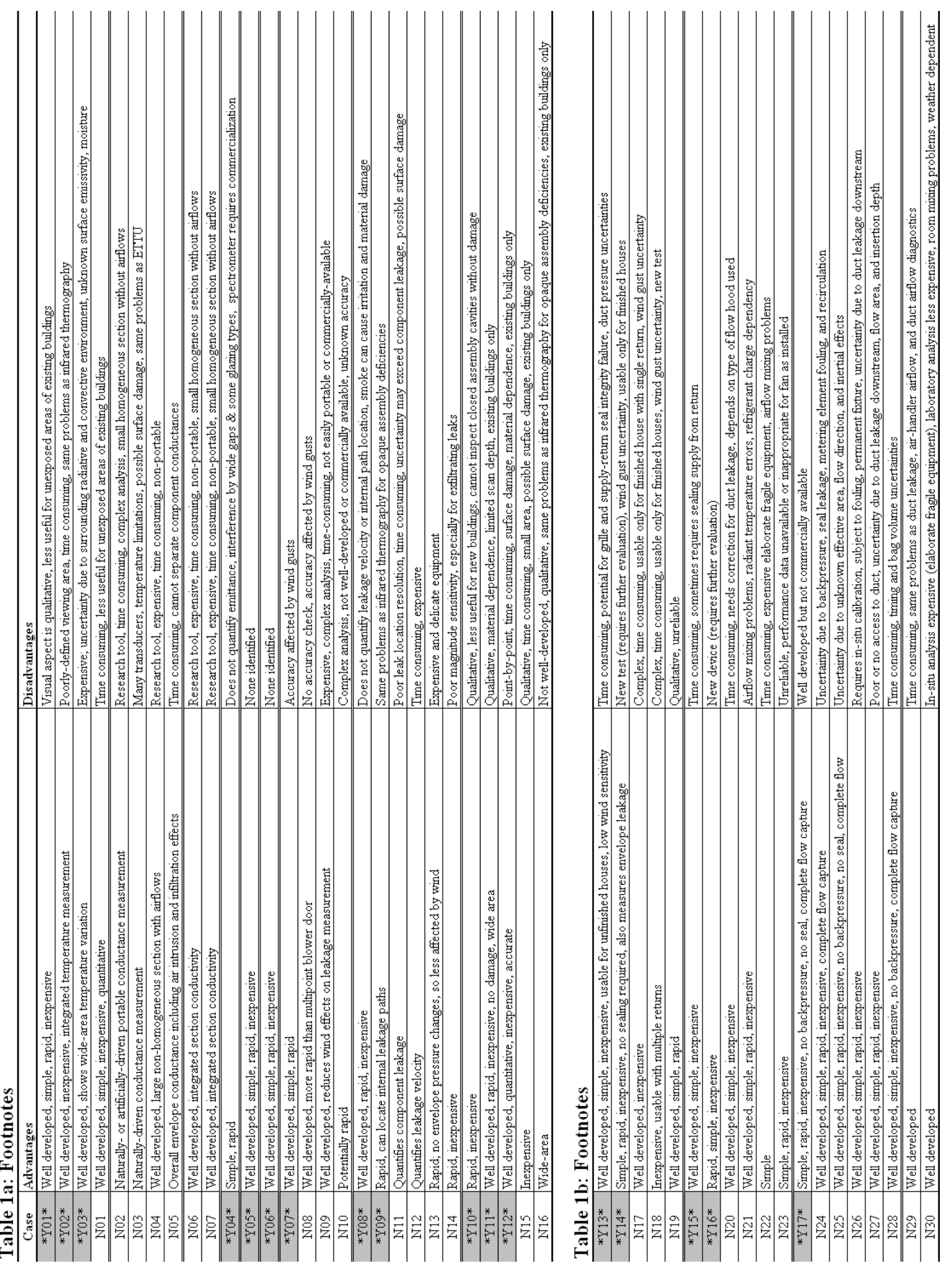


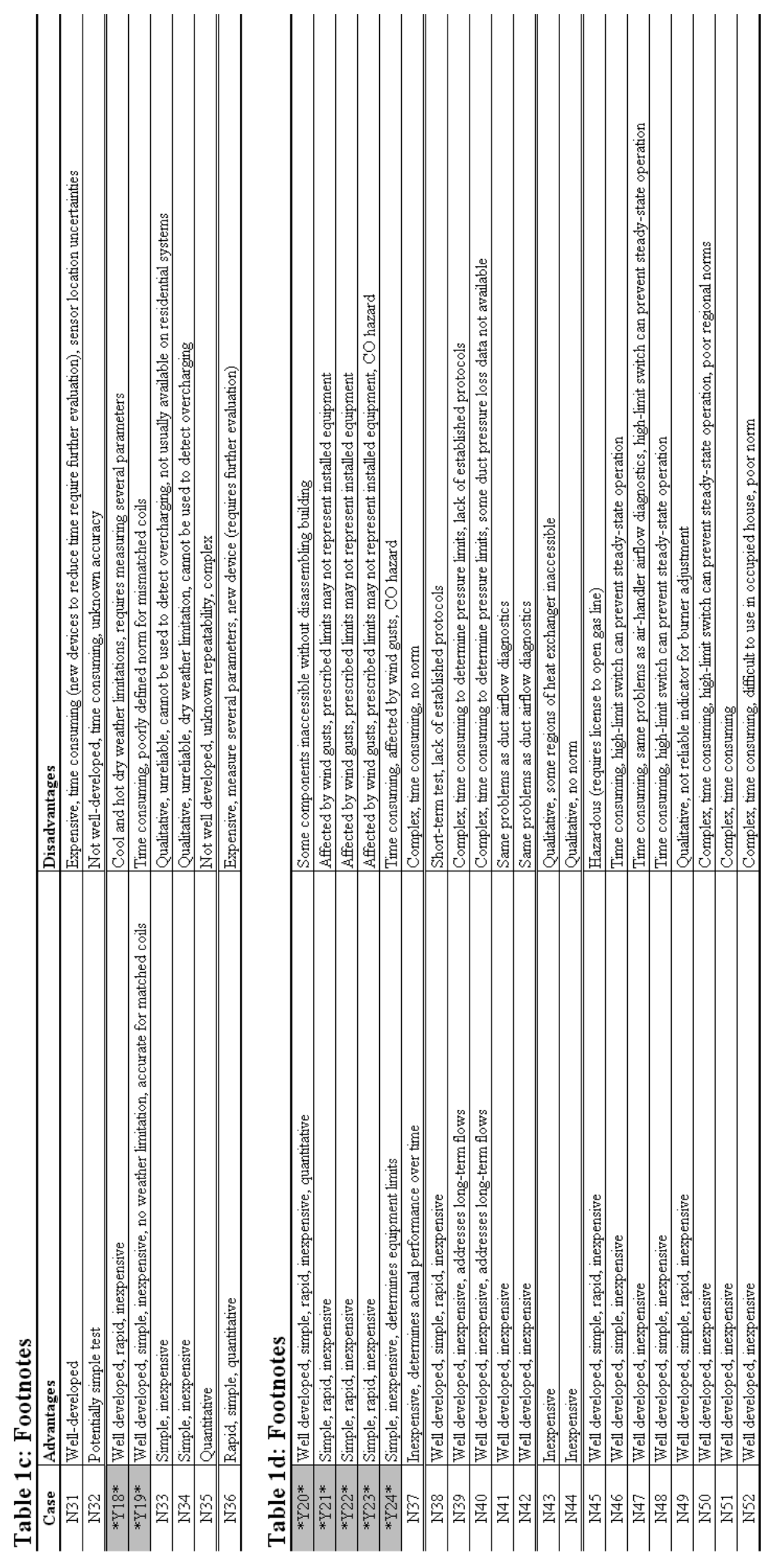



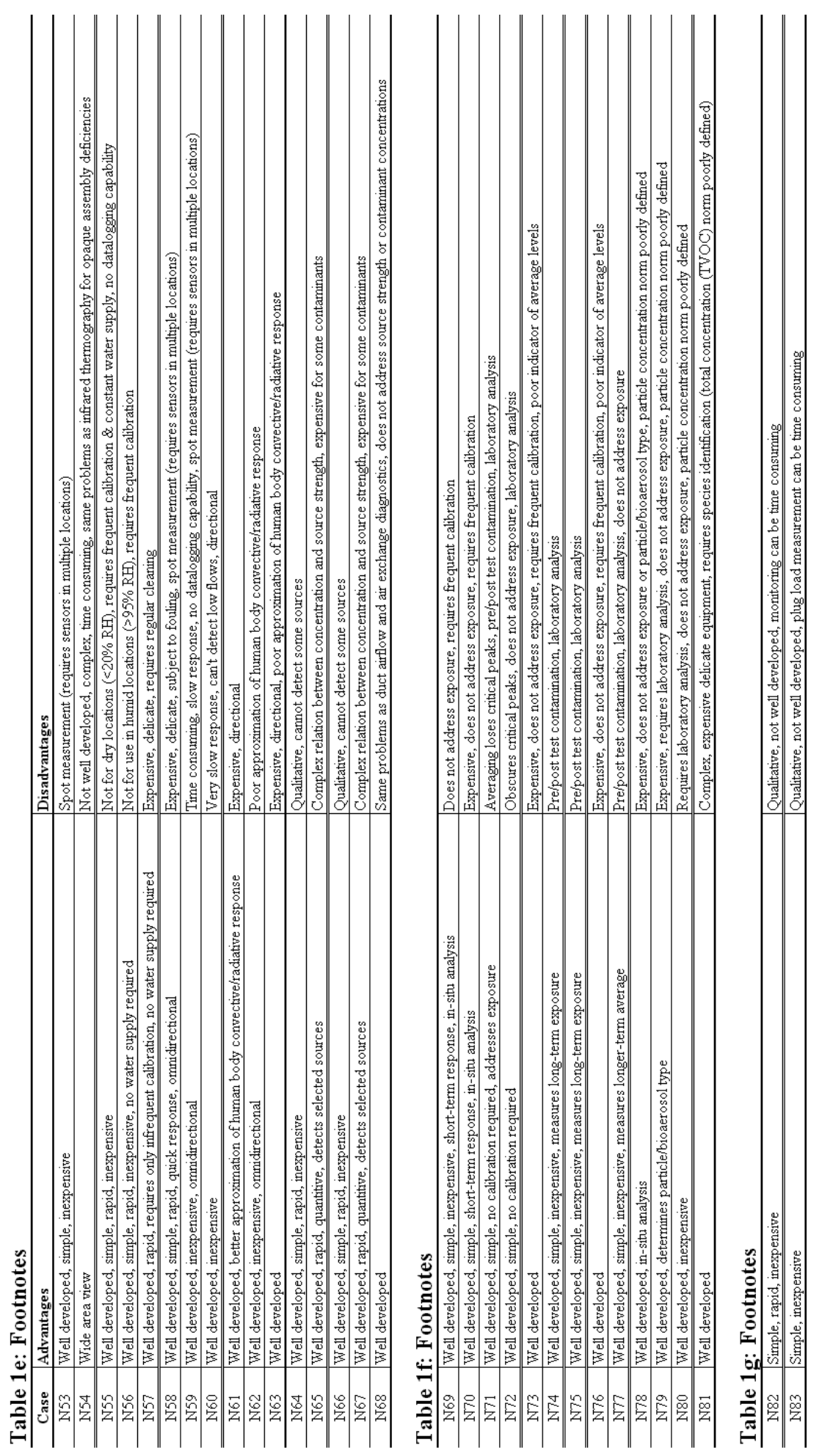


\section{APPENDIX C: DISCUSSION OF EXCLUDED DIAGNOSTICS}

Components and systems in a house that need commissioning include building envelopes, air distribution systems, cooling equipment, heat pumps, combustion appliances, controls, and other electrical appliances. Tables $1 \mathrm{a}$ through $1 \mathrm{~g}$ in the main body of this report provide an overview of metrics and 107 diagnostics that we have considered in this project for residential commissioning. Indexed footnotes to the tables (Appendix B) summarize the advantages and disadvantages of each diagnostic. Our discussion here in Appendix $\mathrm{C}$ describes 83 of the diagnostics that we have examined, but have excluded because they are not ready or are inappropriate for residential commissioning.

\section{BUILDING ENVELOPE}

\section{Envelope Assembly Deficiencies}

Insulation Sampling: Extracting samples of insulation to assess the installed density of blown insulation in walls or ceilings is a well-developed, simple, inexpensive, and quantitative technique. However, it is time consuming and is not useable when insulation is unexposed. Extraction is done using a 6- to 12 -inch $(150$ to $300 \mathrm{~mm})$ diameter and up to about 2 feet $(0.6 \mathrm{~m})$ deep "cookie cutter". Procedurally, three samples are extracted from three or four cavities (nine to 12 samples in total). Samples must be allowed to air dry if insulation is blown in wet to reduce settling, such as stabilized blown cellulose insulation and blown-in-blanket fiberglass insulation used in walls. The drying requires several days. If the moisture content of the insulation as installed is of interest, the sample can be weighed to determine the difference in extraction weight and sample weight (NAHB 1997). The density of the dry sample is based on its dry weight divided by its volume. This metric can then compared to manufacturer's specifications. This technique cannot be easily used on foam-in-place (low- or medium-density polyurethane) installations, because removed insulation is difficult to replace.

Infrared Thermography: Field use of infrared thermography to evaluate insulation homogeneity (ASTM 1990) is limited and may not be repeatable for several reasons. These include:

- Ambient temperature can affect both the performance of the thermographic equipment and the amount of infrared radiation emanating from the surface of the subject. At very high or very low outdoor temperatures, when maximum indoor-outdoor temperature differences occur and an infrared detection system would be most useful, these systems become less stable. Low indoor-outdoor temperature differences do not provide images with high enough contrast to reliably detect building envelope deficiencies. Indoor-outdoor temperature differences should be at least $18^{\circ} \mathrm{F}\left(10^{\circ} \mathrm{C}\right)$ for at least 4 hours before scanning to allow detection of discernable differences.

- Changes in surface temperatures due to solar radiation can obscure thermal patterns that result from the transfer of heat through the building envelope due to indoor-outdoor air temperature differences. Exterior scans should be conducted at night. Interior scans can be conducted at night or on heavily overcast days.

- Objects exposed to solar radiation will store heat and then release it for some time after the surface no longer is in direct view of the sun. Time must be allowed for the stored heat to dissipate before starting the scan. The length of time depends on the object's thermal mass and on the temperature difference between the surface and its environment. Wood frame 
walls with wood or aluminum siding may require as little as 2 hours to release stored heat; heavier construction with brick may require more than 6 hours.

- Wind-driven airflows along exterior surfaces, as well as interior surface airflows (caused by differences in surface temperature and room air temperature or by HVAC air distribution), can cause serious distortion of surface temperature patterns. Wind speed should be no more than $15 \mathrm{mph}(24 \mathrm{~km} / \mathrm{h})$ to minimize their effect on the scan.

- Scanning is subject to complex interactions caused by differential heating or cooling rates of dry and wet areas. Dry areas will cool or warm faster due to lower thermal mass. However, dry areas will also be less conductive. As a result, it is difficult to resolve insulation anomalies from moisture differences. It is particularly difficult to use this technique on roofs, because standing water, roof repairs, and exhaust discharges can mask anomalies below.

- To determine temperature from a scan, the user must describe the emissivity of the scanned surface in a long-wave range (usually 8 to $12 \mu \mathrm{m}$ ). Estimating emissivity is difficult: oxidation, deposition of dust, rainwater, or other foreign matter, as well as surface temperature changes, can alter the surface and its emissivity. Low-emissivity surfaces do not provide good contrast.

- Scan distortions can occur due to the angle of viewing by the infrared camera, its distance from the scanned surface, and on the nature of the surface material, which may radiate specularly (differently in different directions). Although the exterior of walls can simply be viewed from the ground, viewing roofs is more complex. To view roofs at a perpendicular angle, mobile elevated platforms or aerial equipment (e.g., helicopter) must be used (Burch 1980). Due to the cost of that equipment, roof scans for an individual building tend to be impractical. Interior scans in existing occupied houses can be difficult due to the placement of furniture near walls.

\section{Envelope Assembly Thermal Conductance}

ETTU: The Envelope Thermal Test Unit (ETTU) is a field diagnostic tool (Sonderegger et al. 1981) based on the guarded hot box concept. This portable research device (not commercially available) can be used to determine the thermal conductance of an envelope section. The device uses two flexible blankets aligned with each other, with one on each side of the 2-foot $(0.6 \mathrm{~m})$ square test section. Each blanket contains two layers of heaters separated by a central lowthermal-mass insulating layer. Each blanket also contains several surface thermistors and heat flux sensors (thermistor pairs, each separated by a polystyrene slab that has a known thermal conductance). The blankets have a guard (insulated) perimeter region to reduce edge effects on the measurement section.

This method differs from a conventional hot box, which measures heat flows in response to preset steady-state temperatures. ETTU instead measures the temperature response of the envelope section to known heat flows. ETTU can determine the steady-state and dynamic response of an envelope section based on natural thermal driving forces or by cycling its heaters in dynamic tests using pink noise forcing functions (signal with continuous frequency spectrum and equal power in each octave or decade, which provides amplitude weighting toward the lowfrequencies) with a semi-diurnal fundamental frequency. Most of the development work to date has focused on the response to artificial forcing functions. However, the artificial forcing has been found to create lateral conduction effects that are not easily analyzed (Modera et al. 1984). 
Furthermore, air circulation within envelope cavities was also found to be problematic with this device.

An ETTU test does not require that the envelope section reach thermal equilibrium to determine thermal conductance, because complex frequency analyses (using Fourier transforms) are used in the analyses of test data. The average thermal conductance of an envelope test section can be calculated from either the steady-state or dynamic data. However, the device cannot determine the thermal conductance of or deficiencies in separate envelope elements within a test section. ETTU can also determine the time constant for an envelope section, which is a metric for thermal mass.

If this tool is to be used, it must be developed further to deal with lateral conduction and internal air circulation before being commercialized. In addition, the test must be made simpler and less time consuming (a typical test may take one to two days).

Heat Flux Transducer: Heat flux transducers can be used to determine a representative average thermal conductance for an envelope section with negligible lateral conduction (e.g., without wood framing members). As a result, this simple test can be applied to some opaque envelope assemblies, but is not applicable to windows, due to their three-dimensional heat transfer behavior, particularly in the edge of glass regions and in the frame. For use on opaque assemblies, some knowledge about the construction of the assembly must be available to avoid placing the sensor in an area of three-dimensional heat transfer (e.g., near thermal bridges such as wood framing components).

To calculate thermal conductance, the temperature on the envelope face of each transducer or the air temperature near each heat flux transducer must also be measured. Several transducers and sensors should be mounted over the area of the envelope section, because residential building envelopes typically have non-uniform heat flow. These devices need to be located over insulation cavities, but not over framing members.

A disadvantage of the test is that appropriately locating heat flux transducers and temperature sensors requires considerable experience and expertise. Infrared thermography and building plans are useful for determining appropriate locations for these devices (areas of average or extreme heat flow, areas where large surfaces have similar heat flow, and areas of onedimensional heat flow). Further disadvantages of the test are that mounting individual heat flux transducers and temperature sensors is time consuming and their fastening to the envelope can cause surface damage.

Bias errors that are difficult to quantify can occur due to lateral conductive heat flow, air leakage, and air intrusion in envelope components, due to contact resistance, and due to the influence of heat flux transducers on surface characteristics. Pastes or gels can be used on transducers to reduce the contact resistance. Changes in surface characteristics can include additional thermal resistance due to the sensor, as well as mismatches in convective heat transfer coefficients and in emissivity. Coatings may need to be applied to the transducers so they better represent the characteristics of the envelope section being tested.

Instantaneous measurements using heat flux transducers cannot be used to determine the thermal conductance of an envelope section. Instead, recording equipment such as a data acquisition system must be used. In addition, without elaborate frequency analysis of the heat flux and temperature data, long time periods (several days) are required to obtain average thermal conductance based on average temperature differences and average heat fluxes, especially with 
low temperature differences and high thermal mass or large diurnal temperature swings. Natural temperature differences may be too low at some periods of the year to provide a reliable measurement in less than a week for massive walls.

Hot Box: Hot box devices are research tools primarily intended for use in a laboratory on large (e.g., $8 \mathrm{ft}$ by $8 \mathrm{ft}, 2 \mathrm{~m}$ by $2 \mathrm{~m}$ ) non-homogeneous envelope sections. These devices determine assembly thermal conductance under controlled steady-state air temperature, air velocity, and radiation conditions. They cannot determine the conductance of individual assembly elements, unless the elements are mounted within a subassembly of known thermal conductance (e.g., a window mounted in a well-characterized wall section).

A hot box is comprised of a metering chamber on one side of the test section and a climate chamber on the other side. The chambers are large, heavily insulated, and open on one side. A temperature-controlled guard chamber around the metering chamber is sometimes used to limit heat transfer across the metering chamber surfaces.

A computerized data acquisition system controls the environmental chamber and metering chamber guard region to maintain a steady temperature difference across the test section for a long enough period of time that the heat flux across the section is constant. To achieve thermal equilibrium, the test duration may be hours or days. The heat flux across the test section is determined by the heat input to or extraction rate from the metering chamber, which is required to maintain constant conditions. Cyclic operating conditions can also be used to determine the dynamic response of the envelope section. This device can create air velocities that are characteristic of natural or forced airflows parallel or perpendicular to envelope surfaces.

Bias errors can occur due to unmeasured lateral heat (flanking) losses at test section intersections with the chambers. Two- or three-dimensional thermal modeling of this region can be used to estimate the magnitude of the error.

Hot boxes are expensive, not portable, and not commercially available.

Whole-Building Tests: Janssen and Rasmussen (1985) developed a complex technique for determining the thermal conductance of the entire envelope. It relies upon temperature decay and rise during one- to two-hour-long furnace off and on periods respectively and the elimination of infiltration effects. Those effects are removed using infiltration diagnostics during the temperature decay and rise periods and using subsequent calculations.

Sandberg and Jahnsson (1995) describe a technique similar to that of Janssen and Rasmussen, but that does not involve furnace cycling. Instead, it characterizes the total heat loss rate of a house as it is normally operated by its occupants. Actual indoor-outdoor temperature differences and energy consumption are measured. Average heat loss per unit temperature difference is calculated from these data.

Saunders et al. (1994) also describe a related technique that is based on coheating. That technique involves maintaining constant indoor air temperatures using electric heaters and continuously measuring the input power for the heaters. Unlike Sandberg and Jahnsson, Saunders et al. remove infiltration effects. As a result, their technique separates out thermal conductance and is more useful for describing heat transfer characteristics at times other than just during the test.

The whole-building thermal conductance tests can be used as an overall compliance check. However, all of these tests are time consuming and require the use of computerized data 
acquisition systems in conjunction with short-term monitoring. These tests require significant further development to make them practical for use in residential commissioning.

\section{Envelope Material Thermal Conductivity}

Guarded hot plates and heat flow meters are research tools primarily intended for use in a laboratory to measure the thermal conductivity of building materials. These devices are expensive, not portable, and not commercially available. The heat flow meter is less expensive than the guarded hot plate.

Guarded Hot Plate: A guarded hot plate has two isothermal cold plates at similar temperatures that are separated from a central isothermal hot plate by homogeneous test specimens. Nonhomogeneous test specimens cannot be tested, because isothermal plate temperatures cannot be maintained with these specimen types. The edges of the plates and specimens are guarded from the surroundings by insulation. The entire apparatus is typically located in a controlled environmental chamber. A computerized data acquisition system controls the environmental chamber and plates to maintain a steady temperature difference across the specimens for a long enough period of time that the heat flux across the specimens is constant. To achieve thermal equilibrium, the test duration may be hours or days. Heat flux across the test specimens is based on measuring the heat input to the hot plate and heat extraction from the cold plates.

Heat Flow Meter: A heat flow meter is a comparative tool that is calibrated using specimens of known thermal conductivity. It provides more rapid determinations of thermal conductivity than a guarded hot plate, because it is a simpler device and does not need a surrounding controlled climate chamber.

The device has an isothermal cold plate that is separated from an isothermal hot plate by one or two homogeneous test specimens and one or two heat flux transducers. With one specimen, the heat flux transducers may be located on one or both plates adjacent to the test specimen. With two specimens, one heat flux transducer is located between the test specimens. Nonhomogeneous test specimens cannot be tested, because isothermal plate temperatures cannot be maintained with these specimen types. The edges of the plates and specimens are guarded from the surroundings by insulation or guard heaters. In some cases, the entire apparatus is also located in a controlled environmental chamber. However, such a chamber is not necessary. A computerized data acquisition system controls the environmental chamber and plates to maintain a steady temperature difference across the specimens for a long enough period of time that the heat flux across the specimens is constant. To achieve thermal equilibrium, the test duration may be one or more hours, instead of days.

\section{Envelope Airtightness}

Interzonal and Series Leakage: Two or more blower doors operated simultaneously (one for pressure variation and flow measurement and the others as balancing fans) and/or varying the size of leakage openings can be used to determine interzonal leakage, such as between living spaces and the attic or between adjoining dwellings.

In terms of series leakage and air barrier location, blower doors in conjunction with spot pressure differential measurements can also be used to establish the boundaries of the pressure envelope within the envelope assemblies (Fitzgerald et al. 1994, Cummings 1998).

Interzonal and series leakage tests are time consuming and tend to be used in research applications. There are no standard protocols for their use. 
AC Pressurization: The AC pressurization method of assessing envelope airtightness uses a piston assembly mounted in a door or window opening to alternately force air into and out of a building (Sherman and Modera 1986). The device is a research tool and is not commercially available.

Piston movement varies the effective volume of the building. The device creates small (less than $4 \mathrm{~Pa}$ ) pressure differentials typical of those driving infiltration in buildings. To determine the envelope airtightness, analyses compare the pressure response of the building to piston movement, with corrections for compressibility of the air and structural flexing due to oscillating pressure changes.

Synchronous detection (comparison of building pressure frequency response only at the driving frequency of piston) has the advantage that it reduces the interference from wind effects. As a result, this test is more accurate than using a blower door. However, compared to using a blower door, AC pressurization requires equipment that is more elaborate and less portable and analyses that are more sophisticated. It is also more time consuming than a blower door test.

Pulse Pressurization: The pulse pressurization method (Modera et al. 1987) uses a rapid release of air from a container (e.g., compressed air tank) located within the building to create a pressure pulse. The associated pressure response of the building is monitored using a microphone and spectrum analyzer that includes a data acquisition system. Subsequent analyses then compare this response to the pressure pulse to determine envelope airtightness.

The method is not well developed and is not commercially available. Preliminary tests have been carried out by LBNL to evaluate this method, but no field protocol exists. The accuracy of the method is unknown. A disadvantage of this method is that it requires equipment that is more elaborate and analyses that are more sophisticated than those associated with a blower door test. However, it is potentially less time consuming than a blower door test.

Leakage Site Detection: Smoke bombs can be used to locate leaks more rapidly than smoke tubes. However, they are more expensive than smoke tubes and the amount of smoke released must be carefully controlled to avoid difficulties in visualizing leaks, surface contamination, and triggering smoke alarms. The smoke must also be mixed so it is near leak entries and exits. Tracer gases can be used as an alternative to smoke. This more complex technique requires that the indoor air be seeded first before using an active tracer gas detector outdoors, which is expensive and fragile. This technique has all the problems described later in this appendix on using a tracer gas to determine air exchange rates, plus those described above when using smoke.

The most time consuming technique is to mask off regions of the building envelope that are suspected of containing leaks. Differences in airtightness determined using blower door tests can then indicate the magnitude of the leakage. A disadvantage of the test is that small differences between blower door tests might result from test uncertainty rather than the presence of leaks. Another disadvantage is that the technique only indicates that a region is leaky, but does not provide specific information on leak location unless small regions are masked off. Furthermore, in some cases, sealants used in masking off the envelope may cause material damage. A related technique is on-site sealing of leaks, which has the advantages of no material damage and the improvement of the building envelope.

Another method is to use a hot-wire anemometer while pressurizing or depressurizing the building using a blower door. The anemometer has the added advantage that it can quantify leakage velocities, which can be used to indicate the size of a leak. This technique however 
requires that the anemometer be held still for each measurement to avoid confusing anemometer motion with the presence of a leak. As a result, this technique is more time consuming. It also requires more elaborate and expensive equipment, which may not be justifiable by the ability to quantify leakage velocity. As with the smoke and tracer methods, a limitation is that knowledge of likely leak locations is required to minimize the search effort.

Acoustic techniques can also be used to locate leaks. A commercially-available sound detection device such as an ultrasonic probe can be moved over the exterior surface while an associated sound generator placed indoors generates a signal of suitable frequency and amplitude. The generated signal should not be at a frequency that is obscured by ambient noise. The positions of the generator and probe can be reversed to locate interior leak entries and exits. This technique has the advantage that it is rapid, does not require envelope pressurization or depressurization, and is less affected by wind. However, it requires expensive and delicate equipment. As with smoke and tracer methods, a limitation is that knowledge of likely leak locations is required to minimize the search effort.

Draft sensation is a rapid, inexpensive technique to locate leaks, but it has poor magnitude sensitivity, especially for exfiltrating leaks.

\section{Envelope Moisture}

Surface Analysis using Impermeable or Absorbent Materials: Impermeable or absorbent materials can be used in qualitative comparative tests when evaluating envelope moisture problems (Lichtman et al. 1999). The "mat" test involves sealing an impermeable material such as polyethylene sheeting over a suspect surface. After a short period has elapsed (e.g., one day), the surface of the impermeable material is inspected for signs of wetness.

A more quantitative test uses a vapor emission and absorption method. A small airtight preweighed container containing absorbent material is sealed to the suspect surface. After about 6072 hours, the container is weighed again. The weight change of the container (compared to the pre-test weight) indicates the amount of absorbed moisture.

Both tests are time consuming, but can be good indicators of high moisture content that warrants further investigation with a subsurface resistance probe. The most suitable use of these tests is to compare measurements from one region to another (e.g., a suspected wet region to a known dry region of similar material).

\section{AIR DISTRIBUTION SYSTEMS}

\section{Duct Leakage}

House Pressure Test: The house pressure test (HPT) (Walker et al. 1998a) measures the pressure changes across the building envelope and duct system due to air handler operation. It uses the house envelope as a flow meter and therefore requires envelope leakage to be measured also. Test time can be shortened if envelope leakage is not measured, but this reduces the accuracy, depending on how well the envelope leakage can be estimated.

This test is complex. It involves many pressure difference measurements, such as that between the supply and indoors when one supply grille is blocked using a pressure pan and that between the return and indoors across the filter at the return grille (or halfway between the return grille and plenum with the filter removed if the filter is not at the grille). Several configurations are used in the test (return open, supply open, air handler on and off; return open, supply blocked, air handler on; return blocked partially to achieve at least a $100 \mathrm{~Pa}$ pressure difference or fully 
blocked, supply open, air handler on and off; and return blocked, supply blocked, air handler on). In each of these six cases, the pressure difference between the attic and indoors is measured ten times, and measurements are carried out with the air handler off and then on (60 attic-indoor pressure measurements). Averages of these attic-indoor pressure differentials are then used in subsequent calculations. Returns are blocked to avoid a problem: a balanced supply and return duct leakage will appear to be airtight, because the house pressure will not change when the air handler is turned on or off (supply leaks depressurize a house, whereas return leaks pressurize a house). A blocked return has no effect on an airtight system, but unbalances the supply and return leaks in a leaky system.

Most studies have found the accuracy of this test to be too poor for the results to be used in energy analyses (Walker et al. 1998a, Andrews et al. 1998, Francisco and Palmiter 1997). A major problem with this test is that it is sensitive to wind pressure fluctuations across the building envelope. These fluctuations are the same magnitude as the small pressures measured during the test and can violate assumptions used in the calculation procedure. In addition, test sensitivity is strongly dependent on envelope leakage.

The house pressure test should only be used on airtight houses (relative to outdoors and to the attic). A working definition of airtightness is that changes in the attic-indoor pressure difference should be more than 0.5 Pa between air handler "on" and "off" modes (with or without return sealed). In leaky houses, the test repeatability is poor, because the test precision is very sensitive to pressure measurement accuracy (uncertainties of even $0.1 \mathrm{~Pa}$ across ceiling can cause large fractional errors in calculated duct leakage). This uncertainty is due to using the difference between two ceiling pressure differences measured under different conditions, with a difference that is close to the instrument measurement resolution.

Another constraint on the use of the house pressure test is that it should only be used if the standard deviation of each group of 10 attic-indoor pressure differences is less than the differences between the means of each group. This check is an indicator of possible changes in weather-induced pressure differences over the course of the measurements and assesses whether groups of measurements represent the same data population.

To account for the bias caused by the neutral level shift when the air-handler fan is turned on, the duct leakage calculations for this method include a correction factor. A different factor is used depending on whether the ducts are at a high level or low level within the building. No correction is applied if the ducts are located at low and high levels. The correction increases calculated duct leakage for high level ducts and reduces its for low level ones. No correction is made for potentially large precision errors and the minor positive bias that is introduced by a variation in actual envelope leakage distribution from the assumed distribution $(50 \%$ in floor and $50 \%$ in ceiling). The magnitude of these precision errors related to envelope leakage distribution strongly depends on the envelope leakage location and can be of the same order as the duct leakage flow. The bias in duct leakage due to including duct leakage as part of the envelope leakage is reduced by including the intermediate estimates of duct leakage flows and measured duct system pressures in the duct leakage calculations.

An advantage of this test is that it does not require the sealing of all supply grilles or the separation of the supply and return systems at the air handler. This means the test is less timeconsuming and less susceptible to poor sealing or seal failure during test than the duct pressurization test. 
Nulling Pressure Test: The nulling pressure tests (NPT) (Walker et al. 1998a) is similar to the house pressure test except that a fan-assisted flow meter is used to balance the duct leakage flows instead of using the building envelope. This reduces the uncertainty of the measured flows. However, there is still the problem of reliably measuring the small envelope pressures and the added difficulty of controlling a fan to exactly balance the duct leakage flow imbalances. The developers of this technique have produced automated methods for controlling the flow and taking long time-averages of pressures that mitigate these uncertainties. The problem with leaky envelopes resulting in small envelope pressure differences still exists.

Tracer Gas Test: A tracer gas test involves injecting a tracer gas into the house and the duct system at various locations. Samples are than taken from the house and duct system (and outside) and the changes and differences in tracer gas concentration are used to calculate duct leakage flows. This test requires considerable time and expensive, delicate equipment. In addition, the tests can only be reliably performed by highly skilled technicians with many years of experience in tracer gas testing and analysis. Traditionally, tracer gas studies of airflows in buildings have been the standard against which other diagnostics are evaluated. However, for duct leakage, the poor mixing of tracer gas in the various duct locations outside conditioned space and the inability to sample correctly at return leaks means that the tracer gas measurements can have large uncertainties and cannot always be used as a reference.

Pressure Pan Test: The pressure pan test (Siegel and Manclark 1998) uses a blower door and a pressure pan. The latter device is simply a small box that is open on one side and contains a static pressure probe. The open side is pressed against the building surface surrounding a grille. Like a conventional flow hood, the pan edge in contact with the building surface must be well sealed to avoid leakage. "Pan pressure" is the pressure inside the pan (grille side) relative to indoor pressure. This test is used to estimate the ratio between duct-leakage flows to indoors and those flows to outdoors. It involves depressurizing the house to $50 \mathrm{~Pa}$ relative to outdoors. If the pressure pan reading is near zero, then most of the duct leakage (if any) is to indoors. If the reading is near $50 \mathrm{~Pa}$, then the duct leakage is primarily to outdoors. However, intermediate zone (e.g., attic or crawlspace) pressures can affect pressure pan readings. If the ducts leak to the intermediate zone and the zone pressure is less than $50 \mathrm{~Pa}$ relative to outdoors, then the maximum pressure pan reading for those leaks will be the intermediate zone pressure.

This test is not recommended for commissioning except as a rapid screening supplement to more elaborate tests, because its pressure indication does not uniquely determine leakage. The results of this test are susceptible to pressure drops in the duct system caused by dirty air filters or coils and partly closed dampers. Grilles located close together will have similar pressure pan readings. High duct leakage to indoors can mask exterior leaks. Systems with large flows in one branch compared to others can cause duct pressure in low-flow branches to be excessively influenced by exterior conditions (wind and stack effects). This will in turn make duct leakage appear to be larger than it actually is.

\section{Air-Handler Airflow}

Sum of Grille Flows: This method of assessing air-handler airflow uses the sum of all measured grille flows. Methods of measuring grille flow are described elsewhere in this report. The sum of flows must be corrected to account for measured duct leakage. Due to the number of measurements required in a typical house, this test is time consuming. However, the test has the advantage that a separate air-handler flow measurement does not need to be carried out if grille 
flows and duct leakage are being measured anyway. This test is particularly subject to uncertainty due to the type of hood used.

Temperature Split: Software available to assess refrigerant charge (Downey and Proctor 1999) includes the ability to assess air-handler airflow as well. It uses the "temperature split" method to determine whether the airflow rate through the evaporator is adequate.

In this test, the "measured" temperature split is the difference between the dry-bulb temperatures of the return air entering evaporator and the supply air exiting the evaporator. Proper airflow at design conditions is indicated by a measured split within $3.5^{\circ} \mathrm{F}\left(2^{\circ} \mathrm{C}\right)$ of the target split at test conditions. If the measured split is larger than the target split plus $3.5^{\circ} \mathrm{F}\left(2^{\circ} \mathrm{C}\right)$ at test conditions, then this indicates that the evaporator airflow is too low at design conditions. If the measured split is too low, then this indicates low cooling capacity at design conditions due to problems such as high evaporator airflow, a dirty condenser coil, low condenser airflow, restricted refrigerant lines or orifice, compressor problems, or contaminated refrigerant.

The target split at design conditions for cooling equipment with a sensible-only load is about $28^{\circ} \mathrm{F}\left(16^{\circ} \mathrm{C}\right)$, based on the typical assumption of $400 \mathrm{cfm} / \mathrm{ton}$, an air density of $0.075 \mathrm{lbm} / \mathrm{ft}^{3}(1.2$ $\left.\mathrm{kg} / \mathrm{m}^{3}\right)$, and a specific heat of $0.240 \mathrm{Btu} /\left(\mathrm{lbm}^{\circ}{ }^{\circ} \mathrm{F}\right)(1.0 \mathrm{~kJ} / \mathrm{kg})$. The target split at test conditions differs from this value depending on environmental conditions and equipment response at the time of the test, which usually is not the design condition. Specifically, the capacity of the equipment varies as a function of indoor dry- and wet-bulb and outdoor dry-bulb temperatures. The software determines the target split for the part-load test condition based on the expected variation of capacity as a function of these parameters. That split will then result in the appropriate flow at design conditions.

There are several potential problems in using measured plenum air temperatures to calculate airflow. One is the non-uniformity of temperatures in plenums. As Appendix A indicates, this problem is particularly pronounced when the refrigerant charge is low and parts of the evaporator contain superheated refrigerant vapor. A second is the possible radiant errors if a temperature sensor views coil, plenum, or duct surfaces that have a significantly different temperature compared to the air temperature. A third is inappropriate temperature differences. Low differences increase the uncertainty associated with the measurement. High differences introduce an air density error. Differences between $15^{\circ} \mathrm{F}\left(8^{\circ} \mathrm{C}\right)$ and $50^{\circ} \mathrm{F}\left(28^{\circ} \mathrm{C}\right)$ are generally acceptable in the absence of other problems.

Tracer Gas: Tracer gas assessment of air-handler airflow uses a constant injection of a nonreactive tracer gas not typically found in the ambient air (e.g., $\mathrm{SF}_{6}$ ). The concentration of gas in the air downstream of the injection point is sampled and the airflow rate is calculated as the simple ratio of injection rate to downstream concentration. This test requires the use of elaborate, fragile, and expensive test equipment such as a specific vapor analyzer.

The test is subject to error because of poor tracer gas mixing and the type of sampling. Poor mixing can occur due to air handler and duct system topology. If the tracer is not uniformly mixed in the air stream, then single-point sampling is not appropriate. In that case, injection and sampling must occur over the entire plane of the sampled air stream to determine an average concentration. Such injection and sampling requires the use of manifolds, which can be difficult to install in an air handler or duct system. Mixing can be improved in some cases by injecting the tracer gas upstream of the air-handler fan so that the fan mixes the tracer before the tracer is sampled downstream of the fan. 
Fan Curve Interpolation: An approximate method to estimate air-handler airflow uses the manufacturer's fan curve data with the measured total operating pressure difference (sum of operating pressure differentials between the supply and return plenums and the indoor air). There are three problems with this method:

1. Manufacturer's fan curve data may not be available, especially for existing houses.

2. Errors in manufacturer's fan curve data will be propagated in the airflow calculation.

3. Even if the manufacturer's data are accurate, they may not accurately represent the installed performance of the fan due to system effects such as $90^{\circ}$ return duct approaches to the air handler, and how the fan is mounted in the air handler cabinet (often fans are too large for the cabinets containing them, which leads to severe inlet restrictions). These system effects can vary significantly and are difficult to estimate. Consequently, although this method is simple, it has unknown uncertainty.

\section{Thermal Distribution System and Ventilation System Airflows}

Conventional Flow Hood: Commercially-available conventional flow hoods are made of fabric supported by a rigid conical or pyramidal frame. This geometry can sometimes limit hood use, because of interference with surrounding objects. The flow hood is placed over a grille to capture the entire flow. A good seal (e.g., sponge rubber) at the gap between the hood and the adjacent building surface is necessary to avoid air leakage that would not be measured by the hood metering element.

The metering element in these devices is typically a multi-port total pressure manifold (with upstream and downstream holes) located centrally within the flow hood restriction. A hot-wire probe or other flow sensor such as a deflecting vane or a pressure transducer is used to determine the average airflow rate based on air velocity or average pressure response within the manifold. The manifold inlets are subject to blockage by dirt.

Recirculation regions within the hood (along sides) when measuring supply flows can change the flow pattern over the manifold and introduce error. Manufacturers recommend using a flow hood size close to the grille size to reduce the recirculation problem. The extent of this problem also depends on flow rate, duct topology upstream of the grille (e.g., nearby elbows), and grille type. Grilles with more side discharge than direct discharge are more likely to cause recirculation regions. The hood constriction at the flow measuring section can cause backpressure in an air distribution system, particularly when multiple grilles are located near each other on the same distribution system branch. Backpressure reduces measured flow and causes further error.

To determine a flow correction factor that will account for recirculation and back pressure errors, ASHRAE Standard 111 (1988) recommends using a pitot-static-tube traverse of the duct section upstream of a grille, with and without hood in place. In many cases, the correction can be negligible, but in some cases, a correction as large as 50\% may be needed. This correction can be very specific to a given grille due to flow rate, grille type, and duct topology. Carrying out such upstream pitot-static-tube traverses in a house can be difficult or impossible in some cases, which means the conventional flow hood should not be used in these cases. When pitot-statictube traverses upstream of many grilles must be carried out, they make the use of this flow hood redundant.

Anemometry: Anemometry involves external traverses over the plane of a grille, normal to the exiting or entering air stream, using a commercially-available vane or hot-wire anemometer. 
The calculation of the airflow rate uses built-in calibrations based on vane rotation speed or on hot-wire power consumption (temperature dependent) to determine air velocity. This calculation requires good characterization of the effective open area of the grille. However, determining this area in the field can be difficult, because of angled louvers on the grille. Uncertainty in determining this area and off-normal sampling of the air-stream by a vane anemometer or directional hot-wire sensor (which introduces a cosine error in the measured air velocity) can lead to large uncertainty in the calculated airflow.

Vane anemometers may be subject to friction drag at low air velocities (50 ft/min or less), depending on the type of vane shaft bearing. Hot-wire anemometers should be used instead for measuring low air velocities. However, hot-wire anemometers are subject to fouling by dirt and other contaminants, which will reduce their accuracy.

Due to their rapid response, hot-wire anemometers require instrumentation to provide timeaveraged air velocities in fluctuating flows. Vane anemometers are simpler, because their inertial effects provide built-in averaging. However, these inertial effects also introduce a bias error due to the slow response of the device in fluctuating flows.

Flow Grid: A flow grid is a simple, inexpensive device that uses a set of tubes each closed at one end and connected together in a manifold at the other end. It is similar to the flow plate and grid device described in the main body of the report for measuring air-handler airflow, but has no orifice plate. Due to the absence of the flow plate, this device has a negligible effect on airflow. The manifold increases the pressure differential between total and static pressure. As such, it provides better resolution compared to a pitot-static tube.

The device is commercially available and commonly used in air-to-air heat exchanger duct systems to assist balancing of the supply and exhaust flows. A disadvantage is that the equipment typically is integrated as part of the duct system and is a permanent fixture. However, this allows subsequent tests to be carried out more easily. A further disadvantage is that it is often difficult to find a suitable installation location with uniform flow. On-site calibration can be used to correct for the effects of non-uniform flow. However, this step is time consuming.

Flow grid accuracy can be impaired by physical damage (during installation or by duct cleaning), by blockage of pressure ports with dirt or other contaminants, and by leaks in the tubing connecting it to the pressure transducers. Cleaning the pressure ports and surrounding grid often requires duct disassembly.

Pitot-Static-Tube Traverse: This method of determining airflow involves an internal traverse with a commercially-available pitot-static tube over the cross-section of the duct upstream of the grille, normal to the exiting or entering air stream. The pitot-static tube measures total and static pressure at each measuring point.

The calculation of airflow rate requires that the area of the duct be subdivided into sections using the log-Tchebycheff method (ASHRAE 1988). That method minimizes the error associated with improperly accounting for large flow gradients near duct walls. For round ducts, the cross section is divided into annular sectors. For rectangular ducts, the cross section is divided into rectangular sectors. The pitot-static tube must be placed centrally in each area. To accomplish this, the pitotstatic tube is inserted through three holes drilled $60^{\circ}$ apart or two holes drilled $90^{\circ}$ apart.

Accuracy is increased by using more measurements. At least 12 measurements must be made over the cross section of a round duct; rectangular ducts require about double that number. Total and static pressures are then used to determine the velocity pressure for each sampled area. The 
flow rate for each area is then calculated and summed to determine the total flow rate through the duct section. These traverses are time consuming.

Uncertainty in determining the insertion depth, off-normal sampling of the air-stream (which introduces a cosine error in the measured total pressure), velocities below $500 \mathrm{ft} / \mathrm{min}(2.5 \mathrm{~m} / \mathrm{s})$, and flow non-uniformities within the duct can lead to large uncertainty in the calculated airflow.

Further uncertainty is introduced by duct leakage. Reducing this uncertainty by measuring near grilles is problematic for two reasons. First, to reduce the effects of flow non-uniformities, measuring is best carried out at least 7.5 hydraulic diameters downstream and at least 3 hydraulic diameters upstream of turns, flow obstructions, or changes in duct cross-section. However, most residential systems do not permit measurements within these constraints, because of their short duct runs, so accuracy is impaired. Second, in some houses, it is difficult or impossible to access ducts near grilles for such measurements.

Pitot-static tube accuracy can be impaired by physical damage, by blockage of pressure ports with dirt or other contaminants, and by leaks in the tubing connecting it to the pressure transducers.

Plastic Bag Test: A simple inexpensive flow assessment test (CMHC 1998) uses a large plastic bag of known volume with a wire frame fastened to the bag opening to keep it open. To measure supply flows, the bag is deflated by collapsing it away from the grille. Its opening is then held tightly over the grille, while swinging the bag to assist inflation. Time for the airflow to inflate the bag is recorded. The airflow rate is then calculated using the bag volume and inflation time. A similar but reverse technique can be used to assess return or exhaust flows. In that case, the bag must be inflated before placing it over the grille. This can be achieved by moving the bag through the ambient air as the bag approaches the grille.

This technique is limited by the uncertainty in timing inflation or deflation and by the uncertainty in the air volume added to or removed from the bag. To reduce the timing uncertainty effects, several measurements should be made and then averaged.

An advantage of this device is the bag does not have a significant effect on system pressure due to its low mass.

\section{Thermal Distribution System Delivery Efficiency and Room Distribution Effectiveness}

Delivery efficiency and room-by-room distribution system effectiveness are complex metrics that are calculated using diagnostic inputs such as duct location, surface area, and thermal resistance (obtained through a combination of observation and simple calculation), duct leakage, and by determining the flow for each branch of the duct system.

Andrews et al. (1996), as well as Siegel and Davis (1998) have suggested that electric coheating can be used to measure system efficiency before and after retrofits. However, this technique may not be practical for commissioning, because it requires the use of nighttime short-term monitoring over about a half-day to two-day period, which is time consuming. The house is preferably unoccupied during the test, which further limits the utility of this method when testing existing houses. 


\section{Air Exchange}

Tracer Gas: There is a substantial body of literature from the past 20 years related to determining room and whole-building air exchange rates, as well as ventilation effectiveness and efficiency. Most techniques rely upon the use of tracer gases.

There are fundamentally two types of tracer gas tests: active (decay, constant injection, or constant concentration) and passive (e.g., constant emission with integrating samplers). All of these tests can be carried out with or without the air handler operating. Both types of tests are well developed.

The decay test uses rapid (pulse) injection of a non-reactive tracer gas not typically found in the ambient air (e.g., $\mathrm{SF}_{6}$ ). To provide good mixing (uniform concentrations indoors), the tracer is injected in or near an air distribution system return grille with the air-handler fan running and all supply grilles open. Additional mixing by portable oscillating fans may be needed if the air handler is not operating during the decay period. The concentration of the tracer gas in room air is sampled at least twice after injection, often near a return grille. The air exchange rate is then calculated using the difference between starting and ending tracer gas concentrations over the measurement period, the length of that period (nominally two hours), and the building volume. The required time depends on the air exchange rate: high exchange rates require less time, low exchange rates require more time. To measure the tracer gas concentrations, this test requires the use of elaborate and fragile test equipment, such as a specific vapor analyzer that actively samples the air on site. Alternatively, grab samples can be used along with subsequent laboratory analysis.

In the constant injection test, tracer gas is injected at a constant rate into the indoor air either directly or more commonly into the air distribution system (with the air handler operating). The time-varying response of the tracer gas concentration indoors is then monitored, usually with a computerized data acquisition system and a specific vapor analyzer. For each measured concentration, the air exchange rate can be calculated based on the injection rate and building volume. This test requires even more elaborate equipment than the decay test. Grab sampling can be used as an alternative, but due to the large number of concentration measurements involved and subsequent cost of individual analyses, this method of sample collection tends to be impractical.

The constant concentration test uses the most complicated system for injection and concentration measurement. It requires a sophisticated control system that samples the tracer gas concentrations in one or more zones and then adjusts the injection rate to maintain those concentrations. This test is advantageous in occupied buildings, because there is less risk of producing potentially harmful tracer gas concentrations. Another advantage is that this test can be used to null interzonal tracer gas flows, so that only outdoor airflows are determined. The other test methods are subject to uncertainty in determining outdoor airflows if the tracer gas concentrations differ between indoor zones at any time during the test (poor interzonal mixing).

The perfluorocarbon tracer (PFT) test uses constant emission sources and passive integrating absorption samplers that are spread throughout the building. The air exchange rate is based on the ratio of the source emission rate to the total amount of tracer absorbed over the measurement period (few days to several weeks), and on the building volume. This test uses small, relatively inexpensive, and easy to install devices during the test. A disadvantage is that a laboratory must analyze the samplers after the test to determine the amounts of absorbed tracer. 
The air exchange rate determined by the decay and PFT tests is uncertain due to changing weather conditions. The uncertainty increases as building envelope leakage increases. Although all the tests are sensitive to short-term variation in air exchange, only the constant injection and constant concentration tests can separate short-term effects from long-term ones. The other tests reported integrated values over the test period and cannot show the short-term variation (e.g., peaks). Poor room mixing conditions can also cause uncertainty in these two tests.

Interior door closures (changes the flow resistance, flow patterns, and apparent volume of the building) or window opening (changes flow patterns and ventilation rate) in occupied houses can cause further uncertainty if the goal is to assess the impact of the envelope and mechanical ventilation systems on air exchange.

All these techniques are problematic for determining spatial or temporal ventilation effectiveness and the ventilation efficiency of mechanical ventilation systems in houses, because they include infiltration effects that these metrics assume can be ignored (ASHRAE 1997). Also, tests with the air-handler fan operating to mix the tracer gas include infiltration induced by leaks in the duct system and therefore measure the infiltration rate with the air handler operating. For leaky duct systems, this may be significantly different from the air infiltration with the air handler off. Welldeveloped calculation techniques (Sherman 1986) that use ventilation models to estimate infiltration as a function of envelope leakage, weather, terrain, shielding, and mechanical ventilation operation can be used to partly circumvent this problem.

\section{COOLING EQUIPMENT}

\section{Steady-State Capacity, Power Consumption, and Efficiency}

Short-Term Monitoring: Equipment steady-state capacity and efficiency can be calculated using data collected over the period of several hours (ASHRAE 1995). To determine capacity, a computerized data acquisition system is used to monitor the difference between return and supply air enthalpy. The evaporator airflow rate when the air handler is providing cooling is measured separately. Temperature and relative humidity sensors are used to determine the drybulb temperatures and humidity of the air upstream (return plenum) and downstream (supply plenum) of the evaporator coil. Several sensors may be needed in the plenums if the airflow is not thermally well-mixed due to uneven coil temperatures or if duct branches enter or exit the plenum. In humid climates, the condensate flow rate and temperature must also be measured to account for the cooling energy loss. The average condensate flow rate can be measured using a tipping bucket with a pulse output indicating the occurrence of each tip.

Air-handler fan, condenser fan, and compressor power consumption can be measured by separate wattmeters or by using the building's electrical service wattmeter with all other devices turned off or disconnected if necessary. However, turning off devices (or disconnecting them if power is used in standby mode) can be time consuming, especially when many equipment timers and clocks must be reset after their power supply is restored. Using separate closed-loop wattmeters can be problematic due to the electrical hazards involved in attaching them to high-voltage power supply wires. Clamp-on devices are available, but their accuracy is not as good as closedloop ones.

Steady-state efficiency is calculated using the ratio of the calculated steady-state capacity and the measured power consumption.

The calculated steady-state capacity and efficiency and measured power consumption are at test conditions, which are not necessarily the same as equipment rating conditions. Computer 
simulation using cooling equipment models allows these test results to be extrapolated to other operating conditions, such as the rating conditions or to others more representative of the regional climate.

Coheating: Sonderegger et al. (1980) have suggested that electric coheating can be used to determine cooling efficiency (coefficient of performance, COP). That technique involves maintaining constant indoor air temperatures using electric heaters and continuously measuring the input power for the heaters and cooling system while the cooling system is operating. The power input to the heaters indicates the net heat removed by the cooling system. The efficiency of the cooling system can then be calculated as the ratio of the heater power input to the power consumption of the cooling system. This test requires that the cooling system be manually cycled on and off to represent the cycling performance of interest. A computerized data acquisition system is required for this time consuming test. Further research is required to evaluate the accuracy of this technique, because of all the other heat transfer process occurring simultaneously in the house during the testing.

\section{Refrigerant Charge Level}

Sight Glass: This method uses a sight glass in the refrigerant liquid line (between the condenser and refrigerant flow control device). It is a qualitative subcooling test that uses the presence of bubbles to assess insufficient charge level. It is assumed that the charge is correct when liquid with no bubbles can be observed (lack of charge causes bubbles). However, low discharge pressure from the compressor or a restriction upstream of the sight glass can also cause bubbles to appear, regardless of the amount of charge. As a result, the results of this test are unreliable. This method cannot be used to assess overcharging.

TXV Frosting: Observing thermostatic expansion valve (TXV) frosting is a qualitative test that uses the presence of frost as an indicator of charge level. It is assumed that charge is correct when an even layer of frost can be observed on the TXV body as far upstream as the liquid line inlet fitting. Insufficient charge will reduce frosting, especially near the liquid line. Like the sight glass method, this method cannot be used to assess overcharging. It also has limited usefulness, because it cannot be used for above-freezing evaporator operation conditions or in dry environments where there is little humidity in the air to produce frosting.

Motor Signature Analysis: Motor signature analysis (Miller et al. 1989) is a quantitative test that uses an inductive clamp-on current probe attached to the power supply of the condensing unit. Real-time analysis of the electrical signal using a frequency analyzer during system startup can detect motor load variation patterns associated with under or over charging of refrigerant. The repeatability of this test is questionable in field applications when voltage and ambient temperatures cannot be controlled. This method is not well developed and only preliminary research has been carried out to examine the concept.

\section{COMBUSTION APPLIANCES}

\section{Backdrafting and Spillage Potential}

Long-Term Monitoring: An additional method to assess backdrafting and spillage potential is reported by ASTM (1999b) and in part by Fugler (1989). The ASTM method involves continuously monitoring vent differential pressure (static pressure at the base of the common vent relative to indoors), air temperature at the draft hood rim, indoor carbon monoxide and carbon dioxide concentrations, and appliance operation status over the period of about a week or more under natural conditions. A computerized data acquisition system that monitors the 
pressure difference, temperatures, concentrations, and operation status is necessary for the test. The method reported by Fugler involves only the temperature monitoring. Although both methods provide definitive measurements of performance during the monitoring period, they are impractical for commissioning due to their time requirements.

\section{Combustion/Dilution Air Supply}

Airflow Capability: Apart from simple dimensional measurements to ensure that combustion/dilution air supply ducts or grilles (with or without fan assist) meet specifications, the airflow rate through these devices needs to be determined. Air does not necessarily always flow inward from outdoors through these devices. The direction of flow can be influenced by wind and stack effects, as well as by the operation of air-moving devices within the house.

Well-developed diagnostics are available to determine the airflow through combustion/dilution air devices. For passive devices (no fan assist), a fan-assisted flow meter connected to the device can be used to determine its leakage area based on a multi-point test similar to using a blower door to test the envelope. In lieu of testing, commercially-available duct design software could be used to characterize the leakage area. Monitored pressure differentials across the device during normal operation can then be used with its leakage area to determine short- or long-term airflow rate histories. A disadvantage of this technique is the need for extended monitoring of the device pressure differentials and the uncertainty associated with the leakage area determination.

Alternatively, a fan-assisted flow hood, anemometry, or a pitot-static-tube traverse can be used to measure the operating flow under the test conditions for the passive or active (fan-assisted) devices. However, these tests only provide a spot measurement and do not necessarily represent the flows under other operating conditions. An in-situ-calibrated flow grid can be used with either type of device to provide longer-term flow data.

\section{Furnace Heat Exchanger Leakage}

Visual Inspection and Tracer Gas: DeWerth and Sobieski (1985) have described a three-step diagnostic method to detect combustion gas leakage in furnace heat exchangers. Step 1 relies upon visual inspection of the heat exchanger after cleaning. A mirror and bright light are used to examine the heat exchanger inside and outside for split seams, cracks, and holes. Any such defects are unacceptable. A disadvantage of this method is that inspecting the upper internal surfaces and the external surfaces can be difficult due to limited access.

Step 2 involves observing burner flame patterns with and without the air handler operating. Flame lifting, roll out, or other distortion that occurs with the air handler operating and not with it off indicates an unacceptable heat exchanger leak. This step is highly subjective.

Step 3 involves the detection of a tracer gas above a warm heat exchanger that is continuously flooded with tracer gas when the burner and air handler are off. Continuous flooding requires large amounts of tracer (typically on the order of $7 \mathrm{cfm}, 3 \mathrm{~L} / \mathrm{s}$ ), due to the discharge of tracer gas from the open heat exchanger exhaust ports. Detecting the tracer above the heat exchanger can be difficult due to limited access. The tracer gas recommended is $14.3 \%$ non-odorized methane in nitrogen.

No specific data are provided to indicate what concentration of methane in air detected outside the heat exchanger constitutes unacceptable leakage. However, the authors indicate that the concentration should be equivalent to that produced by the heat exchanger leaking 200 ppm airfree carbon monoxide $(\mathrm{CO})$ into the air outside the heat exchanger and producing no more than a 
15 ppm CO concentration indoors over an 8 hour period. The meaning of this constraint will vary from house to house, depending on the pressure difference across the heat exchanger surfaces, the size of heat exchanger defects, the ventilation rate of the house, and the house volume. The only other description of unacceptability is that when an indicator lights on a combustible gas detector, the leakage is unacceptable. The definition of unacceptable leakage requires further research.

The use of a tracer gas such as methane that is lighter than air can be advantageous. The reason is that it tends to rise without aspiration in the heat exchanger toward higher elevation leaks, which can be in air-stream suction regions. However, lower elevation leaks may not be detected. Apart from the potential hazard of using methane, this gas has an advantage that people servicing combustion equipment may already have detectors for such gases.

Other methods exist to detect leakage, such as using combustion gas products, smoke (acidic in some cases), sodium salt spray, halocarbons, or odors (oil of wintergreen or sulfur) as tracers. However, these methods can be less reliable due to their qualitative nature and some may be potentially damaging and/or hazardous.

\section{Fuel- and Electricity-Related Performance}

Spot Measurements: Spot diagnostic methods to assess the fuel- and electricity-related performance of combustion appliances are well developed.

Pressure differential measurements using a manometer or pressure gauge attached to the gas line are used as a diagnostic when adjusting operating fuel pressures.

Steady-state input capacity can be derived using simple methods such as gas meter "clocking" (Dutton 1994). That technique involves measuring the time for one or more revolutions of a gas meter indicator and then multiplying that time with the volume equivalent of those revolutions and the average energy content of a unit volume of the fuel. To test an individual appliance, this test requires that the tested appliance run continuously and that all other appliances using that meter be shut off. A correction needs to be applied to the meter indication to account for the difference between the local barometric pressure and the meter calibration pressure.

Steady-state output capacity for a furnace can be determined using measured air-handler flow and temperature rise across the heat exchanger. Several temperature sensors may be needed in the supply or return plenums if the airflow is not thermally well-mixed due to uneven heat exchanger temperatures or if duct branches enter or exit the plenums.

Visual inspection can be used to assess flame deficiencies such as flame lifting, yellow tipping, quenching, flashback, and roll out. However, this test is subjective and should not be relied upon solely when adjusting the primary air shutters on a burner. Instead, these settings should be based on optimizing steady-state combustion efficiency, which can be determined primarily using measurements of combustion gas product temperature and concentrations of carbon dioxide, supplemented with measurements of combustion gas product carbon monoxide and oxygen concentrations.

Power consumption of the air-handler fan can be measured by a separate wattmeter or by using the building's electrical service wattmeter with all other devices turned off or disconnected if necessary. However, turning off devices (or disconnecting them if power is used in standby mode) can be time consuming, especially when many equipment timers and clocks must be reset after their power supply is restored. Using a separate closed-loop wattmeter can be problematic 
due to the electrical hazards involved in attaching it to a high-voltage power supply wire. Clampon devices are available, but their accuracy is not as good as closed-loop ones.

Steady-state equipment efficiency for a furnace can be calculated using the ratio between the calculated steady-state output and the steady-state input capacity combined with the measured fan power consumption.

Steady-state tests can be difficult to carry out in some houses, because inadequate airflow across the heat exchanger may cause the high-limit control for the furnace to shut the burner off before steady-state is achieved. Many of these tests can be time consuming.

Short-Term Monitoring: Most short-term diagnostic methods to assess the fuel- and electricityrelated performance of combustion appliances are also well developed.

Seasonal efficiency for a furnace, as represented by its annual fuel utilization efficiency (AFUE), is normally determined using a complex time-consuming laboratory test (ASHRAE 1993a). The test uses a computerized data acquisition system to monitor temperatures and energy consumption over a 2 to 4 hour period. A temperature-sensor grid must be installed in the flue for this test. The test involves monitoring the furnace operation from startup to steady-state operation initially, followed by a cool-down period and then another heat-up period. The length of each period is based on how long it takes the flue gas temperature to stabilize in each case. Predefined empirical correction factors are applied in subsequent data analyses to account for operation at part-load conditions. This test can also be carried out as a field diagnostic. However, the test may be difficult to carry out in some houses, because inadequate airflow across the heat exchanger may cause the high-limit control for the furnace to shut the burner off before steadystate is achieved.

ASHRAE (1993b) includes a simple test to determine water heater recovery efficiency, which is the ratio of tank water energy change to energy input. The change in tank water energy is a function of the specific heat of water, tank volume, and the average tank temperature at the start and end of the test. This test uses short-term monitoring over a 2 to 3 hour period with simple temperature sensors and a timer. The test involves heating the tank of cold water to the maximum thermostat temperature setting for the water heater. Initial tank temperature is based on running a hot water faucet (with the main burner off) until the faucet water temperature is within $2^{\circ} \mathrm{F}\left(1^{\circ} \mathrm{C}\right)$ of the cold water supply temperature to the tank. The final hot water temperature is based on the water temperature at the faucet just after the thermostat turns the burner off at the end of the test. Input energy is determined as described above for the steadystate input capacity test.

Water heater cycling efficiency, as represented by the energy factor (EF), is normally determined using a complex time-consuming laboratory test (ASHRAE 1993b). That test uses a computerized data acquisition system to monitor water and air temperatures and energy consumption over a 24 hour period. Six temperature sensors need to be installed inside the tank for this test. Water flow rates are measured using a water meter or weigh scale. The test involves six equal volume water draws at hourly intervals, which are followed by an 18 hour standby period to assess standby losses. Sherman et al. 1987 developed a related but simpler field diagnostic to determine standby losses only. That diagnostic also requires a computerized data acquisition system and long periods without hot water use between two burner cycles (more than 12 hours at a time). The length of the burner off period is based on normal operation, as governed by tank thermostat operation. A disadvantage of both tests is that it is difficult or 
impossible to reliably carry them out in occupied houses, because the periods between hot water use in these houses tend to be too short (on the order of 8 hours). This problem is exacerbated when the water heater is located in a space such as a garage or basement that is warm compared to outdoors. The warm air reduces the standby loss and increases the length of time between burner cycles. Further development of this test is required before it is practical for residential commissioning.

\section{INDOOR ENVIRONMENTAL QUALITY}

Related to the performance of thermal and ventilation distribution systems are a host of indoor environmental quality (IEQ) issues that encompass thermal comfort and indoor air quality (IAQ). IAQ includes the generation, transport, and removal of pollutants. Many types of pollutants might be found in a house. Examples include non-biological gaseous ones (e.g., carbon monoxide, nitrogen oxides, formaldehyde, radon), particulates (e.g., dust, soot), bioaerosols (e.g., molds, fungi, mites), and moisture.

Metrics for thermal comfort include room air temperature, radiant environment temperature, and room air velocity. Spatial asymmetry and cyclic or non-cyclic drift rates of these temperatures are other metrics related to thermal comfort. Another related metric is relative humidity. Complex metrics that combine several parameters in attempts to quantify occupant satisfaction with the indoor thermal environment include operative temperature (ASHRAE 1992), the "Overall Liking Score" of Levermore et al. (1999), standard effective temperature, predicted mean vote, and predicted percent dissatisfied. Pulldown time is another metric associated with thermal comfort (Walker et al. 1998c). It represents the time it takes to reduce the air temperature to an acceptable level after cooling startup, such as when occupants return home on a hot summer afternoon.

For pollutants, generation rates (e.g., emission, desorption), concentration, level, index, and removal rates (e.g., sorption, absorption, deposition) are relevant metrics. Literature on specific metrics for the generation and removal of pollutants is sparse or non-existent, other than to describe pollutant sources in general. Most metrics reported in the literature for pollutants are in the form of a pollutant level or index. Depending on the type of pollutant, these metrics may be in standardized units of PPM, mass per unit volume of air, colony forming or biological units per unit volume, mass of allergen per unit of particulate, particulate mass deposited per unit area, and number of mites per sample sheet. Most of these metrics represent an integrated quantity over a desired period. Airborne moisture itself has several well-known metrics that include vapor partial pressure, relative and absolute humidity, humidity ratio, and dew-point temperature. Related metrics are condensation potential for windows and surface water activity (Flannigan 1992), both of which provide an indication of the availability of moisture for microbial growth. Moschandreas and Sofuoglu (1999) have suggested an "Indoor Pollution Index" metric that attempts to sum the effects of multiple pollutants to determine their synergistic effect.

Many well-developed diagnostics are already available to determine IEQ metrics. However, they tend to be complex, time consuming, and require expensive equipment or analyses and welltrained diagnosticians. Without selecting an appropriate diagnostic to target specific concerns or dissatisfaction of occupants, the cost of attempting to address the apparent myriad of possible comfort and IAQ problems is prohibitive. As a result, most IEQ diagnostics tend to be impractical for residential commissioning at this time. 


\section{Thermal Comfort}

Thermal comfort depends on indoor temperatures, humidity, and air velocities, which change in response to diurnal weather patterns and HVAC operation. It also depends on enclosure temperatures and their resulting radiant output, which also change due to these effects, but less rapidly than air temperature and air velocity. As a result, spot measurements to characterize thermal comfort are not generally useful.

Instead, a computerized data acquisition system with multiple sensors should be used to collect data over time. However, without the use of wireless technology (which is not common), the computerized system must be connected to each sensor. Connecting wires are prone to damage or disconnection, especially in occupied buildings. The computerized system has the advantage that all sensors are monitored by the same system and data are already synchronized for subsequent analyses. Such diagnostics tend to be complex and time consuming.

When only humidity and/or air temperature data are needed, stand-alone recorders can be used instead. This latter system has the advantage that these recorders are commercially-available, relatively inexpensive, easy to install, less obtrusive, and perhaps more secure from tampering compared to the former system. However, stand-alone humidity recorders have the disadvantage of slow response rates, because they are typically not aspirated.

Air Temperature: To characterize the air temperature in a room, measurements at representative locations are necessary. The temperature stratification effect in many houses is small and a single location can be used, such as waist height based on anthropometric measurements of a typical person. When there is the possibility of stratification in a room due to solar heating effects or if the room is a tall "atrium" space such as a modern entrance area, measurement locations should include ankle height, waist height, and neck height. These locations should also be used when making air velocity measurements at these heights. Lateral location is also important, with preferable locations away from nearby walls, direct sunlight, supply grille flows, radiant heaters, and drafts from open windows or doors.

Small aspirated shielded temperature sensors are preferable. Other sensors without these features are subject to error due to slow response rates and radiation effects. A disadvantage of aspirated sensors is that they are more expensive and larger. Although shielded sensors are commercially available, aspirated sensors are not commonly available. Liquid-in-glass thermometers are not recommended, because they generally have too long a response time for use in thermal comfort testing. In addition, they are not amenable to use within a computerized data acquisition system.

Porous media thermography is an uncommon research technique for determining room air temperature patterns (Hassani and Stetz 1994). This technique is based on using infrared thermography to visualize the temperature distribution of a low-thermal-mass, porous fiberglass screen placed within an enclosure. It assumes that the screen does not affect airflow patterns and that it will be in equilibrium with the temperature of the surrounding air that flows through it. This technique has problems similar to those described in the section on using infrared thermography for assessing building envelope deficiencies. It also requires substantial analyses to determine temperatures from the thermographic images, especially if multiple images are used to determine temperature histories. These analyses are also necessary to correct for radiant interchange between the screen and the room enclosure. Care is required to ensure that solar radiation is not incident on the screen. This test, although impractical for residential 
commissioning, could be useful in determining appropriate locations for other temperature sensors.

Humidity: To characterize the humidity in a room, measurements at several representative locations are not necessary, because thermal comfort is only a weak function of humidity (and moisture gradients in the room air are small). A common location is waist height based on anthropometric measurements of a typical person. However, lateral location remains important and preferable locations are away from direct sunlight, supply grille flows, radiant heaters, and drafts from open windows or doors.

To reduce slow response times that can introduce data synchronization errors, an aspirated sensor should be used to measure humidity. The sensor can be one of several inexpensive commercially-available devices. One type is a simple shielded dry-bulb and wet-bulb thermometer matched pair with a constant supply of distilled water to keep the wet-bulb wick moist. Wet-bulb based sensors are inappropriate for measuring low humidity $(<20 \%$ relative humidity), because cooling the wet-bulb to its full depression is difficult under these conditions. Another type is an electronic capacitive relative humidity sensor. Care is required with some capacitive sensors, because exposure to high humidity ( $>95 \%$ relative humidity) can permanently damage the sensor. A chilled-mirror dew point transducer (relies on the presence of fogging at the dew point) can also be used and is very accurate, but its relatively high cost and delicacy makes it less desirable for general field use. Aspiration of these devices is typically achieved using an integrated fan.

All humidity transducers are subject to contamination by dirt or chemicals, which alters their response and introduces a bias error. Other than chilled-mirror transducers (which require regular cleaning), these devices require frequent calibration, which is time consuming. Such calibrations require controlled temperature and humidity conditions (e.g., carefully-mixed salt solutions located within an environmental chamber).

Air Velocity: Measuring air velocity at representative locations is necessary, because people are particularly sensitive to drafts on unclothed areas of their bodies. As a result, measurements should be carried out at ankle height, waist height, and neck height based on anthropometric measurements of a typical person. Discomfort associated with drafts is also a function of frequency effects, such as turbulence with fluctuations on the order of $2 \mathrm{~Hz}$ or less.

These measurements are typically made using an expensive commercially-available omnidirectional hot-wire anemometer with a short time constant to enable the detection of turbulence intensity and low air velocities (down to $2 \mathrm{in} / \mathrm{s}, 50 \mathrm{~mm} / \mathrm{s}$ ). Omni-directionality is important, because airflow direction can change rapidly at these low velocities. Hot-wire anemometers are subject to fouling by dirt and other contaminants, which will reduce their accuracy.

A Kata thermometer can also be used, but its mass will introduce a bias error when air velocities fluctuate substantially, will obscure transients by its integrating effect, and is not amenable to use with a computerized data acquisition system. A Kata thermometer is an alcohol-filled thermometer that is heated in a water bath, dried, and then allowed to stand undisturbed in an airflow. The cooling time of the thermometer over a fixed temperature range (typically $5^{\circ} \mathrm{F}, 3^{\circ} \mathrm{C}$ ) and device calibrations are used to determine the air velocity.

Vane anemometers are inappropriate for measuring room air velocities, because they are incapable of measuring low air velocities and are not omni-directional. 
Radiant Environment: Operative temperature combines both radiation and convective effects to better approximate the response of the human body to these conditions in an enclosure. It is defined as the uniform temperature of a radiantly black enclosure that will transfer as much heat by radiation and convection to an occupant as the actual environment. A disadvantage of measuring this parameter is that, by combining the effects of two heat transfer modes, a problem in one mode cannot be distinguished from the total measurement. Therefore, operative temperature measurements must be supplemented by air temperature and air velocity measurements so that the radiant and convective effects can be separated. Calculations are required to determine these components of the operative temperature.

A black globe thermometer can be used to measure operative temperature. This device is a hollow sphere, such as a painted table tennis ball, with a temperature sensor centrally located. The sensor shell has a low mass material such as thin plastic instead of metal to improve its response to airflow transients. However, its shape, color, and convective to radiative heat transfer ratio are poor representations for the response of lightly-clothed human bodies to enclosure surface temperatures, solar radiation, and convection. A commercially-available gray ellipsoid transducer provides a better approximation. The ellipsoid sensor orientation has the additional advantage that it can be adjusted to represent standing, sitting, and lying positions (each of which have different view factors relative to the enclosure).

Multiple operative temperature measurements are necessary within each room due to possible non-uniformities in airflow patterns and because enclosure view factors change with position in a room. For example, measurements near a window in an otherwise well-insulated room will provide a different operative temperature near the window compared to the opposite side of the room.

Radiant temperature asymmetry is a related measurement. It is the difference between the apparent radiant temperatures on two opposite sides of a small black element. Radiant asymmetry can be determined using a commercially-available handheld plane radiant asymmetry sensor. This sensor consists of two identical faces, each of which detects the hemispherical radiation incident on its surface. Radiative and convective heat transfer effects are separated by measuring the surface temperature of each probe face and by using two materials of different emissivity: one with low emissivity (e.g., gold) and the other with high emissivity (e.g., black). The sensor can be oriented in any direction. As such, it can also be used to evaluate mean radiant temperature of an enclosure.

\section{Sources of Indoor Contaminants}

Source Characterization: Building materials and occupant activities can be sources of indoor contaminants. These include emissions such as:

- formaldehyde from particleboard;

- volatile organic chemicals from carpets, paint, adhesives, cleaning products, and personal hygiene products;

- tobacco smoke;

- unvented combustion appliance use for heating or cooking;

- vehicle exhaust in attached garages;

- dust from renovations or woodworking; 
- ozone from home office equipment;

- biological particles such as mold spores, pollen, insects, and skin flakes;

- moisture, grease, and smoke from cooking; and

- moisture from bathing, showering, plants, clothes drying, and the building envelope.

External contaminant sources can also contribute to indoor contaminant levels. These sources can include outdoor air containing ozone or contaminant types similar to those indoors, as well as soil gases contaminated with radon, land-fill gases, or volatile organic chemical vapors.

Vented combustion appliances, in some circumstances, can also be a source due to backdrafting and spillage or due to furnace heat exchanger leakage. Diagnostics to assess these particular sources are described elsewhere in this report.

Material emission, ambient air, and soil gas testing is complex, so most diagnostics will be limited to a checklist audit of possible sources to determine which sources may be present. Such an audit may also include determining particular contaminant sensitivities of occupants. Sampling of some indoor contaminant concentrations can also be used to identify the presence of contaminant sources (e.g., radon).

Source Control: Preferably, indoor contaminants from stationary indoor sources should be controlled by collection and removal at or as close as possible to their source rather than by whole-house dilution ventilation. This removal can be accomplished by particulate filtration and local ventilation.

Apart from simply checking that equipment is installed correctly, field diagnostics to assess source control are limited. Particulate filtration can be assessed by measuring particle concentrations upstream and downstream of filters in the air distribution systems and by measuring particle concentrations in the indoor air. Assessing the performance of local ventilation systems can include diagnostics for measuring indoor concentrations of the contaminant intended to be controlled, as well as measuring the associated ventilation airflow and air exchange rates. These diagnostics are described elsewhere in this report.

\section{Indoor Contaminant Concentrations}

Indoor contaminant concentrations can be measured using non-aspirated (passive) or aspirated (active) sampling techniques. Currently, it is economically impractical to sample all possible contaminants. Except during the startup period (e.g., at construction completion and 3 and 6 months after), sampling should only be used when obvious sources have been ruled out and problems still exist. Therefore, a checklist audit of possible sources should be used to determine which sources may be present and which samplers are appropriate. Such an audit may include determining particular contaminant sensitivities of occupants.

Regardless of sampling method, a measured concentration that is elevated beyond a threshold is only a snapshot: it indicates that there may be a problem sometimes. Contaminant concentrations below the threshold do not mean there is always no problem. Instead, they mean there is likely no problem at the time of monitoring. This may be due to an absence of sources of concern or due to high ventilation rates that are maintaining low concentrations. Sources or ventilation rates can change over time (e.g., new carpeting, moisture-induced biological growth, air sealing measures). As a result, it may be desirable to sample multiple times over the life cycle of the building. 
Non-Aspirated (Passive) Sampling: Passive samplers are small tubes or canisters that collect contaminants without aspiration using diffusion, permeation, chemical reaction, and/or radioactive decay. Most non-aspirated samplers are meant to be exposed for short periods of time, typically two weeks or less. No air sample pump is required. After sampling, the samplers are sealed and sent to a laboratory for analysis to determine the amount of contaminant that they have absorbed. Using these data along with tube exposure time, the integrated average concentration can be calculated for each tube location. Some samplers use colorimetric elements intended to visually indicate the concentration and avoid subsequent lab analyses. However, these devices have limited accuracy due to the subjectivity involved in interpreting color changes or matches. Some colorimetric samplers can be analyzed in a laboratory to improve their usefulness and accuracy.

Non-aspirated samplers are commercially available and well developed for many of the common chemicals and radioactive elements of concern in houses, such as carbon monoxide $(\mathrm{CO})$, nitrogen dioxide $\left(\mathrm{NO}_{2}\right)$, sulfur dioxide $\left(\mathrm{SO}_{2}\right)$, formaldehyde, volatile organic chemicals, and radon. An advantage of passive samplers is that they can be constructed to be worn as badges on clothing near the breathing zone to indicate occupant exposure. All these samplers are subject to post-test pre-analysis contamination and create storage and data tracking problems. However, they are not subject to the contaminant loss that sometimes occurs in the tubing of aspirated samplers.

Other non-aspirated sampling techniques include tape extraction of sedimentary bioaerosols and particulates. The tape is placed over a sample region. When removed, the media being sampled remain attached to the tape. The tape is then sent to a laboratory for subsequent analyses of number of media and type.

Integrated sampling obscures short-term variations (e.g., peaks) in contaminant concentration. Such obscuration can be hazardous if the time scale of concern is less than the integration period. For example, a rare but brief hazardous concentration of a toxic contaminant would be obscured when the concentration was normally low over the remainder of the sampling period. The sampler would then indicate there was no problem, when in fact there may have been. In spite of this problem, non-aspirated samplers are useful for characterizing long-term exposure to contaminants.

Aspirated (Active) Sampling: Aspirated sampling generally involves collecting air samples using a sample pump contained within a recording monitor that analyzes the sample on-site to determine its concentration. A disadvantage of this equipment is that it tends to be expensive and fragile. Furthermore, sampling pumps tend to be noisy and can be irritating to building occupants. Multiple grab bag samples collected over time can be used instead to reduce the equipment cost and the duration of the noise. The bags are initially evacuated and then are inflated on site with an air sample pump. A disadvantage of the grab bag technique is that chemically-stable sample bags can be expensive to buy and to analyze. However, this analysis step offers the advantage of using laboratory techniques that are more sophisticated to determine which contaminants are present in the sampled air. These techniques include gas chromatography or mass spectroscopy. Due to their size, grab bags cannot be used practically to indicate exposure. As with passive samplers, grab bags are subject to post-test pre-analysis contamination and create storage and data tracking problems.

These aspirated devices are commercially available and well developed, but require more on-site expertise than non-aspirated samplers. In addition to microprocessors, their analytical elements 
include electrochemical cells to detect $\mathrm{CO}, \mathrm{O}_{2}, \mathrm{SO}_{2}, \mathrm{NO}_{2}$, and combustible gases; non-dispersive infrared samplers to detect $\mathrm{CO}$ and $\mathrm{CO}_{2}$; chemiluminesence samplers to detect ozone, $\mathrm{NO}$, and $\mathrm{NO}_{2}$; and portable radiation samplers to detect radon and its decay products. Other aspirated samplers with vacuum sampling and opacity measurement are available to determine bioaerosol and particulate concentrations. Vacuum sampling with filter collection or electrostatic precipitation, followed by laboratory gravimetric and/or microscopic analysis of the filter or electrostatic plate, is also an available technique to determine these concentrations. The latter technique is more expensive than on-site analysis, but has the advantage that bioaerosol and particulate type can be determined. Impingement and precipitation collectors are used in some particulate samplers to separate particles by size.

Aspirated samplers require careful and frequent calibration to reset their zero and span, due to the delicacy of their internal sensors and due to aging and contamination effects. Some samplers include automatic rerouting of the sample air stream on a periodic basis through scrubbers or filters to reset their zero. Sensors are included in some devices to provide automatic compensation for the effects of temperature and humidity. Monitors without these features require careful analysis of the data to correct for zero drift and for the effects of temperature and humidity.

All aspirated samplers also require careful adjustment of their airflows, especially when sampling in another air or gas stream, such as in a flue. If the sampling airflow is too low, much of the air stream will pass the sample tube without entering. This is particularly a problem when particles with large inertia are involved, because they cannot easily change direction into the sampling tube. Equipment used to sample combustion gas products in flues may need to be more robust due to the higher temperature associated with sampling these hot gases. Care must also be exercised to ensure sample tubing does not leak. Leaks outside the desired sample area can bias the measurement.

A disadvantage of aspirated samplers is they cannot be used to indicate occupant exposure, because they are too large to be fastened on clothing near the breathing zone. Some samplers are mounted on belts, but they are awkward, prone to damage, and their accuracy in indicating exposure in the breathing zone is reduced. Unlike passive samplers, aspirated samplers are not subject to post-test pre-analysis contamination of samples and they can facilitate storage and data tracking through a recording feature.

Aspirated samplers with built-in analyzers have the advantage that they can continuously monitor instantaneous contaminant concentrations. These data can then be used to indicate shortterm hazards or can be integrated to indicate longer-term concentrations.

\section{CONTROLS AND OTHER EQUIPMENT}

In commercial commissioning, control problems are the key item of concern. While not as important in residential houses, controls can still play an important role, especially when the systems become complex (e.g., multistage systems, integrated heat-pump/ventilation systems) Even common heating setback / cooling setup thermostats need to be properly commissioned. Heat pumps share many of the same problems associated with cooling systems, but have some unique features. Use of electric resistance ("strip") heaters can significantly increase energy consumption due to malfunctioning or misadjusted controls. Making sure that these controls are doing what was intended or is appropriate is often crucial to achieving good energy performance. 
Except for Keithly (1999), we found no metrics in the literature to describe residential control performance. Even then, Keithly only describes common deficiencies with thermostat installations. Some metrics that are relevant to thermostat performance include accuracy, setup/setback strategy, and anticipator or temperature swing setting. Other controls in the space conditioning system include those for the burner of a heating system and the refrigerant flow control in a cooling system. Specific metrics for the burner include fuel pressure, fuel orifice size, and primary air supply flow. For refrigerant flow controls, relevant metrics are the orifice size, thermostatic expansion valve (TXV) size, as well as the superheat bulb location and bulbline contact resistance. Other metrics include heat pump outdoor thermostat and defrost timer settings, blower and burner thermal limit switch settings, blower motor speed, automatic control sequence for duct damper on outdoor air intake, and ventilation switch settings (e.g., humidistats, or run and defrost timers).

Apart from the HVAC system, there are many other electrical appliances in the house. Some of them (e.g., stoves, water heaters, refrigerators, clothes dryers) can be quite large consumers of electricity. Improper configuration of some appliances (e.g., clogged dryer vent) can cause poor performance. Most of these appliances require only simple commissioning.

Only a few references were located that discuss metrics relevant to the commissioning of residential electrical appliances. For water heaters, one metric is its recovery efficiency. Others include its energy consumption, energy factor, standby energy loss, and how much insulation is located around the tank. For appliances associated with plug loads, such as refrigerators, metrics include energy consumption and interior compartment temperature. An important metric for electric water heaters and these appliances is the electric load, both at startup and while operating.

\section{Controls}

Configuration and Operation Assessment: Diagnostics for controls are often little more than checking configurations and settings. For space conditioning systems, these checks can include verifying indoor thermostat accuracy, setup/setback strategy, deadband width, and anticipator or temperature swing setting. For refrigeration systems, checks can include the orifice size, thermostatic expansion valve (TXV) size, as well as the superheat bulb location and bulb-line contact tightness and cleanliness. Other checks may include heat pump outdoor thermostat and defrost timer settings, blower and burner thermal limit switch settings, blower motor speed, automatic control sequence for duct damper on outdoor air intake, and ventilation switch settings (e.g., humidistats, or run and defrost timers).

Assessing control operation is currently limited to simple observation and timing, or to more complex monitoring using a computerized data acquisition system. Other than diagnostics intended for laboratory use or for commercial energy-management control systems (EMCS), there are no useful diagnostic protocols for quantifying control operation during residential commissioning. As a result, diagnostics to quantify control performance require research and development.

\section{Other Equipment}

Configuration Check: As with controls, diagnostics for electrical equipment separate from the space conditioning and ventilation systems are often little more than checking configurations and settings. The electrical equipment of interest includes water heaters, stoves, refrigerators, freezers, and clothes washers and dyers, which can be large consumers of electricity. 
Configuration checks can include determining whether water supply filters on clothes washers are present or blocked or whether dryer vents are too long or blocked. Water heater thermostat setting, oven control calibration, and settings for refrigerator and freezer compartment temperatures also need to be checked.

A simple diagnostic for all electrical equipment, including smaller appliances connected as plug loads, is to measure the associated power consumption and demand. 